\title{
Individuals' paths to retirement
}

Citation for published version (APA):

Nies, K. (2011). Individuals' paths to retirement. [Doctoral Thesis, Maastricht University]. Datawyse / Universitaire Pers Maastricht. https://doi.org/10.26481/dis.20110218kn

Document status and date:

Published: 01/01/2011

DOI:

10.26481/dis.20110218kn

Document Version:

Publisher's PDF, also known as Version of record

\section{Please check the document version of this publication:}

- A submitted manuscript is the version of the article upon submission and before peer-review. There can be important differences between the submitted version and the official published version of record.

People interested in the research are advised to contact the author for the final version of the publication, or visit the DOI to the publisher's website.

- The final author version and the galley proof are versions of the publication after peer review.

- The final published version features the final layout of the paper including the volume, issue and page numbers.

Link to publication

\footnotetext{
General rights rights.

- You may freely distribute the URL identifying the publication in the public portal. please follow below link for the End User Agreement:

www.umlib.nl/taverne-license

Take down policy

If you believe that this document breaches copyright please contact us at:

repository@maastrichtuniversity.nl

providing details and we will investigate your claim.
}

Copyright and moral rights for the publications made accessible in the public portal are retained by the authors and/or other copyright owners and it is a condition of accessing publications that users recognise and abide by the legal requirements associated with these

- Users may download and print one copy of any publication from the public portal for the purpose of private study or research.

- You may not further distribute the material or use it for any profit-making activity or commercial gain

If the publication is distributed under the terms of Article $25 \mathrm{fa}$ of the Dutch Copyright Act, indicated by the "Taverne" license above, 


\section{Individuals' Paths to Retirement}

Kathrin Nies 
(C)Kathrin Nies, 2010

All rights reserved. No part of this publication may be reproduced, stored in a retrieval system, or transmitted in any form, or by any means, electronic, mechanical, photocopying, recording or otherwise, without the prior permission in writing from the author.

Front cover image: Harbor of Bella Coola, Canada

Back cover image: Harbor of Bella Coola, Canada

This book was typeset by the author using $\mathrm{LAT}_{\mathrm{E}} \mathrm{X}$.

Published by Universitaire Pers Maastricht

ISBN: 978-94-6159-030-5

Printed in the Netherlands by Datawyse Maastricht 


\title{
Individuals' Paths to Retirement
}

\author{
PROEFSCHRIFT
}

ter verkrijging van de graad van doctor

aan de Universiteit Maastricht,

op gezag van de Rector Magnificus,

Prof. mr. G.P.M.F. Mols,

volgens het besluit van het College van Decanen,

in het openbaar te verdedigen

op vrijdag 18 februari 2011 om 16.00 uur

door

Kathrin Nies

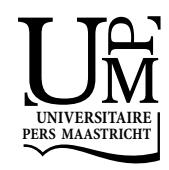




\section{Promotor:}

Prof. dr. P.C. Schotman

\section{Beoordelingscommissie:}

Prof. dr. R.M.M.J. Bauer (voorzitter)

Prof. A. Börsch-Supan, Ph.D.

Prof. dr. A. de Grip

Dit onderzoek is financieel mogelijk gemaakt door de Network for Studies on Saving, Pensions and Retirement (NETSPAR). 


\section{Acknowledgements}

Many people contributed directly or indirectly to the outcome of this dissertation. I would like to take a few minutes to thank them.

Peter Schotman is on the top of this list. He is my supervisor or simply the person, who always listened to my ideas, doubts and whatever else came to my mind, who provided me with answers to my questions, and who gave infinite feedback. I have not heard of many supervisors who found the time to sit down with their $\mathrm{PhD}$ student to find a mistake in the execution of the methodology! Next to mention, are my co-authors Tabea Bucher-Koenen and Frank Lutgens. Both have not only shared their knowledge with me but also turned out to be great friends. It is fun to go climbing or spend a night out with them, have coffee, and valuable conversations. I have always been able to rely on them. I would also like to thank the committee Rob Bauer, Axel Böersch-Supan and Andries de Grip, who took the time to provide me with elaborate and constructive feedback.

More (scientific) conversations were also fostered by Netspar and the MEA in Mannheim. Netspar offered a platform in form of workshops and conferences that gave way to a lot of constructive feedback. Thanks to them, I also received a regular income as a PhD student and was able to go to Mannheim. The MEAs are unique. They are eager to help and during the last 1.5 years they provided excellent suggestions and explanations and made me feel as if I was part of their team. In Maastricht I spent 1.5 truly great years together with Dani in our office over coffee and challenging students matters and at home over a bottle of wine. Kirsten, Thies, Bart, Daniel and Simone have also made my time in Maastricht very enjoyable; Thies on the train rides as well. Francien, Carina, Els and Cécile also assisted me wherever they could. A special thanks goes to Barbara Meller and Jean Pierre Urbain, without whom I, firstly, would not have studied in Maastricht and, secondly, would not have pursued a $\mathrm{PhD}$.

Even though my scientific environment was always very friendly, I still received some moral support from other sources. The first to name here is Dennis. Apart from cheering me up after a day of unsuccessful and yes - sometimes frustrating - research, he often had to listen to my monologues about life-cycle models and individuals' (irrational) behavior. I can hold pretty long monologues. Surprisingly, it turned out that he actually listened to 
most of them and was able to contribute new perspectives. Also my family has always given me the moral support I needed, even though the question "So, are we there yet?" began popping up more frequently during the last half year ;).

All of you can feel proud as you contributed to the development of this dissertation. :) Thank you! 


\section{Contents}

1 Introduction 1

2 Subjective Financial Well-Being at Retirement in the Light of Pension Reforms in Germany 11

2.1 Introduction . . . . . . . . . . . . . . . . . . . . . . . . . 11

2.2 Hypotheses . . . . . . . . . . . . . . . . . . . . . 13

2.3 The ASID Data . . . . . . . . . . . . . . . . . 16

2.4 Estimation . . . . . . . . . . . . . . . . . . . 20

2.4.1 Synthetic Panel Approach . . . . . . . . . . . . . . . . . . . . . 21

2.4.2 Cross-Sectional Approach . . . . . . . . . . . . . . . . . . . 23

2.5 Cohort and Income Effects in the Synthetic Panel . . . . . . . . . . . . . . . 24

2.6 The Influence of Income Sources over the Cross Section _ . . . . . . . . . . 28

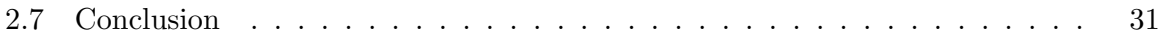

2.A Appendix A: Number of Observations . . . . . . . . . . . . . . . . 33

2.B Appendix B: Regression Output . . . . . . . . . . . . . . . . . . 34

3 Financial Incentives, Labor Force Participation and Retirement Entry in Germany $\quad 37$

3.1 Introduction . . . . . . . . . . . . . . . . . . . 37

3.2 Related Literature and Contribution . . . . . . . . . . . . . . . . . . . . 39

3.2 .1 Incentives to Retire . . . . . . . . . . . . . . . . . . . . . 39

3.2.2 The German Public Pension System . . . . . . . . . . . . . 40

3.2 .3 Hypotheses . . . . . . . . . . . . . . . . . . . . . . 43

3.3 Data . . . . . . . . . . . . . . . . . . 45

3.4 Estimating Incentives to Enter Retirement . . . . . . . . . . . . . . . 47

3.5 Results . . . . . . . . . . . . . . . . . . . . 52

3.5.1 Actual Employment Exit . . . . . . . . . . . . . . . . . 52

3.5.2 Actual Retirement Entry _. . . . . . . . . . . . . . . 53

3.5.3 Estimating Alphas . . . . . . . . . . . . . . . . . . . . 56 
3.5.4 Social Security Wealth and the Option Value of Postponing Retirement 57

3.5.5 Regression Results, Western Germany . . . . . . . . . . . . . . . 61

3.5.6 Regression Results, Eastern Germany . . . . . . . . . . . . . . 66

3.6 Conclusion . . . . . . . . . . . . . . . . . . . . . . . . . . 69

3.A Appendix A: Robustness: West Germany, $I_{i t}=$ entry . . . . . . . . . 71

3.B Appendix B: Literature . . . . . . . . . . . . . . . . . . . . 73

3.C Appendix C: OV with $I_{i t}=$ entry $\ldots \ldots \ldots \ldots 76$

3.D Appendix D: Cohort Trends . . . . . . . . . . . . . . . . . . 78

4 Tax-deferred Saving for Early Retirement: Analysis of the Dutch Life$\begin{array}{lr}\text { Course Savings Scheme } & \mathbf{7 9}\end{array}$

4.1 Introduction . . . . . . . . . . . . . . . . . . . . . . . . . 79

4.2 A Life-Cycle Model with a Tax-deferred Account and endogenous Labor Supply 82

4.3 Optimal Life-Cycle Savings in the Absence of Uncertainty . . . . . . . . . . 90

4.4 Optimal Savings under Uncertainty . . . . . . . . . . . . . . . . . . 96

4.5 Conclusion . . . . . . . . . . . . . . . . . . 106

4.A Appendix A: Dutch Tax Parameters . . . . . . . . . . . . . . . . 108

4.B Appendix B: Pensions and Final Wealth . . . . . . . . . . . . . . . . . . 109

4.C Appendix C: Numerical Optimization . . . . . . . . . . . . . . . 110

5 A Reduced Form Analysis of a Reform in Dutch Early Retirement Ar$\begin{array}{ll}\text { rangements } & 111\end{array}$

5.1 Introduction . . . . . . . . . . . . . . . . . . . . . . . . . . . . 111

5.2 The LLR-Participation Decision in a Life-Cycle Model . . . . . . . . . . . . 113

5.3 Data . . . . . . . . . . . . . . . . . . . 116

5.4 The LLR-Participation Decision empirically . . . . . . . . . . . . . . . . . . 118

5.5 The LLR-Investment Decision in a Life-Cycle Framework . . . . . . . . . . 122

5.6 The LLR-Investment Decision empirically . . . . . . . . . . . . . . . . . . 123

5.7 Conclusion . . . . . . . . . . . . . . . . . . . . . . . 131

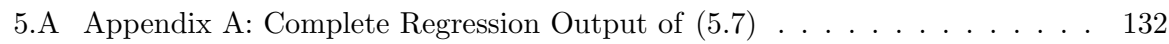

6 Conclusion 133

$\begin{array}{lr}\text { Bibliography } & 139\end{array}$

$\begin{array}{lr}\text { Nederlandse Samenvatting } & 147\end{array}$

$\begin{array}{ll}\text { Curriculum Vitae } & 151\end{array}$ 


\section{Chapter 1}

\section{Introduction}

Bismarck would have turned in his grave, if he had seen what was happening to pension schemes in the second half of the 20th century. Otto von Bismarck was German Chancellor from 1871 to 1890 . He was the first to introduce a country wide social security system. The socialist party became strong during this time period and Bismarck's vision of a social security system may have been accelerated by this development. Nevertheless, Bismarck was rather conservative and in some respects liberal in his political orientation. He also had a strengthening of the economic system in mind when he pursued the social security system. His social security system included a health insurance, casualty insurance and a disability / retirement insurance. The latter was granted as of age 70. A few years later it was adjusted downward to 65 . In the early 20th century life expectancy at birth was 45 and 47 years for men and women, respectively. Thus, retirement insurance was meant for people, who were unable to work.

Many European countries followed and adopted social security systems in the early 20 th century. In the 1970 s social security systems became very generous in Europe. A remarkable feature that originated in the 1970s has been the "early retirement window", which enabled many people to retire two to five years earlier than the original pivotal age of 65 without incurring any actuarial adjustments. At the same time, it also became common to generously grant people disability status to facilitate early retirement in their middle and end 50s (Gruber and Wise 1997). 


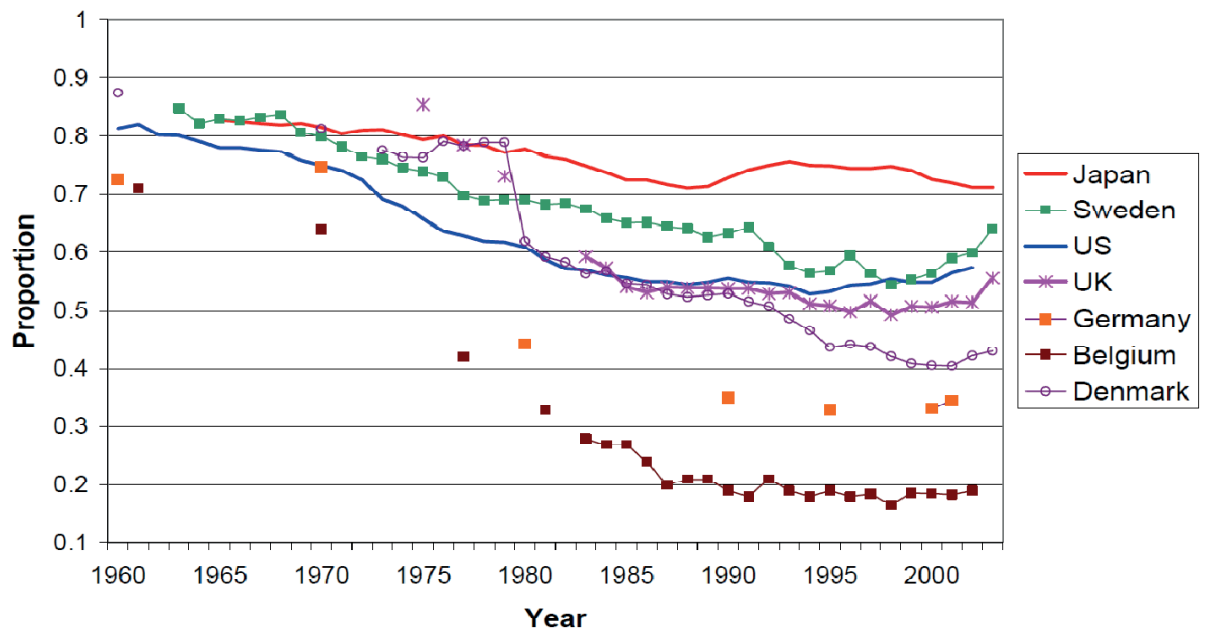

(a)

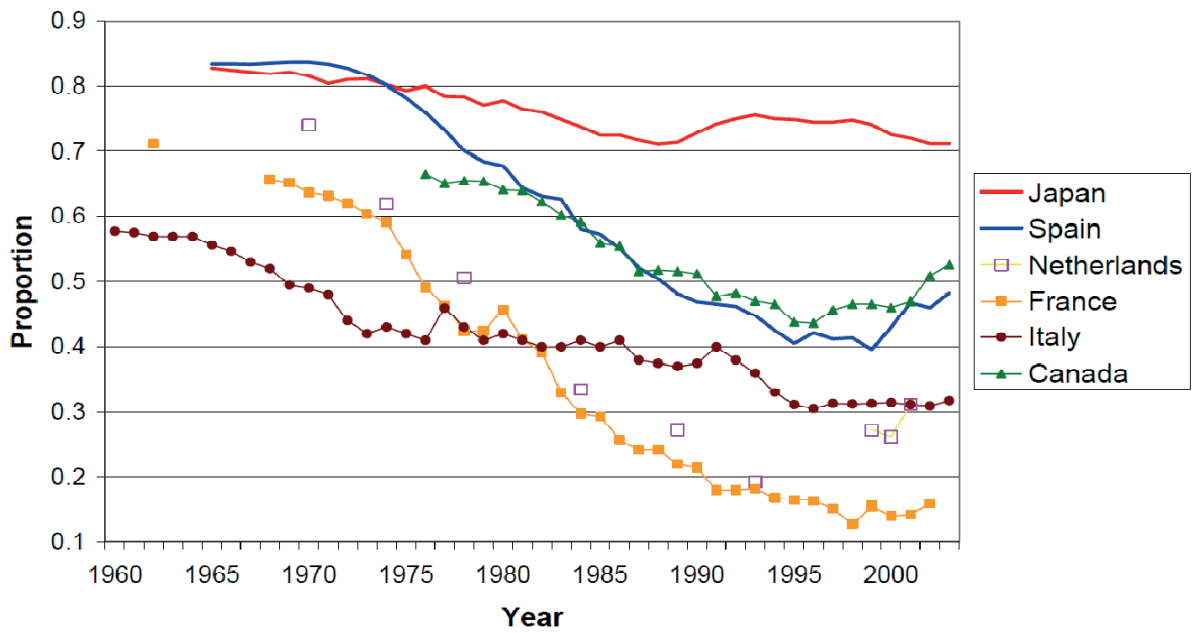

(b)

Figure 1.1: Labor Force Participation Trends of Men Aged 60-64

These figures are taken from Gruber and Wise (2005). They plot the proportion of 60-64 year old men in the labor force over calender years for several countries. 
This had dramatic effects on labor force participation across all countries. Figure 1.1 depicts the negative trend in male labor force participation at age 60-64. In 1990, $72 \%$ of the Dutch males and $65 \%$ of the German males were retired. Parallel to the decreasing labor force participation, we observe an increased life expectancy at birth in Europe as illustrated in Figure 1.2. While in the 1970s life expectancy was 71 years, it has increased to about 76 in 2010. This is 30 years more than people were expected to live at Bismarck's time. Moreover, health has also improved. Mathers, Sadana, Salomon, Murray and Lopez (2001), for instance, find healthy life expectancy at birth to increase to more than 70 years in Europe by the late 20th century. Similarly, Crimmins, Hayward, Hagedorn, Saito and Brouard (2009) show that disability-free life expectancy has significantly increased from 1984 to 2000 in the US.

As people expect to live longer they invest more in their human capital. As simulations of (Borghans, Dohmen and Golsteyn 2009) show, this increases their wage and the years they spent working. However, it has also positive repercussions on the desire for leisure, which reduces the time spent working. Following their simulations, the net effect of increasing conditional life expectancy from 78 to 81 for 60 year old men in the Netherlands is a retirement age increase of only one year. An argument against labor participation of elderly is often decreasing productivity. However, this is not necessarily true. As Borghans and Nelen (2009) argue, the specific skills and the combination of different skills of people accentuate over age. This makes older people valuable to their own company but reduces labor mobility. Also technical innovations as the introduction of computers at workplaces has proven not to be a difficulty for elderly workers (Borghans and Ter Weel 2002).

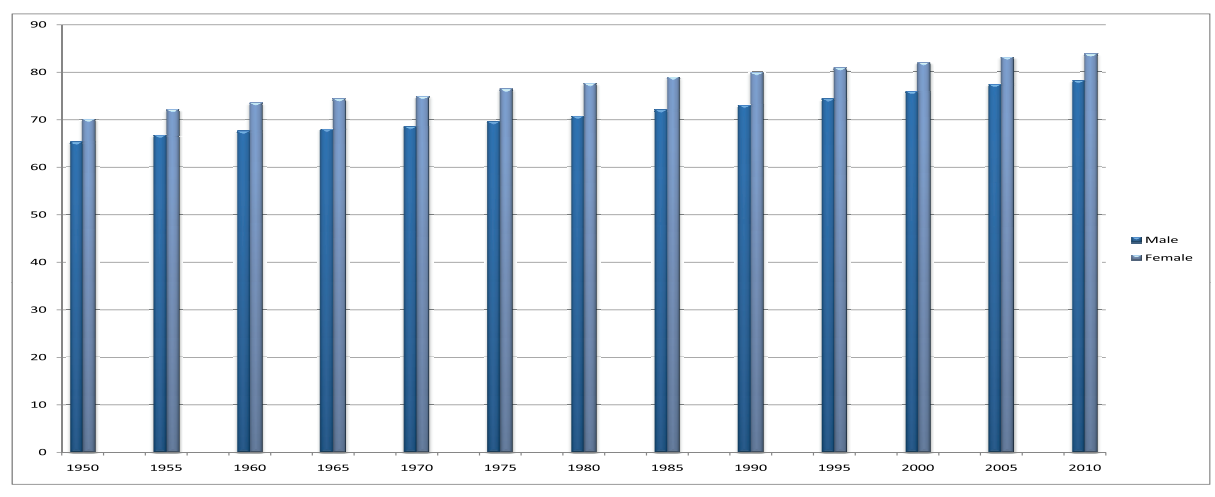

Figure 1.2: Life Expectancy in Europe

This figure is based on the UN world population prospects, 2008. It plots life expectancy in Europe across calender years for men and women.

The ongoing early retirement wave despite good health was certainly not in Bismarck's 
interest as his ultimate goal was, apart from reelection, a prosperous economy. The awakening came in the early 1990s when the increasing life expectancy and decreasing fertility rates and consequently an increasing ratio between the retired and working population was recognized. An extensive multinational research campaign led by Gruber and Wise (Gruber and Wise 1997, Gruber and Wise 2002, Gruber and Wise 2005) and covering 11 (later 12) countries came to the following conclusions.

\section{Phase I (Introduction):}

1. There is a decline in labor force participation of males aged 60-64 in 1995 in all countries. The decline in Europe ranges from $70 \%$ to $20 \%$ in Belgium to from $83 \%$ to $58 \%$ in Sweden.

2. There is a strong connection between people's early retirement age and labor force departure. This correspondence remains strong across gender and countries with different legislation.

3. Apart from eligibility ages, social security incentives, as for instance the implicit tax on work, play an important role in determining labor force exit. Much of the cross country variation of retirement ages can be explained by differences in institutional backgrounds; more specifically replacement rates and improper actuarial adjustments of benefits for deviating from the normal retirement age. The Netherlands has a very high implicit tax at age 60 (141\%), a high capacity of unused labor capacity of worker $(58 \%)$ and consequently a high percentage of males out of the labor force at age 59 $(47 \%)$ in the early 1990s. The figures for Germany are somewhat lower (35\%, 48\%, and $34 \%$, respectively).

\section{Phase II (Micro Estimation):}

1. Regression analyzes of micro data in each country demonstrated that retirement incentive variables such as social security wealth, the option value of postponing retirement, and the implicit tax on work significantly drive labor force departure. ${ }^{1}$ These findings support the findings from Phase I and strongly suggest a causal relationship from incentive variables to labor force departure.

2. The impact of the incentive variables is very similar across the countries despite cultural differences.

\footnotetext{
${ }^{1}$ Social security wealth is defined as the discounted sum of all future retirement income minus the future contributions to the social security system until retirement. The option value is the utility of the cash flow that follows from retiring at the highest utility yielding retirement age less the utility of the associated cash flow from retiring now.
} 
3. A hypothetical reform that increases eligibility ages (early and normal for all programs) by three years decreases the fraction of men aged 56-65 out of the labor force on average by up to 36 percentage points. In the Netherlands it decreases from about $75 \%$ to $50 \%$ (a decrease of 25 percentage points) while in Germany it decreases from about $40 \%$ to $10 \%$, i.e. by 30 percentage points.

\section{Phase III (Fiscal Implications):}

1. The same hypothetical reform leads to a reduction in net fiscal burden of $27 \%$ on average. In line with the previous magnitudes, the decrease would amount to $32 \%$ of net fiscal burden in the Netherlands and to $36 \%$ in Germany.

2. These reductions are heavily dependent on the status quo of the countries' pension systems.

At the same time, policymakers in Europe became aware of the ill incentive structure in social security. We will focus on Germany and the Netherlands as this dissertation deals mainly with these two countries. In Germany, actuarial adjustments to the normal retirement age have been set in place as of 1992 and a multi-pillar system introduced in 2001. The Netherlands has historically already relied on a multi-pillar system. However, its high implicit cost on working at age $60(141 \%)$ demonstrated that something had to be done about their "early retirement window". In 2006, the Dutch government abolished the entire public early retirement program and introduced the "Levensloopregeling" instead, a private savings scheme.

It is difficult for policy makers to know reforms' consequences a priori. Therefore carefully deducted research as the international social security project help to estimate the reforms' consequences. But the world keeps changing. Healthy life expectancy is expected to increase further and human behavior can differ between today and tomorrow. As a result, continuous sound research is needed. To evaluate future retirement pay and state budgets, we need to keep an eye on three questions:

1. How should and how do people save adequately?

2. When should and when do people retire given official retirement regulation?

3. How should and how do people dissave adequately in old age?

The normative aspect of the questions (the "should") is typically addressed in a life-cycle (LC) framework. In the LC framework, we assume agents to be rational in the sense that they decide upon their actions such that they maximize their lifetime happiness subject to, for example, an uncertain wage path and returns on investments. Lifetime happiness is 
measured in terms of utility, which can take several shapes. Because of its mathematical handiness, researchers often use a constant relative risk aversion (CRRA) utility function:

$$
U(C)=\sum_{t=S}^{T} \beta^{T-t} \frac{C_{t}^{1-\gamma}}{1-\gamma},
$$

where $S$ is the current age, $T$ the horizon end, $C$ consumption, $\beta$ the discount factor, and $\gamma$ relative risk aversion. More consumption makes the individual happier. Due to the relative risk aversion parameter $\gamma$ the agent dislikes fluctuations in the marginal utility of consumption, that is in the incremental value of consumption. The discount factor $\beta$ describes the agent's time preference. If he is impatient he prefers consumption today over tomorrow and if he is patient he may prefer consumption tomorrow over today. We can augment this simple utility function with a reward for leisure time to capture human's preference for leisure or with a reward for wealth upon horizon end. The agent has to decide subject to a budget constraint

$$
W_{t+1}=R_{t}\left(W_{t}+Y_{t}-C_{t}\right),
$$

where $W_{t}$ is beginning of period $t$ wealth, $R_{t}$ the gross return on wealth in period $t$ and $Y_{t}$ income in period $t$. Whatever the agent does not consume from his income remains in the wealth account. Thus, the agent implicitly also decides about the savings rate. The optimal solution is where the marginal utility of consumption and the marginal utility of savings (the rate of return) equate. In this simple model, the agent would optimally consume a constant fraction of current wealth and income. As in case of the utility function, we can augment the budget equation by, for example, changing $Y_{t}$ to the offered wage and multiplying it with the time the agent is willing to work.

We can answer Question (1) by using (1.1) and (1.2). To separate Question (1) from Question (3), we replace utility from consumption during old age by a final wealth measure that summarizes consumption during this time period. We can also include another decision variable $X_{t}$ that allows the agent to decide upon the portfolio allocations in his wealth account. Question (2) can be answered by introducing a decision variable $N_{t}$ that captures the amount of work that the agent is willing to supply. Once it remains zero we can call the agent retired. Additionally, we have to model the social security design in this LC model. Question (3) can be answered analogously to question (1) by starting with a certain wealth amount in old age and let the agent decide how much he needs to consume from his savings every period to maximize his utility. Browning and Lusardi (1996) and Browning and Crossley (2001) provide an excellent overview of the application of the LC framework.

The empirical questions (the "do") are usually answered by regression analysis. Given explanatory variables that are motivated through implications from the LC framework or 
through behavioral regularities, we aim to explain (1) the savings rate, (2) the retirement age and (3) the dissavings rate. To estimate the retirement age (Question (2)), two concepts, the social security wealth and the option value of postponing retirement as introduced by Stock and Wise (1990), have proven to be useful in explaining early retirement.

The prevailing conclusion from comparing (complex) LC framework implications and empirical analyses is alarming. Numerous findings in a book collection by Lusardi (2008) demonstrate that the majority of the people are not only saving too few or in an inadequate manner, but they also do not even know their pension plan type, let alone their pension wealth. Reasons for this lie in, amongst others, financial illiteracy, the triangle dilemma, ${ }^{2}$ or simply ignorance or a myopic attitude. Thaler and Sunstein (2008) show that people are able to save responsibly if they receive help.

I address the first two questions in my dissertation. Chapters 2, 4 and 5 deal with savings. Chapter 3 covers the retirement age. Moreover, Chapter 2 and 3 cover pension issues in Germany, while Chapter 4 and 5 deal with the Netherlands.

Whether people believe that they save adequately and what influences this judgement is investigated in Chapter $2 .{ }^{3}$ We look at German elderly in eastern and western Germany in 1992, 1995, 1999 and 2003. The dataset "Alterssicherung in Deutschland" (ASID) comprises multiple income sources at the household level, demographic information and the perception of (future) retirement income. Policy reforms have reduced the generosity for future retirees. We find that younger generations understand this. There are negative cohort effects, which demonstrate that the younger generations feel worse prepared for retirement than the older ones. Despite its importance for younger generations, these individuals only recognize the benefit of additional income sources to a limited extent over time, once we correct for the income level. Lastly, there are major differences in the magnitude of the effect of income and age on the adequacy of retirement income between eastern and western Germany.

Chapter $3^{4}$ discusses the consequences of female labor supply changes on individuals' retirement decision. While men's labor force participation profiles take on an inverted "Ushape", women's historically took on an "M-shape" due to very common and long maternity leaves (especially in western Germany). However, labor force participation profiles of young female birth cohorts have been becoming more similar to men's. Related to this change are emancipation, higher opportunity costs of work due to higher education, fewer children and higher divorce rates. As a result, women in western Germany are changing their retirement entry behavior. We undertake an analysis similar to that of the second international social

\footnotetext{
${ }^{2}$ This refers to the problem that very often there is an intermediary between the agent and the ultimate supplier of a product. The intermediary, a financial service provider for instance, is supposed to advice the client but at the same time receives a provision from the product supplier if he sells the product.

${ }^{3}$ This chapter is based on joint work with Peter C. Schotman.

${ }^{4}$ This chapter is based on joint work with Tabea Bucher-Koenen.
} 
security project. In calculating the option value we exogenously take into account future unemployment and disability risk but differentiate between the former generous and current stricter interpretation of disability. Regression analysis based on the administrative records of the German public pension provider (GRV) shows that cohort effects related to the average number of children significantly influence the retirement entry decision.

In Chapter 4 and 5, we analyze the saving decisions again (Question (1)) by looking at individuals' behavior with respect to the newly introduced life-course savings scheme (Levensloopregeling) in the Netherlands. This savings scheme was set up after the Dutch generous pre-retirement scheme, the "VUT", was abolished. Thereby, the government shifted responsibility for early retirement from the state to the individual. People use this scheme in order to finance maternity leave, to take a sabbatical, or to retire up to three years early. We focus on the latter in these chapters. The state stimulates this savings scheme by tax deferral, tax reductions and subsidies. One year after the introduction the participation rate remained low at $5.5 \%$.

To characterize people for whom tax deferred investing is a suitable we set up a life-cycle model that is tailored to the Dutch life-course savings scheme in Chapter $4 .{ }^{5}$ Interestingly, the implied participation rate is almost invariant to initial wealth levels. Participation steadily increases after age 45 . Complying with intuition, participation increases with the degree of impatience. But there is no clear pattern with respect to the preference for leisure. Our simulations show that people are better off using the scheme (versus no scheme) by up to $1.5 \%$ of certainty equivalent consumption, which amounts to additional consumption of $€ 3000$ to $€ 10,000$ on average over the lifetime. The exact amount depends on the parameters chosen. In the base line case, it is about $€ 5,600$. The government loses at the same time almost $15 \%$ of prior taxes or about $€ 12,000$. We conclude that individuals shift most of their savings from the regular to the tax deferred account and do not create additional savings. This allows them to increase their leisure and retire early, while the government is paying for this.

In Chapter $5^{6}$ we analyze the participation decision of the Dutch life-course savings scheme empirically, given a dataset of Dutch civil servants. Our analysis reveals that the use of the scheme (i.e. sabbatical or early retirement) plays an important role for the participation influencing factors. Once we eliminate the people who are likely to have a sabbatical or maternity leave in mind, participation increases in age (and income) as implied by LC theory. It also proves to be independent of wealth. Conditional on participation, we look at people's portfolio choices. In line with LC theory, a participant's portfolio weight on bonds increases with age and that on equity decreases with age. However, their portfolio

\footnotetext{
${ }^{5}$ This chapter is based on joint work with Frank Lutgens and Peter C. Schotman.

${ }^{6}$ This chapter is based on joint work with Peter C. Schotman.
} 
weight on a life-cycle fund, which is constructed as age-invariant, also decreases with age. Consequently, we see that people still need help in making the adequate savings decisions. Chapter 6 concludes. 



\section{Chapter 2}

\section{Subjective Financial Well-Being at Retirement in the Light of Pension Reforms in Germany}

\section{$2.1 \quad$ Introduction}

Happier people earn higher incomes, are more likely to get married, and have a higher life expectancy (Diener and Seligman 2004). Subjective Well-Being (SWB) is a relatively new quality of life measure, which goes beyond economic indicators but yet does not ignore them. Consequently, SWB measures are a useful tool for policy makers. Not only is it important to know past or current SWB, but also to learn about the driving factors of it in order to understand and estimate people's reactions to future political reforms. In this paper, we analyze the drivers of people's sentiment towards their financial situation, being one component of SWB, in old age.

Germany, as most countries, underwent severe political reforms of its pension system to deal with the retirement approaching baby-boomer generation, generally lower fertility rates as well as increasing life expectancy. From the reforms in 1972 until 1992, the German state pension was extremely generous and actuarially unfair. It hardly punished early retirees, nor rewarded late retirees sufficiently. Moreover, retirement income was indexed to gross wages rather than the cost of living as in the US (Börsch-Supan and Wilke 2004). As Börsch-Supan, Reil-Held, Rodepeter, Schnabel and Winter (2001) point out, the German state pension was so generous that individuals did not have to save for retirement on their own account, leading, amongst others, to a flat (positive) savings profile over age. This is referred to as the "German Savings Puzzle".

In 1992, major pension reforms took place. With regard to retirement incentives, the 
regular retirement age was raised for women and disabled and unemployed people as well as actuarial adjustments with respect to the retirement entry age were introduced. The implementation, however, only started in 1997 and most noticeably as of 2001. Analyzes by Börsch-Supan and Schnabel (1998) and Berkel and Börsch-Supan (2004) reveal that these amendments were not sufficient. In 1998, the demographic factor was introduced to adjust the replacement rate according to a function of life expectancy. But it was revoked only a year later. Also in 1999, the special state pension arrangement for women was abolished. The retirement window of the public old age pension (GRV) was thus substantially reduced. Only long-service life pensioners still have a retirement window. The following Riester Reform in 2001 became famous for a cut in the public pension replacement rate and its promotion of funded occupational and private pension schemes in order to arrive at a more stable multi-pillar pension system. ${ }^{1}$ Additionally, it has set a boundary on contribution rates of $20 \%$ until 2020 and $22 \%$ until 2030. Some institutes come to the conclusion that the real rate of return to the German Pay-As-You-Go (PAYG) system may even become negative for single males. Ottnad and Wahl (2005) find the real rate of return steadily decreasing until birth cohorts $2010 .^{2}$ For around $85 \%$ of the German population contributions to the GRV are mandatory. Consequently, the majority of the German population is affected by these reforms.

This paper analyzes how Germans' subjective financial well-being (SFWB) at retirement varies across several characteristics. SFWB of survey respondents is given by their perception of their financial situation in old age. ${ }^{3}$ We look at SFWB in the sense of retirement income adequacy and especially investigate how it is determined by individuals' birth years as the pension reforms since 1992 caused the return of the public pension to be cohort dependent. In order to analyze individuals' perception of their retirement income and therefore the role of savings as a function of the other characteristics, we argue from a life-cycle theory perspective. The life-cycle framework is a powerful tool to analyze rational behavior of individuals. A variety of empirically observed saving motives, such as precautionary savings and life-cycle savings (i.e. borrow when young, save for retirement when getting older),

\footnotetext{
${ }^{1}$ Reforms after the Riester Reform such as the reforms following the proposals of the Rürup Commission are irrelevant for this paper due to data constraints.

${ }^{2}$ Wilke (2005) provides real rates of return until birth years 1980 and finds them to be small but positive. The predicted returns of the Sachverständigenrat (2004) lie substantially above the predictions of the above studies. The main reason lies in different calculation approaches. The latter use a deterministic approach while the former two use a stochastic approach. Other differences stem from assumptions about the economic and demographic situation.

${ }^{3}$ In the survey, individuals were asked how well they thought they were financially prepared for old age (=Was würden Sie sagen: Wie gut sind Sie im Alter finanziell gesichert?). Respondents were asked to check "very well" (=sehr gut, 0), "good" (= gut, 1), "rather not so good" (=weniger gut, 2), "rather bad" (=eher schlecht, 3) or "very bad" (=sehr schlecht, 4$)$.
} 
can even be explained by the most standard life-cycle model of consumption ${ }^{4}$ (Browning and Lusardi 1996). To accommodate the empirically observed positive correlation between (expected) income growth and savings growth, which is at odds with the standard version, Carroll and Weil (1994) introduce habit formation to the standard life-cycle model. In this model, utility does not only depend on the consumption level but also on the relationship between current and future consumption. We base our hypotheses about the determining factors of SFWB on this life-cycle model.

The hypotheses are tested based on data from the survey "Alterssicherung in Deutschland" (ASID) in 1992, 1995, 1999 and 2003. In each of these years, a representative sample of approximately 30,000 individuals was interviewed regarding their subjective financial well-being, numerous income sources, and assets. The cross sections do not coincide over the years, which renders classical panel data analysis impossible. To identify cohort effects, we construct a synthetic panel as suggested by Deaton (1985). Following this, we use individual data in a cross-sectional regression to dig deeper into the effect of various income sources. In both estimations, we employ a probit adopted OLS regression (van Praag and Ferrer-i-Carbonell 2004). Our panel approach demonstrates that young birth cohorts perceive their SFWB worse than older birth cohorts. This indicates that they are aware of the implications and political and demographic risk that is associated with the pension reforms. Using the cross-sectional regressions, we find mixed results concerning the importance of additional income sources. The subsample that is largely unaffected by the reforms because they are already retired appreciates additional income sources, while the subsample that is predominantly still working is hardly doing so. Individuals' characteristics as education, income and wealth are in line with life-cycle theory implications. Differences in the perception between eastern and western Germany also become apparent.

The next section explains the hypotheses. Section 2.3 introduces the cross-sectional ASID waves, followed by the description of the methodology in Section 2.4. The synthetic panel results are presented in Section 2.5, and the cross-sectional ones in Section 2.6. A conclusion will be provided in Section 2.7 .

\subsection{Hypotheses}

\section{Relationships between SFWB and Individual Characteristics}

Previous research has demonstrated that individuals with high education have stronger income growth rates than people with low education (see Fitzenberger, Schnabel and Wunderlich (2004) for Germany). According to the life-cycle model with habit formation, this

\footnotetext{
${ }^{4}$ That is, we assume intertemporal additive utility, complete markets and rational agent behavior.
} 
will lead to a higher savings rate. Moreover, better educated people are also more knowledgeable and can make more sophisticated savings decisions. Therefore,

(1) we expect better educated people to evaluate their SFWB at retirement superior.

Individuals are said to save adequately if they succeed in smoothing their consumption over the life cycle (Fornero, Lusardi and Monticone 2009). This does not imply that they always consume the same, but that they try to avoid jumps. Given an uncertain earnings path, it may happen that an individual is surprised by a large negative income shock due to unemployment for instance. The individual will reduce consumption and live on precautionary savings. Thus, the savings rate decreases. High income earners, however, can adopt to this savings rate decrease more easily than low income earners. Therefore,

(2) we expect individuals with high income to be more positive about their SFWB at retirement than those with low income.

More wealth also facilitates consumption smoothing. Consequently,

(3) we expect people to perceive their SFWB at retirement better the wealthier they are.

As Banks, Blundell, Disney and Emmerson (2002) note, saving is a forward looking activity. Accordingly, young people do not perceive their (future) financial situation as bad because they anticipate that they will accumulate savings over the lifetime. ${ }^{5}$ As a result, we can assume that there will be no age effect on SFWB if we correct for all other influences (such as income). Two related effects are the cohort and the time effect. From the course of public pension reforms in Germany, we know that the real rate of return to the public pension system is decreasing (i.e. Ottnad and Wahl 2005, Wilke 2005). The younger cohorts carry the financial burden of current retirees and responsibility for their own retirement income. Moreover, as a result of the shift towards funded occupational and private pension plans, the overall retirement income risk has changed for individuals (Börsch-Supan and Reil-Held 1998). While former retirees mainly faced (reasonably low) demographic and political risk through the unfunded PAYG system, younger cohorts, who are investing directly and indirectly through strengthened occupational and private pension plans in stocks and bonds, face capital market risk on top of this. Ongoing political discussions in the media about the sustainability of the state pension demonstrate the increasing political and demographic risk, especially for the younger generation. Consequently, their perception about retirement income should be changing. Older cohorts, who are already retired, still benefit to a large extent from the old rules. Thus, they should indicate higher SFWB at retirement than the younger ones. Therefore,

\footnotetext{
${ }^{5}$ The behavioral finance literature suggest that people procrastinate saving. Given, this interpretation people still start later in life and do not feel bad about it in the present.
} 


\section{(4) we expect to see a negative cohort effect on SFWB at retirement. ${ }^{6}$}

The time effect is ambiguous because it captures various changes.

The 2001 reform requires individuals to save additionally in the second and third pillar if they want to fill the emerging gap caused by reduction in the first pillar pension (see Börsch-Supan and Wilke (2004)). Additional income sources facilitate extra saving and therefore help to achieve an adequate retirement income level. In a second analysis, we investigate whether individuals acknowledge the advantage of additional income once we control for the total level of income. From a life-cycle perspective additional income sources are recommendable because of diversification. However, more dominant may be a behavioral effect of additional income sources on SFWB. As Thaler and Sunstein (2008) explain, people keep mental accounts or piggy banks. A woman may have one for shopping grocery, one for shopping labels and one for retirement. Depending on where the money comes from it is allocated to one of the piggy banks. Therefore,

(5) we expect the young generation to acknowledge additional income sources for their evaluation of SFWB at retirement more over time.

\section{The Meaning of SFWB differs between Old and Young People}

People in old age already know their retirement income. They only have to judge how well it makes them off. For young people, who are still in the labor force, it is more difficult to assess their SFWB. Their first step is to predict their future labor income path and the resulting retirement income. It is only the second step, the assessment of this income path, that they have in common with the retirees. The non-retirees therefore answer this question with more uncertainty compared to the retirees because they do not know their total income path yet and secondly have more difficulties in assessing whether it will be sufficient for their standard of living. Given risk averse individuals, uncertainty can lead to different SFWB evaluations. To control for this aspect we split the sample into two subsamples at the mean retirement age. The average retirement age in 1995 was 60.5 for males and 58.4 for females (Banks et al. 2002). We therefore split the sample into an older than 60 (including those who are 60 years old) and a younger than 60 sample. ${ }^{7}$ The ASID waves aim at individuals older than 50 . Therefore the proportion of the older subsample is relatively high around $70 \%$. We refer to these subsamples as the young and the old sample.

Because of risk aversion and uncertainty, we expect the income effect on SFWB to differ between people in old age and people in the labor force. In contrast to the elderly

\footnotetext{
${ }^{6}$ There have been no other legal amendments between 1992 and 2003 that were cohort related and affect people's finances.

${ }^{7}$ We take age 60 instead of the retirement status as a selection point because it is exogenous to the dependent variable.
} 
sample the young sample faces uncertainty in their wages. Risk averse individuals require some percentage more income to feel equally well about their financial situation than an individual that does not face any risk as the elderly sample. Therefore,

(2a) we expect the slope of the income effect on SFWB at retirement in the old sample to be steeper than in the younger sample.

Most of the old sample is already retired when the reforms take place. Everyone is affected by the change in indexation. But only the cohorts born after 1937 are affected to different extents by the changes in eligibility ages, contribution and replacement rates. As a result,

(4a) we expect the cohort effect on SFWB at retirement to be flat in the old sample and

(4b) we expect the cohort effect on SFWB at retirement to be negative in the young sample.

\subsection{The ASID Data}

In order to investigate individuals' evaluation of their financial well-being at retirement, we make use of the data set "Altersicherung in Deutschland" (ASID) from the Zentralarchiv für Empirische Sozialforschung situated in Cologne. The first survey was conducted in 1986, however restricted to the old federal states of Germany. Thus, we discard this first wave. It was followed by another wave in 1992, which then also incorporated the new federal states in the east. The questionnaire was sent to a random sample of couple and single households, who were older than 55 . In the former case, the questionnaire was to be completed by husband and wife. In order to achieve a high response rate the respective individuals were once reminded by a letter and then called by an interviewer. Further, incomplete surveys were completed over the phone by an interviewer whenever possible. The respondents were asked numerous questions about their current accommodation, education, job and firm characteristics, income sources, socio-demographics, and perceived financial well-being. Data cleaning ensured that an individual's responses were consistent to establish internal validity. External validity, concerning the representativeness of the German population, was established by comparing sample statistics to reference statistics from the Federal Statistical Office with regard to gender, age, state, and especially the state pension (GRV for regular employees and BVG for civil servants). In 1995 another survey was conducted in the same manner only for residents of the new federal states. Since no major changes in regulation had taken place for the people in the old states, their responses from 1992 were projected to 1995 on the basis of a special microsimulation model.

Two survey waves followed in 1999 and 2003, which closely follow the previous two cross-sectional waves. We exclude people living in institutions (=Heimbewohner) as they 
might not be able to assess their financial well-being. Further, we drop those individuals who did not indicate an evaluation of their financial well-being and/or income. Appendix 2.A breaks down the final number of observations by cohort, region(east/west) and year.

\section{Descriptive Statistics of SFWB at Retirement}

The original five point Likert Scale of SFWB, 0 to 4, was extended ex-post, 0 to 8, to be able to rank double checking as some respondents checked, for instance, good and very good simultaneously. Throughout the paper, we interpret the SFWB in terms of retirement income adequacy. For the sake of illustration we work with the negative of this scale, such that the best feeling corresponds to the highest number.

Table 2.1 illustrates how SFWB varies with demographic characteristics. Moreover, it distinguishes the years before and after the pension reforms kicked in and people older and younger than the average retirement age of 60 in the respective year. We assume that the pension reforms have been realized as of 1999. The amendments from 1992 started to become into effect in 1997 and media exposure was large at that time. The German government revoked the demographic adjustment factor to pension income, which was only introduced a year earlier, and increased the VAT to secure sustainable contribution rates. Moreover, the special treatment of women with regard to the state pension was finally eliminated. Therefore, it is safe to assume that from 1999 on, people have incorporated the reform implications into their expectations of SFWB at retirement or have started to feel the political and demographic risk at least. The descriptive statistic for the overall SFWB shows that there is no systematic decrease in SFWB over time. Consequently, people's mood with regard to their pensions is not generally decreasing.

If we distinguish by region, we observe higher SFWB scores in western than in eastern Germany. In eastern Germany, the time trend is positive for the young and the old sample before and after 1999. In western Germany, it is negative for the young sample over the entire period, while it is positive for the old sample until 1999 and decreases thereafter. The discrepancy between the young and the old in western Germany is in line with the return cutting reforms. It is also interesting to observe that males feel better about their financial situation than females in the old sample, whereas it is the opposite way around in the young sample. Women, born before 1952 and given a certain number of service years, still enjoy younger eligibility ages. Distinguishing the years before and as of the realization of pension reforms, we observe much lower means of SFWB for both genders in the young sample and only slightly lower means for both genders in the old sample. Again, this is in line with the nature of the reforms. 


\begin{tabular}{|c|c|c|c|c|c|c|c|c|}
\hline & \multicolumn{4}{|c|}{ Before Reform Realization } & \multicolumn{4}{|c|}{ As of Reform Realization } \\
\hline & \multicolumn{2}{|c|}{1992} & \multicolumn{2}{|c|}{1995} & \multicolumn{2}{|c|}{1999} & \multicolumn{2}{|c|}{2003} \\
\hline & Young & Old & Young & Old & Young & Old & Young & Old \\
\hline \multicolumn{9}{|l|}{ Overall } \\
\hline & \multicolumn{2}{|c|}{-3.261} & \multicolumn{2}{|c|}{-3.163} & \multicolumn{2}{|c|}{-3.045} & \multicolumn{2}{|c|}{-3.323} \\
\hline \multicolumn{9}{|l|}{$\underline{\text { Region }}$} \\
\hline East & -4.248 & -3.478 & -4.118 & -3.226 & -3.829 & -2.973 & -4.314 & -3.367 \\
\hline West & -3.100 & -2.913 & -3.100 & -2.913 & -3.158 & -2.868 & -3.472 & -3.128 \\
\hline \multicolumn{9}{|l|}{ By Gender } \\
\hline Male & -3.552 & -3.097 & -3.472 & -2.990 & -3.439 & -2.877 & -3.800 & -3.186 \\
\hline Female & -3.519 & -3.140 & -3.424 & -3.045 & -3.342 & -2.927 & -3.694 & -3.230 \\
\hline \multicolumn{9}{|l|}{ By Jobtype } \\
\hline$\overline{J o b 1}$ & -3.487 & -3.215 & -3.487 & -3.215 & -3.892 & -3.201 & -4.253 & -3.583 \\
\hline Job2 & -3.145 & -2.943 & -3.147 & -2.943 & -3.574 & -2.922 & -3.979 & -3.343 \\
\hline Job3 & -2.852 & -2.580 & -2.846 & -2.579 & -3.155 & -2.641 & -3.474 & -2.985 \\
\hline Job4 & -2.731 & -2.310 & -2.589 & -2.258 & -2.836 & -2.508 & -3.026 & -2.660 \\
\hline Job5 & -2.345 & -2.094 & -2.343 & -2.092 & -2.749 & -2.397 & -2.895 & -2.526 \\
\hline \multicolumn{9}{|l|}{ By Income } \\
\hline less 500 & -5.333 & -6.059 & -5.444 & -5.941 & -4.000 & -5.795 & -5.716 & -5.285 \\
\hline$(500,1000)$ & -5.119 & -4.691 & -5.478 & -5.127 & -5.544 & -4.993 & -5.213 & -4.409 \\
\hline$(1000,1500)$ & -4.688 & -3.779 & -4.883 & -4.258 & -5.084 & -4.506 & -4.518 & -3.494 \\
\hline$(1500,2000)$ & -4.368 & -3.534 & -4.433 & -3.504 & -4.661 & -3.609 & -3.947 & -3.118 \\
\hline$(2000,3000)$ & -3.962 & -3.239 & -4.134 & -3.194 & -4.057 & -3.128 & -3.556 & -2.725 \\
\hline$(3000,4000)$ & -3.630 & -2.854 & -3.654 & -3.061 & -3.836 & -2.919 & -3.209 & -2.507 \\
\hline$(4000,5000)$ & -3.403 & -2.667 & -3.523 & -2.731 & -3.651 & -2.711 & -2.850 & -2.194 \\
\hline more 5000 & -3.213 & -2.514 & -3.286 & -2.634 & -3.391 & -2.509 & -2.766 & -2.058 \\
\hline \multicolumn{9}{|l|}{ By Age } \\
\hline less 55 & -3.473 & & -3.320 & & -3.333 & & -3.751 & \\
\hline$(55,58)$ & -3.539 & & -3.480 & & -3.404 & & -3.778 & \\
\hline$(58,60)$ & -3.568 & & -3.475 & & -3.384 & & -3.656 & \\
\hline$(60,62)$ & & -3.453 & & -3.357 & & -3.255 & & -3.577 \\
\hline$(62,65)$ & & -3.253 & & -3.193 & & -3.078 & & -3.454 \\
\hline$(65,70)$ & & -3.085 & & -2.955 & & -2.906 & & -3.243 \\
\hline$(70,75)$ & & -2.977 & & -2.874 & & -2.727 & & -3.113 \\
\hline$(75,80)$ & & -2.948 & & -2.841 & & -2.648 & & -3.010 \\
\hline$(80,85)$ & & -2.953 & & -2.880 & & -2.762 & & -2.812 \\
\hline more 85 & & -3.068 & & -2.927 & & -2.971 & & -2.831 \\
\hline \multicolumn{9}{|l|}{ By Cohort } \\
\hline less 1917 & & -2.971 & & -2.905 & & -2.888 & & -2.895 \\
\hline$[1917,1922)$ & & -2.966 & & -2.847 & & -2.691 & & -2.696 \\
\hline$[1922,1927)$ & & -3.046 & & -2.869 & & -2.696 & & -2.989 \\
\hline$[1927,1932)$ & & -3.271 & & -2.993 & & -2.789 & & -3.052 \\
\hline$[1932,1937)$ & -3.557 & -3.522 & -3.508 & -3.304 & & -2.973 & & -3.191 \\
\hline$[1937,1942)$ & -3.497 & & -3.463 & & -3.384 & -3.225 & & -3.395 \\
\hline$[1942,1947)$ & -3.463 & & -3.296 & & -3.371 & & -3.685 & -3.577 \\
\hline$[1947,1952)$ & -3.511 & & -3.437 & & -3.359 & & -3.741 & \\
\hline more 1952 & -3.455 & & -3.223 & & -3.566 & & -3.888 & \\
\hline
\end{tabular}

Table 2.1: Mean SFWB by Demographic Characteristics

This table contains average SFWB scores $(-8,0)$. Along the Columns, we distinguish the survey years and the young (younger than 60 years) and the old (older than 60 years) sample. Along the rows, we distinguish between several characteristics. The job types from 1 to 5 refer to respectively blue-collar worker, skilled worker, qualified employee, qualified employee in leading position and executive. Income is defined as monthly income after taxes. 
Education has a profound impact on people's savings. In our sample, most people underwent the same education. In the 1999 sample, two thirds of the people had only basic education (=Volksschulabschluss) as it was common until the middle of the 20th century. A higher degree of heterogeneity in our sample is found in the type of job, which also gives us an indication about people's abilities as the degree of responsibility and intellectual challenge increases with the job type. Therefore it is not surprising to see average SFWB increasing from job type 1 (blue-collar worker) to job type 5 (executive). Comparing again the years before and since reform realizations for the old sample, we can observe a slight decrease from -3.215 to -3.583 in average SFWB of job type 1 and a slight decrease from -2.094 to -2.526 in average SFWB of job type 5. The drop is much larger for the young sample. Here, average SFWB drops from -3.487 to -4.253 for job type 1 and from -2.345 to -2.895 for job type 5. Again, this shows that the young sample expects to be worse off in old age than the old sample.

Similar observations can be made for the level of monthly after tax income. In all subsamples, there is a monotonic increase in average SFWB over income when income is larger than $€ 500$. Earning higher income thus pays off in terms of perceived financial security in old age. Furthermore, the means are always greater for the older than for the younger than 60 sample. There is no clear time trend in these categories.

Typical subjective well-being profiles are U-shaped over the life-cycle (Blanchflower and Oswald 2008). In this paper, however, we study subjective FINANCIAL well-being AT RETIREMENT in the sense of retirement income adequacy. As argued above, this should not vary over age. Table 2.1, however, depicts a systematic pattern of SFWB over age. For the old sample, SFWB increases from age group 60-62 until age group 75-80 or 80-85 in all years. SFWB decreases again for the (two) oldest age groups. For the young sample, there is also a clear trend prior to the realizations of pension reforms: SFWB becomes worse with age. After the reforms have been kicking in, the means are less dispersed and the middle age group 55-58 always feels worst. This demonstrates that the reforms have an effect on the relationship between SFWB and age or a function of age.

This function of age could be the birth or the calender year. As argued before, we expect a negative relationship between the birth years after 1937 and SFWB. ${ }^{8}$ Table 2.1 illustrates that, before the reforms were realized in the public, SFWB of the young sample increases from the earliest cohort born till the (second to) last cohort born. Once the reforms were realized, the worst SFWB always corresponds to the cohort born after 1950. In case of the old sample, SFWB simply decreases with birth cohorts, disregarding the oldest cohort in 1995 and 1999. In summary, while the cohort pattern of the old sample remains roughly constant the cohort pattern of the young sample, which is affected more by the reforms,

\footnotetext{
${ }^{8}$ Individuals born before 1937 are unaffected by the reforms, except for the change in indexation.
} 
is altered in favor of the hypothesis that the reforms lead to negative changes in SFWB for young cohorts. Formally we can test whether the differences between the affected and unaffected cohorts differs before and after 1999.

$$
\begin{array}{cc}
H_{0}: & \Delta_{\text {prior }}=\Delta_{\text {after }} \\
H_{1}: & \Delta_{\text {prior }} \neq \Delta_{\text {after }} \\
\Delta_{\text {prior }}=\frac{\sum_{t=\{1992,1995\}} \sum_{i \in\{C<1937\}} y_{i t}}{\sum_{t=\{1992,1995\}} \sum_{i} I_{C<1937}}-\frac{\sum_{t=\{1992,1995\}} \sum_{i \in\{C \geq 1937\}} y_{i t}}{\sum_{t=\{1992,1995\}} \sum_{i} I_{C \geq 1937}} \\
\Delta_{\text {after }}=\frac{\sum_{t=\{1999,2003\}} \sum_{i \in\{C<1937\}} y_{i t}}{\sum_{t=\{1999,2003\}} \sum_{i} I_{C<1937}}-\frac{\sum_{t=\{1999,2003\}} \sum_{i \in\{C \geq 1937\}} y_{i t}}{\sum_{t=\{1999,2003\}} \sum_{i} I_{C \geq 1937}}
\end{array}
$$

where $C$ is the cohort birth year, $y_{i t}$ is SFWB of individual $i$ in year $t$ and $I_{C<1937}\left(I_{C \geq 1937}\right)$ an indicator for people born prior to (after) 1937. The t-statistic is 13.40. The rejection of $H_{0}$ at the $1 \%$ level confirms that there has been a change in the young cohort's perception of financial well-being once the reforms have been realized.

Three important findings from these observations should be kept in mind. First, the young sample always feels worse than the old sample. Second, the reforms turn the cohort patterns of SFWB around in the young sample, while they remain stable in the old sample. And third, a difference in difference test confirms a switch in younger cohort's perception about SFWB at the time that individuals have understood the reforms. These intermediate conclusions stem from descriptive evidence, which does not control for various other influences. In the next section, we control for them and show that cohort effects are also present when controlling for other determinants such as time, income and other demographic information.

\subsection{Estimation}

Given the measurement of SFWB, which will serve as the dependent variable, an ordered probit or logit model is the appropriate tool for our analysis. We assume that there are $i=1, \ldots, N$ individuals, each of which chooses a response $y_{k}$ out of a finite number of ordered response categories $k \in\{1, \ldots, K\}$. Van Praag and Ferrer-i-Carbonell (2004) propose a method to transform the responses $y_{k}$ into a variable that is approximately distributed as a standard normal variable. Consequently, we can estimate the model by OLS. Implicitly, we allow for a cardinal meaning of the responses now. We apply the empirical transformation as, for instance, used by Börsch-Supan and Jürges (2006) for each survey year separately:

$$
y_{k}^{*}=\Phi^{-1}\left(\frac{1}{N} \sum_{i=1}^{N} I\left(y_{i} \leq y_{k}-1\right)+\frac{1}{2} \frac{1}{N} \sum_{i=1}^{N} I\left(y_{i}=y_{k}\right)\right),
$$

where $\Phi^{-1}$ is defined as the inverse of the standard normal distribution and $I$ is the indicator function. The first term in the bracket represents the proportion of individuals, who have 
checked response categories lower than or equal to $k$. The second term in the bracket calculates the proportion of individuals, who have checked response category $k$.

\subsubsection{Synthetic Panel Approach}

To analyze cohort, income, education and wealth effects (Hypotheses 1 to 4) on SFWB while controlling for various other influences, we estimate the following equation:

$$
y_{i t}^{*}=\alpha+\boldsymbol{\beta} \boldsymbol{C}_{i t} \otimes \text { east }_{i t}+\boldsymbol{\gamma} \boldsymbol{T}_{i t} \otimes_{\text {east }_{i t}}+\boldsymbol{\delta} \text { Inc }_{i t} \otimes_{\text {east }_{i t}}+\boldsymbol{\lambda} \text { controls }_{i t}+e_{i t},
$$

where $y_{i t}^{*}$ is a function of SFWB as defined in 2.1; $\mathbf{C}_{\mathbf{i t}}$ consists of all relevant cohort dummies; $\mathbf{T}_{i t}$ of all times dummies $(1995,1999,2003)$ and $\mathbf{I n c} \mathbf{n}_{i t}$ of the second order polynomial of income. east $i t$ is a dummy for people living in the east of Germany. The controls $i t$ consist of household size, number of household earners, gender, a dummy for marriage, home ownership, a dummy for self-employed people, a dummy for people who indicate to have health problems and the job type. $e_{i t}$ are the residuals.

- For the more than 60 year olds, $\mathbf{C}_{\mathbf{i t}}$ contains cohort dummies from cohort $1, c 1$, till cohort $7, c 7$, except for cohort $5(c 5)$.

- For the less than 60 year olds, $\mathbf{C}_{\mathbf{i t}}$ contains cohort dummies from cohort 6 , c6, till cohort $9, c 9$, except for cohort $5(c 5)$.

$c 2$ till $c 8$ are five year birth cohorts between 1917 and 1952. $c 1$ are all birth cohorts before 1917 and $c 9$ all birth cohort born after 1952. Five year dummies is the result of a tradeoff between degrees of freedom and precision of cohort effects. The threshold years are selected such that there is a break in year 1937, which corresponds to the last cohort not affected by the cohort specific reforms. The reference group is born between 1932 and $1937\left(c_{5}\right)$. We include time dummies for each year. 1992 is the base year. Their impact is ambiguous because they can capture anything during these periods. We use household income after taxes as opposed to before taxes to account for the different tax treatment of civil servants and regular employees. Further, we model income as a second order polynomial to account for the impact of income to decrease at higher income levels. Also, we distinguish between eastern and western Germany. There still are cultural and price level differences between eastern and western Germany due to differing state regimes between World War II and the reunification in 1990. Tigges, Rieger, Jonitz, Brengelmann and Engel (2000) find that people in the east are more risk averse than people in the west. Income inequality is also shown to be significantly lower in the east (Biewen 2000). Therefore, we allow all effects that we are interested in to differ between eastern and western Germany. 
To correct for wealth, we include a dummy for people who live in their own house. People can borrow against their house and have therefore access to more money than people who do not have a house. Next to income, wealth, birth cohort and time, we include standard explanatory variables for $\mathrm{S}(\mathrm{F}) \mathrm{WB}$ or the adequacy of retirement income include socio-demographic variables such as gender, marital status, education and health (Diener and Biswas-Diener (2002), Seghieri, Desantis and Tanturri (2006), Headey (1993)). Related, are the corrections for household size and the number of earners, which also affect SFWB through household income. All of them are included as dummies. By controlling for these variables and age (through time and cohort) we can isolate the income effect. The comparative European study of Seghieri et al. (2006) identifies marriage to have a positive effect on financial satisfaction in all countries but Portugal and Greece. Next to different tax treatments of singles and married couples, marriage also indicates a strong social support system, which leads to better general well-being and may have repercussion on SFWB. Seghieri et al. (2006) find the gender effect to differ between Northern and Southern European countries: Males are more satisfied with their financial situation in the South while women are more satisfied with it in the North. In line with Headey (1993), they demonstrate that bad health has a distressing effect on financial well-being. Bad health often depresses individuals, especially when chronic, and can, due to lower productivity, also deprive labor income. Moreover, sick people also need more medication which can consume a large share of their earnings. We therefore include a dummy for self-assessed bad health.

As our data consists of several cross sections we use a synthetic panel as proposed by Deaton (1985). Individuals are sorted into groups according to certain criteria, which are in our case: cohort membership and east / west residence. This leads to 88 groups or equivalently 88 new synthetic "individuals". Our groups exhibit large differences in the number of observations per group. Therefore, the new synthetic "individuals" are weighted by the square root of number of observations in the respective group. As the individual observations differ from their respective group means (the synthetic "individual" response), an errors-in-variables estimator is applied to all variables but cohort, east and year. The variables cohort, east and year are exactly identified by the definition of the groups. According to Deaton (1985), the estimator and its covariance matrix can be calculated as follows:

$$
\begin{aligned}
\hat{\beta}= & \left(X^{\prime} X-T S\right)^{-1}\left(X^{\prime} y^{*}-T s\right) \\
V(\hat{\beta})= & \widehat{\Omega}^{-1}\left[T^{-1} X^{\prime} X e^{\prime} e+T^{-2} X^{\prime} e e^{\prime} X\right] \widehat{\Omega}^{-1} \\
& +v^{-1} \widehat{\Omega}^{-1}\left[S\left(s_{00}-2 s^{\prime} \beta+\beta^{\prime} S \beta\right)+T^{-2} X^{\prime} e e^{\prime} X\right] \widehat{\Omega}^{-1} \\
S= & \operatorname{cov}\left(X_{i t c}-\bar{X}_{t c}\right) \\
s= & \operatorname{cov}\left(X_{i t c}-\bar{X}_{t c}, y_{i t c}^{*}-\bar{y}_{t c}^{*}\right)
\end{aligned}
$$




$$
\begin{aligned}
s_{00} & =\operatorname{var}\left(y_{i t c}^{*}-\overline{y_{t c}^{*}}\right) \\
\widehat{\Omega} & =X^{\prime} X-S,
\end{aligned}
$$

where $\hat{\beta}$ consists of the parameter estimates of $\alpha, \boldsymbol{\beta}, \boldsymbol{\gamma}, \boldsymbol{\delta}$ and $\boldsymbol{\lambda}$ from equation (2.2); $X$ are the explanatory variables as given in (2.2); $T$ is the number of observations in the synthetic panel (number of groups times number of time series observations), $v$ is the average number of individuals in each group, and $e$ the residuals from (2.2).

\subsubsection{Cross-Sectional Approach}

We also use cross-sectional regressions to identify the importance of individuals' income sources (Hypothesis 5). For each survey year, we estimate:

$$
y_{i}^{*}=\alpha+\boldsymbol{\beta} \boldsymbol{C}_{\boldsymbol{i}} \otimes \text { east }_{\boldsymbol{i}}+\boldsymbol{\gamma} \boldsymbol{T}_{\boldsymbol{i}} \otimes \mathrm{east}_{\boldsymbol{i}}+\boldsymbol{\delta} \text { Inc }_{\boldsymbol{i}} \otimes \text { east }_{\boldsymbol{i}}+\boldsymbol{\kappa} \text { Inc sources }_{\boldsymbol{i}}+\boldsymbol{\lambda} \operatorname{controls}_{\boldsymbol{i}}+e_{i},
$$

where Inc sources ${ }_{i}$ consists of several dummies that indicate whether an individual receives income from a specific source. As the level of income is already corrected for, the nature of the income source effect $\boldsymbol{\kappa}$ is only psychological. Additional to the controls of 2.2, controls in 2.5 also include the dummies for the industries that people are or used to be employed in. Assuming that the norm is to receive labor or state pension income, these income sources should be insignificant. The effects of the following income sources are ambiguous:

- work

- regular state pension, GRV (only for old sample)

- state pension for civil servants, BVG (only for old sample)

- KLG, a special pay for women who gave birth before 1921, so called Trümmerfrauen (only for old sample) $)^{9}$

- early retirement pay (state pension).

As people prefer to receive a certain amount of income without working for it over working for it, we expect the effect of the income source work to be smaller than that of GRV, BVG, early retirement and KLG. Additional income or wealth sources should have a positive effect:

- occupational pension (only for old sample)

\footnotetext{
${ }^{9}$ These women did not get the years in which they cared for their children accredited. As a result, the German state passed a law that entitles these women to monthly payments that range between 27 and 35 DM. (ASID Information)
} 
- savings and securities

- rent and lease

- home ownership

Income from social security aids should depress SFWB:

- unemployment insurance

- health insurance.

Recall that couples had to fill out two questionnaires to leave them scope for diverging opinions or different demographic characteristics. As they are likely to behave similarly though, we correct for the correlation between couples' residuals by employing Feasible Generalized Least Squares (FGLS). Thus, we regress the transformed SFWB on the explanatory and control variables in first step, compute the (positive) correlation, $\rho$, between partners and assume no correlation across households. The second step is to estimate the model by FGLS, which then incorporates a twofold weighting matrix: ${ }^{10}$

$$
\Omega=\left[\begin{array}{ccccccc}
1 & \rho & 0 & 0 & 0 & 0 & 0 \\
\rho & 1 & 0 & 0 & 0 & 0 & 0 \\
0 & 0 & 1 & \rho & 0 & 0 & 0 \\
0 & 0 & \rho & 1 & 0 & 0 & 0 \\
& & & \ddots & & & \\
0 & 0 & 0 & 0 & 0 & 1 & 0 \\
0 & 0 & 0 & 0 & 0 & 0 & 1
\end{array}\right] ;
$$

to be precise an estimate of the former, where $\rho$ is replaced by the estimate $\hat{\rho}$ in $\hat{\Omega}$. For every cross section $\hat{\beta}$ and $V(\hat{\beta})$ can be retrieved as:

$$
\begin{aligned}
\hat{\beta} & =\left(X^{\prime} \hat{\Omega}^{-1} X\right)^{-1}\left(X^{\prime} \hat{\Omega}^{-1} y^{*}\right) \\
V(\hat{\beta}) & =\left(\frac{e \widehat{\Omega}^{-1} e}{N-m}\right)\left(X^{\prime} \hat{\Omega}^{-1} X\right)^{-1},
\end{aligned}
$$

where $\hat{\beta}$ now consists of the parameter estimates and $X$ of the variables from equation 2.5; $N$ refers to the number of observations and $m$ to the number of independent variables.

\subsection{Cohort and Income Effects in the Synthetic Panel}

In order to analyze Hypotheses 1 to 4 we investigate the outcome of regression equation (2.2) for the old and the young sample in this section.

\footnotetext{
${ }^{10}$ We order the observations such that couples are sorted in front of singles.
} 


\section{The old sample}

The complete estimates of regression equation (2.2) can be found in the left half of Table 2.B1 in Appendix 2.B. Figure 2.1 depicts the cohort effects for the older than 60 sample. Note that we normalize with respect to the cohort born between 1932 and 1937. We plot the coefficients of the respective cohort dummies against cohorts.

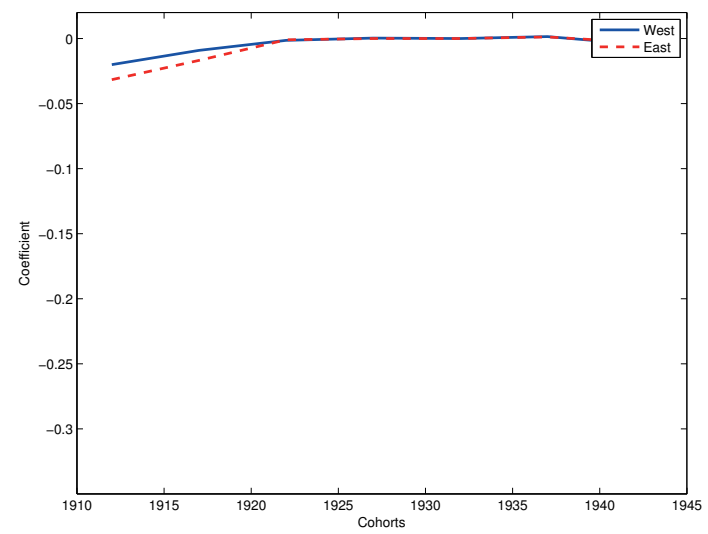

Figure 2.1: Cohort Effects for the old Sample in eastern and western Germany

This figure plots the cohort effects of the elderly (older than 60 years) sample. The cohort effects are the coefficients of the dummies from regression (2.2). The solid blue line corresponds to western and the dashed red line to eastern Germany.

Figure 2.1 demonstrates that there is hardly any difference between the cohort effects in eastern (dotted red) and western (solid blue) Germany for the old sample. Both are negative for the early cohorts and soon converge to zero. The t-statistics in Table 2.B1 confirm the indistinguishability from zero after the first cohort. Thus, their cohort effect is flat. The non-existing cohort effect is exactly what we hypothesized as these people were largely unaffected by the reforms. When individuals born prior to 1937 retired, there was hardly any actuarial adjustment to earlier retirement. The time effects in Table 2.B1 show a negative trend until 1999 and improve thereafter. Moreover, people in eastern Germany exhibit a significantly more accentuated negative trend in 1999 than in western Germany.

In Figure 2.2 we plot the income effect, which results from multiplying the income coefficients and income. As Table 2.B1 demonstrates, the second order polynomial of income and its interactions are significant at the respectively $1 \%$ and $10 \%$ level. For both regions in Germany the income effect is upward sloping. In western Germany (solid blue), the relationship between SFWB and income is linear, which implies that each €income increase 


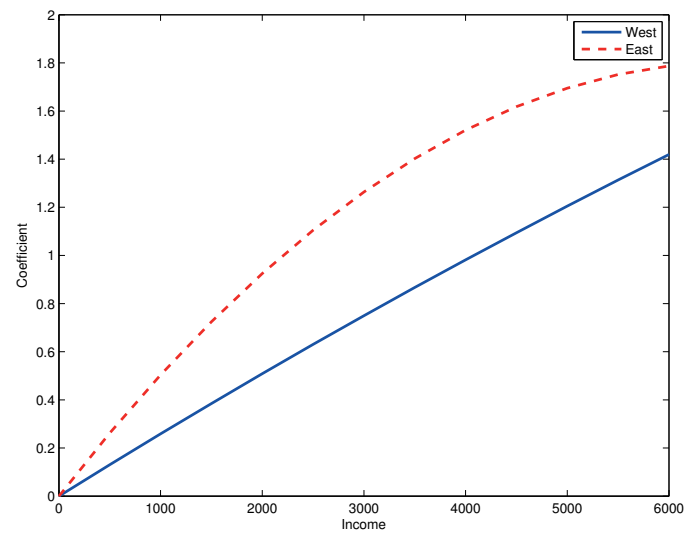

Figure 2.2: Income Effects for the old Sample in eastern and western Germany

This figure plots the income effect of the elderly (older than 60 years) sample. The income effect is equal to $\delta_{1}$ inc $+\delta_{2}$ inc $^{2}$ based on regression (2.2). The solid blue line corresponds to western and the dashed red line to eastern Germany.

is equally valuable and therefore it is independent of the income level. In eastern Germany (dashed red), however, the relationship exhibits a logarithmic shape. Here, a €income increase leads to greater changes in SFWB at a low income level than at a high income level. Consequently, there seems to exist an income threshold for the people in eastern Germany, whereafter they are not so worried about their financial situation anymore. For people in western Germany, income gains are always equally important. Finally, the income effect is stronger in eastern relative to western Germany. Part of it can be explained by the lower price level in eastern relative to western Germany. The greater part can be attributed to the improper correction for wealth. People with lower wealth appreciate income substantially more than people with higher wealth. Ammermüller, Weber and Westerheide (2005) find that people have less wealth in eastern than in western Germany. Consequently, people in eastern Germany value income more. This leads to a stronger income effect if we cannot sufficiently correct for liquid wealth.

\section{The young sample}

The complete estimates of regression equation (2.2) are in the right half of Table 2.B1. Figure 2.3 depicts the cohort effects for labor force participants, that is people younger than 60 years. Note that we also normalize here with respect to the cohort born between 1932 and 1937. We plot the coefficients of the respective cohort dummies against cohorts. 


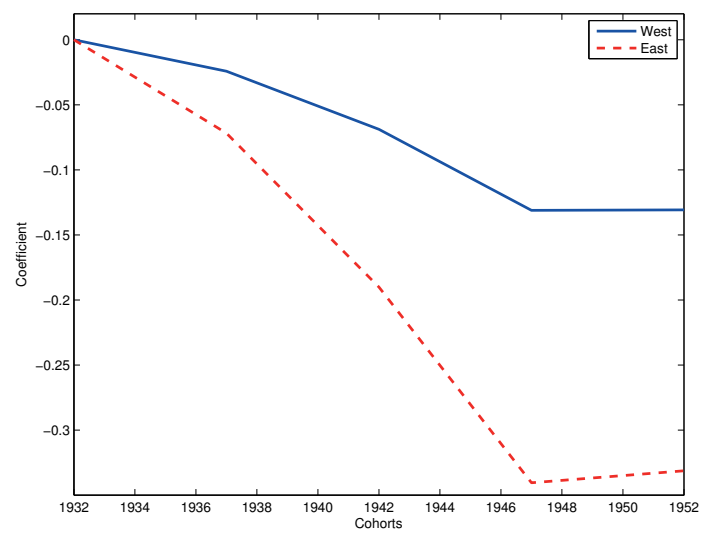

Figure 2.3: Cohort Effects for the young Sample in eastern and western Germany

This figure plots the cohort effect of the young (younger than 60 years) sample. The cohort effects are the coefficients of the dummies from regression (2.2). The solid blue line corresponds to western and the dashed red line to eastern Germany.

Figure 2.3 looks considerably different from Figure 2.1. The overall picture indicates a negative cohort effect that flattens out towards younger cohorts. All cohorts born after 1937 and thus the majority of this sample are affected by the reforms that led to decreasing real rates of return across cohorts. The deviation from this in the last cohort may be driven by a small number of observations in the last cohort. The significance level of the cohort dummies increases from $52 \%$ to $11 \%$. Again, the cohort effects are more extreme in eastern (dashed red) than in western (solid blue) Germany. The significance level of interaction terms increases from $36 \%$ to $9 \%$. Younger cohorts in eastern Germany, who extremely suffer from high unemployment rates, feel worse off than the younger cohorts in western Germany, who do not face unemployment risk to this extent. Note that being unemployment for longer than a year substantially decreases your future state pension pay. ${ }^{11}$ As a result, the situation is much worse for young people in eastern than in western Germany.

As Figure 2.4 demonstrates, the income effect is somewhat weaker for the younger than for the older sample. In comparison to Figure 2.2, the slope for the young sample is smaller than the one for the old sample. The young sample still faces a high labor income uncertainty. As argued above, more risk averse individuals require more income for the same level of SFWB, which implies a flatter slope as apparent in Figure 2.4. Again, the

\footnotetext{
${ }^{11}$ In the first year of unemployment, people still receive about $60-67 \%$ of their former income and get $80 \%$ of their former earning points accredited at the German state pension. As of the second year, however, this decreases to a fixed amount.
} 


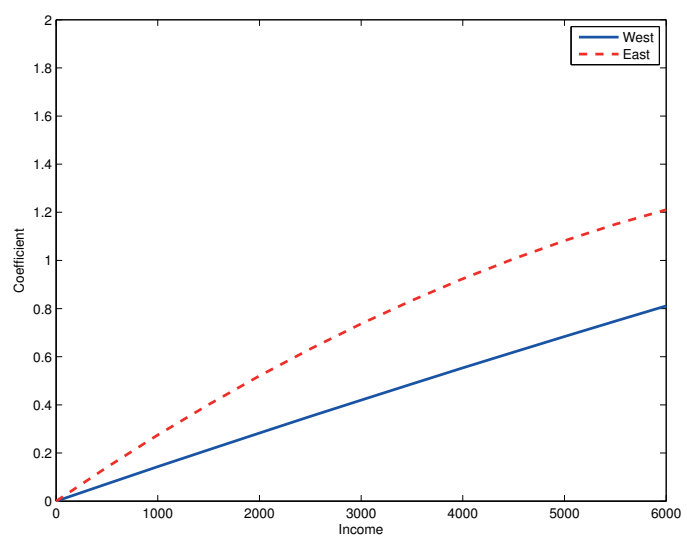

Figure 2.4: Income Effects for the young Sample in eastern and western Germany This figure plots the income effect of the young (younger than 60 years) sample. The income effect is equal to $\delta_{1}$ inc $+\delta_{2}$ inc $^{2}$ based on regression (2.2). The solid blue line corresponds to western and the dashed red line to eastern Germany.

income effect is stronger in eastern (dashed red) than in western (solid blue)Germany.

\subsection{The Influence of Income Sources over the Cross Section}

In order to analyze the effect of additional income sources on the perceived retirement income adequacy (Hypothesis 5) we investigate the outcome of regression equation (2.5) for the old and the young sample. We will only discuss the effects of income sources in this section. People can have multiple income sources. Therefore, the reference group of each income source dummy is the group that does not receive income from the respective source. The complete set of regression results can be found in Tables 2.B2 and 2.B3 in Appendix 2.B. Recall, that these are only psychological effects. The income level has already been accounted for.

\section{The old sample}

Table 2.2 summarizes the effects from various income sources and home ownership on SFWB for the old sample. It is interesting to note that more and more additional income dummies become significant over time. GRV, KLG and BVG and early retirement are positive but indistinguishable from zero throughout the entire period. As these income sources represent the status quo, this is not surprising. Civil servants in Germany are regarded as having a very generous retirement income. The coefficient of BVG is therefore larger than that of 
Chapter 2 Subjective Financial Well-Being

\begin{tabular}{|c|c|c|c|c|}
\hline Variable & Coef 1992 & Coef 1995 & Coef 1999 & Coef 2003 \\
\hline GRV & 0.002 & 0.003 & 0.006 & 0.002 \\
\hline KLG & 0.004 & 0.006 & 0.005 & 0.019 \\
\hline occupational pension & 0.006 & 0.006 & 0.010 * & $0.011 \star \star$ \\
\hline BVG & 0.006 & 0.006 & 0.012 & 0.005 \\
\hline work & $-0.024^{\star \star \star}$ & $-0.020^{\star \star \star}$ & $-0.034^{\star \star \star}$ & $-0.033^{\star \star \star}$ \\
\hline unemployment insurance & -0.006 & $-0.022^{\star \star}$ & -0.013 & $-0.043^{\star \star \star}$ \\
\hline early retirement & 0.013 & 0.022 & & \\
\hline health insurance & -0.017 & -0.015 & -0.018 & $-0.087^{\star}$ \\
\hline rent and lease & -0.001 & -0.003 & 0.001 & 0.002 \\
\hline savings and securities & $0.011^{\star \star \star}$ & $0.007^{\star \star}$ & $0.014^{\star \star \star}$ & $0.019^{\star \star \star}$ \\
\hline homeowner & $0.075^{\star \star \star}$ & $0.083^{\star \star \star}$ & $0.178^{\star \star \star}$ & 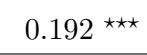 \\
\hline $\bar{R}^{2}$ & 0.209 & 0.194 & 0.182 & 0.216 \\
\hline $\mathrm{N}$ & 24,818 & 23,869 & 21,364 & 28,423 \\
\hline
\end{tabular}

Table 2.2: Source of Income Effect on SFWB for the old Sample

This table contains the coefficients of the dummies that indicate income sources from the cross-sectional regression (2.5) based on the old (older than 60 years) sample for each survey year. See Appendix 2.B for other control variables. ${ }^{* * *} \mathrm{p}<0.01,{ }^{* *} \mathrm{p}<0.05$, and ${ }^{*} \mathrm{p}<0.1$ indicate the significance level.

GRV in every year, but the difference is not significant (T-Statistics: 0.43, 0.40, 0.61 and 0.33 , respectively). Receiving income from GRV while also enjoying leisure is perceived as significantly better than receiving income from work as expected. As people in the old sample are older than or equal to 60 years, the work dummy may simply indicate a selection effect. If someone is still working in old age while the pension system is quite generous for this subsample, the person may not have accumulated sufficient wealth (earning points) in the state pension. Moreover, he might feel bad about himself due to social comparison.

People in the old sample acknowledge additional income sources as from occupational pension plans and savings and securities more over time: the magnitude and the significance of both sources increase over time. Owning a house also becomes increasingly important over time despite relatively stable real estate prices in Germany. According to BörschSupan et al. (2001), only $40 \%$ of all Germans live in their own house. The real estate fraction of wealth, however, has been estimated to be $75 \%$ (Jäntti and Sierminska 2007). Because we cannot control for liquid wealth, this effect may proxy a wealth effect, indicating that wealthier individuals feel financially better prepared for retirement. Income from rent 
and lease remains insignificant. Income from social insurances as the health insurance or unemployment insurance is negative. In the former case it is occasionally significant while in the latter case it only becomes significantly negative in 2003.

Although the old sample is affected by the reforms only to a limited extent, these people come to acknowledge certain additional income sources, such as from occupational pension, savings and securities and owning their own house.

\section{The young sample}

\begin{tabular}{|c|c|c|c|c|}
\hline Variable & Coef 1992 & Coef 1995 & Coef 1999 & Coef 2003 \\
\hline work & -0.002 & -0.002 & -0.006 & -0.011 \\
\hline unemployment insurance & -0.001 & -0.002 & -0.010 & $-0.032 \star \star \star$ \\
\hline early retirement & 0.005 & 0.003 & & \\
\hline health insurance & -0.005 & -0.006 & -0.013 & -0.040 \\
\hline rent and lease & 0.001 & 0.000 & 0.003 & 0.000 \\
\hline savings and securities & 0.005 & 0.004 & 0.007 & $0.016 \star \star$ \\
\hline homeowner & 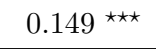 & $0.188^{\star \star \star}$ & $0.253^{\star \star \star}$ & $0.312^{\star \star \star}$ \\
\hline $\bar{R}^{2}$ & 0.237 & 0.215 & 0.237 & 0.250 \\
\hline $\mathrm{N}$ & 12,937 & 12,174 & 08,978 & 07,790 \\
\hline
\end{tabular}

Table 2.3: Source of Income Effect on SFWB for young Sample

This table contains the coefficients of the dummies that indicate income sources from the cross-sectional regression (2.5) based on the younger (younger than 60 years) sample for each survey year. See Appendix 2.B for other control variables. ${ }^{* * *} \mathrm{p}<0.01,{ }^{* *} \mathrm{p}<0.05$, and $* \mathrm{p}<0.1$ indicate the significance level.

Table 2.3 summarizes the income source effects on SFWB for individuals, who are younger than 60 years old. Most of them are still in the labor force, which represents the status quo and therefore explains the insignificance of income from work. Income from early retirement also remains insignificant as for the old sample. The same holds for income from rent and lease. Income from savings and securities becomes increasingly important over time, but it is only significantly positive in 2003. Thus, also the young sample becomes aware that additional income sources help to increase their financial well-being at retirement. However, the coefficients for their sample are much less significant than those for the old sample. Only owning their own house is significantly positive throughout the sample period; even to a larger extent than for the old sample.

Moreover, income from social insurances as the unemployment insurance and health insurance is also only significant in 2003. Since the young sample is substantially more 
exposed to the reforms, they should realize the importance of additional income sources and the disadvantage of being unemployed more than the old sample. Our evidence suggests, though, that they do not. In the previous section, we found that the young sample feels worse about their financial well-being at retirement the later they are born. The limited appreciation of the income sources supports this conclusion. If they valued additional private income sources they would be able to fill the pension gap that emerges from decreasing replacement rates more easily and therefore would not have to feel worse about their SFWB.

\subsection{Conclusion}

In light of recent pension reforms in Germany, this chapter investigated several possible determinants of subjective financial well-being in the life-cycle framework. Particularly, we expected young cohorts to feel substantially better than old cohorts, whose GRV benefits have been cut severely (Hypothesis 4). As a result, it has becomes more important for younger generations to have additional income sources now and in old age (Hypothesis 5). Throughout the paper, we interpreted SFWB as people's perception of their retirement income adequacy.

Section 2.5 demonstrated that people, who are still working, are aware of the decreasing real rate of return across birth cohorts. Using a synthetic panel approach, we found negligible cohort effects in the old sample, who are to a large extent unaffected by the birth year specific reforms because they were already retired, and substantial negative cohort effects in the young sample. In line with this evidence, Section 2.6 showed that the young sample hardly appreciate additional income sources until 2003. Also, despite substantial cuts in public retirement income the recipients of unemployment income have not perceived their financial situation at retirement worse than those who do not in the young sample until 2003. If the young sample instead appreciated their additional income sources, making an effort to fill their pension gap due to lower replacement rates, younger cohorts would not have to feel worse about their SFWB at retirement than older cohorts.

Additionally, we found the usual suspects as education, income and wealth to be in line with life-cycle theory if we allow for habit formation (Hypotheses 1-3) in Section 2.5. People evaluate their financial well-being better the more challenging their job is, approximating education, because they face higher income growth. Moreover, higher income levels also lead to improvements in people's perception about retirement income. This effect is steeper for the old sample than for the young sample, since the latter still face labor income uncertainty. As a result, the young sample requires more income to be equally convinced of a good retirement income as the old sample. Taking house ownership as a proxy for wealth, we showed that wealth also generates higher SFWB scores. In the cross-sectional regressions, 
we saw this effect to become stronger over the years. Many of these effects, in particular the cohort and the income effect, are stronger in eastern than in western Germany. This can have several reasons. Among these are higher risk aversion (Tigges et al. 2000), improper correction for wealth (Ammermüller et al. 2005) and high unemployment rates in eastern Germany after the reunification.

Concluding, younger people are aware of their relative disadvantage in the public pension system or have a least become aware of the political and demographic risk that is attached to the public pension. However, they do not seem to take the appropriate steps to fill their pension gap. Further research is necessary to analyze why young cohorts are not trying to improve their financial situation at retirement, given that they know their position. Explanations could lie in procrastination, or insecurity about further reforms reforms. Because of the forward looking nature of saving for retirement political stability is an important "must" for individuals to make, first of all, savings decisions and secondly make adequate savings decisions. The appreciation of additional income sources for retirement income may therefore only evolve slowly. 


\section{A Appendix A: Number of Observations}

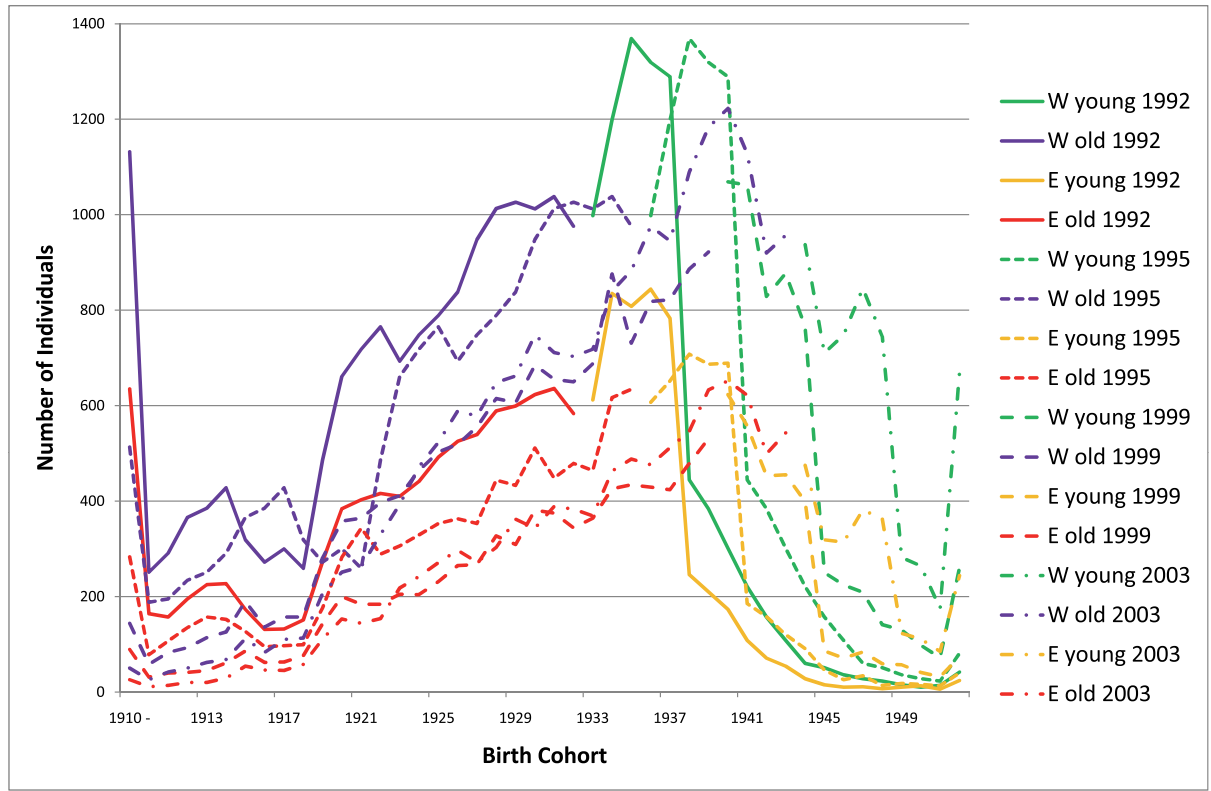

Figure 2.A1: Number of Observations by Birth Cohort

This figure contains the number of observations that the analysis is based on by birth cohort. We distinguish between the survey years (1992 - solid, 1995 - dotted, 1999 - dashed, 2003 - dash dotted), the young (younger than 60) sample in western (green), the old (older than 60) sample in western (blue), the young (younger than 60) sample in eastern (orange), and old (older than 60) sample in eastern (red) Germany. 


\section{B Appendix B: Regression Output}

\begin{tabular}{|c|c|c|c|c|c|c|c|}
\hline & \multicolumn{3}{|c|}{ Old } & \multicolumn{3}{|c|}{ Young } & \multirow{2}{*}{$\begin{array}{r}\text { T-Stat } \\
\text { young=old }\end{array}$} \\
\hline & Coef & StE & T-Ratio & Coef & StE & T-Ratio & \\
\hline constant & -0.020 & 0.007 & -2.940 & -0.017 & 0.031 & -0.55 & 0.094 \\
\hline cohort(less1917) & -0.020 & 0.010 & -2.087 & & & & \\
\hline cohort $[1917,1922)$ & -0.009 & 0.008 & -1.206 & & & & \\
\hline cohort $[1922,1927)$ & -0.001 & 0.006 & -0.252 & & & & \\
\hline cohort $[1927,1932)$ & 0.000 & 0.005 & 0.064 & & & & \\
\hline cohort $[1937,1942)$ & 0.001 & 0.007 & 0.219 & -0.024 & 0.038 & -0.636 & -0.647 \\
\hline cohort $[1942,1947)$ & -0.004 & 0.010 & -0.404 & -0.069 & 0.054 & -1.271 & -1.184 \\
\hline cohort $[1947,1952)$ & & & & -0.131 & 0.083 & -1.576 & \\
\hline cohort(more1952) & & & & -0.131 & 0.086 & -1.525 & \\
\hline 1995 & -0.007 & 0.005 & -1.590 & 0.028 & 0.028 & 1.016 & 1.231 \\
\hline 1999 & -0.020 & 0.006 & -3.401 & 0.062 & 0.048 & 1.296 & 1.695 \\
\hline 2003 & 0.001 & 0.007 & 0.173 & 0.111 & 0.067 & 1.654 & 1.633 \\
\hline east* constant & -0.021 & 0.011 & -1.959 & -0.022 & 0.044 & -0.501 & -0.022 \\
\hline east*cohort(less1917) & -0.012 & 0.014 & -0.803 & & & & \\
\hline east* cohort $[1917,1922)$ & -0.008 & 0.012 & -0.620 & & & & \\
\hline east*cohort $[1922,1927)$ & 0.000 & 0.008 & 0.052 & & & & \\
\hline east*cohort $[1927,1932)$ & 0.000 & 0.007 & -0.042 & & & & \\
\hline east*cohort $[1937,1942)$ & 0.001 & 0.010 & 0.140 & -0.048 & 0.053 & -0.906 & -0.908 \\
\hline east*cohort $[1942,1947)$ & -0.006 & 0.014 & -0.445 & -0.121 & 0.076 & -1.587 & -1.488 \\
\hline east* cohort $[1947,1952)$ & & & & -0.209 & 0.119 & -1.759 & \\
\hline east*cohort(more1952) & & & & -0.201 & 0.12 & -1.678 & \\
\hline east*1995 & -0.008 & 0.009 & -0.980 & 0.057 & 0.035 & 1.637 & 1.799 \\
\hline east*1999 & -0.023 & 0.012 & -1.839 & 0.099 & 0.067 & 1.476 & 1.792 \\
\hline east*2003 & -0.005 & 0.009 & -0.581 & 0.159 & 0.101 & 1.574 & 1.617 \\
\hline female & 0.071 & 0.094 & 0.756 & 0.098 & 0.114 & 0.857 & 0.183 \\
\hline married & -0.145 & 0.164 & -0.880 & -0.04 & 0.214 & -0.188 & 0.389 \\
\hline homeowner & 0.144 & 0.082 & 1.768 & 0.217 & 0.131 & 1.663 & 0.472 \\
\hline healthprob & -0.058 & 0.082 & -0.704 & -0.054 & 0.112 & -0.481 & 0.029 \\
\hline selfemployed & -0.135 & 0.174 & -0.776 & -0.057 & 0.243 & -0.232 & 0.261 \\
\hline job2 & 0.106 & 0.123 & 0.860 & 0.102 & 0.171 & 0.595 & -0.019 \\
\hline job3 & 0.156 & 0.139 & 1.125 & 0.144 & 0.192 & 0.754 & -0.051 \\
\hline job4 & 0.159 & 0.188 & 0.850 & 0.187 & 0.23 & 0.813 & 0.094 \\
\hline job5 & 0.124 & 0.202 & 0.611 & 0.145 & 0.252 & 0.575 & 0.065 \\
\hline hhsize2 & 0.043 & 0.220 & 0.194 & 0.124 & 0.283 & 0.437 & 0.226 \\
\hline hhsize3 & -0.076 & 0.288 & -0.264 & 0.064 & 0.373 & 0.172 & 0.297 \\
\hline hhsize4+ & -0.093 & 0.353 & -0.263 & -0.045 & 0.399 & -0.113 & 0.090 \\
\hline hhsizeNaN & 0.007 & 0.533 & 0.013 & 0.013 & 0.719 & 0.018 & 0.007 \\
\hline hhearn2 & -0.053 & 0.140 & -0.381 & -0.069 & 0.15 & -0.458 & -0.078 \\
\hline hhearn3 & 0.039 & 0.271 & 0.142 & 0.017 & 0.313 & 0.054 & -0.053 \\
\hline hhearn4+ & 0.061 & 0.461 & 0.132 & 0.018 & 0.396 & 0.046 & -0.071 \\
\hline hhearnNaN & -0.071 & 0.699 & -0.102 & -0.2 & 0.945 & -0.211 & -0.110 \\
\hline inc & 0.026321 & 0.004 & 6.675 & 0.014464 & 0.004 & 3.799 & -2.096 \\
\hline inc2 & $-4.44 \mathrm{E}-05$ & 0.000 & -3.702 & $-1.57 \mathrm{E}-05$ & 0.000 & -2.254 & 0.171 \\
\hline east*inc & $2.82 \mathrm{E}-02$ & 0.017 & 1.659 & 0.01447 & 0.019 & 0.75 & -0.537 \\
\hline east*inc2 & -0.00037 & 0.001 & -1.721 & -0.00013 & 0.000 & -0.801 & 0.370 \\
\hline
\end{tabular}

Table 2.B1: Synthetic Panel Results

This table contains the regression results from (2.2) for the young (younger than 60 years) and the old (older than 60 years) sample. The job types from 1 to 5 refer to respectively blue-collar workers, skilled worker, qualified employee, qualified employee in leading position and executive. 
Chapter 2 Subjective Financial Well-Being

\begin{tabular}{|c|c|c|c|c|c|c|c|c|}
\hline & \multicolumn{2}{|c|}{1992} & \multicolumn{2}{|c|}{1995} & \multicolumn{2}{|c|}{1999} & \multicolumn{2}{|c|}{2003} \\
\hline & Coef & T-Stat & Coef & T-Stat & Coef & T-Stat & Coef & T-Stat \\
\hline constant' & -0.606 & -29.715 & -0.662 & -35.018 & -0.738 & -35.351 & -0.807 & -43.867 \\
\hline female' & 0.018 & 5.693 & 0.015 & 5.507 & 0.026 & 7.106 & 0.032 & 10.253 \\
\hline married' & -0.271 & -14.260 & -0.311 & -16.412 & -0.181 & -8.951 & -0.268 & -15.716 \\
\hline cohort(less1917)' & 0.067 & 6.093 & 0.053 & 6.114 & 0.119 & 7.522 & 0.219 & 10.290 \\
\hline $\operatorname{cohort}[1917,1922)$, & 0.045 & 4.519 & 0.039 & 5.029 & 0.092 & 7.758 & 0.171 & 11.858 \\
\hline $\operatorname{cohort}[1922,1927)$, & 0.029 & 3.242 & 0.025 & 4.274 & 0.075 & 7.868 & 0.122 & 11.151 \\
\hline cohort $[1927,1932)$, & 0.013 & 1.637 & 0.012 & 2.613 & 0.051 & 6.408 & 0.084 & 9.051 \\
\hline cohort $[1932,1937)$ & & & & & 0.025 & 4.031 & 0.052 & 6.337 \\
\hline $\operatorname{cohort}[1937,1942)$, & & & & & & & 0.025 & 3.544 \\
\hline healthprob' & -0.053 & -5.408 & -0.045 & -4.408 & -0.024 & -2.201 & -0.022 & -2.327 \\
\hline hhsize -2 & -0.032 & -1.351 & 0.004 & 0.183 & -0.007 & -0.255 & 0.058 & 2.186 \\
\hline hhsize _3' & -0.153 & -4.813 & -0.101 & -3.149 & -0.213 & -5.115 & -0.181 & -5.176 \\
\hline hhsize _more4' & -0.111 & -2.810 & -0.047 & -1.163 & -0.327 & -6.540 & -0.186 & -4.341 \\
\hline hhsize _NaN' & 0.024 & 0.322 & 0.127 & 1.714 & -0.126 & -2.963 & 0.056 & 1.016 \\
\hline hhearners _2' & -0.048 & -2.882 & -0.076 & -4.448 & -0.019 & -0.780 & -0.036 & -1.638 \\
\hline hhearners _3' & 0.053 & 1.671 & -0.011 & -0.338 & 0.112 & 2.607 & 0.156 & 4.179 \\
\hline hhearners _more4' & 0.012 & 0.229 & -0.035 & -0.664 & 0.330 & 4.834 & 0.131 & 2.100 \\
\hline hhearners _NaN' & -0.121 & -1.404 & -0.183 & -2.046 & 0.084 & 0.962 & -0.137 & -1.809 \\
\hline selfemployed' & -0.003 & -0.539 & 0.002 & 0.374 & -0.003 & -0.384 & -0.002 & -0.292 \\
\hline homeowner' & 0.075 & 7.079 & 0.083 & 7.565 & 0.178 & 12.941 & 0.192 & 16.195 \\
\hline income' & 0.033 & 61.949 & 0.031 & 61.216 & 0.023 & 53.013 & 0.046 & 68.546 \\
\hline income2' & 0.000 & -33.441 & 0.000 & -32.063 & 0.000 & -29.235 & 0.000 & -42.367 \\
\hline income_GRV' & 0.002 & 0.541 & 0.003 & 0.713 & 0.006 & 1.141 & 0.002 & 0.493 \\
\hline income _KLG' & 0.004 & 0.452 & 0.006 & 0.694 & 0.005 & 0.236 & 0.019 & 0.628 \\
\hline income _occ' & 0.006 & 1.230 & 0.006 & 1.389 & 0.010 & 1.660 & 0.011 & 2.164 \\
\hline income _BVG' & 0.006 & 0.826 & 0.006 & 0.904 & 0.012 & 1.379 & 0.005 & 0.708 \\
\hline income _work' & -0.024 & -3.157 & -0.020 & -2.865 & -0.034 & -4.909 & -0.033 & -4.789 \\
\hline income _unemplinsurance' & -0.006 & -0.744 & -0.022 & -2.032 & -0.013 & -0.744 & -0.043 & -3.320 \\
\hline income _earlyret' & 0.013 & 0.685 & 0.022 & 1.067 & & & & \\
\hline income _healthinsurance' & -0.017 & -1.169 & -0.015 & -1.250 & -0.018 & -0.397 & -0.087 & -1.697 \\
\hline income_rentlease' & -0.001 & -0.213 & -0.003 & -0.501 & 0.001 & 0.102 & 0.002 & 0.234 \\
\hline income _savingssec' & 0.011 & 3.072 & 0.007 & 2.100 & 0.014 & 3.267 & 0.019 & 5.166 \\
\hline job1' & 0.009 & 1.304 & 0.010 & 1.465 & 0.010 & 1.241 & 0.002 & 0.290 \\
\hline job2' & 0.016 & 2.308 & 0.016 & 2.404 & 0.020 & 2.525 & 0.013 & 1.681 \\
\hline job3', & 0.016 & 2.197 & 0.016 & 2.302 & 0.022 & 2.647 & 0.018 & 2.133 \\
\hline job4 & 0.014 & 1.574 & 0.014 & 1.680 & 0.016 & 1.608 & 0.016 & 1.713 \\
\hline job5 & 0.007 & 0.663 & 0.008 & 0.904 & 0.013 & 1.301 & 0.010 & 1.085 \\
\hline industries $\_2$ & 0.009 & 0.911 & 0.007 & 0.724 & 0.015 & 1.180 & 0.011 & 0.829 \\
\hline industries _3' & -0.005 & -0.761 & -0.007 & -1.126 & -0.001 & -0.156 & -0.008 & -1.041 \\
\hline industries _4' & -0.009 & -1.295 & -0.010 & -1.576 & -0.002 & -0.220 & -0.009 & -1.085 \\
\hline industries $\_$' & -0.010 & -1.553 & -0.010 & -1.752 & -0.005 & -0.650 & -0.015 & -1.906 \\
\hline industries $\_$' & 0.000 & -0.028 & -0.006 & -0.774 & 0.000 & -0.012 & -0.001 & -0.058 \\
\hline industries -7 & -0.010 & -1.547 & -0.007 & -1.094 & 0.006 & 0.520 & -0.001 & -0.142 \\
\hline industries $\_9^{\prime}$ & -0.008 & -0.711 & -0.005 & -0.455 & 0.003 & 0.227 & -0.022 & -1.783 \\
\hline industries_NaN' & -0.013 & -0.773 & -0.013 & -0.955 & -0.024 & -0.717 & -0.074 & -2.292 \\
\hline east*constant' & -0.408 & -9.752 & -0.535 & -12.095 & 0.007 & 0.239 & 0.013 & 0.783 \\
\hline east*cohort(less1917)' & 0.074 & 4.268 & 0.091 & 5.938 & 0.115 & 4.219 & 0.130 & 3.530 \\
\hline east*cohort $[1917,1922)$, & 0.047 & 2.981 & 0.062 & 4.739 & 0.092 & 4.685 & 0.111 & 4.751 \\
\hline east*cohort $[1922,1927)$ & 0.033 & 2.347 & 0.048 & 4.599 & 0.067 & 4.181 & 0.087 & 4.824 \\
\hline east*cohort $[1927,1932)$ & 0.020 & 1.577 & 0.025 & 3.063 & 0.042 & 3.253 & 0.064 & 4.201 \\
\hline east*cohort $[1932,1947)$ & & & & & 0.020 & 1.897 & 0.040 & 2.980 \\
\hline east*cohort $[1937,1942)$, & & & & & & & 0.013 & 1.177 \\
\hline east*income' & 0.038 & 12.355 & 0.037 & 14.216 & -0.160 & -6.487 & 0.003 & 0.233 \\
\hline east*income2 & -0.001 & -14.199 & -0.001 & -14.601 & 0.002 & 1.951 & -0.150 & -7.310 \\
\hline $\bar{R}^{2}$ & & 0.209 & & 0.194 & & 0.182 & & 0.216 \\
\hline $\mathrm{N}$ & & 24,818 & & 23,869 & & 21,364 & & 28,423 \\
\hline $\begin{array}{l}\text { This table contains the } \\
\text { elderly (older than } 60 \text { y } \\
\text { blue-collar worker, skill } \\
\text { Industries } 1 \text { till } 9 \text { denot } \\
\text { Building / Trade, Com } \\
\text { details / Associations a }\end{array}$ & $\begin{array}{l}\text { d worke } \\
\text { respecti } \\
\text { nerce / } \\
\text { d Priva }\end{array}$ & $\begin{array}{l}\text { qualifie } \\
\text { ely Agri } \\
\text { ervices, } \\
\text { econor }\end{array}$ & $\begin{array}{l}\text { loyee, } \\
\text { re / Fo } \\
\text { c und } \\
\text { thout }\end{array}$ & $\begin{array}{l}\text { a the cr } \\
\text { ear. The } \\
\text { ualified } \\
\text { estry (re } \\
\text { takings, } \\
\text { rther de }\end{array}$ & $\begin{array}{l}\text { oyee in } \\
\text { se grou } \\
\text { servic }\end{array}$ & $\begin{array}{l}\text { regress } \\
\text { m } 1 \text { to } \\
\text { eading } \\
\text { ), Mini } \\
\text { Civil }\end{array}$ & $\begin{array}{l}\text { f.5) ba } \\
\text { fer to } r \\
\text { ion and } \\
\text { Energy- } \\
\text { e with }\end{array}$ & $\begin{array}{l}\mathrm{d} \text { on the } \\
\text { pectively } \\
\text { xecutive. } \\
\text { Industry, } \\
\mathrm{t} \text { further }\end{array}$ \\
\hline
\end{tabular}

Table 2.B2: Cross-Sectional Regressions based on the old Sample 


\begin{tabular}{|c|c|c|c|c|c|c|c|c|}
\hline & \multicolumn{2}{|c|}{1992} & \multicolumn{2}{|c|}{1995} & \multicolumn{2}{|c|}{1999} & \multicolumn{2}{|c|}{2003} \\
\hline & Coef & T-Stat & Coef & T-Stat & Coef & T-Stat & Coef & T-Stat \\
\hline 'constant' & -0.581 & -20.557 & -0.656 & -22.647 & -1.085 & -32.039 & -0.946 & -26.074 \\
\hline 'female' & 0.006 & 1.747 & 0.005 & 1.373 & 0.008 & 1.955 & 0.016 & 2.548 \\
\hline 'married' & -0.063 & -2.131 & -0.035 & -1.156 & -0.101 & -2.952 & -0.153 & -4.374 \\
\hline 'cohort $[1937,1942)$ ' & -0.001 & -0.193 & 0.002 & 0.281 & & & & \\
\hline 'cohort $[1932,1947)$ ' & -0.004 & -0.625 & 0.000 & -0.046 & -0.006 & -1.231 & & \\
\hline 'cohort $[1947,1952)$ ' & -0.006 & -0.364 & -0.005 & -0.422 & -0.011 & -1.407 & -0.011 & -1.553 \\
\hline 'cohort(more1952)' & 0.002 & 0.106 & 0.000 & -0.006 & -0.014 & -1.348 & -0.026 & -2.395 \\
\hline 'healthprob' & -0.074 & -5.415 & -0.083 & -5.896 & -0.010 & -0.617 & -0.036 & -1.984 \\
\hline 'hhsize_2' & 0.136 & 3.669 & 0.108 & 2.885 & 0.123 & 2.627 & 0.121 & 2.540 \\
\hline 'hhsize_3' & 0.091 & 2.194 & 0.059 & 1.397 & -0.087 & -1.568 & 0.004 & 0.070 \\
\hline 'hhsize_more4' & -0.009 & -0.188 & -0.041 & -0.886 & -0.210 & -3.524 & -0.185 & -3.028 \\
\hline 'hhsize_NaN' & 0.232 & 1.355 & -0.011 & -0.076 & -0.198 & -2.114 & 0.126 & 0.887 \\
\hline 'hhearners_2' & -0.122 & -6.565 & -0.113 & -6.051 & -0.028 & -0.887 & -0.081 & -2.523 \\
\hline 'hhearners_3' & -0.053 & -1.765 & -0.047 & -1.525 & 0.110 & 2.395 & 0.033 & 0.675 \\
\hline 'hhearners_more4' & -0.104 & -2.081 & -0.068 & -1.322 & 0.177 & 2.392 & 0.029 & 0.350 \\
\hline 'hhearners_NaN' & -0.427 & -2.056 & -0.315 & -1.630 & 0.039 & 0.245 & -0.206 & -1.406 \\
\hline 'selfemployed' & -0.002 & -0.331 & 0.001 & 0.182 & 0.000 & -0.030 & 0.000 & -0.009 \\
\hline 'homeowner' & 0.149 & 10.341 & 0.188 & 12.573 & 0.253 & 13.976 & 0.312 & 15.909 \\
\hline 'income' & 0.015 & 35.025 & 0.014 & 32.980 & 0.022 & 31.099 & 0.035 & 32.777 \\
\hline 'income2' & 0.000 & -18.751 & 0.000 & -16.785 & 0.000 & -16.639 & 0.000 & -19.468 \\
\hline work' & -0.002 & -0.471 & -0.002 & -0.682 & -0.006 & -1.259 & -0.011 & -1.485 \\
\hline unemployment insurance' & -0.001 & -0.178 & -0.002 & -0.362 & -0.010 & -1.504 & -0.032 & -2.357 \\
\hline early retirement' & 0.005 & 0.502 & 0.003 & 0.250 & & & & \\
\hline health insurance' & -0.005 & -0.483 & -0.006 & -0.559 & -0.013 & -0.936 & -0.040 & -1.345 \\
\hline rent and lease' & 0.001 & 0.246 & 0.000 & 0.071 & 0.003 & 0.358 & 0.000 & 0.018 \\
\hline savings and securities' & 0.005 & 1.441 & 0.004 & 0.992 & 0.007 & 1.596 & 0.016 & 2.091 \\
\hline job1 & -0.003 & -0.381 & 0.000 & 0.038 & -0.001 & -0.126 & 0.000 & -0.024 \\
\hline job2' & 0.002 & 0.245 & 0.005 & 0.638 & 0.004 & 0.395 & 0.013 & 0.655 \\
\hline job3' & 0.002 & 0.275 & 0.005 & 0.651 & 0.005 & 0.472 & 0.018 & 0.925 \\
\hline job4' & 0.004 & 0.391 & 0.008 & 0.829 & 0.006 & 0.460 & 0.017 & 0.792 \\
\hline job5 & 0.002 & 0.233 & 0.006 & 0.607 & 0.004 & 0.280 & 0.018 & 0.795 \\
\hline industries_2' & 0.017 & 1.462 & 0.013 & 0.980 & 0.013 & 0.671 & 0.003 & 0.107 \\
\hline industries_3' & 0.005 & 0.740 & 0.002 & 0.236 & 0.009 & 0.820 & -0.004 & -0.209 \\
\hline industries_4' & 0.004 & 0.573 & 0.001 & 0.130 & 0.006 & 0.533 & -0.007 & -0.372 \\
\hline industries_5' & 0.004 & 0.495 & 0.001 & 0.091 & 0.006 & 0.597 & -0.008 & -0.409 \\
\hline industries_6' & 0.010 & 1.113 & 0.007 & 0.714 & 0.009 & 0.807 & 0.002 & 0.105 \\
\hline industries_7, & 0.006 & 0.865 & 0.005 & 0.677 & 0.009 & 0.682 & -0.005 & -0.244 \\
\hline industries_9' & 0.000 & 0.031 & 0.001 & 0.070 & -0.002 & -0.154 & -0.010 & -0.340 \\
\hline industries_NaN' & -0.001 & -0.024 & -0.013 & -0.609 & -0.010 & -0.288 & -0.025 & -0.322 \\
\hline 'east*constant' & -0.428 & -9.789 & -0.517 & -11.542 & -0.089 & -3.510 & -0.228 & -9.371 \\
\hline 'east*cohort $[1937,1942)$ ' & -0.005 & -0.799 & -0.013 & -1.411 & & & & \\
\hline east*cohort $[1942,1947)$ & -0.004 & -0.283 & -0.015 & -1.330 & -0.001 & -0.150 & & \\
\hline 'east*cohort $[1947,1952)$ ' & -0.003 & -0.123 & -0.011 & -0.599 & -0.001 & -0.126 & -0.005 & -0.444 \\
\hline 'east*cohort(more1952)' & -0.016 & -0.464 & -0.011 & -0.372 & 0.002 & 0.083 & -0.006 & -0.382 \\
\hline 'east*income' & 0.008 & 3.195 & 0.012 & 6.290 & 0.000 & -4.405 & 0.012 & 0.796 \\
\hline 'east*income2' & 0.000 & -3.463 & 0.000 & -6.269 & 0.002 & 0.189 & 0.012 & 0.582 \\
\hline $\bar{R}^{2}$ & & 0.237 & & 0.215 & & 0.237 & & 0.250 \\
\hline $\mathrm{N}$ & & 12,937 & & 12,174 & & 08,978 & & 07,790 \\
\hline $\begin{array}{l}\text { This table contains th } \\
\text { young (younger than } 6 \\
\text { blue-collar worker, skill } \\
\text { Industries } 1 \text { till } 9 \text { denot } \\
\text { Building / Trade, Com } \\
\text { details / Associations }\end{array}$ & $\begin{array}{l}\text { years) } \\
\text { d worke } \\
\text { respect } \\
\text { nerce / } \\
\text { a Priv }\end{array}$ & $\begin{array}{l}\text { its and } \\
\text { mple fo } \\
\text { qualifi } \\
\text { ely Agr } \\
\text { ervices, } \\
\text { econo }\end{array}$ & $\begin{array}{l}\text { ure / Fo } \\
\text { lic und } \\
\text { ithout }\end{array}$ & $\begin{array}{l}\text { ualified } \\
\text { taky (re } \\
\text { takings, } \\
\text { rther de }\end{array}$ & $\begin{array}{l}\text { loyee in } \\
\text { ace gro } \\
\text { il servi }\end{array}$ & $\begin{array}{l}\text { rom } 1 \text { to } \\
\text { leading } \\
\text {, Mini } \\
\text {, Civil }\end{array}$ & $\begin{array}{l}2.5) \text { b } \\
\text { fer to } \\
\text { ion an } \\
\text { Energy } \\
\text { e witl }\end{array}$ & $\begin{array}{l}\text { ed on th } \\
\text { spectivel } \\
\text { executive } \\
\text { Industry } \\
\text { it furthe }\end{array}$ \\
\hline
\end{tabular}

Table 2.B3: Cross-Sectional Regressions based on young Sample 


\section{Chapter 3}

\section{Financial Incentives, Labor Force Participation and Retirement Entry in Germany}

\subsection{Introduction}

Labor force participation has changed substantially in many developed economies in recent years. The prominent patterns of labor force participation differ fundamentally between men and women. Predominant trends in Germany are the increasing labor market participation of western German women, a reduction of labor force participation of eastern German women, and an overall reduction of men's labor force participation. The reasons for these trends are seen mainly in the variation of socio-economic circumstances. In particular the changes in the division of labor within the family, the lower number of children, higher educational levels of women and higher divorce rates increase women's incentives to have their own source of income. Additionally, changes in social security plan provision change labor force participation of the elderly (see e.g. Gruber and Wise (1997)).

These shifts in labor force participation do not only have an impact on the current income of households but also influence retirement income. Over their working lives women of younger cohorts in western Germany acquire more pension claims compared to those of older cohorts and as a consequence their incentives to enter retirement change. The financial consequences of the changing labor force participation over the life cycle for retirement is reflected in the accumulated social security wealth (SSW) and in the option value of postponing retirement $(\mathrm{OV}) .{ }^{1} \mathrm{Up}$ to this point, literature has taken birth cohorts only

\footnotetext{
${ }^{1}$ Social security wealth is defined as the discounted sum of all future retirement income minus the future contributions to the social security system until retirement. The option value is the utility of the cash flow
} 
implicit into account by varying institutional regulations when calculating the SSW and OV. But no cohort related effects per se were taken into consideration to explain retirement entry behavior. The objective of this study is to estimate retirement entry behavior of German individuals and explicitly consider changes in labor force participation decisions across cohorts. Our paper can be seen as an advancement of the micro-econometric analysis of the economic incentives to retire by Börsch-Supan (1992), Börsch-Supan (2000a), BörschSupan (2001), Berkel and Börsch-Supan (2004) and Börsch-Supan, Schnabel, Kohnz and Mastrobuoni (2004).

Increasing female labor participation has been proposed as one of the instruments to ease the burden of demographic change on the labor market and social security systems. Börsch-Supan (2000a) argues that increasing female labor force participation could at least temporarily buffer the decline in labor force pending in the coming 20 to 30 years. However, the consequences of increasing female labor force participation at younger ages by offering child care and similar policy measures for overall female labor force participation are not clear ex ante. It could on the one hand be that women become more attached to the labor market and thus keep working at older ages, too. On the other hand, it might well be that women retire earlier because they have higher pension claims. In our analysis, we analyze the effects of changes in female labor force participation on retirement behavior.

We find that the accumulated SSW and the OV change across cohorts. This is not only due to institutional changes but also due to a change in employment patterns. Our estimation results suggest that men and women in eastern and western Germany have different leisure preferences. These estimates also turn out to differ between using employment exit versus retirement entry as the dependent variable. Our regression results point towards a widening time span between employment exit and retirement entry for younger cohorts of western Germany. For men this is driven by earlier employment exit of younger cohorts, for women this is driven by later retirement entry of younger cohorts. In eastern Germany, we find later employment exit and entry and therefore no change in the gap for men, and later exit and no change in entry and therefore a narrowing gap for young female cohorts.

The remaining of this analysis is organized as follows. In Section 3.2 we examine related literature and give an overview of the main trends in labor force participation in Germany. It also introduces the most important institutional features of the German public pension system. Our empirical analysis is based on an administrative panel data set of the German public retirement insurance (Versichertenkontenstichprobe 2006). We describe the data set briefly in Section 3.3. In Section 3.4, we introduce our estimation strategy. The results of our analysis are presented in Section 3.5. Section 3.6 concludes.

that follows from retiring at the highest utility yielding retirement age less the utility of the associated cash flow from retiring now. 


\subsection{Related Literature and Contribution}

\subsubsection{Incentives to Retire}

The sociological and economic debate about retirement behavior of individuals distinguishes pull and push factors of retirement entry. The push factors are perceived as factors beyond the influence of the individual, like the general labor market situation for example. The pull factors, however, are closely related to individuals' preferences. The most prominent pull factors are financial incentives, social factors, and health. In the course of our analysis we will focus on the pull factors of retirement, specifically the economic incentives as these were identified to play a major role in individuals' retirement decision. ${ }^{2}$

Economic incentives relate to personal wealth, public pension wealth (the SSW) and eligibility to pension schemes. Previous research has shown that individuals react very sensitively to the financial incentives of retirement schemes. Ground breaking analyzes were conducted, for instance, by Stock and Wise (1990). Gruber and Wise (1998) provide a very enlightening comparison of retirement behavior around the world. The central insight is that individuals in all countries react very sensitively to the design of their pension system. They find a strong positive relationship between incentives created by the social security systems (which pose an implicit tax on the continuation of work) and participation decisions of the elderly across countries. Similarly, Börsch-Supan (2000a) argues that despite the variation of the design of early retirement provisions between European countries and over time there is a surprising consistency in the reaction of individuals to financial incentives. Börsch-Supan, Brugiavini and Enrica (2008) confirm these findings on the basis of the Survey of Health Aging and Retirement in Europe (SHARE) data. The authors find that differences in the institutional design of pensions systems can explain much of the variation of individuals' retirement patterns in different European countries. There are several studies of retirement behavior in Germany that document the sensitivity to the institutional design of the pension system, which we will discuss below.

Social factors that influence retirement choices include retirement behavior of peer groups and in case of couples also that of their partners. A variety of studies find evidence that retirement decisions are highly interdependent among couples (see e.g. Mastrogiacomo, Alessie and Lindeboom (2004) and Gustman and Steinmeier (2004)). Blau and Riphahn (1999) find a high interdependence of employment decisions of elderly couples in Germany. An individual is much more likely to leave the labor force if the spouse has already left the

\footnotetext{
${ }^{2}$ Riphahn (1997) show that the drop in labor force participation of the elderly in the late 1970ies and early 1980ies was not driven by the high unemployment rate but rather by the incentives to retire early after the reform in 1972. Börsch-Supan (2000a) comes to similar conclusions. In our estimation we will include GDP growth and the unemployment rate to account for demand driven changes in the labor market.
} 
labor force and vice versa individuals with a partner in the labor force are much more likely to reenter the labor force themselves.

Furthermore, physical and psychological health has a direct effect on the ability and willingness to work (see e.g. Börsch-Supan (2000b) and Siddiqui (1997)). Börsch-Supan et al. (2008) find that despite institutional variation in European countries, health and the subjective survival probability play an important role for retirement entry on the individual level. One of the major challenges of estimating the effect of health on retirement choices is the endogeneity of health. Individuals who are granted disability status are likely to report poor health on the one hand because they are truly unhealthy but on the other hand to legitimate their disability status. Börsch-Supan (2001) compares different estimation techniques and finds that ignoring the endogeneity problem leads to an overestimation of the coefficient of the OV. We follow his approach and use the age-specific sample probability to be granted disability status as an instrument.

\subsubsection{The German Public Pension System}

Germany has a very old (introduced by Chancellor Bismarck in 1889) and - up to now - quite generous public pension system. Since 1957, it is organized as a Pay-As-You-Go system and covers about $85 \%$ of the German work force. ${ }^{3}$ As it was designed to extend the standard of living that individuals maintained during their working life to retirement, about $90 \%$ of current retirees' income is provided by public pensions (Börsch-Supan and Wilke 2006). The pensions are roughly proportional to lifetime income and eligibility depends additionally on the duration of the contribution period. There are few redistributive properties in the system. The role of occupational and private pensions, respectively the second and third pillar, is limited at the moment but growing in importance. ${ }^{4}$

Retirement age. Prior to 1972 the legal retirement age was 65 and the average age to enter old-age retirement of western German men was even slightly above this threshold (see Figure 3.1). The 1972 reform introduced a window of retirement between age 60 and 65 for the first time. The normal legal retirement age was still 65. However, women, the unemployed, and workers who could not be properly employed due to health or labor market reasons were able to leave the labor force and claim their full pensions from age 60

\footnotetext{
${ }^{3}$ For a very detailed description of the institutional features of the German public pension system see Börsch-Supan and Schnabel (1999) and Börsch-Supan and Schnabel (1998). For an overview of the historical development of the institutional details of the German public pension system as well as different reforms and reform options see Börsch-Supan (2000b) and Börsch-Supan and Wilke (2004).

${ }^{4}$ The transition to a three-pillar-system was introduced in the 2001 pension reform (called "Riester Reform" after the former minister for labor Walter Riester). The replacement rate in the first pillar will be reduced substantially in future years due to the introduction of a sustainability factor and second and third pillar pensions are strengthened by offering subsidies and tax reliefs to these plan participants.
} 
on. Workers with a long service life, i.e. more than 35 years of contributions, were able enter retirement from age 63 on without deductions. These generous rules led to a dramatic reduction of the average retirement entry age (see Figure 3.1). The retirement reforms in 1992 and 1999 both aimed at increasing the average retirement age and stop the trend to retire early that started with the 1972 reform. Eligibility ages for entry into retirement without deductions are gradually increased for women, the unemployed and disabled people. The special treatment of women and unemployed people is phased out for individuals born after 1951. In 2007, an additional reform increased the legal retirement age from 65 to 67 . The transition will take place between 2012 and 2029. Figure 3.2 gives an overview of the legal retirement ages applicable to certain cohorts.

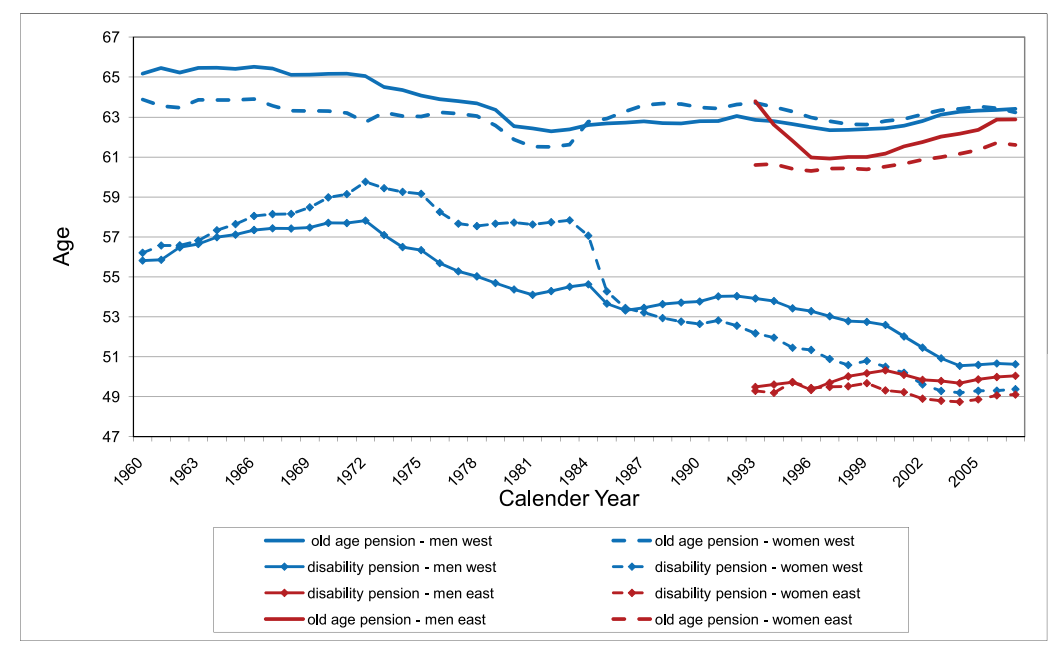

Figure 3.1: Average Pension Receipt Ages across Time

This figure plots the average ages of first receiving old age and disability pension over calender years. It is given for men and women living in eastern and western Germany. It is based on data from the German Public Pension Provider (GRV).

Actuarial Adjustment. In addition to the increase in the eligibility ages in 1992, adjustment factors for individuals that enter retirement before or after age 65 were introduced. Individuals' pension income is on the one hand reduced by $3.6 \%$ per early retired year and on the other hand increased by $6 \%$ per later retired year. Börsch-Supan and Schnabel (1998) show that these adjustment factors are not actuarially fair. Thus, there is still a substantial incentive to retire early. They interpret the loss in retirement income when postponing retirement as an implicit tax and estimate that this tax was above $50 \%$ prior to the 1992 reform and still exceeds $20 \%$ after the reform when shifting retirement entry by one year from 59 to 60 .

Disability Pensions. Besides the old age pension, disability pensions can be granted 


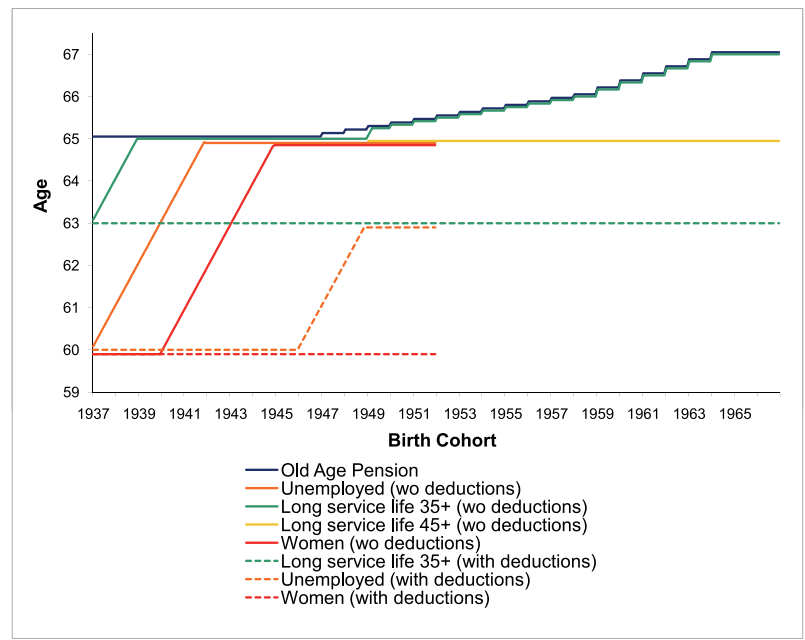

Figure 3.2: Eligibility Ages across Cohorts

This figure plots the institutional retirement eligibility ages for different pension types over birth years.

for health reasons. Prior to the 2001 reform disability pensions used to be allocated very generously so that people could easily retire early without sacrificing an actuarial fair amount of retirement income. Moreover, usually individuals were granted full disability status and for an unlimited period. Another important amendment is the redefinition of disability in the 2001 reform. Since 2001, people are only temporarily granted disability status and rules for full disability as opposed to partial disability are interpreted in a stricter manner. Additionally, disabled individuals face a reduction of their pensions of $3.6 \%$ ( $\max 10.8 \%$ ) per early retired year before age 63. This reference age increases to 65 until 2024 .

Consequences of the Reforms. Consequentially, it has become more difficult to retire early. Firstly, because the respective "normal" retirement ages have been raised and will increase even further; Secondly, because of the actuarial adjustment of $-3.6 \%$ / $+6 \%$; And thirdly, because of stricter disability rules. Most of the studies on retirement behavior in Germany analyze retirement behavior on the basis of the 1972 legislation and simulate the effect of the 1992 reform on retirement behavior. ${ }^{5}$ Börsch-Supan (2000a) models the effect of the 1992 reform using an option value model à la Stock and Wise (1990) and finds that the introduction of adjustment factors of $3.6 \%$ increases the average retirement age of people in western Germany by about half a year. The hypothetical introduction of actuarially fair adjustment factors could increase retirement ages by about

\footnotetext{
${ }^{5}$ See e.g. Börsch-Supan (1992), Schmidt (1995), Siddiqui (1997), Börsch-Supan (2000a), Börsch-Supan (2001), Börsch-Supan et al. (2004).
} 
two years. Börsch-Supan (2001) shows that these results are robust to alternative model specifications. Siddiqui (1997) comes to the same conclusions on the basis of a survival rate model without option value. Börsch-Supan et al. (2004) estimate the retirement age to increase by about eight months after the 1992 reform and seventeen months if almost actuarially fair adjustment factors of $6 \%$ were introduced. Berkel and Börsch-Supan (2004) conduct a similar experiment. They estimate that the combined effect of the 1992 and 1999 reforms increases retirement age of western German men from 61.2 to 63 years and for west German women from 61.7 to 62.4 years. Additionally, they simulate the effects of reform proposals discussed by the so-called Rürup commission. Appendix 3.B gives an overview of the econometric models of retirement incentives in Germany. The most recent study on retirement behavior in Germany is conducted by Hanel (2009). She estimates the effect of the 1999 reform on actual retirement patterns in Germany on the basis of an administrative data set (Versichertenkontenstichprobe 2002). Her analysis reveals that individuals shift exit from employment by about 10 months and the claiming of benefits by about 14 months on average. Thus, the gap between labor force exit and retirement entry widens due to the 1999 legislation.

\subsubsection{Hypotheses}

Over the last decades labor force participation and employment rates in Germany have changed substantially. Labor supply decisions not only vary over the life cycle for a given cohort but also differ across cohorts. The trends are different for men and women in eastern and western Germany. While men overall decreased their employment (Figure 3.3(a)), women's employment rates (ER) over the life cycle increased across cohorts (Figure 3.3(b)) in western Germany. Besides the level shift the age specific profile of female employment patterns converges towards the male profile. Specifically, male ER profiles exhibit an inverted "U-shape", while that of women used to be "M-shaped". The reasons for these shifts are manyfold. Economists like to argue that the relative price of formal sector employment has changed relative to household work or homemaking, which in turn changed the intra household allocation of human resources. In particular, the number of children declined, educational levels of women increased and divorce rates increased. Also, the legal situation for divorcees has changed. ${ }^{6}$ This is reflected in a declining gender wage gap such that overall the difference in employment rates between men and women decreased.

\footnotetext{
${ }^{6}$ See e.g. Bäcker, Bispinck, Hofemann and Naegele (2008) and Jansen, Kümmerling and Lehndorff (2009).
} 

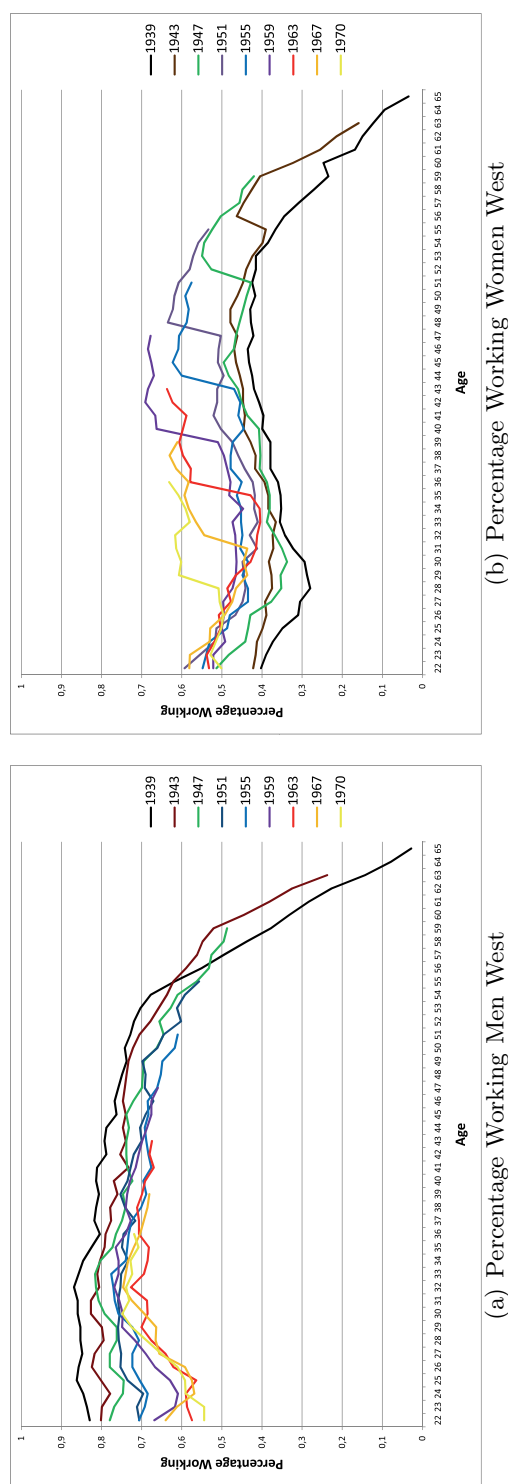

हैं.

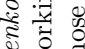

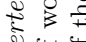

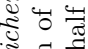

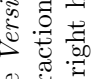

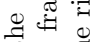

I

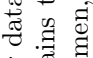

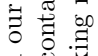

\&:

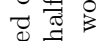

足

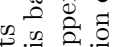

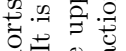

牙迅

U

으렬

800 0.

$\begin{array}{rl}7 & 0 \\ -10 & 0\end{array}$

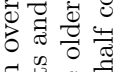

두웛

월

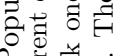

ค.

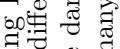

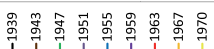

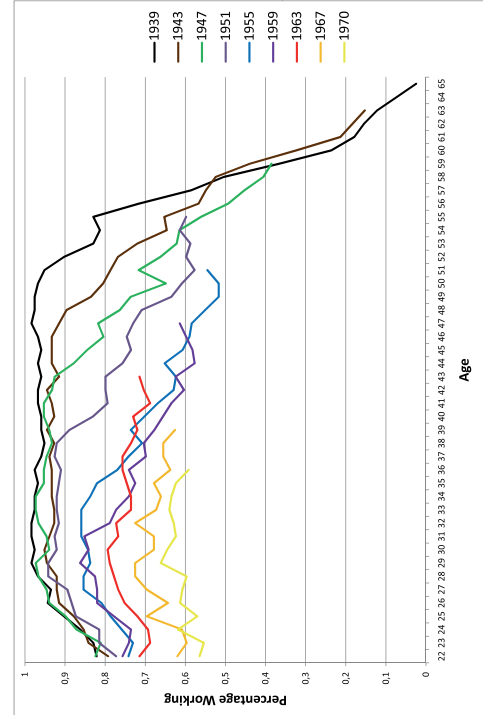

.

0.00
4
0

ํㅓㄹ

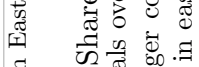

¿

r.

․․․

5000.

宕莒

पै

范

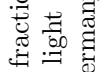

\&

†े

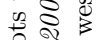

용.

융

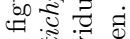

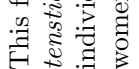


As Figures 3.3(c) and 3.3(d) demonstrate, life-cycle patterns are slightly different in eastern Germany. During the communist regime employment of men and women was close to $100 \%$. After unification the labor market situation for both men and women was difficult and strongly influenced by high unemployment and early retirement. However, it seems that eastern German women were hit more severely by unemployment at unification: the decline in their ER is much sharper than the decline in male ER.

These changes in employment do not only have an impact on the current income of households in Germany but also influence retirement income. However, the higher (lower) labor market participation of women (men) at younger ages has ambiguous effects on SSW and therefore retirement behavior. For example due to longer contribution periods, relatively higher income due to higher educational degrees and longer experience, western German women of younger cohorts acquire more pension claims of their own, but also contribute more. When deciding to leave the labor force higher pension claims might, on the one hand, shift retirement entry to earlier ages. On the other hand, if women of younger cohorts earn higher wages during their working lives the opportunity cost of leaving the labor force are also higher and women might decide to work longer. The overall effect is unclear. At the same time changes in the institutional framework led to a declining social security wealth for younger cohorts. In our analysis of retirement behavior we try to take account of these cohort trends by including proxies for the opportunity cost of work. In a first step, we control for the gap in ER between men and women. Later on, we control for the number of children per cohort and the share of individuals with higher education. By including these variables we aim at estimating cohort trends besides the purely financial effects already captured by SSW and OV.

\subsection{Data}

For the estimation of the retirement age we require, amongst others, information on the retirement incentives that the elderly face and their labor force status. The former heavily depends on individuals' earning histories. The German Public Pension provider (GRV), the Deutsche Rentenversicherung, releases a scientific use file (Versichertenkontenstichprobe 2006 ) on an annual basis since 2005. ${ }^{7}$ It contains socio-demographic information, labor force participation and full earnings histories in terms of earning points on a monthly basis from age 14 till age 65. 60,000 individuals were randomly selected out of the entire pool of individuals that the GRV administers. This pool includes everyone who, at some point in

\footnotetext{
${ }^{7}$ We would particularly like to thank Ingmar Hansen, Tanja Müller and Michael Stegmann from the Versicherungsdatenzentrum des Deutschen Rentenversicherung Bundes for their helpful, friendly and fast support.
} 
his life, made mandatory or voluntary contributions to the GRV. In Germany, a fraction of around $20 \%$ of labor income is automatically redistributed from labor income to the GRV for every employee. ${ }^{8}$ The sample contains individuals who are born between 1939 and 1976. As the sample was constructed in 2006, it covers calender years 1953 until 2006.

Compared to the earlier work by Börsch-Supan et al. (2004) and Berkel and BörschSupan (2004), we do not only know the earning points that accrue from employment but we also know the sum of all retirement relevant earning points. Additional earning points may come from periods of unemployment, education, or children. We can therefore calculate retirement income very precisely. Additionally, we overcome the problem of measuring health based on subjective information in surveys by using administrative information on days missing from work due to illness. Thus, the endogeneity bias arising from the need to legitimate disability status by having bad health does not prevail in our context. In fact, the contemporaneous correlation between receiving disability pension and the number of sick months within a year is low at around $38 \%$ ( $25 \%$ if only yes/no is considered). We do not have information on households' assets and other pension income. According to BörschSupan and Schnabel (1999) less than $10 \%$ of the retirement income stems from private pensions, firm pensions or assets. We therefore argue that we can abstract from these sources of income and attribute all incentives for retirement to the social security system. The administrative data set also lacks information on the household context. We do have information on the number of children and their age. However, we do not know individuals' marital status or the income of the spouse. We generate an artificial marriage variable by randomly matching a marriage (yes/no) status based on descriptive statistics from the Federal Statistical Office, which document that $74.9 \%$ of the population are married at age 54 in 2006.

We are interested in estimating the retirement probabilities at certain ages. Therefore, we condition on being employed or self-employed at age 54. After age 54, people can chose any state to remain in the sample. Note that we need individuals to take at least one decision. That is, individuals need to be observed at least until age 55. Consequently, the reduced sample consists of people born between 1939 and 1951. Additionally, we drop people who earn less than $€ 1,000$ of labor income in any year that they work and people, who are not marginally employed but earn less than the common marginal employment income of $€ 400$ per month. This results in 9,491 individuals who we observe almost eight years on average. In total, we have 74,439 data points.

Table 3.1 describes our dataset. At the beginning of our sample period, age 54, about half of the observations are comprised of females. Our sample consists to $70 \%$ of people in western and to $30 \%$ of people in eastern Germany. The condition of still working at

\footnotetext{
${ }^{8}$ There are exceptions for special job-groups such as doctors, chartered accountants, and civil servants.
} 
Chapter 3 Labor Force Participation and Retirement Entry in Germany

\begin{tabular}{lrrrr}
\hline \hline & Mean & Std & Min & Max \\
\hline Female (\%) & 49.51 & 50.00 & & \\
East (\%) & 30.19 & 45.91 & & \\
Age & 58.18 & 3.16 & 54.00 & 65.00 \\
Income/€1000 & 28.64 & 13.96 & 1.04 & 76.81 \\
Service Years & 30.03 & 7.96 & 6.00 & 50.00 \\
Nr Kids (women) & 1.73 & 1.16 & 0.00 & 10.00 \\
Married (\%) & 72.70 & 44.55 & & \\
Obs Time (years) & 7.84 & & & \\
\hline \hline
\end{tabular}

Table 3.1: Sample Description - Estimation Sample

This table contains the descriptive statistics of our entire sample of the Versichertenkontenstichprobe 2006, where $N T=74,439$. They are evaluated at the beginning of the sample period, age 54 .

age 54 explains the relatively high proportion of people in eastern Germany in our sample (see Figures 3.3(a) to 3.3(d)). Our mean age is about 58 years. The proportion of married individuals is given by the Federal Statistical Office by construction. Women in our sample give birth to 1.73 children on average, which is quite high compared to recent trends. Mean annual income before taxes of working individuals in our sample, which we deduce from the earning points, lies around $€ 28,640$ at age 54 .

\subsection{Estimating Incentives to Enter Retirement}

There is a variety of different approaches to model the incentives to enter retirement. Winter (1999) gives an overview of alternative methods. In general, retirement entry is modeled as a binary dynamic choice problem. Besides simple dynamic probit models ${ }^{9}$ structural models of retirement entry were developed. Here one can distinguish between structural models that take full account of the intertemporal optimization algorithm ${ }^{10}$ and reduced form models. Reduced form models or option value models were introduced by Stock and Wise (1990). These models explicitly take account of the intertemporal optimization problem without fully solving it: At every age the household trades off the income streams from retiring immediately versus retiring at any future point in time. The individual continues to work as long as the option value of postponing retirement is positive. Most of the analysis on retirement incentives in Germany mentioned in Section 3.2 follow variants of this approach. Lumsdaine, Stock and Wise (1992) compare the results of a simple probit

\footnotetext{
${ }^{9}$ Simple hazard rate models were estimated for example by Meghir and Whitehouse (1997) for the UK and by Siddiqui (1997) using German SOEP data.

${ }^{10}$ E.g. by Gustman and Steinmeier (1986), Rust (1987), Berkovec and Stern (1991), Rust and Phelan (1997).
} 
model, a full structural model and the option value model. Their results suggest that both, the full structural model as well as the OV approach, perform equally well and substantially better than the simple probit. They argue that the OV model has the advantage of less computational effort compared to a full structural model.

In our analysis, we build on the approach of Börsch-Supan et al. (2004) and Berkel and Börsch-Supan (2004). They estimate the probability to retire at a certain age by fitting a binary probit to a retirement indicator with help of socio-demographic information and economic incentives. Central to the economic indicators is SSW and the OV. Both require an expectation about future income streams. These income streams depend on the pathway into retirement that an individual chooses. We will first discuss the assumptions that are related to the structure of the pathways and then discuss assumptions that are related to the income levels.

As the individuals in our data set can be in different states, pathways can also consists of several states. These are working, being unemployed, receiving a disability pension, receiving an old age pension or doing nothing, where doing nothing means that there is no spell in our dataset, which implies that the individual is in a state that is not retirement relevant (for instance, someone who has decided not to participate in the labor force at all). ${ }^{11}$ We model three types of pathways. The first pathway into retirement goes via unemployment, the second via disability and the third is the regular pathway. Suppose an individual, aged $S$, plans to retire at age $R$. If $R$ lies below the regular retirement age, he can theoretically take either of the three pathways. In the first case, he would receive unemployment benefits until the regular retirement age. In the middle case, he would first receive benefits from disability and later receive old age pension benefits, but the transition does not matter because it is only a formal redefinition of the state and the transition does not imply a change in pension income. As of 2001, the amount of both benefit types are adjusted downwards the younger an individual disables ( $\max 10.8 \%$ ). If an individual takes the regular retirement pathway, he would receive nothing from age $R$ until the first possible eligibility age. If $R$ is above or equal to the regular retirement age, he can only take the regular pathway.

To determine the value of retirement in the future $(R>S)$, we assume that the currently not working individual starts to work again and the currently working individual continues to work. At age $R$ both types stop working and have the possibility to retire on the above mentioned pathways. Because the individuals cannot be certain to receive disability status or become unemployment in order to access the first or second pathway, we attach agedependent probabilities to the pathways as given in Table 3.2. To determine the value of

\footnotetext{
${ }^{11}$ We cannot distinguish part- and full-time work. Neither can we distinguish full and partial disability. We do distinguish between the unemployment benefits ALG1, ALG2 and the former Arbeitslosenhilfe.
} 
immediate retirement $(R=S)$, the same probabilities apply independent of the current status to avoid endogeneity.

\begin{tabular}{rrrrrrrrrrrrrrr}
\hline \hline & \multicolumn{1}{c}{} & \multicolumn{11}{c}{ Age } \\
& 54 & 55 & 56 & 57 & 58 & 59 & 60 & 61 & 62 & 63 & 64 & 65 & 66 \\
\hline From W & & & & & & & & & & & & & \\
To U & 0.06 & 0.07 & 0.07 & 0.09 & 0.09 & 0.08 & 0.07 & 0.08 & 0.04 & 0.04 & 0.04 & 0.04 & 0.04 \\
To D & 0.08 & 0.09 & 0.09 & 0.10 & 0.11 & 0.13 & 0.13 & 0.09 & 0.23 & 0.37 & 0.37 & 0.37 & 0.37 \\
\hline \hline
\end{tabular}

Table 3.2: Transition Probabilities

U refers to the unemployment pathway. D refers to the disability pathway. W refers to the state of working.

We assume that the individuals form their expectations based on these outlined pathways. In case a person works in the future he expects to receive the same labor income as he received the last time that he worked (i.e. zero wage growth, which is a common assumption after age 50 (Börsch-Supan 2001) and supported by our data). Contributions to the social security system, which include the old age pension, unemployment, health and disability insurance in Germany, and benefits from the social security system are expected to take on the values as the individual observes them at the current age $S$.

\section{Dependent Variable}

One can define retirement in terms of leaving the labor force or starting to receive pension benefits. As explained in Section 3.2, there is often a gap between the two. There is no consensus on the definition of retirement in earlier studies. Studies based on GSOEP data often used self-reported retirement status, i.e. a very wide definition of retirement to estimate incentive structures. Most individuals consider pension income from pre-retirement schemes (Vorruhestand) also as retirement income. ${ }^{12}$ Our administrative record does not include subjective information. We cannot know whether someone decides to become unemployed, disabled or to do nothing or whether he was hit by a random event and put in the position.

Therefore, we will deal with both possibilities. We will first use permanently leaving employment as the dependent variable. If someone does nothing, becomes unemployed or disabled or claims a regular pension, we say that he has left employment. This corresponds to the belief that people have chosen their actual states. We will refer to this as "exit". Using this definition we can use all data from birth cohort 1939 to 1951. Thereafter, we will use old age pension claiming as the dependent variable to accommodate the possibility that people have not chosen their employment exit. We refer to this dependent variable as

\footnotetext{
${ }^{12}$ See Börsch-Supan et al. (2004) for estimations based on different definitions.
} 
"entry". As regular pension benefit claiming is only possible as of age 60, our sample is reduced to birth cohorts 1939 to 1946.

\section{Explanatory Variables}

Social Security Wealth. In line with the literature (Berkel and Börsch-Supan 2004, Börsch-Supan et al. 2004, Stock and Wise 1990), we calculate social security wealth (SSW) - the net present value of all future social security benefits - as the expected present value of all future benefits $\left(a Y(R)_{t}^{R E T}\right)$ minus the contributions levied on gross earnings $\left(c_{t} Y_{t}^{L A B}\right)^{13}$. The SSW of an individual who is $S$ years old and plans to retire at age $R$ is

$$
S S W_{S}(R)=\sum_{t=R}^{\infty} a Y(R)_{t}^{R E T} p_{t} \delta^{t-S}-\sum_{t=S}^{R-1} c_{t} Y_{t}^{L A B} p_{t} \delta^{t-S}
$$

where

$S \quad$ is the planing age

$R \quad$ is the retirement age

$Y_{t}^{L A B} \quad$ is labor income before taxes at age $t$

$a Y(R)_{t}^{R E T}$ is retirement income after taxes at age $t$ when retirement age is $\mathrm{R}$

$c_{t} \quad$ is contribution rate to the pension system at age $t$

$p_{t} \quad$ is survival probability until age $t$, conditional on survival until age $S$

$\delta \quad$ is discount factor

Option Value of Delayed Retirement. In contrast to SSW, the OV trades off the economic consequences of different retirement ages. Moreover, it is defined in terms of utility from income streams. Receiving income without working is worth $\alpha$ more than receiving income from labor. ${ }^{14}$ Define $V_{S}(R)$ as the expected discounted future utility from retiring at age $R$, is

$$
V_{S}(R)=\sum_{t=S}^{R-1} u\left(a Y_{t}^{L A B}\right) p_{t} \delta^{t-S}+\alpha \sum_{t=R}^{\infty} u\left(a Y(R)_{t}^{R E T}\right) p_{t} \delta^{t-S}
$$

where

$a Y_{t}^{L A B}$ is labor income after taxes and other charges at age $t$

$\alpha \quad$ is the relative utility of leisure

$u(x) \quad$ is $=x$

The discount rate is commonly set to 0.03 in Germany (Börsch-Supan et al. 2004), which results in a discount rate of 0.97 . Similarly, we adopt the utility function from previous

\footnotetext{
${ }^{13}$ According to the Alterseinkünftegesetz from 2004 the contributions are tax deductable. Since we ignore this, the SSW is slightly biased downwards

${ }^{14}$ We assume $\alpha$ to be constant across individuals and time. We differentiate between men and women and eastern and western Germany though.
} 
analyzes. Let $V_{S}(R)^{*}$ be the largest value of the expected discounted future utility over all retirement ages $R$

$$
V_{S}^{*}=\underset{R}{\operatorname{argmax}} V_{S}(R) .
$$

The option value is then defined as

$$
O V_{S}=V_{S}^{*}-V_{S}(S)
$$

We obtain age dependent survival probabilities from the Federal Statistical Office for the years 2005, 2020 and 2050. Survival probabilities are linearly interpolated for the remaining years. As Börsch-Supan et al. (2004), we estimate $\alpha$ by employing a grid search over a series of $\alpha$ s, using regression (3.5) below. We keep the price level at 2005 Euros. Our model thus consists of real values.

Other Control Variables. Other economic incentives for retirement entry include private wealth, labor income, the number of service years, and the number of children. The number of children in the household has been found to have a negative influence on retirement, because it implies that parents still have higher financial obligations. Sociodemographic variables include age-specific dummies and marital status. To correct for time effects we include GDP growth and unemployment rates for western and respectively eastern Germany.

We run separate regressions for people living in eastern and western Germany and men and women. The former is necessary because there are still price level and structural differences between eastern and western Germany (Tigges et al. 2000, Biewen 2000). The latter is common in the literature and necessary for us to identify the differences in the determinants.

$$
\begin{aligned}
I_{i t}= & \alpha_{0}+\alpha_{1} D_{56_{i t}}+\ldots+\alpha_{10} D_{65_{i t}}+\alpha_{11} Y_{i}+\alpha_{12} Y_{i}^{2}+\alpha_{13} S Y_{i t}+\alpha_{14} S Y_{i t}^{2}+\alpha_{15} K_{i t} \\
& +\beta_{0} O V(\alpha)_{i t}+\gamma_{0} S S W_{i t}+\kappa X_{i t}+\epsilon_{i t}
\end{aligned}
$$

where $I_{i t}$ indicates whether individual $i$ at age $t$ is retired (1) or not (0), $D_{56_{i t}} \ldots D_{65_{i t}}$ are the age-specific dummies, $Y_{i}$ is gross income earned at age 54, $S Y_{i t}$ the number of service years, $K_{i t}$ the number of kids, and $X_{i t}$ includes the average number of months that a person is sick over the sample period as well as the controls for a time trend. Compared to previous studies, we lack information about spouses and private wealth. We estimate a simple probit model with robust standard errors. Börsch-Supan (2001) argues that the improper specification underestimates the true effect of explanatory variables, as multiple experiments with the error structure in his study show.

Changes in Women's Employment. In Section 3.2.3, we argued that especially labor force behavior of women in western Germany has changed across cohorts due to reasons 
that are related to family issues (fewer children, more divorces) and due to economic reasons (higher education, higher wages). These factors are related to the opportunity cost of work and determine the employment rate. We use the estimates from Fitzenberger et al. (2004) to construct a cohort trend. These are, however, only available for western Germany. As Figure 3.D1 in Appendix 3.D demonstrates the difference between male and female employment rates, i.e. the ER gap, is steadily decreasing across cohorts. In a first step, we will therefore augment regression (3.5) by including a cohort specific ER gap between men and women in order to provide evidence for the importance of cohort related economic factors:

$$
\begin{aligned}
I_{i t}= & \alpha_{0}+\alpha_{1} D_{56_{i t}}+\ldots+\alpha_{10} D_{65_{i t}}+\alpha_{11} Y_{i}+\alpha_{12} Y_{i}^{2}+\alpha_{13} S Y_{i t}+\alpha_{14} S Y_{i t}^{2}+\alpha_{15} K_{i t} \\
& +\alpha_{16} E R G_{i}+\beta_{0} O V_{i t}+\gamma_{0} S S W_{i t}+\kappa X_{i t}+\epsilon_{i t}
\end{aligned}
$$

where $E R G_{i}$ is the cohort-specific gap between male and female employment rates in western Germany. In the second step, we decompose the cohort-specific ER gap into a cohort trend that is equal to the average number of children per woman in each cohort, which captures the changes in roles within families, and a cohort trend that is equal to the percentage of university graduates in each cohort in the respective subsample, which captures the changes in job skills. As Figure 3.D2 in Appendix 3.D shows, the percentage of west German women holding a university degree increases most. None of the subsamples faces a decreasing share of university graduates. Therefore, a high percentage corresponds to young cohorts. Figure 3.D3 in Appendix 3.D depicts the decreasing number of children per woman in eastern and western Germany across cohorts. It decreases faster in western than in eastern Germany. Here, a low number corresponds to young cohorts. We run the following regression that includes the kids and the education trend.

$$
\begin{aligned}
I_{i t}= & \alpha_{0}+\alpha_{1} D_{56_{i t}}+\ldots+\alpha_{10} D_{65_{i t}}+\alpha_{11} Y_{i}+\alpha_{12} Y_{i}^{2}+\alpha_{13} S Y_{i t}+\alpha_{14} S Y_{i t}^{2}+\alpha_{15} K_{i t} \\
& +\alpha_{17} P E_{i}+\alpha_{18} K T_{i}+\beta_{0} O V_{i t}+\gamma_{0} S S W_{i t}+\kappa X_{i t}+\epsilon_{i t}
\end{aligned}
$$

where $P E_{i}$ is the cohort-specific share of university graduates in the respective subsample, and $K T_{i t}$ is the cohort-specific average number of children of woman in the respective subsample.

\subsection{Results}

\subsubsection{Actual Employment Exit}

We first consider the retirement definition in the sense of permanent employment exit. Figures 3.4(a) to 3.4(d) plot the percentage of the sample leaving work over age. In western Germany, many women start exiting at age 55, whereas most men wait until age 60 as 
illustrated in Figure 3.4(a) and 3.4(b). Another difference between men and women is the number of pivotal retirement ages. We can detect two for men but only one for women. According to Figure 3.4(a), most men exit the labor force at age 60 and age 63, while according to Figure 3.4(b), there is a striking single peak at age 60 for women. For both groups, we see declining exit rates at age 60 as people are born later. This is especially obvious for women in western Germany. The peak at age 60 decreases from $33 \%$ to $15 \%$. At the same time, a second peak emerges at age 63 . The picture differs very much in eastern Germany. Especially for men, there is no clear pivotal retirement age. Men (and women) start retiring immediately. The average exit rate in Figure 3.4(c) is rather flat across all ages. In Figure 3.4(d), there is a peak at age 60 but less accentuated than in the case of western German women.

Reasons for the difference between eastern and western Germany lie in the high unemployment rates in the former East. They made it possible for older cohorts to receive unemployment aid or a disability status at relatively young ages, thereby retiring much earlier than the regular retirement age. Differences between men and women lie in the institutional retirement framework. The now abolished female pension made it possible for women born prior to 1952 to receive an old age pension much earlier (and with lower adjustment factors) than their male equivalent.

\subsubsection{Actual Retirement Entry}

Figures 3.5(a) to 3.5(d) plot the fraction of individuals who start to receive an old age pension over age for different birth cohorts. The entry rate is more similar between eastern and western Germany than the exit rate. It is zero for everyone until age 60 because this is the first age at which it becomes possible for anyone to receive regular pension payments. Thereafter, the pictures differs greatly between men and women. Almost $60 \%$ of all women in eastern and western Germany, who were born in 1939, retire at age 60. In line with the increasing regular retirement age for women, this percentage decreases to about $20 \%$ (35\%) for women born in 1946 in western (eastern) Germany. This drop is much larger than in the exit case. Additionally, a second peak at age 63 is emerging. This is the new minimum eligibility age for women with a long service life. For men, there are again two peaks; one at age 60 and one at age 63 . In contrast to the exit rate, the entry rate is more accentuated at the second peak and not at the first. Age 63 is the minimum eligibility age for men with a long service life. We can also see the trend of a decreasing first and increasing second peak as people are born later. This indicates that people are responding to recent pension reforms and that they postpone benefit claiming. They also postpone exiting the labor force, but by less than entering regular retirement. This is in line with the findings of Hanel (2009). 

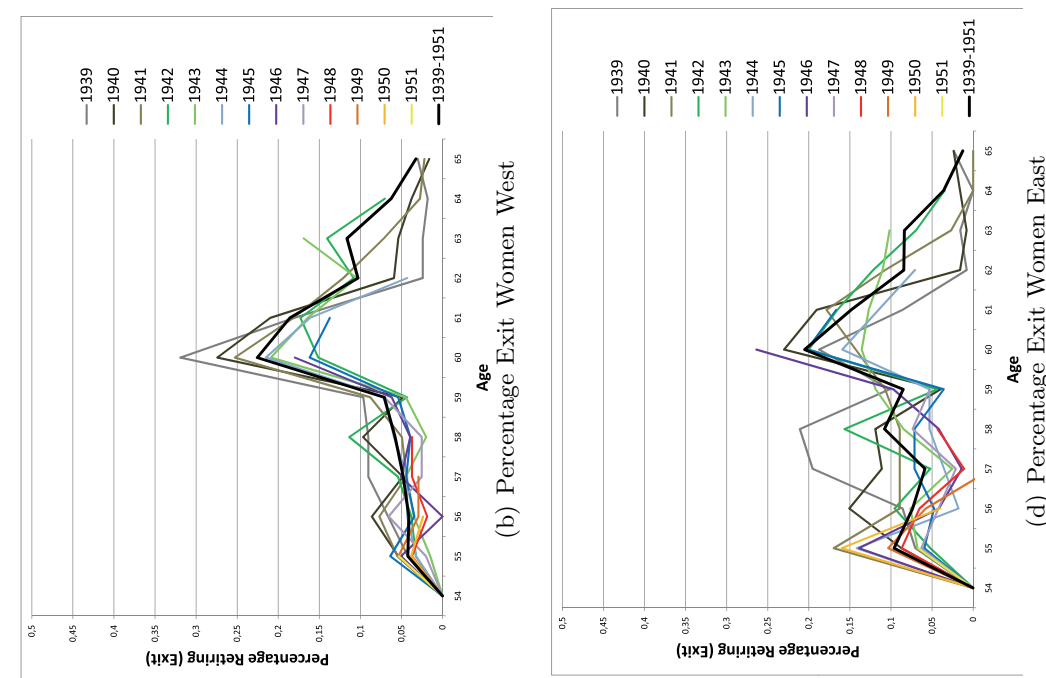

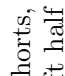

焉

$\stackrel{0}{\oplus}$

实

害

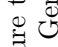

范焉

.

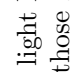

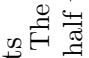

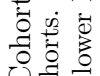

उद्व

के

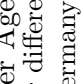

वे

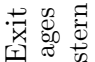

of

00.9

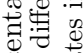

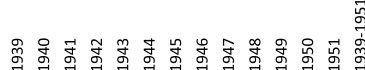

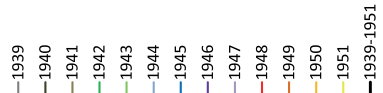

诺范

获: 获
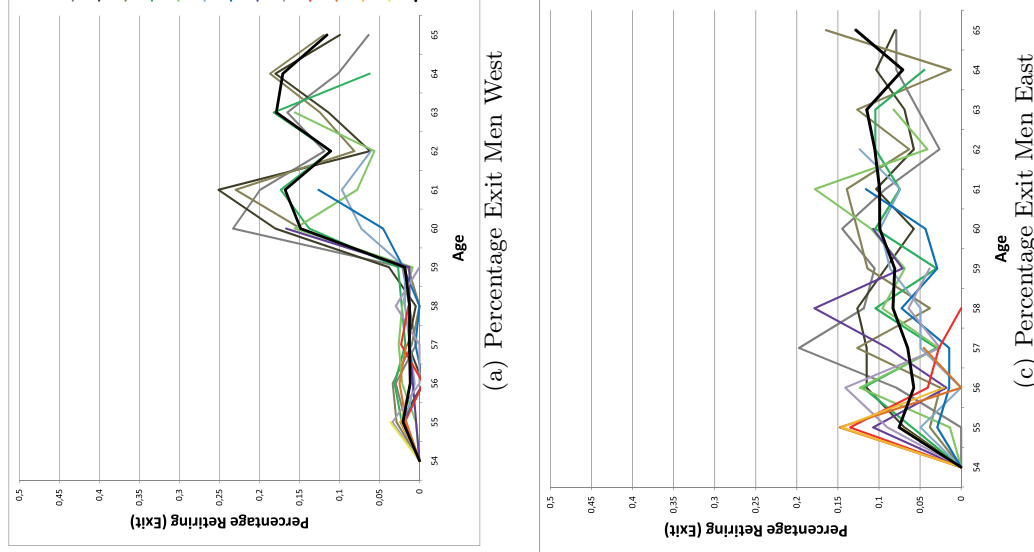

즈 음

두월

«눙 ?

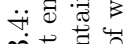

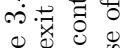

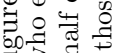

诖出

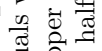

छे

踏

要

:

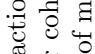

焉离

罂焉

요웡

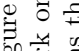

$\underset{\sim}{5}$

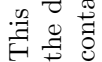



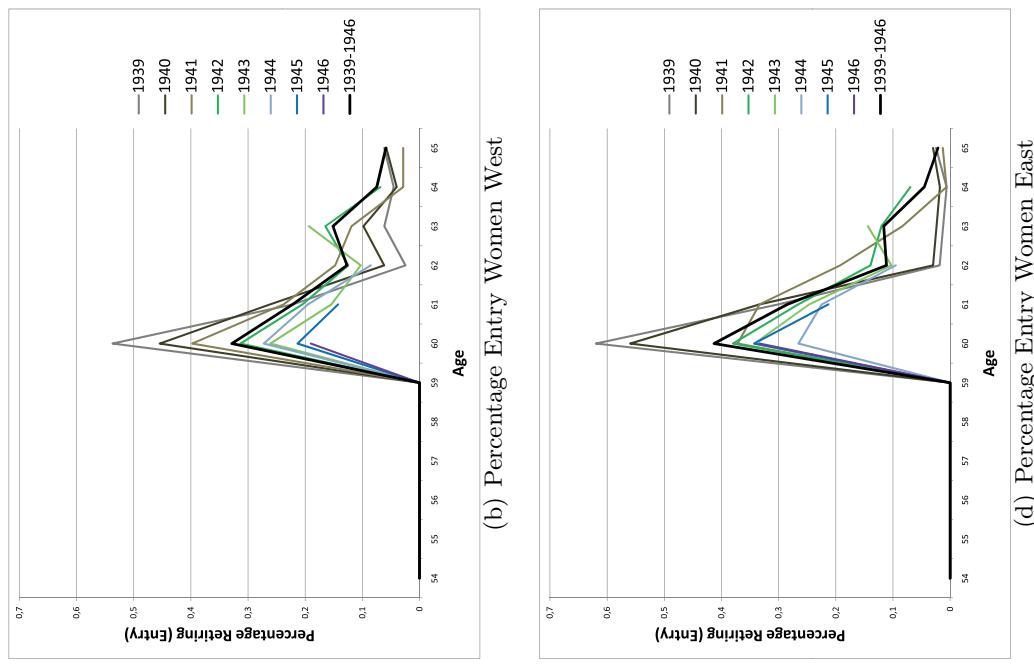

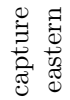

कै :

$\exists$ 范

$+\frac{7}{50}$

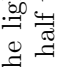

E.

홍

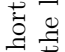

8

च

突苛

象完

궁

$0 \%$

곡료

80.

$\varangle:=$

范苟

ชี ซี ซี

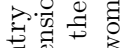

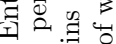

\& $80 \pi$
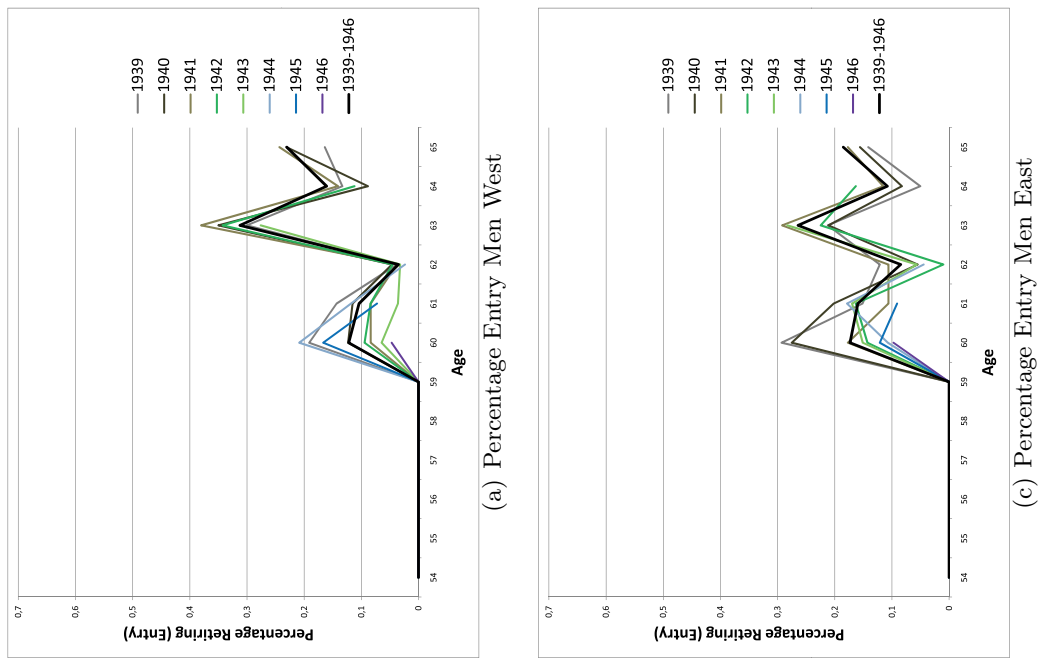

중워

ฮี่

$0 \&$ 茫

ฮี

엉 웜

ये

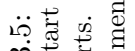

⿵人一

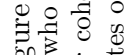

社昰

질

웜

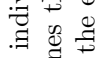

पै 0

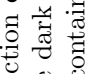

幽

is

要

응

0 औ

$\because 8$

50 ำ สำ

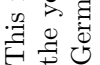




\subsubsection{Estimating Alphas}

$\alpha$ indicates the preference for income while not working over income while working. It may also be influenced by the benefits from home production. However, it is commonly interpreted as the preference for leisure. We expect the preference for leisure to be higher when taking exit than when taking entry as the dependent variable because people retire earlier in the former case, which implies that they must value leisure more. Similarly, as women stop working and start claiming old age pension benefits earlier than men they should have a higher preference for leisure.

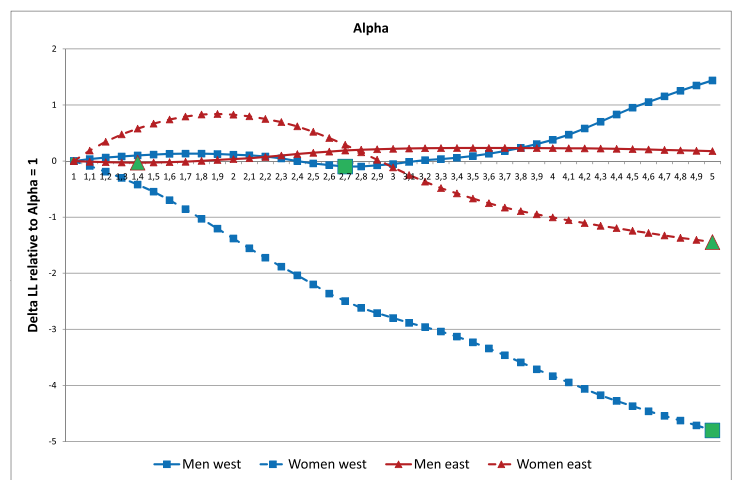

(a) Estimated Alpha, $I_{i t}=$ exit

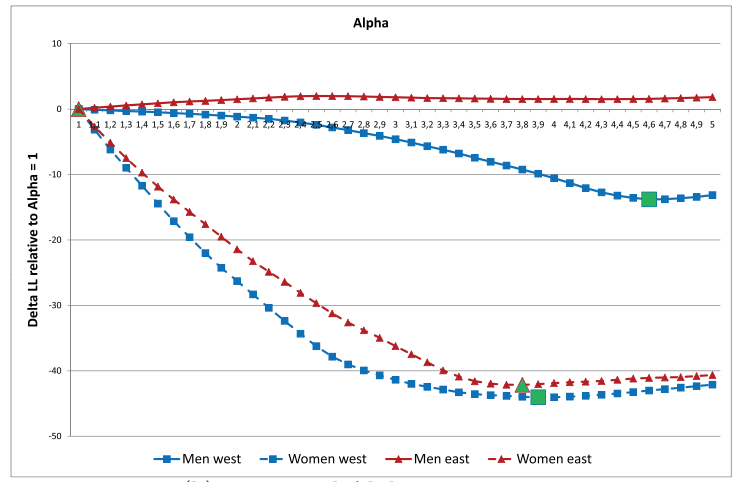

(b) Estimated Alpha, $I_{i t}=$ entry

Figure 3.6: Estimated Alphas

This figure plots the $\log$ likelihood for increasing $\alpha$ s in deviation from the log likelihood of $\alpha=1$ for men (solid) and women (dashed) in eastern (red, triangles) and western (blue, squares) Germany. The upper panel refers to the case where the dependent variable is employment exit, the lower one to the case where the dependent variables is retirement entry.

Figures 3.6(a) and 3.6(b) depict the log likelihood for increasing $\alpha$ s in deviation from the $\log$ likelihood of $\alpha=1$. The upper graph, which results from the regressions with exit 
as the dependent variables, shows that $\alpha$ for women is not converging yet within the values in our grid. The largest $\alpha$ in our grid implies that an individual is indifferent between receiving $€ 100$ from work and $€ 20$ leisure. Since we doubt that anyone would accept even less than $€ 20$, we set women's $\alpha=5.0$ in case of exit from work as the dependent. Men's $\alpha$ s are somewhat lower. West German men are best described by an $\alpha=2.7$ and east German men by an $\alpha=1.4$. This implies indifference between $€ 100$ from work and respectively $€ 37$ and $€ 71$ from leisure.

If we take retirement entry as the dependent variable instead, west and east German women have an estimated $\alpha$ of respectively 3.8 and 3.9, implying indifference between receiving $€ 100$ from work and about $€ 25$ while enjoying leisure. West German men indicate a preference for leisure of 4.6. For east German men $\alpha=1.0$. Previously estimated $\alpha$ s from Börsch-Supan et al. (2004) lie between 2.5 and 4.0. They explain that the $\alpha$ s are higher the fewer information one has about the individuals. We lack private wealth and income of the spouse, which may play a role for retirement entry decision.

Our estimates suggest that preference for leisure is indeed higher for women than for men and the preference for leisure is higher in case of exit from work than in case of retirement entry. West German men appear to be an exception.

\subsubsection{Social Security Wealth and the Option Value of Postponing Retire- ment}

Figures 3.7(a) to 3.7(d) depict SSW for men and women in western and eastern Germany. It plots the SSW associated with immediate retirement over age for different birth cohorts, where the light lines refer to the young and the dark to the old cohorts.

In all figures, SSW monotonically increases with age until a certain age. In case of men it peaks around age 63 as shown in Figures 3.7(a) and 3.7(c). This pattern reflects the minimum eligibility ages to the pension for people with a long service life, which allows people to retire at some discount. Women's SSW peaks at the normal retirement ages (i.e. the age at which no actuarial adjustment apply) of the special female pension that applies to all women born prior to 1952. Their eligibility age increases by one year for each cohort born between 1940 and 1945. Figure 3.7(b) and 3.7(d) exhibit a peak at age 60 for cohorts born in 1939 and 1940, a peak at age 62 for cohorts born in 1941, and lastly a peak at age 63 for cohorts born in 1942. The following peaks we cannot observe anymore, but we can see SSW of the younger cohorts to still be increasing. It is interesting to observe the differing slopes before the peaks. SSW of men increases more than that of women. There is more at stake for men than for women because the former have accumulated more earnings points. 

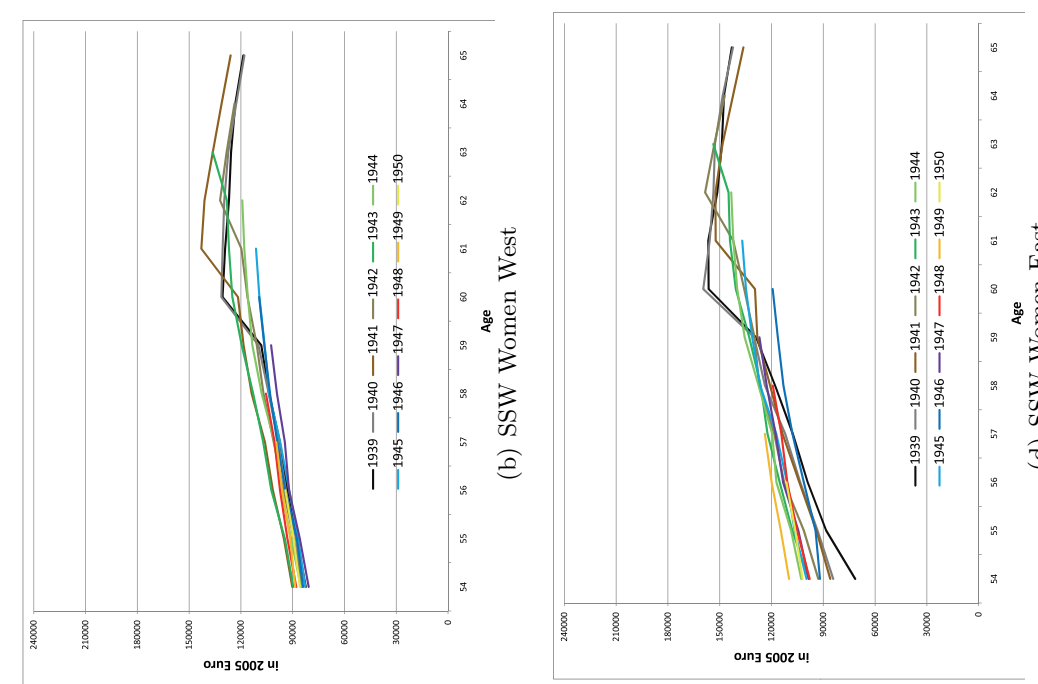

我

웅

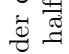

륭

욤

क्ष

ชี क्ष

閔

空

की

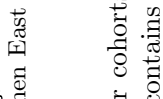

\&

$>$ 范

永

()

玄荌

पू

굴
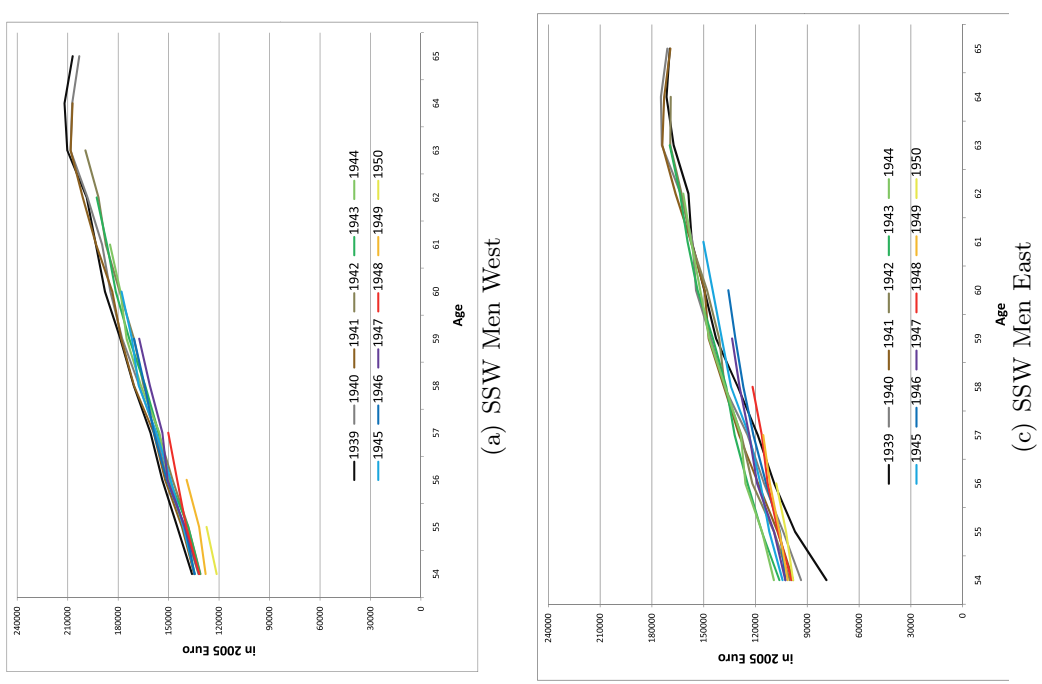

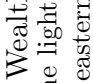

B.

节菏

造造

붕

की

药

0

$\exists$

$\therefore$ 용

它䜦

임ำ

बल

(I) .9

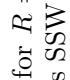

永

늉.

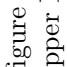

品 家

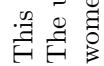


Apart from the difference in the slopes, we can also observe substantially different levels between men and women in western Germany. Despite higher survival probabilities and more generous pension eligibility ages for women, their SSW remains substantially below that of men. This is mainly due to their lower labor force participation. However, as documented in Section 3.2.3, women in younger birth cohorts have been changing their behavior. They have started to behave more similar to men. In Figure 3.7(b), we can observe the birth cohorts 1948 to 1950 (yellow, orange and red) to be above the birth cohorts 1945 to 1947 (blue and purple lines), for instance. As the younger cohorts' SSW would rather decrease as a response to the regulatory pension amendments, this must be driven by more earnings points. We do not observe this for men. This gender difference is weaker in eastern Germany, because there is a smaller difference between male and female employment rates. Even today, women in eastern Germany return to work after maternity leave more often and faster compared to their counterparts in western Germany. We can also observe a generally lower SSW level in eastern than in western Germany, which is in line with the generally lower income level in the former. Accordingly, the pension level is adjusted downwards in the former East. If we adjust for the price level difference between 1995 and 2005 and look at average SSW of all cohorts across age, these shapes and levels are comparable to the ones in Börsch-Supan et al. (2004). Note that we also include the possibility of receiving unemployment benefits in the calculation of SSW and OV.

Figures 3.1(a) to 3.1(d) depict the OV of postponing retirement for men and women in western and eastern Germany. We plot the OV with alpha from the regressions with exit as the dependent variable. ${ }^{15}$ The optimal retirement age corresponds to an OV of 0 . It becomes negative if people are worse off in terms of utility by working than by retiring next period. All of the lines are downward sloping as it becomes more attractive to enter retirement as one gets older. There is a striking difference between the patterns of men and women. For all cohorts, women's OV decreases until age 59. Thereafter, they exhibit a sharp drop in regular intervals of one year in line with the normal retirement age for women. If we take 1941 as an example, we see the sharp drop at age 61, which is their first eligibility age without actuarial adjustments. After the normal retirement age of the respective cohort, the OVs of the cohorts converge at age 65. This makes sense because all women are subject to the same rules as of age 65 . The younger cohorts will therefore not exhibit this sharp drop anymore but will smoothly decline until age 65 . The OVs are more dispersed across cohorts for women because their high alpha makes the cash flow differences more extreme. Again, we observe higher OVs in western Germany for female cohorts born after 1948 (yellow, orange and red) than for female cohorts born between 1945 and 1947 (blue and purple lines).

\footnotetext{
${ }^{15}$ Appendix 3.C contains the OVs with alpha from the regressions with entry as the dependent variable.
} 

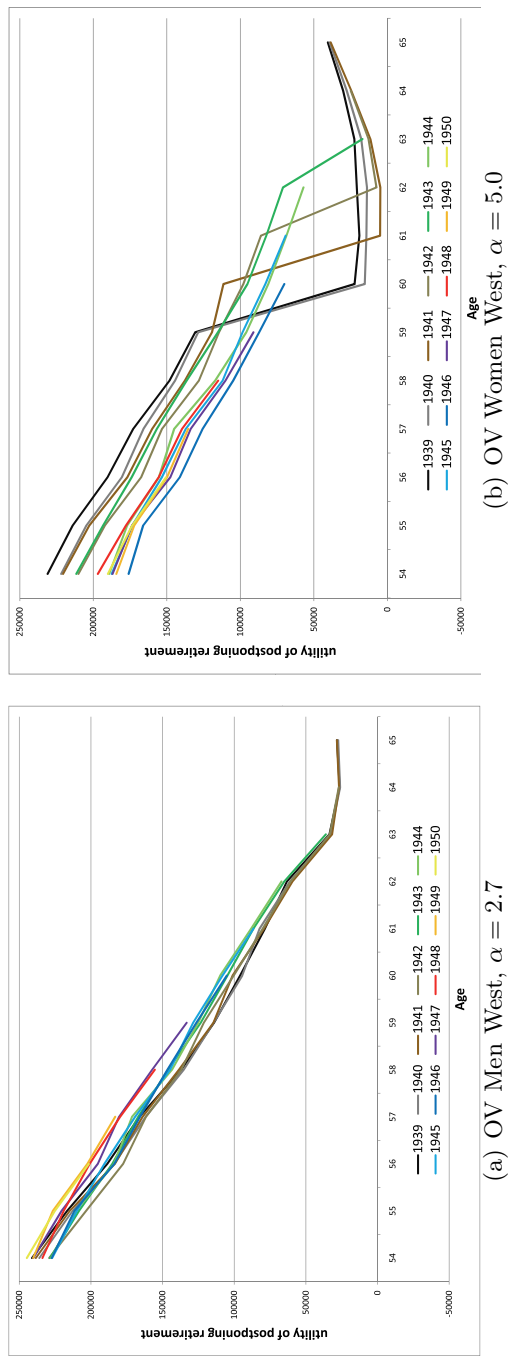

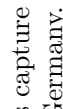

$\stackrel{\Xi}{\Xi}$

$\stackrel{00}{=}$

..$\exists$
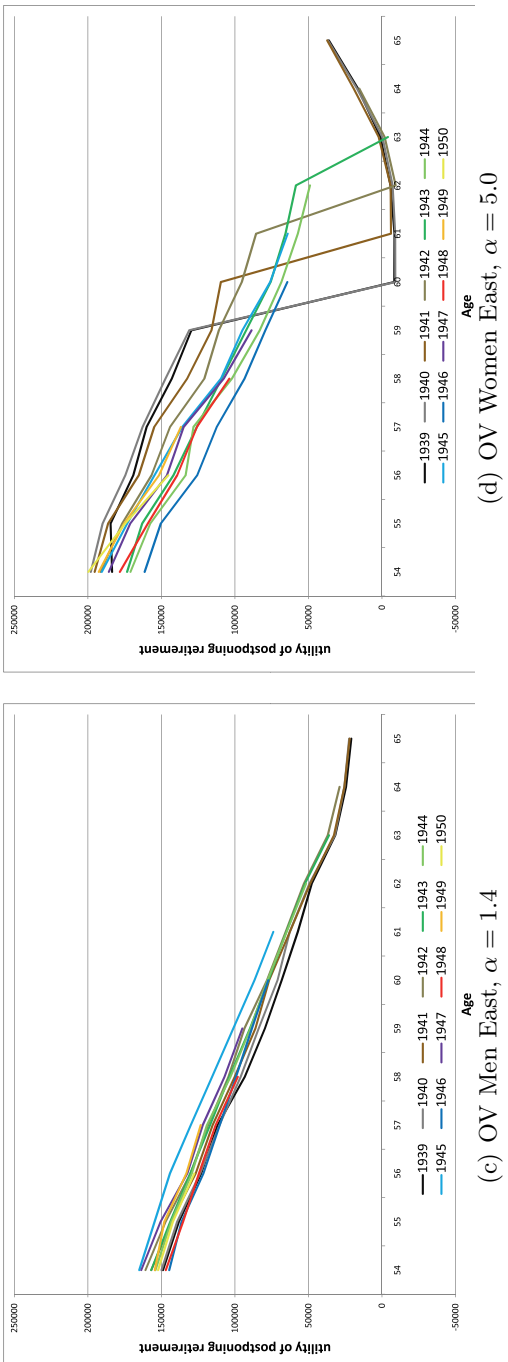

E.

ज़

疋

त्ञ

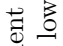

幽 要

$\underset{乛}{\$}$

का 记

总

ن

ㄱ. ㅋ.

40

एँ

\&.

需

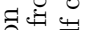

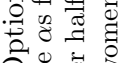

ธै

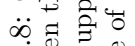
$\therefore$.

品 कo 工 8 웅 궁 过苛 : 㧜 \& 范 3 讨 b靑 के on 응 它穿 识焉

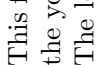




\subsubsection{Regression Results, Western Germany}

As explained in Section 3.4, we look at the relationship between exit from work and the individual characteristics and the relationship between entering old age pension and the individual characteristics. In the former case, we use all cohorts while in the latter we restrict ourselves to cohorts born prior to 1947. We only use observations as of age 59 in the latter case because individuals are not able to start claiming old age pension benefits prior to age 60 . In both subsamples, we drop individuals' observations along the time series dimension as soon as they leave work, respectively start claiming an old age pension.

\section{$I_{i t}=$ employment exit}

Table 3.3 contains the marginal effects and their T-Ratios from regression (3.5) to (3.7) and taking $I_{i t}=$ employment exit for people living in western Germany; The left panel gives the results for women and the right panel gives the results for men. The first columns serve as the benchmark against which we compare the results of the cohort trend augmented regressions. We first discuss the women. The pseudo- $R^{2}$ indicates that the benchmark equation can explain $39.5 \%$ of the variation in the retirement status. Comparable results from Börsch-Supan et al. (2004) yield a pseudo- $R^{2}$ of $25.8 \%$.

The marginal effects of income and the number of service years are significantly negative and therefore indicate labor attachment. The longer women in western Germany have been working the less likely they are going to stop working. SSW is significantly positive. If considered along the time-series dimension, decreasing SSW should trigger retirement. If considered along the cross-sectional dimension, individuals with higher SSW can afford to stop working earlier than those with lower SSW. Here, it seems that the cross-sectional nature dominates. Since we cannot control properly for private wealth, the OV and SSW may capture this instead. ${ }^{16}$ The OV affects exit from work significantly negative, as it should. A high OV indicates a lot of retirement income potential in the future compared to now. Thus, along the time-series dimension, individuals should retire the smaller the OV. Note that being or having ever been marginally employed or unemployed both trigger retirement. The latter's significance is spoiled by endogeneity though. The age dummies are all positive and, especially those referring to age 60 and 61, highly significant. Moreover, there is a notable jump of the marginal effects between age 59 and 60 , which appears to be the pivotal retirement age for women (cf Figures 3.4(b)). We observe women, who are sick more often, to retire earlier and women, who have more children, to retire later. The highest education dummy indicates labor attachment again.

\footnotetext{
${ }^{16}$ The results are robust to including a cohort specific fraction of home ownership and of individuals who do not possess any private wealth. These variables are constructed on the basis of the SAVE data set.
} 


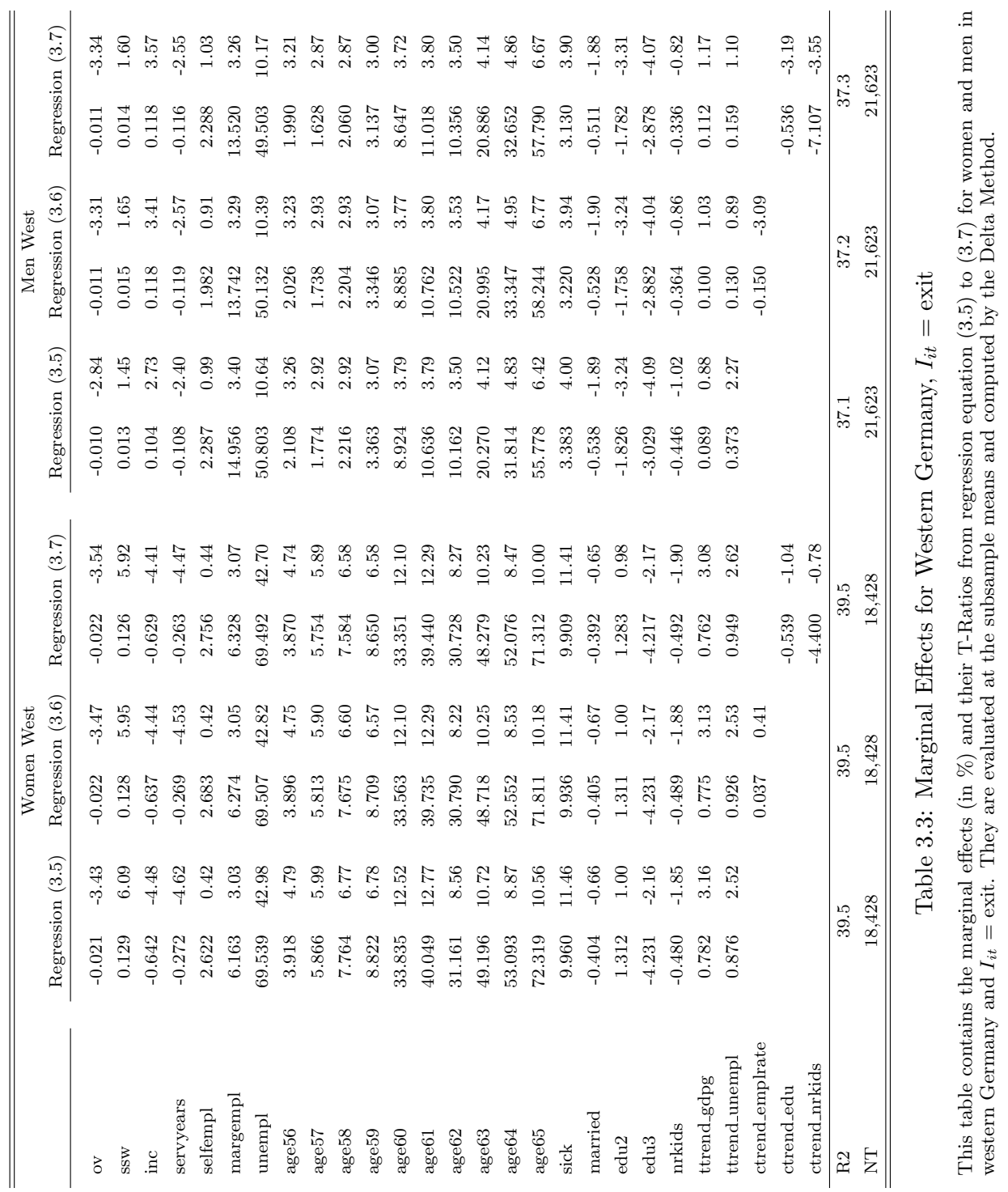


Columns 2 and 3, which summarize the cohort-trend augmented regressions (3.6) and (3.7), show that the augmentation does not improve the regression fit. The T-Ratios also indicate that there is no systematic pattern in the exiting behavior of western German women with respect to the cohort trends that are related to the opportunity cost of labor.

The regression results for men (right panel in Table 3.3) are similar to those for women in western Germany. Notable differences are 1) a less than $10 \%$ (positive) significant marginal effect of SSW, 2) a positive income effect, 3) less significant age dummies and 4) no jump of the marginal effects. The fact that the age dummies are less significant and the absence of a jump suggest that the financial incentive variables capture the age-specific variation with regard to the exiting behavior better for men than for women in western Germany. For men, marriage has also a negative effect on the probability to retire.

In contrast to women, the ER gap in regression (3.6) carries a significantly negative sign for men. Thus, the smaller the gap between male and female employment rates (i.e. the younger cohorts) the more likely men leave work. The decomposition in regression (3.7) demonstrates that the skill related and the kids trend have an influence. The skill trend points towards later retirement of young cohorts. The kids trend, capturing the growing instability of families, points towards earlier retirement of young cohorts. The larger magnitude of the kids trend compared to skill trend supports the direction of the ER gap.

\section{$I_{i t}=$ retirement entry}

Table 3.4 contains the equivalent regression results to Table 3.3 if we take retirement entry as the dependent variable. We can explain about $15 \%$ of all entries for women and $33 \%$ of all entries for men. We first discuss the results of women again.

The results of the regressions with retirement entry as the dependent variable are somewhat different to those with employment exit as the dependent variable. Women are now more likely to retire the more they earn and the longer they have been working. Consequently, we can conclude that women with longer service lives are less likely to exit from work but more likely to start claiming old age pension benefits; equivalently for labor income. The option value still carries a significantly negative sign. The impact of SSW on retirement is now indistinguishable from zero. ${ }^{17}$ The age dummies still capture some age related incentives. Entering retirement at age 61, 63 and 65 is especially likely. Entering retirement at age 62 is very uncommon. As previously observed in the literature, self-employment leads to later retirement because these people are more attached to their

\footnotetext{
${ }^{17}$ In Appendix 3.A, we show regression results for western Germany if we do not cut off all observations prior to age 59 and $I_{i t}=$ entry. For women, the effect of SSW is then more negative but still not significant at a $10 \%$ level. The signs and significance of the economic cohort trend remain unaffected.
} 
work. It is also interesting to observe that the marginal employment dummy is negatively significant. It illustrates that women, who are marginally employed, are less likely to start claiming pension benefits while they are more likely to leave work (previous regression). Consequently, marginally employed women have a large gap between stopping to work and starting to claim old age pension benefits. Women with many kids, on the other hand, have a relatively smaller gap: The number of kids has significantly positive effect on old age pension claiming but a significantly negative effect on stopping to work.

By including the cohort-related economic trends in Columns 2 and 3, we can increase the pseudo- $\mathrm{R}^{2}$ by $1.9 \%$, the largest percentage increased observed in this analysis. The ER gap in (3.6) has a significantly positive marginal effect on entering retirement. Comparing this to the regression results (3.7), the skill trend has an insignificantly negative and the kids trend an insignificantly (but stronger than the skill trend) positive effect on claiming old age pension benefits. Consequently, both indicate that younger cohorts retire later. Thus, we observe that women do not change their employment exit but postpone old age pension claiming the later they are born. As a result, the time span between employment exit is wider for younger than for older female cohorts, which is in line with the findings of Hanel (2009). Moreover, we can conclude that this pattern is not only related to economic incentives as captured by the OV and SSW but by other cohort-specific determinants related to the opportunity cost of work.

For men, the results for retirement entry are also somewhat different from the results for employment. While income affects stopping to work positively, it does not affect retirement entry at all. The marginal effect of the number of service years becomes more negative. The OV is still significantly negative while SSW is now significantly positive at the $5 \%$ level. ${ }^{18}$ At the same time the age dummies gain in importance in comparison to the previous regression for men in western Germany. Age 63 and 65 appear to be the pivotal retirement entry ages for men. These observations indicate that our explanatory variables are better suited to explain men's exit than men's entry behavior.

Including the cohort-dependent ER gap in regression (3.6), yields a positive effect on retirement. However, it is less than the $10 \%$ significant. Note that the sign here goes into the opposite direction than when taking exit as the dependent variable. The decomposition of the ER gap into the skill and kids trend shows that both are pointing towards earlier retirement for older cohorts (insignificantly though) as the ER gap. These results imply that the time span between leaving work and entering retirement is also widening for younger male cohorts.

\footnotetext{
${ }^{18}$ In Appendix 3.A, we show regression results for western Germany if we do not cut off all observations prior to age 59 and $I_{i t}=$ entry. For men, the effect of SSW is then indistinguishable from zero. The signs and significance of the economic cohort trend remain unaffected.
} 


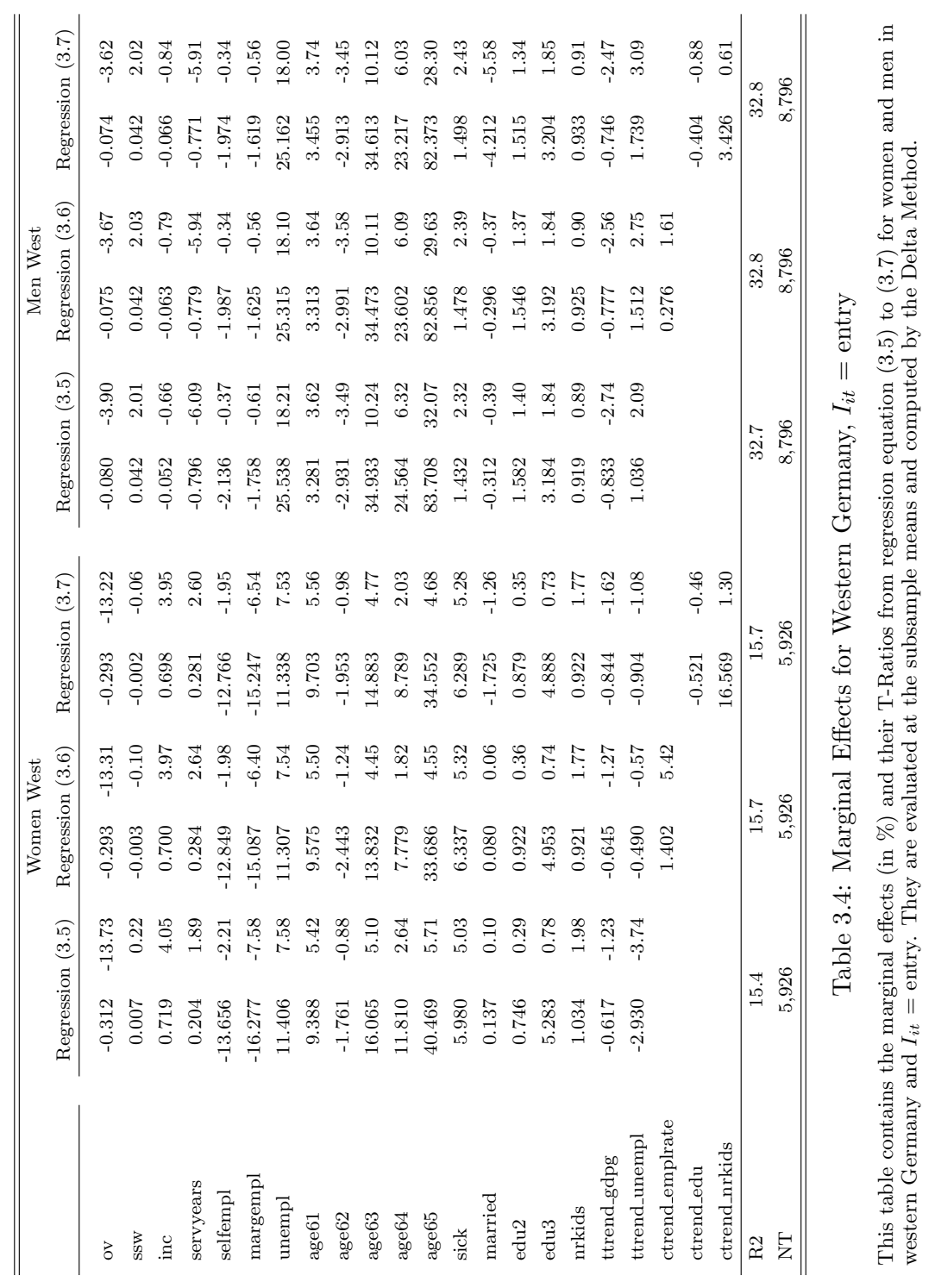




\subsubsection{Regression Results, Eastern Germany}

\section{$I_{i t}=$ employment exit}

Table 3.5 summarizes the results of regression (3.5) and (3.7) for people living in eastern Germany and $I_{i t}=$ employment exit. We have to skip (3.6) due to a lack of data. The left panel refers to women; the right to men. The pseudo- $\mathrm{R}^{2} \mathrm{~s}$ are around $43 \%$. We discuss the women first.

Women's exit in eastern Germany is unaffected by their labor income but positively affected by number of years they have been working. These women do not show signs of labor attachment. Self-employment affects exit significantly positive. This implies that selfemployed women in eastern Germany are more likely to stop working, which is at odds with the previous observations and evidence in the literature (cf Börsch-Supan et al. (2004)). ${ }^{19}$ The marginal effects of OV and SSW are significantly negative as they should. The age dummies are again significantly positive and increasing. As for women in western Germany, we observe a jump between age 59 and 60 .

The marginal effects of the skill and the education trend in Column 2 indicate an increasing likeliness for younger cohorts to retire early due to the skill trend on the one hand, but a decreasing likeliness for the younger cohorts to retire early due to the kids trend on the other hand. The magnitude and significance of the latter effect is substantially greater. Therefore the overall effect points to later exits of younger cohorts.

The regression results (3.5) for men differ from the ones for women in eastern Germany along several dimensions. Firstly, the OV is insignificant but SSW is significantly negative. Secondly, income has a significantly negative effect on exiting employment, indicating that men evaluate the opportunity cost of work as too high to leave work in eastern Germany (or, as a results of unemployment wave after the reunification poorly skilled men in eastern Germany (earning few) were laid off.) Thirdly, the age dummies do not exhibit an extreme jump.

In the cohort-trend augmented regressions, we observe a significantly positive effect of the skill trend and a positive and similarly significant effect of the kids trend on exiting employment. Since the magnitude of the latter is larger, eastern German men of younger cohorts are less likely to leave work than those of older cohorts.

\footnotetext{
${ }^{19} \mathrm{~A}$ new law, the Gesetz zur Förderung von Kleinunternehmern und zur Verbesserung der Unternehmensfinanzierung implemented in 2003, offers financial support to unemployed individuals who want to start their own one-man business. Self-employed women in eastern Germany may, to a large extent, belong to this group and therefore represent a selection of self-employed individuals.
} 
Chapter 3 Labor Force Participation and Retirement Entry in Germany

\begin{tabular}{|c|c|c|c|c|c|c|c|c|}
\hline \multirow[b]{3}{*}{ ov } & \multicolumn{4}{|c|}{ Women East } & \multicolumn{4}{|c|}{ Men East } \\
\hline & \multicolumn{2}{|c|}{$\operatorname{Regr}(3.5)$} & \multicolumn{2}{|c|}{ Regr (3.7) } & \multicolumn{2}{|c|}{ Regr (3.5) } & \multicolumn{2}{|c|}{ Regr (3.7) } \\
\hline & -0.014 & -2.38 & -0.014 & -2.72 & 0.016 & 0.66 & 0.015 & 0.61 \\
\hline ssw & -0.028 & -2.42 & -0.024 & -2.32 & -0.052 & -1.86 & -0.053 & -1.87 \\
\hline inc & -0.064 & -0.56 & -0.037 & -0.35 & -0.910 & -2.23 & -0.948 & -2.26 \\
\hline servyears & 0.247 & 3.66 & 0.227 & 3.55 & 0.378 & 2.09 & 0.419 & 2.23 \\
\hline selfempl & 28.503 & 2.05 & 26.867 & 1.96 & 38.292 & 4.43 & 37.747 & 4.40 \\
\hline margempl & 0.982 & 0.28 & 1.190 & 0.35 & 4.103 & 0.36 & 4.373 & 0.36 \\
\hline unempl & 54.430 & 16.81 & 52.900 & 15.76 & 59.193 & 14.50 & 59.623 & 14.66 \\
\hline age56 & 1.462 & 2.31 & 1.252 & 2.12 & 6.292 & 3.28 & 6.227 & 3.22 \\
\hline age 57 & 1.597 & 2.32 & 1.203 & 1.95 & 8.375 & 3.57 & 8.080 & 3.45 \\
\hline age 58 & 3.764 & 3.57 & 3.052 & 3.26 & 11.945 & 3.88 & 10.905 & 3.67 \\
\hline age 59 & 4.987 & 3.72 & 4.161 & 3.47 & 17.666 & 4.35 & 16.679 & 4.19 \\
\hline age60 & 27.020 & 6.38 & 24.401 & 5.98 & 25.423 & 4.78 & 24.068 & 4.59 \\
\hline age61 & 36.958 & 6.73 & 34.368 & 6.35 & 32.566 & 5.06 & 31.703 & 4.95 \\
\hline age62 & 30.445 & 4.99 & 28.644 & 4.79 & 30.518 & 4.34 & 30.349 & 4.31 \\
\hline age63 & 41.515 & 4.89 & 39.426 & 4.63 & 42.476 & 4.73 & 41.960 & 4.66 \\
\hline age64 & 42.498 & 3.71 & 36.549 & 3.21 & 45.011 & 4.18 & 45.108 & 4.16 \\
\hline age65 & 78.897 & 6.82 & 71.604 & 5.03 & 90.314 & 23.66 & 90.053 & 23.73 \\
\hline sick & 7.502 & 6.13 & 7.029 & 6.02 & 10.583 & 5.10 & 10.728 & 5.11 \\
\hline married & -0.486 & -0.88 & -0.461 & -0.89 & -1.930 & -1.54 & -2.113 & -1.65 \\
\hline edu2 & 2.593 & 2.14 & 1.929 & 1.78 & 6.407 & 2.59 & 6.680 & 2.63 \\
\hline edu3 & 3.185 & 1.62 & 2.126 & 1.26 & 4.502 & 1.30 & 4.926 & 1.34 \\
\hline nrkids & 0.246 & 0.95 & 0.162 & 0.69 & -2.447 & -0.89 & -2.421 & -0.87 \\
\hline ttrend_gdpg & 0.449 & 1.96 & 0.350 & 1.64 & 0.209 & 0.51 & 0.362 & 0.86 \\
\hline ttrend_unempl & 0.480 & 1.59 & 0.702 & 2.34 & 2.975 & 3.88 & 3.166 & 3.96 \\
\hline ctrend_edu & & & 0.108 & 1.09 & & & 0.782 & 2.91 \\
\hline ctrend_nrkids & & & 12.068 & 3.60 & & & 12.871 & 2.13 \\
\hline $\mathrm{R} 2$ & \multicolumn{2}{|c|}{44.2} & \multicolumn{2}{|c|}{44.5} & \multicolumn{2}{|c|}{42.5} & \multicolumn{2}{|c|}{42.7} \\
\hline NT & \multicolumn{2}{|c|}{8,744} & \multicolumn{2}{|c|}{8,744} & \multicolumn{2}{|c|}{7,549} & \multicolumn{2}{|c|}{7,549} \\
\hline
\end{tabular}

Table 3.5: Marginal Effects for East Germany, $I_{i t}=$ exit

This table contains the marginal effects (in \%) and their T-Ratios from regression equation (3.5) and (3.7) for women and men in eastern Germany and $I_{i t}=$ exit. They are evaluated at the subsample means and computed by the Delta Method. 


\begin{tabular}{|c|c|c|c|c|c|c|c|c|}
\hline \multirow[b]{3}{*}{ ov } & \multicolumn{4}{|c|}{ Women East } & \multicolumn{4}{|c|}{ Men East } \\
\hline & \multicolumn{2}{|c|}{ Regr (3.5) } & \multicolumn{2}{|c|}{ Regr (3.7) } & \multicolumn{2}{|c|}{ Regr (3.5) } & \multicolumn{2}{|c|}{ Regr (3.7) } \\
\hline & -0.432 & -14.02 & -0.437 & -13.49 & -0.324 & -3.46 & -0.310 & -3.34 \\
\hline ssw & -0.070 & -1.57 & -0.073 & -1.63 & 0.053 & 1.18 & 0.051 & 1.16 \\
\hline inc & 0.517 & 2.19 & 0.541 & 2.26 & 0.450 & 1.53 & 0.431 & 1.47 \\
\hline servyears & -0.213 & -0.84 & -0.234 & -0.92 & -1.090 & -3.78 & -1.081 & -3.75 \\
\hline selfempl & 19.779 & 1.22 & 19.305 & 1.19 & -10.645 & -2.66 & -11.374 & -3.53 \\
\hline margempl & 1.970 & 0.18 & 2.839 & 0.25 & & & & \\
\hline unempl & 13.606 & 7.52 & 13.539 & 7.43 & 28.563 & 14.04 & 28.761 & 14.15 \\
\hline age61 & 19.261 & 7.55 & 19.014 & 7.34 & 7.754 & 3.82 & 8.330 & 4.07 \\
\hline age62 & 1.623 & 0.51 & 0.963 & 0.29 & -1.630 & -0.78 & -1.277 & -0.61 \\
\hline age63 & 7.734 & 1.54 & 6.367 & 1.22 & 34.764 & 5.75 & 34.983 & 5.79 \\
\hline age64 & 15.665 & 1.85 & 15.034 & 1.78 & 22.653 & 2.94 & 22.336 & 2.91 \\
\hline age65 & 46.223 & 3.21 & 45.953 & 3.18 & 84.737 & 19.86 & 84.007 & 17.65 \\
\hline sick & 8.455 & 4.00 & 8.517 & 4.01 & -1.322 & -1.00 & -1.520 & -1.14 \\
\hline married & 2.541 & 1.35 & -3.880 & -1.96 & -1.950 & -1.14 & -9.956 & -6.15 \\
\hline edu2 & 7.322 & 2.73 & 7.350 & 2.72 & 0.700 & 0.36 & 0.537 & 0.27 \\
\hline edu3 & 16.917 & 3.15 & 16.889 & 3.14 & 2.807 & 0.86 & 2.518 & 0.79 \\
\hline nrkids & -0.719 & -0.86 & -0.720 & -0.85 & 13.311 & 2.75 & 13.362 & 2.79 \\
\hline ttrend_gdpg & -1.436 & -2.04 & -1.206 & -1.51 & -0.040 & -0.07 & -0.428 & -0.71 \\
\hline ttrend_unempl & -2.601 & -2.25 & -2.190 & -1.70 & -2.061 & -2.10 & -0.985 & -0.91 \\
\hline ctrend_edu & & & -0.305 & -0.74 & & & 0.585 & 1.09 \\
\hline ctrend_nrkids & & & -8.401 & -0.66 & & & 37.545 & 2.97 \\
\hline $\mathrm{R} 2$ & 19 & & & .2 & 30 & & 30 & \\
\hline NT & 3,1 & & 3 & 43 & 3,0 & & 3,0 & \\
\hline
\end{tabular}

Table 3.6: Marginal Effects for Eastern Germany, $I_{i t}=$ entry

This table contains the marginal effects (in \%) and their T-Ratios from regression equation (3.5) and (3.7) for women and men in eastern Germany and $I_{i t}=$ entry. They are evaluated at the subsample means and computed by the Delta Method. The two east German men that are or have ever been marginally employed retire immediately. Therefore we exclude this variable and their observations from the regression. 


\section{$I_{i t}=$ retirement entry}

Table 3.6 contains the equivalent results to Table 3.5 if we take $I_{i t}=$ retirement entry. As in the exit case, eastern German women are more likely enter retirement the lower the $\mathrm{OV}$ and SSW. The marginal effect of income on retirement is positive and, contrary to before, significant. The number of service years has turned insignificant though. Also, selfemployment has lost significance. Interesting to observe is the lower significance of the age dummies compared to the exit case. Together with negative significance of the financial incentives, it shows that the financial incentives are able to capture most of the age-related effects on retirement. Only age 61 and 65 remain significant at the $1 \%$ level.

Including the cohort-related economic trends increases the explanatory power only by $0.7 \%$ but the trends are not significant. The skill trend points towards later retirement of younger cohorts while the kids trend points towards earlier retirement of younger cohorts. The overall effect is inconclusive.

The regression results for men in eastern Germany with entry as dependent variable are different from the ones with exit as dependent variable along several dimensions. Sign and significance of the OV and SSW switch again such that the OV is now significantly positive and SSW indistinguishable from zero. Income is positive but hardly significant. Conflicting with the regression results with exit as the dependent variable, the impact of the number of service years is significantly negative, indicating labor attachment, while it was significantly positive before. The significance of the age dummies hardly changes compared to the results with exit as the dependent variable.

Including the skill and kids trend increases the explanatory power by $1.3 \%$ as Column 2 for men shows. Again, it is the kids trend that is making the difference. It is significantly positive, thus, implying the younger cohorts are more likely to retire later.

\subsection{Conclusion}

Women's labor force participation has changed across cohorts. As a result of higher education, higher divorce rates and fewer children, women particularly in western Germany have become more active in the labor force. Their employment life-cycle pattern converges to that of men. As they work more, they also acquire more earning points. Jointly with increasing self responsibility, this should affect retirement entry behavior.

To investigate retirement behavior, we use the option value framework. Our results show that the choice of the dependent variable is important. When taking employment exit we get a substantially higher preference for leisure than when taking retirement entry. We also see that there is a difference in this preference between men and women and people in eastern and western of Germany. The drops in SSW and the OV in Figures 3.4(a) to 3.5(d) 
for women illustrate that there are cohort effects related to the institutional design. But these figures also show that there are cohort effects that are not related to the institutional design, since SSW, for instance, is larger for cohorts 1948 to 1950 than for cohorts 1945 to 1947 despite their relative disadvantage caused by the institutional regulation.

Our benchmark regression results demonstrate that the choice of the dependent variable is also important for the direction and significance of variables such as the financial incentive variables, income, and the cohort trend that is to capture the opportunity cost of work. Among the economic variables, the OV and income are the only ones that remain (significantly) negative, respectively positive. We include cohort trends that are related to the opportunity cost of work, proxied by the number of children and by the proportion of university graduates. The opportunity cost of work affects the employment rate and, as hypothesized, employment exit / retirement entry behavior.

In the beginning, we argued that the increasing labor force participation of women can affect retirement positively or negatively. It depends on whether women feel that there is more at stake or whether they feel that they can afford to retire early. As we observe the gap between labor force exit and retirement entry to widen for women (and men) in western Germany (in line with the observations made by Hanel (2009), individuals appear to be able to afford a longer time without public pension income. Furthermore, note that the skill trend has always a negative effect on retirement, indicating that the increasing investment in human capital leads to postponing retirement. The picture is different in eastern Germany. Here, the gap between labor force exit and retirement entry narrows for women due to postponement of labor force exit and is largely unaffected for men due to simultaneous postponement of exit and entry. Consequently, people in eastern Germany do not appear to be able to afford early retirement anymore or to want to use their human capital somewhat longer.

Thus, overall we do not find strong evidence that increasing female labor force participation when young also leads t overall higher labor force participation of women. Younger western German women tend to leave the labor force earlier while younger eastern German women tend to postpone labor force exit. However, their behavior is still influenced strongly from market transition during the 1990s. It will be interesting to extend our analysis of retirement behavior to future cohort in order to see how recent changes in labor and child policies will influence labor market participation later in life. 
Chapter 3 Labor Force Participation and Retirement Entry in Germany

3.A Appendix A: Robustness: West Germany, $I_{i t}=$ entry 


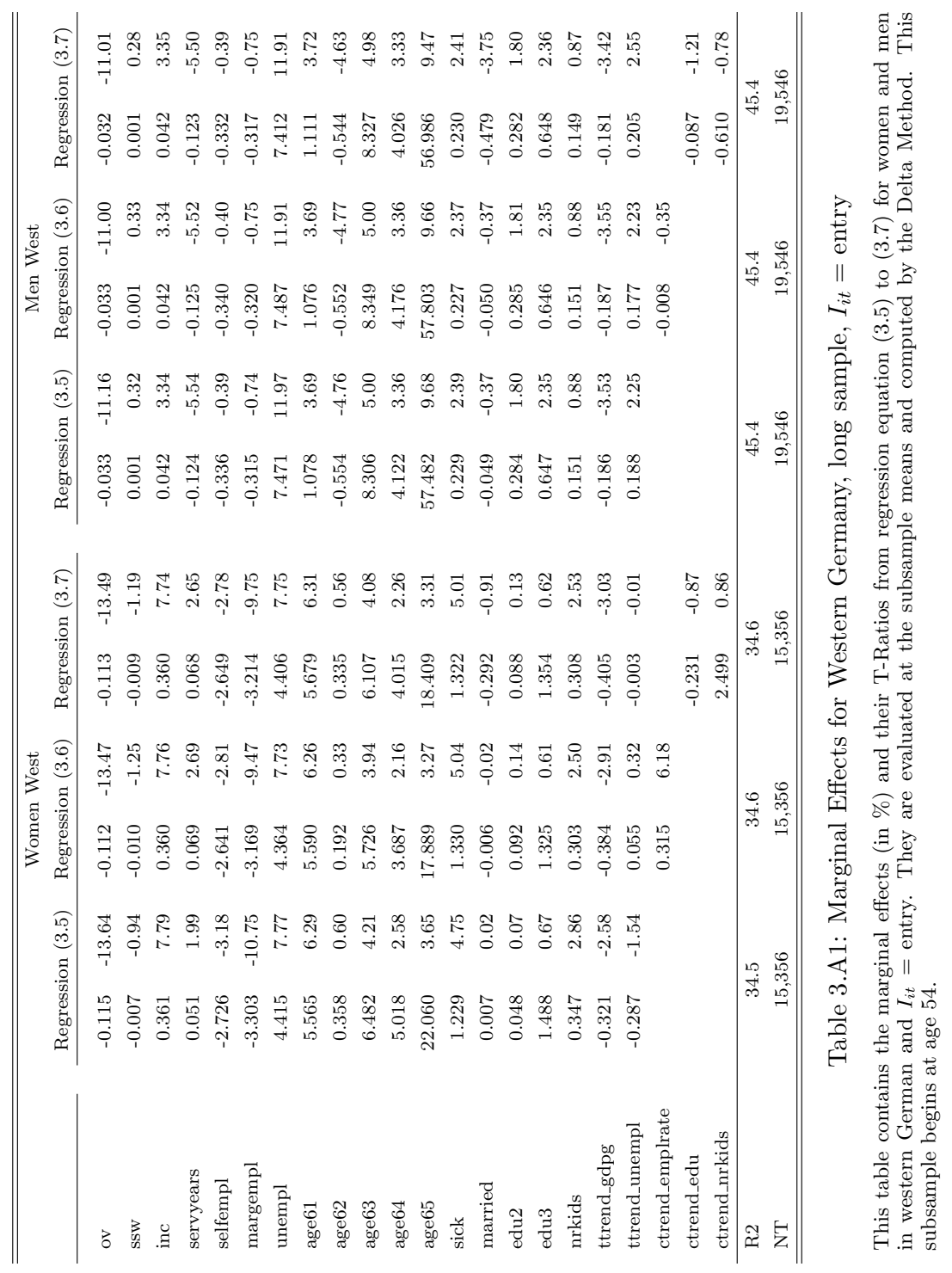


Chapter 3 Labor Force Participation and Retirement Entry in Germany

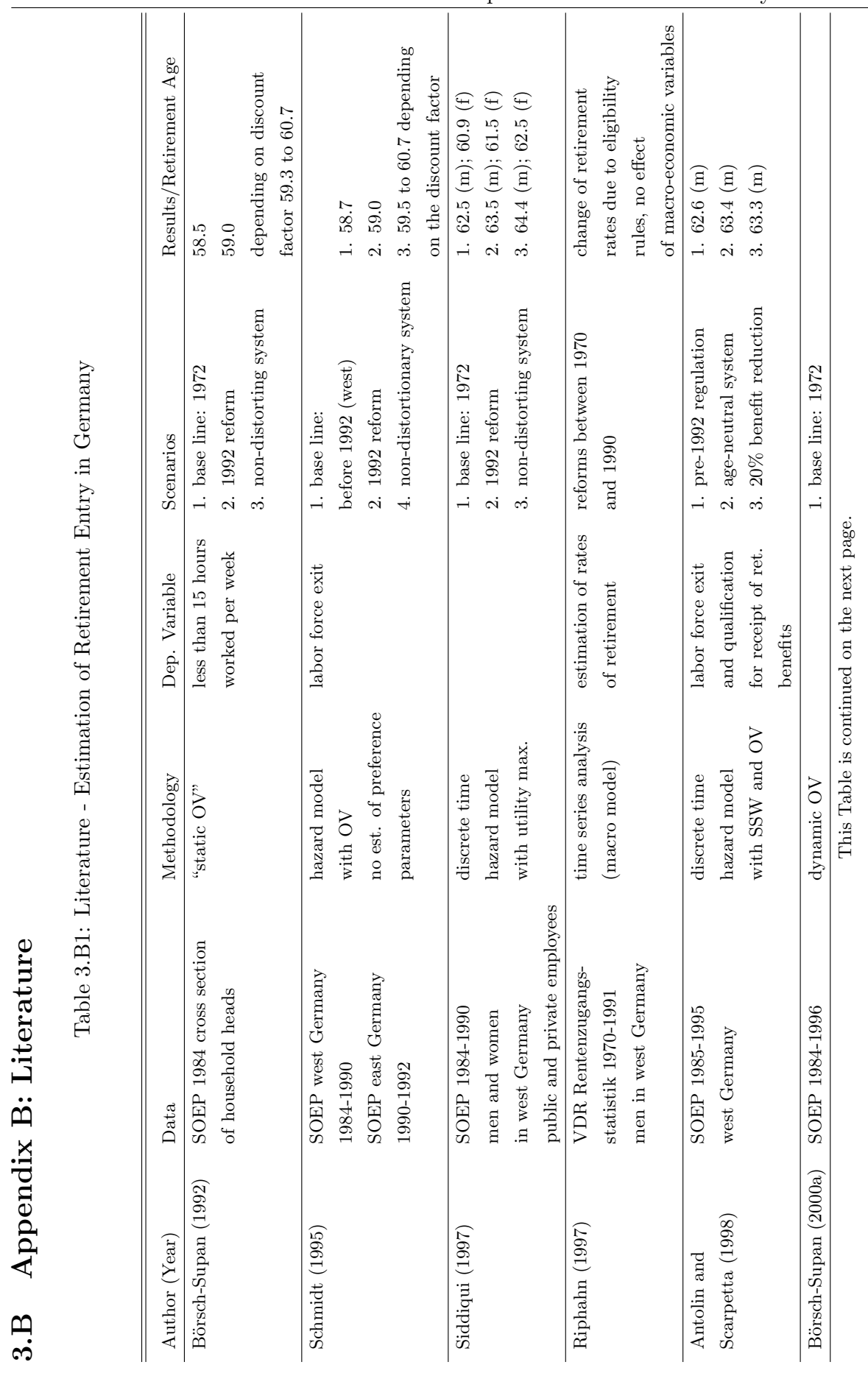




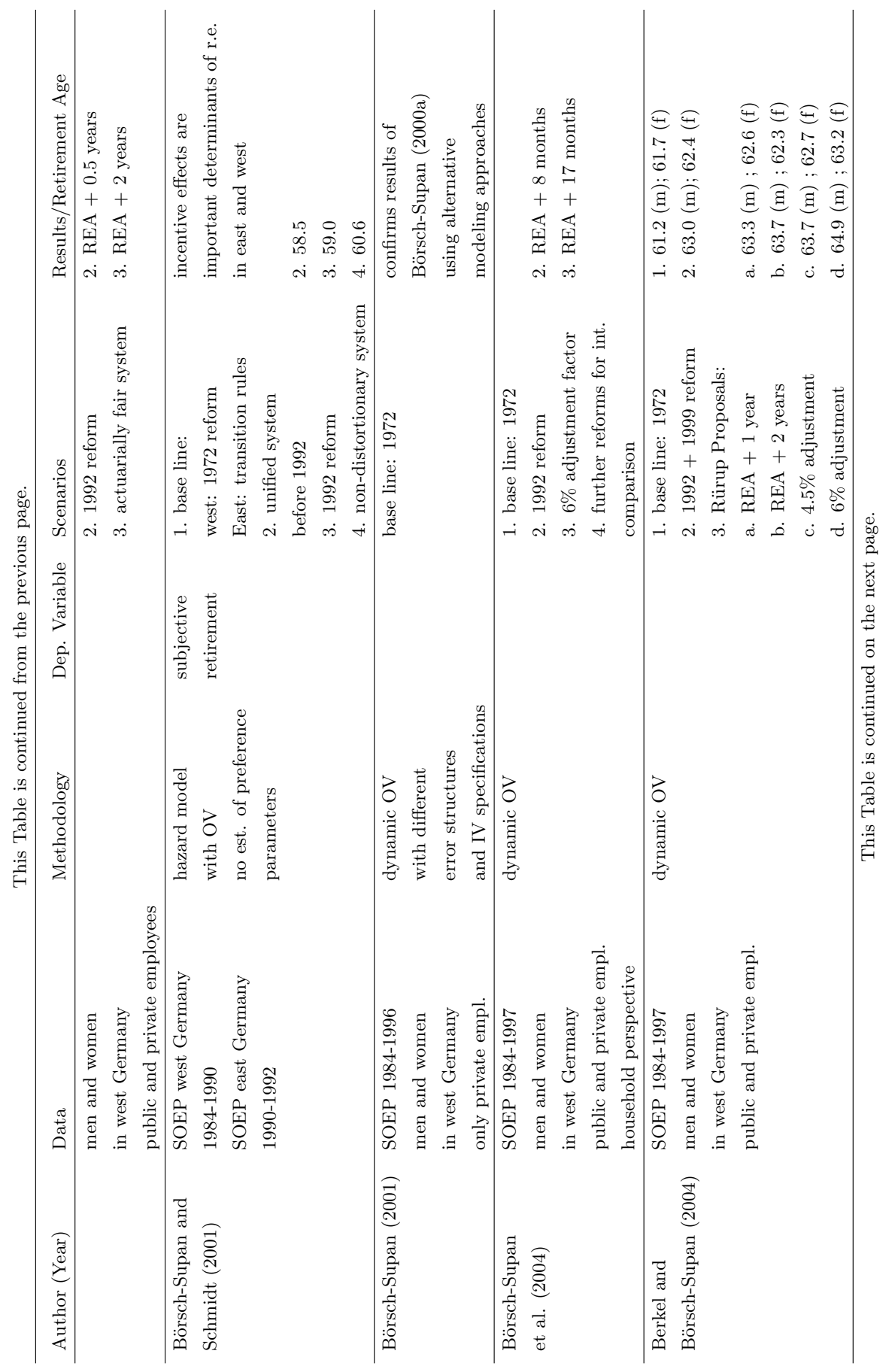




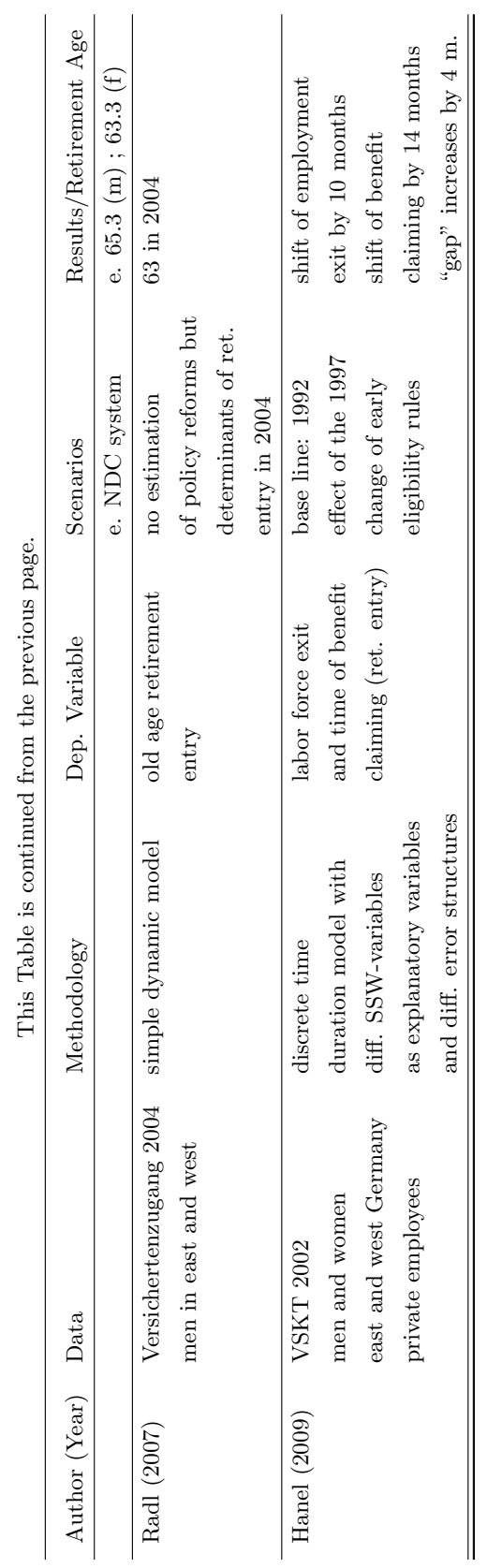


3.C Appendix C: OV with $I_{i t}=$ entry 

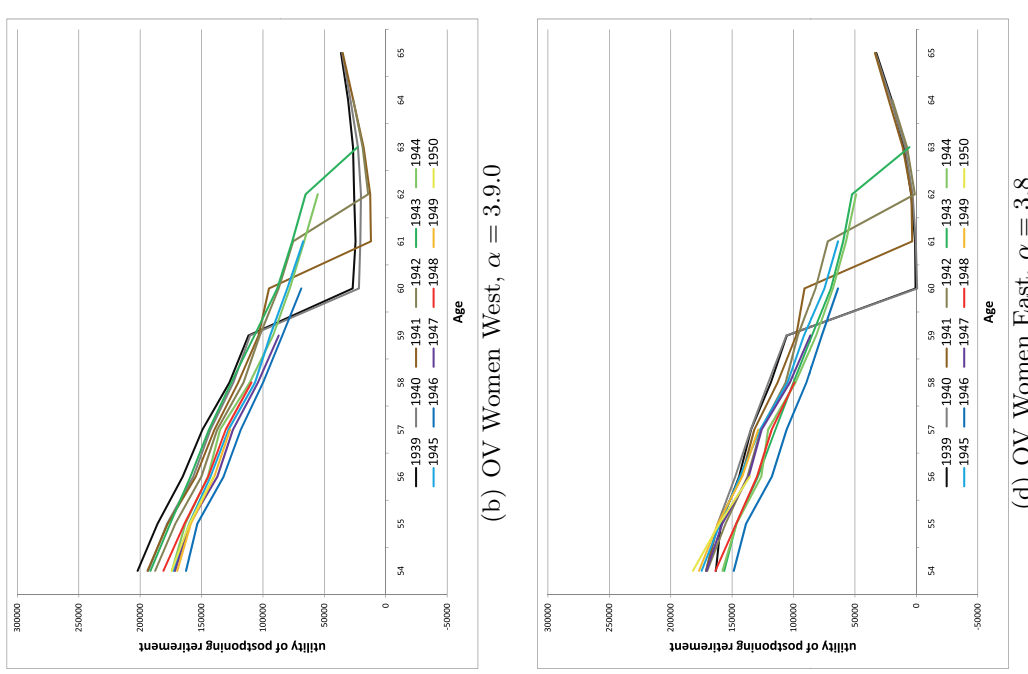

营

$\exists$

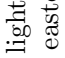

E.

के

葛

范

苞菅

过

웜

为

艁

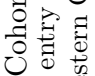

字承范

B.

ये

它出

o.듬

䨌
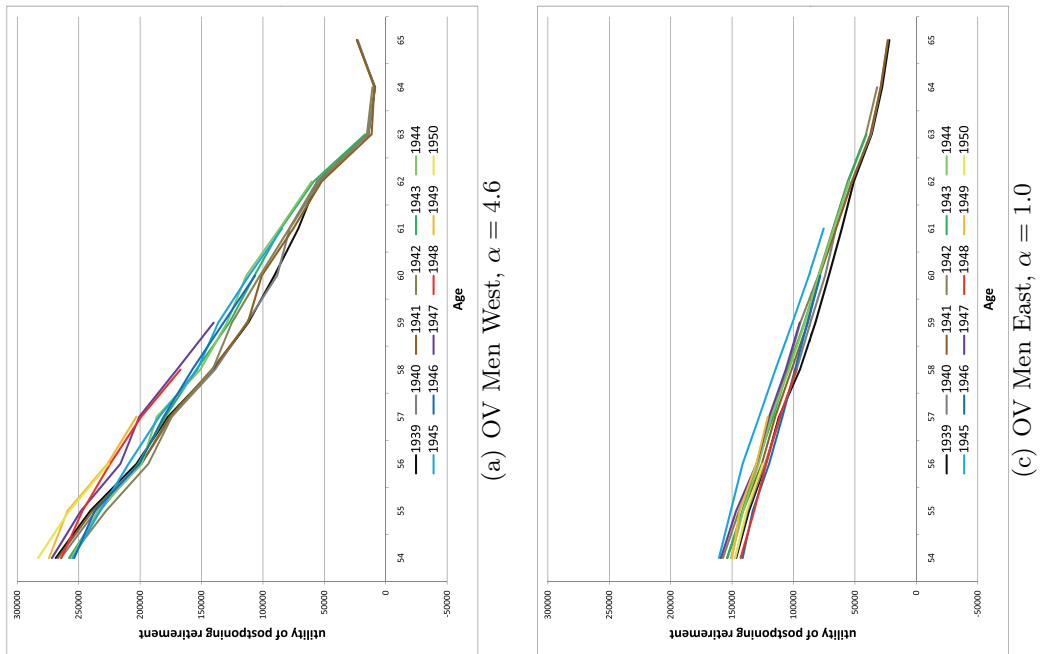

푱

울 票

0 ○े

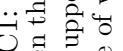

0.000

$\exists$ की

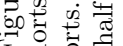

용 궁

牙苛

比劳

o

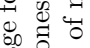

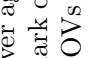

3 .

子焉

热需

on

을 8

㟧

密苛

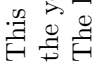




\section{D Appendix D: Cohort Trends}

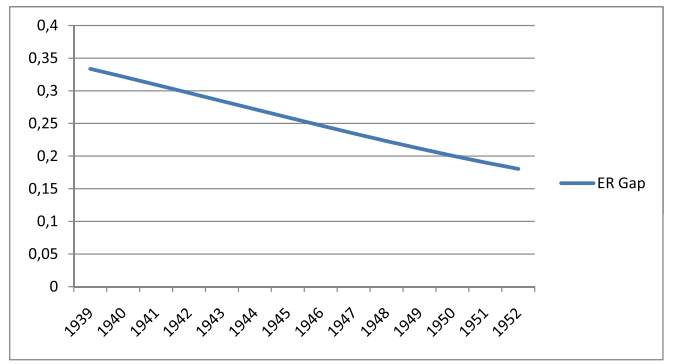

Figure 3.D1: Employment Rate Gap

This figure plots the percentage of employed men less the percentage of employed women in western Germany across cohorts as implied by the regression results of Table 4 in Fitzenberger et al. (2004).

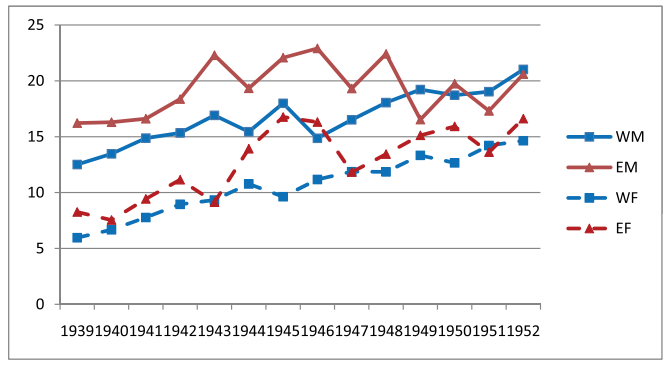

Figure 3.D2: Percentage University Graduates

This figure plots the percentage of university graduates across cohorts by region and gender. It is based on the Mikrozensus.

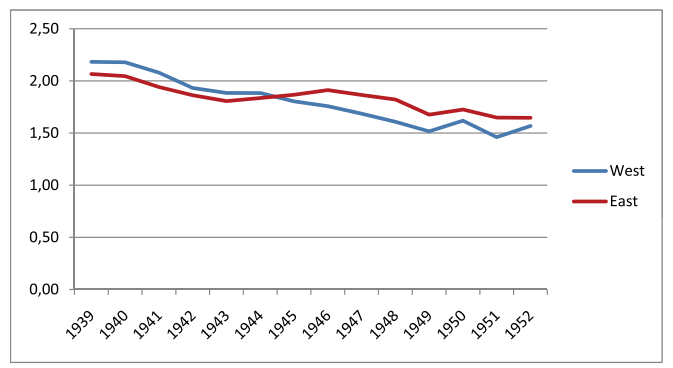

Figure 3.D3: Average Number of Children

This figure plots the average number of children of women across cohorts by region. It is based on our data, the Versichertenkontenstichprobe 2006. 


\section{Chapter 4}

\section{Tax-deferred Saving for Early Retirement: Analysis of the Dutch Life-Course Savings Scheme}

\subsection{Introduction}

The increasing dependency ratio of pension beneficiaries to pension contributors has made Pay-As-You-Go (PAYG) state pensions untenable (e.g. Gruber and Wise 1997, Gruber and Wise 2002, Gruber and Wise 2005, Bonoli 2003) and lead to the abolishment of generous state early retirement schemes and a general shift to occupational and private pensions. This requires participants to save for their own pension during their working life. The shift in responsibility is accompanied by fiscal stimuli. The most evident are tax-deferred saving arrangements such as the individual retirement accounts and 401(k) plans in the US (Attanasio, Banks and Wakefield 2004), the Riester Rente in Germany (Börsch-Supan and Wilke 2005) and the life-course savings scheme in the Netherlands (Bovenberg and Wilthagen 2008).

The Dutch scheme combines tax-deferred saving with early retirement which allows participants to reduce the effective tax rate beyond that of regular tax deferment while also enjoying leisure. This is because withdrawals can be spread over the early retirement years. For this system, we study the effect of tax-deferred saving and early retirement on optimal life-cycle planning, lifetime utility and fiscal costs in an uncertain environment. This lifecourse savings scheme was introduced in 2006 after the former generous early retirement scheme (Vervroegde UitTreding) was abolished. Thereby, the government discourages early retirement compared to before 2006, which reduces state responsibility and expenses. But at the same time, the government also introduced a possibility to retire early that individu- 
als themselves are responsible for. The new life-course savings scheme (Levensloopregeling) enables individuals to transfer leisure within their life course. If they work hard and accumulate $210 \%$ of their income in the tax-deferred savings account (TDA), they can retire comfortably three years earlier by receiving $70 \%$ of their previous income each early retired year. From here on we refer to the life-course savings scheme account as the TDA.

Contributions to the TDA are made from pre-tax income and the savings accumulate tax free. Taxes are only paid upon withdrawal of the funds. Because consumers discount future payments, tax deferment has a positive effect on lifetime utility. Withdrawals from the TDA are restricted to specific purposes, e.g. retirement or extended unpaid leave. ${ }^{1}$ This makes the savings illiquid and unsuitable as a buffer for periods of low income or disappointing investment returns. Participants cannot borrow against their TDA.

Next to tax deferment, the TDA may also facilitate an effective tax rate decrease. Given a progressive income tax system, a participant may contribute to the TDA exactly when the marginal income tax rate is high, as when working, and withdraw from the TDA when the marginal income tax rate is low, as when retired. Early retirement extends the opportunity window for this tax advantage as the participant may withdraw the savings over a period of several years. Thereby, he reduces each withdrawal balance and thus the corresponding marginal tax rate. Tax credits and subsidies offer further opportunities for tax advantages in combination with the TDA.

Despite these financial advantages, the participation rate in the life-course savings scheme three years after its introduction is still only about 6\% (Maas 2009). The low participation is seen as puzzling, since the tax benefits should be substantial and clear. The scheme has also been widely discussed in the media. Thus, public awareness should exist. This paper's purpose is to gain an understanding of this participation puzzle through a life-cycle model.

The analytical part of our paper demonstrates that the TDA increases the marginal propensity to save. As a result, individuals are willing to save for more. The optimal TDA savings are adjusted to the income tax brackets. Horan (2005) points out that participants should save in a TDA account only if the marginal tax rate is lower at (early) retirement. Otherwise, upfront taxation, as in the regular wealth account, may be preferable. We find that this is horizon dependent as the regular wealth account in the Netherlands faces a cost of carrying in the form of a wealth tax. If retirement is far ahead, the TDA may still be preferred despite a negative difference between marginal income taxes today and in the

\footnotetext{
${ }^{1}$ The German and US arrangement are intended to support regular state pension payments only. The Dutch life-cycle arrangement also serves to smooth income over working and non-working periods and allows participants to use the funds for unpaid extended leave up to three years. Most participants use it to retire early (NIBUD 2007). Other schemes adopt a benefit formula with benefits decreasing with early retirement.
} 
future due to the long horizon of wealth tax payments.

Indeed, our simulations show that all participants gain by using the TDA. In all parameter constellations and for different initial wealth levels, we find that using a TDA is optimal. Compared to the situation without TDAs, the government foregoes up to $€ 29,000$ over the lifetime. In terms of certainty equivalent consumption the individual gains up to $1.5 \%$ of annual consumption (up to $€ 10,000$ over the lifetime) by the TDA's introduction. The certainty equivalent consumption percentage increases with consumers' patience for almost all given other parameters. There is no systematic pattern with regard to leisure preferences or initial wealth levels. The tax effects go into the same direction. Investigating US fiscal stimuli to trigger individuals to save privately, Attanasio et al. (2004) find that the fiscal costs outweigh the gain in utility. The large difference between the consumer's certain consumption gain of $€ 10,000$ and the government's loss of $€ 29,000$ are in line with Attanasio et al. (2004).

Gourinchas and Parker (2002) find that people only start saving for retirement if they build up a sufficient liquidity buffer to protect consumption from income shocks. This buffer amounts to $12 \%-15 \%$ of gross income. In our model, individuals start at age 40 with the average liquid wealth balance of a 40 year old Dutch and postpone saving until the late $40 \mathrm{~s}$ in the baseline case. We find that the only parameter to get them to save earlier is more patience. Neither leisure preferences nor initial wealth play a major role for the age at which the individual first saves for early retirement.

The introduction of the TDA may lead to a substitution effect, shifting savings from the regular wealth account to the TDA, and an income effect, increasing total savings. Tax incentives increase the effective interest rate. This increases the marginal utility of saving, which again increases savings and reduces optimal consumption and leisure. We observe a small income effect if there is uncertainty. Overall, however, the substitution effect dominates as in analysis of Attanasio et al. (2004).

Reasons for the low participation rate despite the apparent advantages may lie in the problem that individuals are humans and not econs (Thaler and Sunstein 2008). Individuals postpone complicated decisions. These inertia represent a substantial hurdle for participation. US 401(k) experiments have demonstrated that they may be overcome by setting the default to participation or save-more-tomorrow programs. Providing a well diversified default asset allocation has also proven to reduce mistakes according to acknowledged life-cycle theory. Lastly, education programs have provided mixed evidence. If education programs offer follow-up meetings or another form of continuation, individuals tend to participate more and make smarter and more frequent decisions in retirement programs (Lusardi 2008).

The following section introduces the life-cycle model and the specific parameters that 
make up the potential participant. We discuss the participant's optimal strategy and its fiscal implications of several versions of the model, with and without TDA and early retirement, given certainty in Section 4.3. Section 4.4 discusses the equivalent results in the more realistic setting of uncertainty in wages and returns. We consider the optimal solution for different individuals and different situations in Section 4.4. We conclude in Section 4.5 by summarizing which participants profit most from the TDA and early retirement and in what cases the fiscal costs for the government are most severe.

\subsection{A Life-Cycle Model with a Tax-deferred Account and endogenous Labor Supply}

\section{Model}

We model an individual's annual decision on consumption $C$, labor supply $N$, and contributions to a tax-deferred account $Q$ from current age $s=40$ until the regular retirement age $T=65$. The preferences over consumption and leisure are modeled by a time separable Cobb-Douglas function,

$$
U\left(\mathbf{C}, \mathbf{N}, W_{T}\right)=\mathrm{E}\left[\sum_{t=s}^{T-1} \beta^{t-T} \frac{\left(C_{t}\left(1-N_{t}\right)^{\theta}\right)^{1-\gamma}}{1-\gamma}+\phi \frac{\left(W_{T}^{*}\right)^{1-\gamma}}{1-\gamma}\right],
$$

where the boldface symbols $\mathbf{C}$ and $\mathbf{N}$ denote the entire vectors of consumption $(\mathbf{C}=$ $\left.C_{40}, \ldots, C_{64}\right)$ and labor supply $\left(\mathbf{N}=N_{40}, \ldots, N_{64}\right)$. The utility function has constant relative risk aversion $\gamma$, implying an intertemporal rate of substitution equal to $1 / \gamma$. The discount factor $\beta$ represents the time preference of the individual. Real consumption and leisure $(1-N)$ are imperfect substitutes. The relative preference for leisure is modeled by $\theta$ and may be time varying. We follow the specification of Gomes, Kotlifkoff and Viceira (2008) and restrict labor supply to at most twothird's of a total time budget of one hundred hours per week: $0 \leq N_{t} \leq 2 / 3$.

As Gourinchas and Parker (2002), we only model behavior up to retirement age $T$. Thereafter, we assume that the individual derives utility from several sources of income, which are summarized by final wealth $W_{T}^{*}$ and will be defined below. The parameter $\phi$ provides the weight of final wealth in the lifetime utility.

Participants can save in a regular wealth account and a TDA. Contributions to the regular wealth account are paid from after-tax income, whereas contributions to the TDA are made from pre-tax income. Thus, taxes must be paid when withdrawing money from the TDA. Wealth in the regular account is liquid, whereas wealth in the TDA cannot be used until (early) retirement. In the Dutch tax system the TDA offers a further tax advantage since, in contrast to the regular account, wealth in the TDA is not subject to a 
wealth tax. We assume that participants cannot borrow against future labor income and the TDA, meaning that both accounts are required to have a non-negative balance. The regular wealth account $W_{t}$ and the TDA $L_{t}$ receive the same real return before tax equal to $R_{t}$. The two accounts evolve as:

$$
\begin{aligned}
W_{t+1} & =R_{t+1}\left(W_{t}+N_{t} Y_{t}-Q_{t}-\mathcal{T}_{t}-C_{t}\right), \\
L_{t+1} & =R_{t+1}\left(L_{t}+Q_{t}\right)
\end{aligned}
$$

where $Y_{t}$ is the wage rate, $Q_{t}$ are TDA contributions, and $\mathcal{T}_{t}$ are total taxes.

Some restrictions apply to the contributions to the Dutch TDA. First, contributions are limited to $12 \%$ of gross labor income per year and may not cause the TDA balance to exceed $210 \%$ of current annual income,

$$
Q_{t} \leq \min \left(0.12 N_{t} Y_{t}, L_{t-1}-2.1 N_{t} Y_{t}\right)
$$

The latter condition is based on the idea that the savings scheme is intended to finance a maximum of three years of early retirement at an approximate replacement rate of $70 \%$ of annual income per year. ${ }^{2}$ Second, withdrawals from the TDA $\left(Q_{t}<0\right)$ are restricted to years that a participant is outside the labor force $\left(N_{t}=0\right)$, so that at all times we have the constraint

$$
N_{t} Q_{t} \geq 0 .
$$

Qualified withdrawals include sabbaticals, maternity leave, long-term care or early retirement (though not unemployment). In the model we assume that withdrawals from the TDA are restricted to early retirement. This assumption reduces the optimization complexity, but is in line with the intended use of most scheme's participants. If anything is left in the TDA upon the 65th birthday, the remainder is taxed as income and added to final wealth.

Total taxes $\mathcal{T}_{t}$ are the sum of income tax and wealth tax,

$$
\mathcal{T}_{t}=\mathcal{T}^{Y}\left(Z_{t}\right)+\mathcal{T}^{W}\left(W_{t-1}\right),
$$

where $Z_{t}=N_{t} Y_{t}-Q_{t}-D_{t}$ is taxable labor income. Income tax is progressive, and age dependent tax credits $D_{t}$ apply. The progressive form comes from stepwise increases in the marginal rate so that the income tax is piecewise linear in pre-tax income. Appendix 4.A provides details of the tax parameters. The wealth tax is a function of last period's liquid wealth $W_{t-1}$. It is also progressive, as the first $€ 46,300$ are tax-exempt. The remainder is taxed at a flat rate of $\tau_{w}=1.2 \%$. The Dutch wealth tax is not related to realized gains or losses.

\footnotetext{
${ }^{2}$ If the account later on exceeds the $210 \%$ bound due to high returns, funds in the TDA do not have to be withdrawn, and in fact cannot even be withdrawn for that reason. Rules for withdrawals are independent of the balance in the account.
} 
Final wealth $W_{T}^{*}$ is the sum of liquid wealth $W_{T}$, the present value of state and occupational pensions $B_{T}$ and the after-tax TDA balance $L_{T}-\mathcal{T}^{Y}\left(L_{T}\right)$.

$$
W_{T}^{*}=W_{T}+B_{T}+L_{T}-\mathcal{T}^{Y}\left(L_{T}\right)
$$

Values for $\phi$ and $B_{T}$ are derived in Appendix 4.B.

The individual faces two types of uncertainty in this model: financial returns $R_{t}$ and wages $Y_{t}$. We assume that the regular wealth account and the TDA offer the same real return $R_{t}$, which we assume to be lognormally distributed with constant mean and variance. We need $R_{t}$ to be independent over time in order to limit the number of state variables in the model. Since the individual can only invest in one asset class, the same in both accounts, there is no asset allocation decision. For this reason we do not introduce separate parameters for risk aversion and intertemporal substitution like Epstein-Zin preferences.

When working, the individual earns an exogenously given wage $Y_{t}$. The wage process $\ln Y_{t}$ follows a three factor model. Following Gomes et al. (2008), we consider an age related component $f(t)$, a permanent income component $x_{t}$ and a transitory income component $\epsilon_{t}$,

$$
\begin{aligned}
\ln Y_{t+1} & =f(t)+x_{t}+\epsilon_{t} \\
x_{t+1} & =x_{t}+u_{t+1} \\
f(t) & =\alpha_{0}+\alpha_{1}(t-20)+\alpha_{2}(t-20)^{2}
\end{aligned}
$$

The permanent $u_{t}$ and transitory shocks $\epsilon_{t}$ are assumed to be uncorrelated. The permanent shock may be correlated to return innovations. The age component differs across individuals according to job and education level. Timing of income shocks is such that the consumer bases his decision at time $t$ on his known wage $Y_{t}$. Future returns and wages remain uncertain, however.

\section{Solution}

The individual needs to solve for the optimal consumption, leisure and TDA contributions over the life cycle given the tax rules, the budget equations (4.2) and (4.3), and the inequality constraints on $Q$ (4.4) and $N$ (4.5). Due to the nonlinearity of the tax scheme, the problem is not homogenous in wealth and permanent income. This means that we have three state variables: $S=(W, L, x)$. At time $T$ no decisions are made and the value function just depends on the state variables $S_{T}=\left(W_{T}, L_{T}, x_{T}\right)$ :

$$
V_{T}\left(S_{T}\right)=\phi \frac{\left(W_{T}^{*}\right)^{1-\gamma}}{1-\gamma} .
$$

We can express the Bellmann equation for all other time periods $t=s, \ldots, T-1$ as

$$
V_{t}\left(S_{t}\right)=\max _{C_{t}, N_{t}, Q_{t}}\left\{\frac{\left(C_{t}\left(1-N_{t}\right)^{\theta}\right)^{1-\gamma}}{1-\gamma}+\beta \mathrm{E}_{t}\left[V_{t+1}\left(S_{t+1}\right)\right]\right\} .
$$


To derive first order conditions, we define the objective function

$$
J_{t}\left(C_{t}, N_{t}, Q_{t}\right)=\frac{\left(C_{t}\left(1-N_{t}\right)^{\theta}\right)^{1-\gamma}}{1-\gamma}+\beta \mathrm{E}_{t}\left[V_{t+1}\left(S_{t+1}\right)\right]
$$

The objective function (4.11) is not differentiable with respect to $\left(1-N_{t}\right)$ and $Q_{t}$ at the kinks of the tax schedule. Despite this problem, we can derive a partially analytical solution. The objective function is everywhere differentiable with respect to consumption, meaning that we can use the first order condition

$$
\left(\frac{\partial J_{t}}{\partial C_{t}}=0\right) \rightarrow \frac{\left(C_{t}\left(1-N_{t}\right)^{\theta}\right)^{1-\gamma}}{C_{t}}=\beta \mathrm{E}_{t}\left[\frac{\partial V_{t+1}\left(S_{t+1}\right)}{\partial W_{t+1}} R_{t+1}\right]
$$

For the derivative of $J_{t}$ with respect to leisure, we have to exclude the points at which taxable income $\left(Z_{t}\right)$ is at one of the kinks $I_{j}$ in the marginal tax rate,

$$
Z_{t}=N_{t} Y_{t}-Q_{t}-D_{t}=I_{j} \quad(j=1,2,3)
$$

At all other points the derivative is equal to

$$
\begin{aligned}
\frac{\partial J_{t}}{\partial\left(1-N_{t}\right)} & =\frac{\theta\left(C_{t}\left(1-N_{t}\right)^{\theta}\right)^{1-\gamma}}{\left(1-N_{t}\right)}-\beta \mathrm{E}_{t}\left[\frac{\partial V_{t+1}\left(S_{t+1}\right)}{\partial W_{t+1}} R_{t+1}\right]\left(1-\tau_{Y}\left(Z_{t}\right)\right) Y_{t} \\
& =\left(C_{t}\left(1-N_{t}\right)^{\theta}\right)^{1-\gamma}\left(\frac{\theta}{\left(1-N_{t}\right)}-\frac{\left(1-\tau_{Y}\left(Z_{t}\right)\right) Y_{t}}{C_{t}}\right) .
\end{aligned}
$$

The second equality results from plugging (4.12) into the first equality. Since $\left(C_{t}(1-\right.$ $\left.\left.N_{t}\right)^{\theta}\right)^{1-\gamma}$ is always positive, the sign of $\frac{\partial J_{t}}{\partial\left(1-N_{t}\right)}$ is the same as the sign of $\left(\frac{\theta}{\left(1-N_{t}\right)}-\frac{\left(1-\tau_{Y}\left(Z_{t}\right)\right) Y_{t}}{C_{t}}\right)$. We can rewrite $Z_{t}$ in terms of leisure $\left(1-N_{t}\right)$ instead of labor $N_{t}$

$$
Z_{t}=N_{t} Y_{t}-Q_{t}-D_{t}=-Y_{t}\left(1-N_{t}\right)+Y_{t}-Q_{t}-D_{t}
$$

to see that $Z_{t}$ is decreasing in leisure. Thus, (4.14) is downward sloping in $\left(1-N_{t}\right)$, but not defined at the kinks $Z_{t}=I_{j}$. When leisure hits a tax kink the consumer faces a downward jump in the marginal tax rate

$$
\tau_{Y}\left(Z_{t}\right)=\left\{\begin{array}{ll}
\tau_{j} & \text { if } Z_{t} \geq I_{j} \\
\tau_{j-1} & \text { if } Z_{t}<I_{j-1}
\end{array} .\right.
$$

Since $\tau_{j}>\tau_{j-1}$ jumps are always downward, and $\frac{\partial J_{t}}{\partial\left(1-N_{t}\right)}$ is monotonically decreasing in $\left(1-N_{t}\right)$ at a given consumption level $C_{t}$ and wage $Y_{t}$. Figure 4.1 depicts the derivative $\frac{\partial J}{\partial\left(1-N_{t}\right)}$ at a given $C_{t}$ as a function of $\left(1-N_{t}\right)$ for two values of $Q_{t}+D_{t}$ and a fixed $Y_{t}$. In the first case $Q_{t}+D_{t}=0$ and therefore no tax deductions apply (solid blue line). In the second case $Q_{t}+D_{t}>0$ and thus tax deductions apply (dashed red line). An internal optimum exists if there is a $\left(1-N_{t}\right)$ at which the derivative is equal to zero. In this case, the first order conditions have an internal optimum for $\left(1-N_{t}\right)$ and $C_{t}$. In Figure 4.1, this 


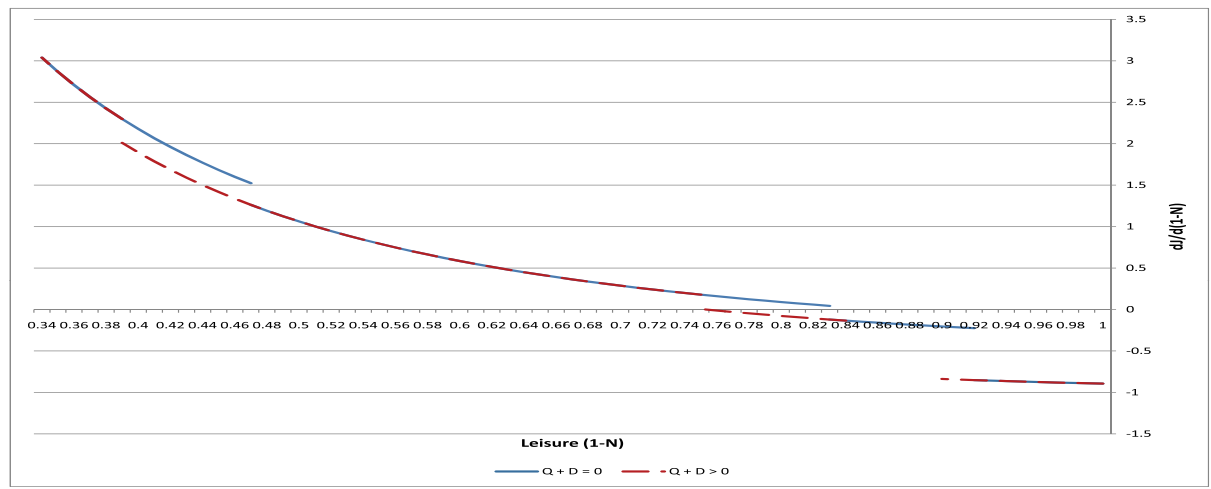

Figure 4.1: $\frac{\partial J}{\partial(1-N)}$ as a function of 1-N

This figure plots the derivative of $\mathrm{J}$ with respect to leisure (1-N) (4.14) as a function of leisure. The offered wage for $100 \mathrm{hrs}$ is fixed at 100 . Consumption is set to 25 . Moreover, $\theta=2$ and $\gamma=1.5$. In the first case, no tax deduction apply: $Q_{t}+D_{t}=0$ (solid blue line). In the second case, tax deductions apply: $Q_{t}+D_{t}=8$ (dashed red line).

is the case for $Q_{t}+D_{t}>0$. If the function never crosses the horizontal axis as in case of $Q_{t}+D_{t}=0$, the optimal value for $\left(1-N_{t}\right)$ is at the point between the two marginal tax rates that are closest to the $\mathrm{x}$-axis ( 0.83 here).

The monotonicity of $\frac{\partial J}{\partial\left(1-N_{t}\right)}$ implies that there is a unique value of $\left(1-N_{t}\right)$ that maximizes $J\left(C_{t}, N_{t}, Q_{t}\right)$ for a given $Q_{t}$. We can trace out the entire relation between $C_{t}$ and $\left(1-N_{t}\right)$ by varying wealth $W_{t}$. Minimum leisure is $\left(1-N_{t}\right)=1 / 3$, in which case the consumer faces the highest possible tax bracket. At an interior optimum the relationship between $C_{t}$ and $\left(1-N_{t}\right)$ is

$$
\left(1-\tau_{Y}\left(Z_{t}\right)\right) Y_{t}\left(1-N_{t}\right)=\theta C_{t} .
$$

At an interior optimum taxable income is between the income tax thresholds.

$$
\begin{aligned}
I_{j-1} & < & Z_{t} & <I_{j} \\
I_{j-1} & < & N_{t} Y_{t}-Q_{t}-D_{t} & <I_{j} \\
\frac{I_{j-1}+Q_{t}+D_{t}}{Y_{t}} & < & N_{t} & <\frac{I_{j}+Q_{t}+D_{t}}{Y_{t}}
\end{aligned}
$$

A corner solution occurs if income or tax deductions are such that

$$
N_{t}=\frac{I_{j}+Q_{t}+D_{t}}{Y_{t}}
$$

If income increases beyond a certain level the optimal value $N_{t}$ hits a kink in the tax schedule and induces the consumer to work less.

Figure 4.2 depicts the relationship between $C_{t}$ and $\left(1-N_{t}\right)$ for two values of $Q_{t}+D_{t}$. It shows that $C_{t}$ adjusts at the points where $N_{t}$ hits a kink. Once the maximum of leisure is achieved, the consumer can only improve his utility by consuming more. 


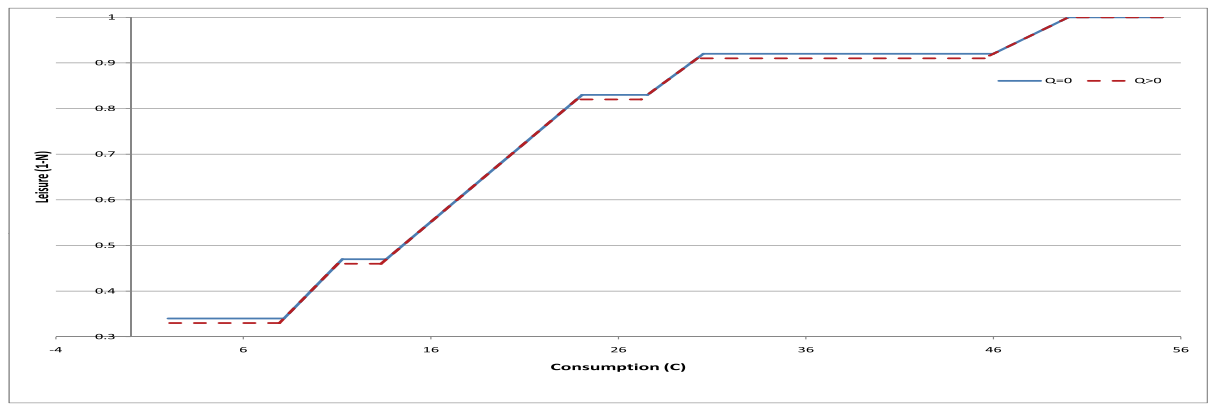

Figure 4.2: Leisure and Consumption at Optimum

This figure illustrates the relation between $C_{t}$ and $\left(1-N_{t}\right)$, which follows from the first of conditions (4.12) and (4.14) and is given by (4.16). The offered wage for $100 \mathrm{hrs}$ is fixed at 100. Moreover, $\theta=2$ and $\gamma=1.5$. In the first case, no tax deduction apply: $Q_{t}+D_{t}=0$ (solid blue line). In the second case, tax deductions apply: $Q_{t}+D_{t}=8$ (dashed red line).

The relation between $C_{t}$ and $N_{t}$ holds for any given $Q_{t}$. If $Q_{t}=0$, the relationship between leisure and consumption is represented by the solid blue line in Figure 4.2. If $Q_{t}>0$, i.e. if the individual contributes to the TDA, the individual can earn more without moving into the next tax bracket because TDA contributions reduce taxable income. Consequently, the consumption leisure relationship shifts down to the red line in Figure 4.2. The lines coincide in case of maximum leisure, because the marginal tax rate is zero here. Contributions to the TDA have an intertemporal effect through the differences in tax rates that apply to the liquid account and the TDA. The optimal $Q_{t}$ therefore requires numerical optimization.

During potential early retirement, $N_{t}=0$ and $Q_{t}$ is negative. Dependent on time and leisure preferences and the realized stochastic processes, the individual allocates the withdrawals from the TDA over a maximum of three years. This allocation $Q_{t}$ is taxed as income. When making the decision to contribute to the TDA, the individual thus has to compare the marginal tax rates upon contribution and the marginal tax rate upon withdrawal. Without loss of generality, let $R_{t}=\mathrm{R}$ and consider an additional unit of gross income at time $t .^{3}$ If saved in the wealth account, it will be taxed against the marginal tax rate $\tau_{Y}$. Hence, the marginal effect of an additional unit of gross income at time $t$ is $\left(1-\tau_{Y}\right)$. At time $T-s-t$, the individual can withdraw $\left(1-\tau_{Y}\right) R^{T-s-t}$ for $s=0,1,2,3$. Alternatively, if the extra unit is saved in the TDA, it is taxed at time $T-s-t$ at the marginal tax rate $\tau_{L}$. The marginal final wealth effect of an extra unit of gross income is then $\left(1-\tau_{L}\right) R^{T-s-t}$. Hence a consumer is better off saving for retirement using the TDA

\footnotetext{
${ }^{3}$ We can assume that $R_{t}$ is fixed because the liquid account and the TDA earn the same rate of return before taxes.
} 
at time $t$ if

$$
R^{T-s-t}\left(1-\tau_{L}\right)>\left(1-\tau_{Y}\right) R^{T-s-t} \text { for } s=\{0,1,2,3\}
$$

or simply $\tau_{L}<\tau_{Y}$. In case the regular wealth account exceeds the threshold of $€ 46,300$, a wealth tax rate of $1.2 \%$ applies. In this case, a consumer is better off if

$$
\begin{aligned}
R^{T-s-t}\left(1-\tau_{L}\right) & >\left(1-\tau_{Y}\right)\left(\left(1-\tau_{W}\right) R\right)^{T-s-t} \quad \text { for } s=\{0,1,2,3\} \\
\text { or } t & <T+\frac{\ln \left(1-\tau_{Y}\right)-\ln \left(1-\tau_{L}\right)}{\ln \left(1-\tau_{W}\right)}
\end{aligned}
$$

Higher wealth taxes and low $\tau_{L}$ relative to $\tau_{Y}$ make the TDA attractive and reduce the age at which investment in the TDA is the more attractive option. Table 4.1 illustrates this point. The ratio of income taxes $\tau_{L}$ relative to $\tau_{Y}$ is important to understand the TDA

\begin{tabular}{ccc}
\hline \hline Tax Wealth & Income Tax & Preferred location \\
\hline$\tau_{W}=0$ & $\tau_{Y} \leq \tau_{L}$ & $W \succcurlyeq L$ \\
$\tau_{W}=0$ & $\tau_{Y} \geq \tau_{L}$ & $W \preccurlyeq L$ \\
$\tau_{W}>0$ & $\tau_{Y} \leq \tau_{L}$ & $W \preccurlyeq L$ for $t \leq t^{*}$ \\
$\tau_{W}>0$ & $\tau_{Y} \geq \tau_{L}$ & $W \preccurlyeq L$ \\
$\tau_{W}=1.2 \%$ & $\left(\tau_{Y}, \tau_{L}\right)=(42 \%, 52 \%)$ & $t^{*}=49$ \\
\hline \hline
\end{tabular}

Table 4.1: TDA versus regular wealth account

This table summarizes the optimal location for savings in Column 3 depending on the marginal wealth tax rate, given in Column 1, and the relationship between the marginal income tax rate when contributing $\tau_{Y}$ and when withdrawing $\tau_{L}$, given in Column 2, according to (4.18). $s=0$.

contribution until the age of 61 . In the absence of progressive tax rates, i.e. if $\tau_{L}$ and $\tau_{Y}$ are equal, the individual would be indifferent unless the wealth tax applies. In case of progressive tax rates, the attractiveness of savings in the TDA depends on the marginal tax rates. If $\tau_{L}<\tau_{Y}$, TDA savings are most attractive. However, if $\tau_{L}>\tau_{Y}$, TDA contributions may be preferred until age 49 only (see Table 4.1) as the exemption from wealth tax needs to be balanced against the higher marginal tax rate when withdrawing from the TDA .

Because of the non-differentiability problem we cannot derive an analytical intertemporal relationship. To solve the model we use numerical optimization. We construct a decision grid of $C$ and $Q$ and a state grid of $W, L$, and $X$. In each state, we go through the decision grid and calculate $N$ according to (4.16) for each decision grid point $C$ and $Q$. If the calculated $N$ is not internally consistent, a corner solution applies. Once we find the decision grid point that leads to the highest utility (sum of instantaneous utility associated with this decision and average future utilities associated with the resulting future states) we construct a refined grid around this solution and start all over again. ${ }^{4}$

\footnotetext{
${ }^{4}$ Details about the numerical optimization procedures are provided in Appendix 4.C.
} 
In summary, we consider the Dutch system as a system of progressive income taxes. This implies that taxable income, that is labor income that is not saved in the TDA plus withdrawals from the TDA, is taxed at increasing marginal tax rates. An individual who does the math may hence engage in tax planning by shifting taxable income from periods with high income and high marginal tax rates to periods with low income and low marginal tax rates.

\section{Benchmark Model Parameters}

In line with the findings of Gourinchas and Parker (2002) we use a discount factor $\beta=0.96$ and a coefficient of relative risk aversion $\gamma=1.5$. In this case, consumption profiles are hump-shaped if income is uncertain as also observed empirically. Following Gomes et al. (2008), we set the leisure preference parameter to the value that leads to an average working week of about 38 hours in the absence of a TDA. In our model, this is $\theta=1.5$. By varying $\theta$ between 1.25 and 2.00, we obtain 41.5 to 31.5 hour working weeks. Moreover, leisure preferences vary over age. Gustman and Steinmeier (2005) show that leisure becomes on average $8 \%$ more valuable every life year. Moreover, the results from NIBUD (2007) indicate that people want to retire early and therefore must have a preference for leisure in old age. We distinguish between two life phases to account for increasing leisure preferences. The first one lasts from age 40 till including age 61 , where we set $\theta=1.5$. The second phase is the potential early retirement phase with twice the leisure preference, $\theta=3.0$, which leads to 8.5 hours per week in the absence of a TDA. The parameter $\phi=22.19$ weighs the value of an annuity after retirement with a $90 \%$ chance to survive each year. ${ }^{5}$

The remaining parameters are representative for the Dutch life-course savings scheme. The wage process is calibrated to the empirical wage process in the Netherlands (Kalmijn and Alessie 2008), in particular to match the wage peak at age 52. This yields $\alpha_{0}=$ $4.2, \quad \alpha_{1}=0.033$ and $\alpha_{2}=-0.0005$ in (4.8). The base pension is set equal to $65 \%$ of the previous net permanent income. The return process is based on a Dutch bond fund over the last 30 years (Dimson, Marsh and Staunton 2002) with a mean log real return of $1.1 \%$ and a standard deviations of $9.4 \%$. The permanent and non-permanent income shocks $u$ and $\epsilon$ are normally and i.i.d. with standard deviations $17.7 \%$ and $17.9 \%$ respectively (Meghir and Pistaferri 2004). The contemporaneous correlation between the permanent income shock and the return process is $17 \%$. Findings by Alessie and Kapteyn (1999) suggest that individuals hold approximately $€ 12,000$ (1996) of financial wealth at age 40. Assuming $2 \%$ inflation, this yields about $€ 15,000$ in 2008 . In the stochastic benchmark life-cycle model we use these $€ 15,000$ as initial wealth. Consumers with different income, risk aversion,

\footnotetext{
${ }^{5}$ Appendix 4.B provides further details for the utility of terminal wealth.
} 
leisure preferences and initial wealth will be considered in Section 4.4.

To demonstrate that the baseline parameters yield standard solutions, Figure 4.3 depicts the optimal paths with uncertain income and returns (but without a TDA) that correspond to 25 th, 50 th and 75 th percentile of lifetime utility as well as the average profiles. Apart from the progressive income taxes, it is the classical life-cycle model, which has been widely studied in literature, (e.g. Campbell and Viceira 2001, Browning and Crossley 2001), and confirms the plausibility of the parameter values. Figure 4.3(a) captures optimal consumption and labor supply choices. The fat blue line depicts the hump-shaped profile of mean consumption. It starts decreasing after the (deterministic) age dependent income component peaks. Average consumption in the first (second) life phase is around $€ 28,800$ $(€ 25,800)$. The fat green line illustrates average labor supply. It increases steadily until age 61 . The average working week is 37.5 hours. After this, leisure preferences double and labor supply decreases in line with the consumption drop to 5.6 hours per week. The percentile decisions are not smooth because of the unforeseeable shocks that the individual has to cope with. $N$ is smoother than $C$ because the first order conditions imply that only $C$ adjusts at corner solutions. The resulting wealth account balance is captured in Figure 4.3(b). The individual starts to accumulate wealth for retirement in the late 40s, which is somewhat later than what Gourinchas and Parker (2002) find. ${ }^{6}$ The average individual consumes part of his liquid wealth during the potential early retirement years because of his lower labor income. He enters regular retirement with around $€ 15,000$.

\subsection{Optimal Life-Cycle Savings in the Absence of Uncer- tainty}

We first consider optimization under certainty in order to demonstrate the mechanism of the tax incentives. We assume that the gross returns are fixed at $1.1 \%$ and that real wages only follow $f(t)$ in (4.8). In this deterministic model we set initial wealth to $€ 0$ as individuals will not hold precautionary savings. Based on the deterministic example we study the effects of the introduction of a TDA, subject to progressive income taxation, in isolation. In the next section, we show what happens to the mechanism if income and returns are uncertain.

\footnotetext{
${ }^{6}$ They fit their model to the US population, who receive less public pension in old age. Therefore their agents need to save more, which can lead to an earlier starting age.
} 


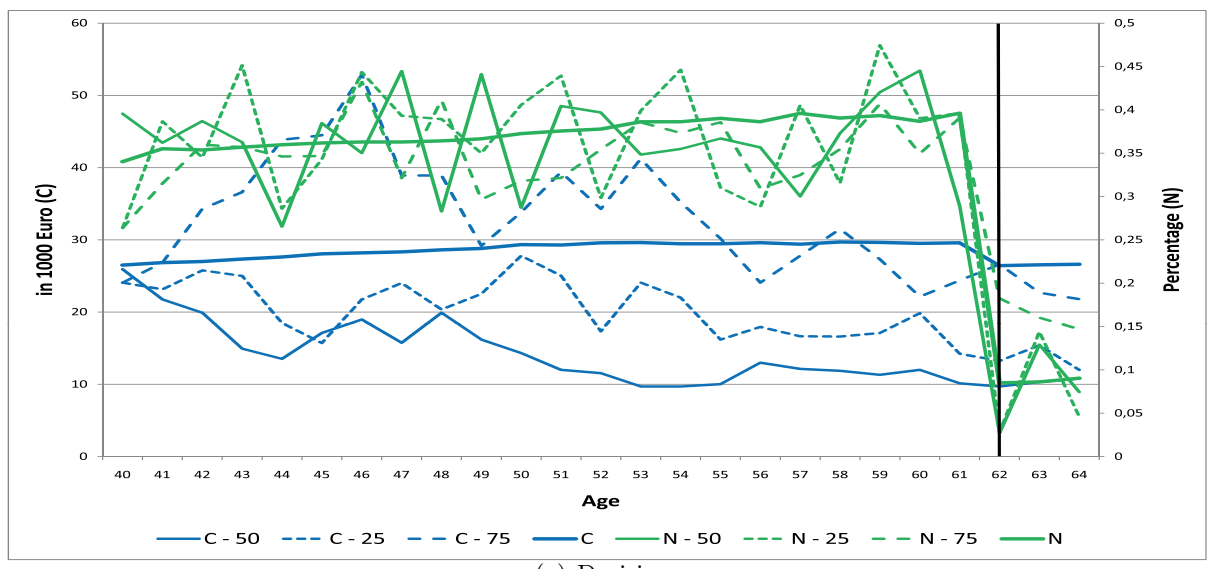

(a) Decisions

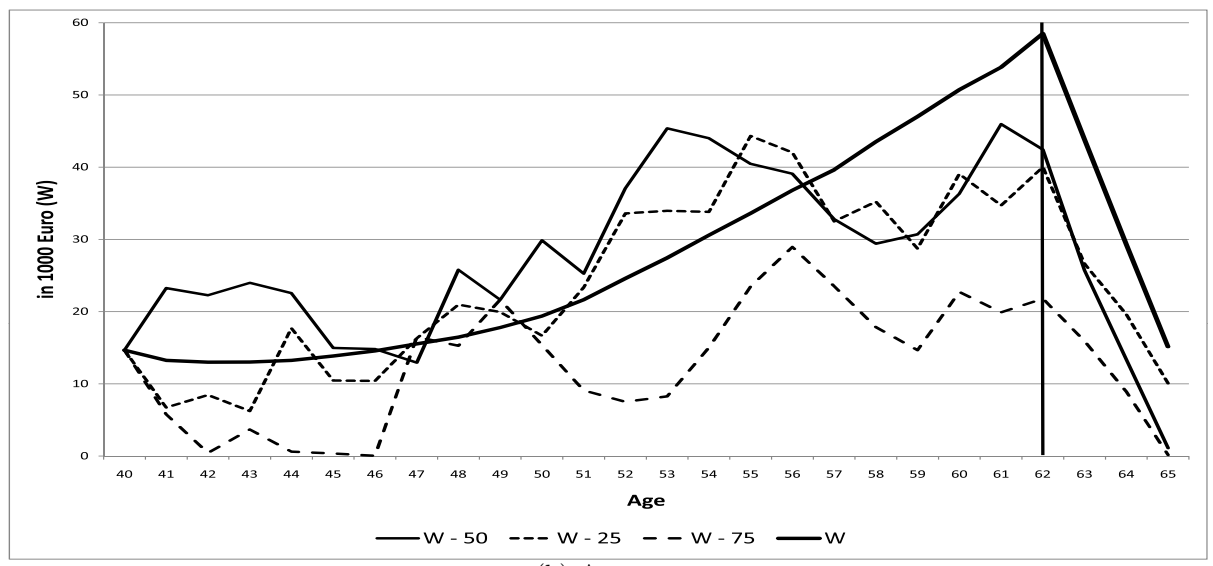

(b) Accounts

Figure 4.3: Standard Life-Cycle Model with Uncertainty

This figure illustrates the optimal decisions $(4.3(\mathrm{a}))$ and resulting regular wealth account balances (4.3(b)) of the simple life-cycle model version without a TDA as described in Section 4.2. The preference parameters are $\theta=1.5 / 3.0, \beta=0.96$ and $\gamma=1.5$. The uncertainty describing parameters are tailored to the Netherlands. Investment returns are time independent and lognormally distributed with mean $1.1 \%$ and standard deviation $9.4 \%$. Moreover, returns are correlated to permanent wage shocks, which are also lognormally distributed with mean 0 and standard deviation $17.7 \%$. Transitory wage shocks follow a lognormal distribution with mean 0 and standard deviation $17.9 \%$. The age dependent deterministic component is described by (4.8). The figures plots the average path (bold) and the paths corresponding to the 25 th, 50 th and 75 th percentile of utility. 


\section{Optimal Savings without the TDA}

We start by studying a consumer without access to the TDA. To derive implications from first order conditions, we assume that we stay below the wealth tax threshold. In the absence of a progressive taxation, the intertemporal relationship of consumption evolves as

$$
\frac{C_{t+1}}{C_{t}}=(R \beta)^{-\frac{1}{\theta(1-\gamma)-\gamma}}\left(\frac{Y_{t+1}}{Y_{t}}\right)^{\frac{\theta(1-\gamma)}{\theta(1-\gamma)-\gamma}} .
$$

Consumption growth is a trade-off between the future consumption preference $\beta$, which favors decreasing consumption, and income growth, which increases consumption (both exponents in (4.19) are positive). Given the benchmark parameters, consumption evolves as $C_{t+1}=0.987\left(Y_{t+1} / Y_{t}\right)^{1 / 3} C_{t}$. Consumption grows if wage growth exceeds $1.75 \%$ and decreases otherwise.

The dashed lines in Figure 4.4 visualize the optimal solution to this life-cycle problem. Figure 4.4(a) shows the optimal decisions and Figure 4.4(b) the resulting account balance. Consumption is given by the dashed blue line and labor supply by the dashed green line. At the beginning of the planning horizon, the individual consumes $€ 26,850$. As a response to the offered wage process consumption exhibits a hump shape until age 61, as also reported by a.o. Campbell and Viceira (2001) and Bloom, Canning and Graham (2003). Thereafter it drops to a lower level of around $€ 21,000$. Labor supply stays relatively constant around $38 \%$, that is a 38 hour week, until age 55 . A period of more work follows to accumulate the savings. As a response to stronger leisure preferences in old age, labor supply drops to a lower level of around 15 hours in the second life phase. The marginal tax rates in the first and second life phase are respectively $42 \%$ and $33.6 \%$. The main reason for the lower marginal tax rate in the second life phase is the individual's lower labor supply. A minor reason lies in the increasing age dependent tax credits (see Appendix 4.A). The simultaneous drop in consumption is implied by (4.16). Note that consumers' labor supply does not fall to zero in this model without a TDA. They do not retire early.

The dashed black line in Figure 4.4(b) shows the regular wealth holdings over age. Given no initial wealth, the individual saves small amounts in the beginning of the planning horizon. The exponential shape of the wealth account implies that the individual increases his saving rate from age 55 to 61 , where his savings amount to around $€ 27,500$. The decreasing wealth level after age 61 shows that consumption in old age is partially financed by regular wealth. Upon regular retirement, the individual holds $€ 1,040$. 


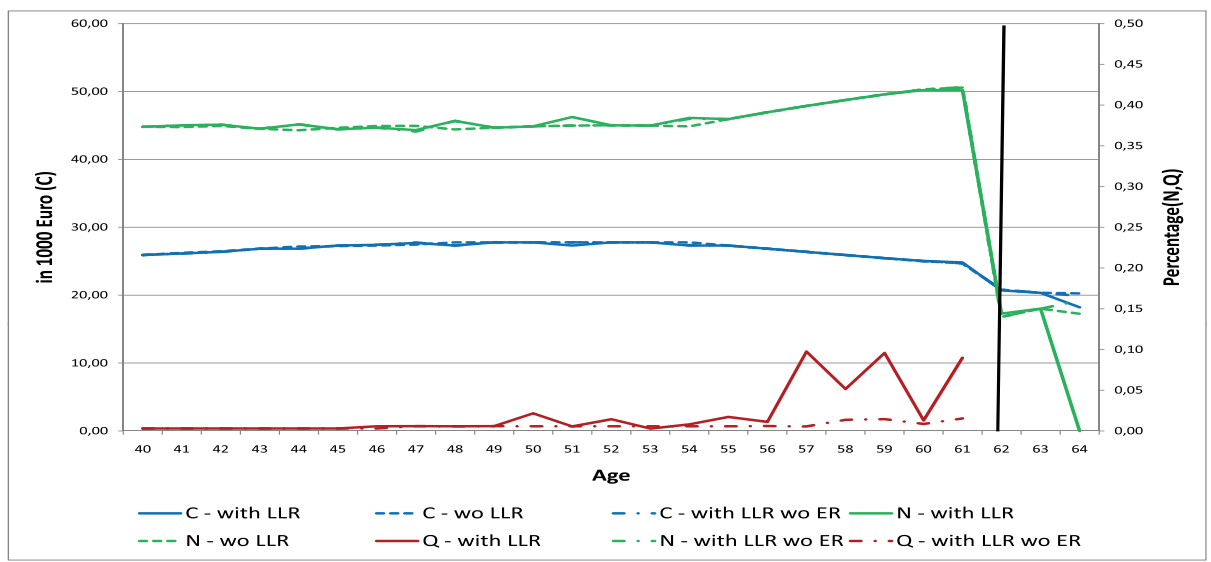

(a) Decisions

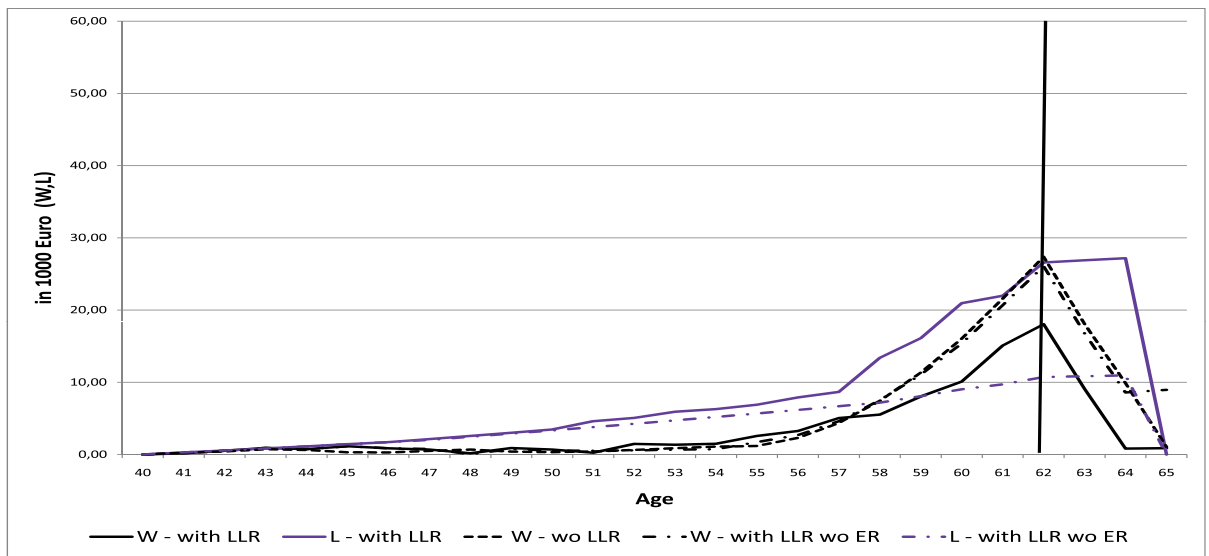

(b) Accounts

Figure 4.4: Life-Cycle Model without Uncertainty

This figure illustrates the optimal decisions (4.4(a)) and resulting regular wealth account balances (4.4(b)) of the simple life-cycle model version without a TDA as described in Section 4.2. The preference parameters are $\theta=1.5 / 3.0, \beta=0.96$ and $\gamma=1.5$. The parameters are tailored to the Netherlands. Investment returns are fixed at $1.1 \%$. Wages follow the age dependent deterministic process as in (4.8). 


\section{Optimal Savings with the TDA}

Suppose the consumer may use the TDA as an alternative to save for final wealth. The introduction of the TDA increases the propensity to save by offering a more profitable alternative. In Section 4.2 we showed that TDA contributions shift the relationship between leisure and consumption down. Therefore, the individual can work more without incurring higher marginal taxes. Furthermore, the marginal utility of saving increases. In equilibrium, the marginal utility of optimal consumption and leisure must also increase. This puts a downward pressure on consumption and motivates to work more.

To analyze the tax effects in isolation from the early retirement, we solve a life-cycle model that includes the TDA as a savings account but excludes the possibility to retire early. The dash dotted lines in Figure 4.4 show the solution to this model. Consumption and labor supply look very similar to the previous case. At the beginning of the planning horizon, the individual works 38.4 hours a week. This is 6 minutes $(0.1 \mathrm{hrs})$ more than the individual who may not use the TDA. As a response to more work (4.16), the individual increases his consumption by $€ 450$ to $€ 27,400$ in the first phase. Thus, the consumer with a TDA enjoys less leisure but more consumption in the first phase. The dash dotted red line in Figure 4.4(a) plots the contributions to the TDA as a fraction of labor income. Contributions stay around $1 \%$ as of age 47 until age 61 . The marginal tax rate, i.e. the tax rate that would have applied to the contributions, is $42 \%$ in the first life phase. In the second life phase he faces a marginal tax rate of $33.6 \%$. Since the individual is not retiring early, the marginal tax rate drop is only due to the lower level of labor supply and the increasing age dependent tax credits (see Appendix 4.A).

The purple dash dotted line in Figure 4.4(b) represents the TDA balance and demonstrates that the individual builds up about $€ 11,000$ until age 61 . Upon regular retirement this is taxed at a marginal tax rate of $33.6 \%$, which is substantially lower than the $42 \%$ that the individual would have had to pay on the contributions if he had not put his money in the TDA. Regular wealth holdings peak around $€ 27,500$ as in the model without a TDA. The larger amount of savings at age 61 translate into a higher final wealth balance. The individual who invests in the TDA holds almost $€ 9,000$ at age 65 . This substantial increase lends evidence to an enormous income effect.

Despite obvious income effects, the fiscal effect of the TDA is low. The discounted lifetime ${ }^{7}$ taxes paid decrease by only $0.29 \%$ to $€ 216,000$. The decrease stems from the substitution of the $42 \%$ marginal income tax rate for a lower marginal tax rates upon withdrawal of the TDA contributions and the annual TDA subsidy.

\footnotetext{
${ }^{7}$ Lifetime refers to the 25 modeled years.
} 


\section{Optimal Savings under Early Retirement}

We now consider the role of TDAs for early retirement. Early retirement allows the individual to further exploit the TDA because it offers the opportunity to withdraw the TDA balance over several years. This implies that the total balance is not taxed at once, but in parts. Due to the progressive income tax system, this can lead to a further reduction in total taxes. Referring to the trade-off (4.18) between wealth tax and the marginal income tax rates on labor and TDA, this makes saving in the TDA even more attractive.

The solid lines in Figure 4.4 depict the solutions of the full model, that is with the possibility to use the TDA and to retire early. The consumption and labor supply profiles until age 64 look again similar to the previous cases. At age 64 labor supply (solid green line) now drops to 0 . The consumer in the full model thus retires one year early. His consumption drops accordingly. TDA contributions become larger than $1 \%$ as of age 46 , which is one year earlier than in the model without early retirement, and accumulate to $€ 26,600$ after age 61 . As of age 51, the individual saves additionally in the regular wealth account to finance greater leisure during age 62 and 63 . Early retirement at age 64 is paid by the TDA. Upon regular retirement, his final wealth amounts to almost $€ 880$, which is less than the individual without the TDA holds. The individual faces a marginal tax rate of $42 \%$ during the contribution period. The marginal tax rate drops to $33.6 \%$ as he enters the second life phase due to the decreased labor supply. At age 64 it increases again to $42 \%$ due to a large withdrawal. As we showed in Table 4.1, it is still preferable to save in the TDA instead of the regular wealth account if marginal income tax rates upon contribution and withdrawal are equal. The remaining balance in the TDA is taxed at $33.6 \%$ again. In contrast to the previous case, the individual was able to spread his TDA wealth over two withdrawals: one in at age 64, where the employee personal income tax credit still applies, and one upon regular retirement. Thereby, he achieved much lower tax rates.

Fiscal effects amount to a $0.87 \%$ decrease in discounted lifetime taxes $(€ 1,880)$. This reduction can again be attributed to the lower marginal tax rate upon withdrawal of the TDA balance compared to the marginal tax rate upon contribution and the TDA subsidy. While the government loses some taxes, the introduction of the TDA increases the lifetime utility of consumers. We express the utility effect in terms of certainty equivalent (CEQ) lifetime consumption. This is the extra annual consumption that needs to be provided to the consumer without TDA to achieve the same utility as a consumer with TDA. The utility increase due to the TDA in the deterministic case is equivalent to a $0.2 \%$ increase in certainty equivalent annual consumption, which amounts to approximately $€ 840$ over the lifetime (see Table 4.3). 


\begin{tabular}{|c|c|c|c|c|c|c|}
\hline \multirow[b]{2}{*}{$\theta / \beta$} & \multicolumn{3}{|c|}{ CEQ (in \%) } & \multicolumn{3}{|c|}{ CEQ (total disc $€ 1000)$} \\
\hline & 0.93 & 0.96 & 0.99 & 0.93 & 0.96 & 0.99 \\
\hline 1.25 & 0.06 & 0.35 & 1.10 & 0.23 & 1.64 & 6.92 \\
\hline 1.50 & 0.04 & 0.20 & 1.29 & 0.14 & 0.84 & 7.39 \\
\hline 1.75 & 0.02 & 0.38 & 1.49 & 0.06 & 1.48 & 7.80 \\
\hline \multirow[t]{2}{*}{2.00} & 0.08 & 0.59 & 1.52 & 0.20 & 2.06 & 7.30 \\
\hline & \multicolumn{3}{|c|}{$\Delta$ taxes $($ in $\%)$} & \multicolumn{3}{|c|}{$\Delta$ taxes $($ total disc $€ 1000)$} \\
\hline$\theta / \beta$ & 0.93 & 0.96 & 0.99 & 0.93 & 0.96 & 0.99 \\
\hline 1.25 & 0.07 & 0.69 & 5.05 & 0.13 & 1.72 & 18.85 \\
\hline 1.50 & 0.08 & 0.87 & 5.38 & 0.12 & 1.88 & 17.30 \\
\hline 1.75 & 0.55 & 2.96 & 5.89 & 0.76 & 5.65 & 16.52 \\
\hline 2.00 & 0.52 & 2.87 & 5.23 & 0.64 & 4.85 & 12.82 \\
\hline
\end{tabular}

Table 4.2: Utility gains and Tax Losses due to TDAs (Deterministic)

This table contains a measure of utility increase due to the TDA introduction to assess individuals' gain of it and a measure of change in taxes to assess the fiscal burden of the TDA introduction for the deterministic model. The upper panel contains information on the former, the lower on the latter. The left part of the upper panel reports the additional percentage of certain consumption that the individual without the TDA needs to receive to be as well off as the individual with a TDA (Certainty Equivalent Consumption, CEQ). The right half of the upper panel translates the percentage of CEQ into total discounted consumption over the lifetime. Similarly the left half of the lower panel contains the percentage change in taxes for the government due to the introduction of the TDA, the right half the absolute difference of the discounted tax revenues. These numbers are reported for several leisure preference $\theta$ (along the columns) and discount factor $\beta$ (along the rows) values. Initial wealth $=€ 0$ and risk aversion $\gamma=1.5$.

\subsection{Optimal Savings under Uncertainty}

We have shown that, under certainty, the individual saves in the TDA, retires early and thereby improves his utility by a CEQ increase of $0.2 \%$ of annual consumption. Under uncertainty, liquidity motives and risk aversion may change these conclusions. We consider uncertainty in the returns and income process, while keeping the means of them (respectively 0,0 , and 1.01) equal to the deterministic case. We consider 1000 simulations of random, realized shocks.

\section{Life-Cycle Profiles}

Figure 4.5 depicts the solution with the baseline parameters. It includes the optimal paths that correspond to the 25th, 50th and 75th percentile of lifetime utility as well as the average. The optimal strategy depends on the permanent income state and the history of returns and income shocks. The shocks therefore determine the accumulated regular and tax-deferred savings. We observe limited dispersion in consumption and labor in Figure 4.5(a). Consumption ranges between $€ 15,000$ and $€ 53,000$ on a scale from $€ 0$ till infinity, and labor supply between 27 and 47 on a scale from 0 to 66 hours per week in the first life phase. Dispersion of TDA contributions amounts to the full scale; from 0 to almost $12 \%$ (Figure 4.5(b)). Given a precautionary savings buffer and a higher after-tax return in 

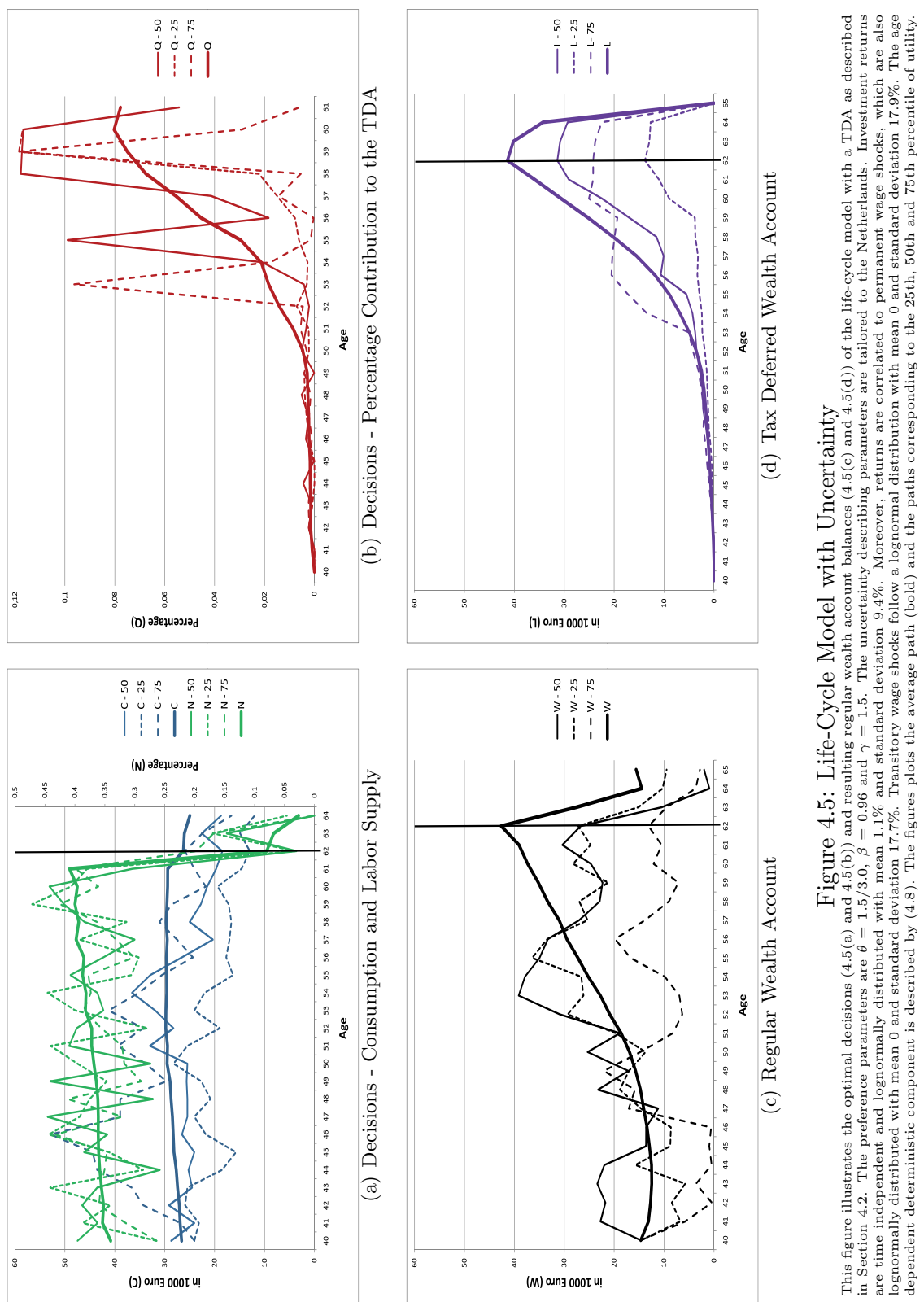
the TDA, income shocks immediately affect TDA contributions.

On average we observe the typical hump-shaped consumption pattern again. Labor supply increases until age 61. As in the deterministic case, TDA contributions become meaningful in someone's late 40s. However, contrary to the deterministic case, average contribution rates increase steadily in the stochastic case. Both wealth accounts in Figures $4.5(\mathrm{c})$ and $4.5(\mathrm{~d})$ grow as of the mid 40 s at the latest and lead to balances of around $€ 42,000$ just before potential early retirement, which is much larger than in the deterministic case (regular wealth account $€ 18,000$ and TDA $€ 26,600$ ). Consumption during potential early retirement is first supported by the regular wealth account. During the last year, where the median and the 75th percentile realizations lead to one year of early retirement, consumption is mostly financed by the TDA. On average, contributions in the first life phase would have been taxed at the marginal tax rates of $42 \%$ and $52 \%$. During the potential early retirement years the marginal tax rate drops to $33.6 \%$ and $42 \%$. The remaining average TDA balance upon regular retirement is taxed at a marginal tax rate of $33.6 \%$. As the marginal tax rate upon withdrawal is lower than upon contribution, we observe that the individual saves a lot of money by deferring his taxes on contributions.

The final wealth balance amounts to about $€ 15,600$, which is $€ 450(3 \%)$ more than the same model without a TDA yields (not shown). The individual mostly shifts his savings from the regular account to the TDA and only acquires few additional wealth. In line with Attanasio et al. (2004), we find the substitution to dominate the income effect.

To measure the gain of the TDA introduction for individuals we compute the CEQ lifetime consumption. In this benchmark case, one would have to give the individual without a TDA $1.24 \%$ of certain annual consumption more to make him as happy as the equivalent individual with a TDA. Over the lifetime, this corresponds to discounted total of $€ 5,630$. Due to deferred taxation and subsidies the government loses discounted taxes of $€ 12,000$ (14\%) per individual compared to the model without a TDA. This is mainly due to the substitution towards a lower marginal income tax rate. In essence, the government pays about $50 \%$ of average consumption at age 64 . The individual feels only half of that better off.

\section{Participation and Retirement}

The previous life-cycle profiles demonstrated that on average people should use the TDA. Figure 4.6 plots the fraction of a 1000 random consumers that save more than $1 \%$ of their income in the TDA as a function of age. This fraction increases monotonically from age 48 till 61 , where it reaches $87 \%$. Until age 48 no one saves more than $1 \%$ in the TDA, which reflects the impatience of people. They value immediate consumption more than immediate saving (or later consumption). As a result, they postpone saving until the utility of future 
consumption and leisure outweighs the immediate one. The participant gain slows down at age 53 , where he faces the first negative wage growth, and as of age 58 , whereafter it becomes less useful to save for early retirement due to a too short horizon (3 years).

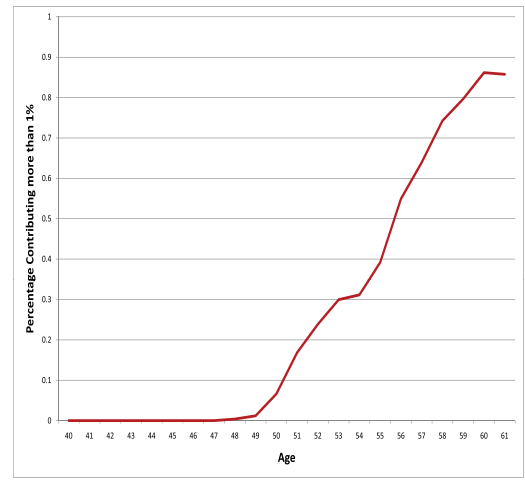

Figure 4.6: Percentage TDA users over Age Figure 4.7: Percentage Early Retirees over Age

Given all realizations as in Figure 4.5, Figure 4.6 plots the fraction of the thousand realizations that lead to participation in the TDA as a function of age. TDA participation is defined as contributing more than $1 \%$ of gross income $N_{t} Y_{t}$. Figure 4.7 plots the fraction of the thousand realizations that lead to early retirement as a function of age. Early retirement is defined as 0 labor supply, $N_{t}=0$. The bold line depicts the percentage retirees in this life-cycle model. For comparison, we show the proportions from the same model but without a TDA as the dashed line.

Figure 4.7 illustrates the proportion of people retiring early. It becomes immediately clear that there are far more early retirees in the model with (bold line) than without the TDA (dashed line). Around $80 \%$ of the retirees in the model with the TDA are TDAparticipants, defined as contributing more than $1 \%$ of labor income at age 61 (100\% if $0 \%$ is used). The percentage of early retirees increases monotonically until regular retirement. 230 of 1000 people retire at age 62, another 150 retire at age 63 and another 370 at age 64, leading to 750 retirees at age 64 .

\section{Different Consumers}

We studied the impact of the TDA and early retirement for a specific type of consumer with $€ 15,000$ of initial wealth, leisure preference parameters $\theta=(1.5,3.0)$ and time preference $\beta=0.96$. The reaction, utility and tax effect differ among consumers. This section reviews the effects on the main solutions of our model for individuals with different preferences and initial levels of wealth. Each time we look at the optimal decisions, in particular average consumption and leisure in both life phases, the average contribution rate, the percentage of people participating in the TDA in the first life phase and the percentage of early retirees in the potential early retirement phase. We also investigate the costs, the lost taxes for the 
government, and benefits, the utility increase for consumers.

Different initial wealth levels $W_{0}$. Figure 4.8 summarizes our solutions as we vary the level of initial wealth. Figure 4.8(a) depicts average consumption, labor supply and TDA contributions in each life phase as a function of initial wealth. Changes in initial wealth affect consumption and leisure in a positive manner in the first life phase. In the second life phase these variables are largely unaffected. Interestingly, the average contribution rate is also independent of initial wealth. The same holds for the percentage participants over age, which is presented in Figure 4.8(b). The level and the slope of this profile are almost identical for all initial wealth levels. The percentage of retirees is also invariant to initial wealth (see Figure 4.8(c)). These results illustrate that the individual is too impatient to put parts of his initial wealth aside for old age. ${ }^{8}$

Column 1 in Table 4.4 contains the percentage increase of final wealth from the model without to a model with a TDA. For the benchmark parameters it remains fairly stable, around $2 \%-3 \%$, for all initial wealth levels. We can therefore conclude that the small income effect we observed before is stable over initial wealth. In line with these observations, certainty equivalent consumption due to the introduction of TDAs is also robust to changes in initial wealth as the second column in Table 4.4 demonstrates.

\begin{tabular}{ccc}
\hline \hline$W_{0}$ & $\Delta W_{T}$ (in \%) & CEQ (in \%) \\
\hline 0 & 3.00 & 1.22 \\
15 & 3.02 & 1.24 \\
45 & 2.07 & 1.24 \\
80 & 3.16 & 1.24 \\
\hline \hline
\end{tabular}

Table 4.3: Sensitivity of Final Wealth Balance Differences and Utility Gains (Stochastic)

This table contains the percentage difference in average final wealth balance between a model with and without a TDA and the percentage of certain consumption that the individual without the TDA needs to receive to be as well off as the individual with a TDA (Certainty Equivalent Consumption, CEQ) for several values of initial wealth $W_{0}$.

Different time preferences $\beta$. The effect of different time preferences is depicted in Figure 4.9. A higher discount factor, in particular such that $R \beta>1$, as in case of $\beta=0.99$, leads to a higher preference for future consumption, leisure and retirement wealth. Accordingly, current consumption and leisure should decrease and savings increase. As a result, future consumption and leisure should increase. Figure 4.9(a) is in line with the deduction. The increasing labor supply and TDA contributions in the first life phase imply that the tax advantage of the TDA becomes larger the more patient a consumer is. This also affects the percentage of people participating in the TDA positively. The participation

\footnotetext{
${ }^{8}$ For $\beta=0.99$, the main message is unaltered. The contribution rate to the TDA remains independent of initial wealth. Consumption and Leisure in the second life phase increase slightly.
} 
profile over age in Figure 4.9(b) shifts to the left as $\beta$ increases. More patient individuals thus start to save earlier in life. The repercussions on early retirement are less systematic. As Figure 4.9(c) shows, most people retire at the earliest early retirement age 62 if $\beta$ $(=0.99)$ is largest. At age 63 and 64 , the percentage of early retirees is lowest for the highest $\beta(=0.99)$ and highest for the lowest $\beta(=0.93)$. We can therefore conclude that the fraction of three-year early retirees increases with $\beta$. However, the fraction of one or two-year early retirees decreases with $\beta$.

\begin{tabular}{|c|c|c|c|c|c|c|c|c|c|}
\hline \multirow[b]{2}{*}{$\theta / \beta$} & \multicolumn{3}{|c|}{ CEQ (in \%) } & \multicolumn{3}{|c|}{$\Delta$ taxes (in $\%)$} & \multicolumn{3}{|c|}{$\Delta W_{T}($ in $\%)$} \\
\hline & 0.93 & 0.96 & 0.99 & 0.93 & 0.96 & 0.99 & 0.93 & 0.96 & 0.99 \\
\hline 1.25 & 1.02 & 1.41 & 1.49 & -10.69 & -6.17 & -1.78 & -6.71 & 3.28 & 3.32 \\
\hline 1.50 & 1.06 & 1.24 & 1.35 & -17.91 & -14.18 & -4.55 & -19.01 & 3.02 & 4.84 \\
\hline 1.75 & 0.85 & 1.03 & 1.21 & -24.99 & -23.07 & -10.64 & -15.96 & -0.58 & 7.14 \\
\hline \multirow[t]{2}{*}{2.00} & 1.14 & 1.03 & 0.87 & -29.06 & -30.36 & -17.28 & -19.58 & -8.68 & 6.39 \\
\hline & \multicolumn{3}{|c|}{ CEQ (total disc €1000) } & \multicolumn{3}{|c|}{$\Delta$ taxes (total disc $€ 1000)$} & \multicolumn{3}{|c|}{$\Delta W_{T}($ total disc $€ 1000)$} \\
\hline$\theta / \beta$ & 0.93 & 0.96 & 0.99 & 0.93 & 0.96 & 0.99 & 0.93 & 0.96 & 0.99 \\
\hline 1.25 & 3.80 & 6.98 & 10.06 & -7.26 & -15.17 & -28.85 & -0.83 & 0.73 & 1.83 \\
\hline 1.50 & 3.61 & 5.63 & 8.36 & -6.24 & -11.97 & -23.11 & -1.88 & 0.46 & 2.01 \\
\hline 1.75 & 2.67 & 4.29 & 6.93 & -5.29 & -9.77 & -18.32 & -1.33 & -0.07 & 2.18 \\
\hline 2.00 & 3.32 & 3.97 & 4.67 & -4.66 & -8.34 & -14.99 & -1.70 & -0.95 & 1.49 \\
\hline
\end{tabular}

Table 4.4: Utility gains and Tax Losses due to TDAs (Stochastic)

This table contains a measure of utility increase due to the TDA introduction to assess individuals' gain (CEQ) of it in the first panel, the change in taxes due to the introduction of the TDA in the second panel and the difference in final wealth balances between a model with and without a TDA in the third panel for the stochastic model. The upper panel contains this information in percentage terms, the lower panel in discounted €terms over the lifetime. These numbers are reported for several leisure preference $\theta$ (along the columns) and discount factor $\beta$ (along the rows) values. Initial wealth $=€ 15,000$ and risk aversion $\gamma=1.5$.

Table 4.4 summarizes the CEQ consumption gains, the tax losses and the changes in final wealth for several $\beta$ and $\theta$ combinations. Given an initial wealth level and leisure preference, $W_{T}$ increases as we move to the right, that is as patience becomes stronger. As individuals value the future more, the marginal utility of saving increases and thus they have a stronger motive to save more. In line with the previous observations, CEQ consumption in percentage of annual discounted consumption becomes larger with $\beta$ except for the case where $\theta=2$. In €terms though, CEQ consumption increases always with $\beta$. The same patterns can be observed for the changes in taxes due to the TDA. Keeping $\theta=1.5$, lifetime discounted CEQ consumption increases from $€ 3,610(\beta=0.93)$ to $€ 8,360(\beta=0.99)$ and lifetime discounted losses increase from $€ 6,240(\beta=0.93)$ to $€ 23,110(\beta=0.99)$. In the last case, the government finances almost a whole year of early retirement while individuals' utility gain is only a third of annual early retirement consumption. The main reason for the differences lies in the definition of CEQ consumption. As the word says, it provides a consumption stream with certainty which is valued more than the actual sum by risk-averse 
people. Consequently, individuals feel less well off than the government's losses imply (in €terms).

Different leisure preferences $\theta$. The effect of different leisure preferences is depicted in Figure 4.10. Consumption, labor supply and savings are reduced with $\theta$. The preference for early retirement also increases with $\theta$. Whether individuals actually save enough to retire early is a trade-off between current and future leisure. Figure 4.10(a) captures a clear declining trend in most decision variables as $\theta$ increases. Consumption and labor supply decrease in both life phases while the contribution rates are roughly constant with respect to leisure preferences. Also, there is no trend visible in the percentage of participants in Figure 4.10(b). Despite invariant contribution and participation rates, Figure 4.10(c) demonstrates that people with higher leisure preferences retire early more commonly. The higher leisure preferences make lower consumption possible. Therefore, individuals need fewer savings per year of early retirement and the same savings rate as in the lower leisure preference cases suffice.

We can observe a negative relationship between leisure and the percentage difference of final wealth between a model with and without TDA in Table 4.4. Given an initial wealth level and patience, the difference becomes more negative as we increase $\theta$. Individuals with higher $\theta \mathrm{s}$ have a larger preference for leisure versus final wealth compared to individuals with lower $\theta$ s. Consequently, individuals with high leisure preferences spend their savings rather than on retirement. This motive is stronger for people with a TDA because leisure is much cheaper than final wealth due to the nature of taxes. As the left half of Table 4.4 shows, there is no clear trend in the CEQ consumption percentage and the percentage tax change. The discounted lifetime $€$ values however exhibits a negative trend. Individuals gain less certain consumption and the government pays less as the leisure preference becomes stronger. 


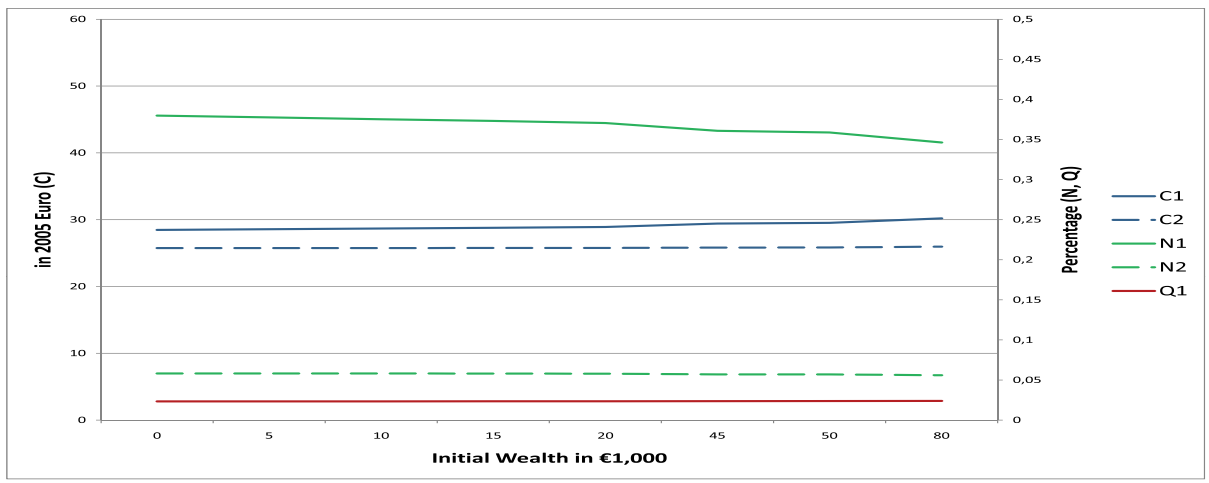

(a) Consumption, Labor Supply and TDA Contribution Sensitivity

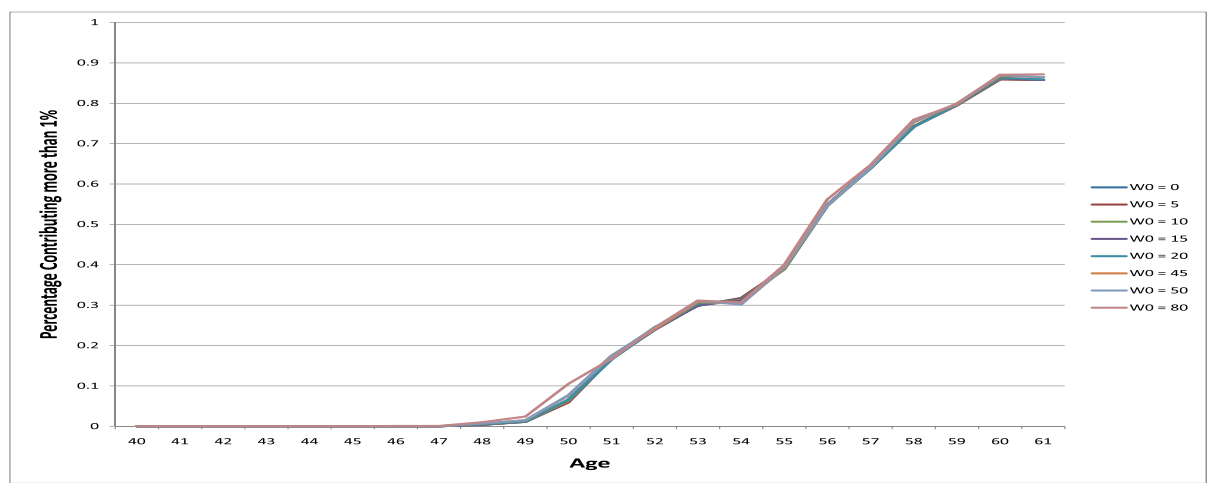

(b) Participation Sensitivity

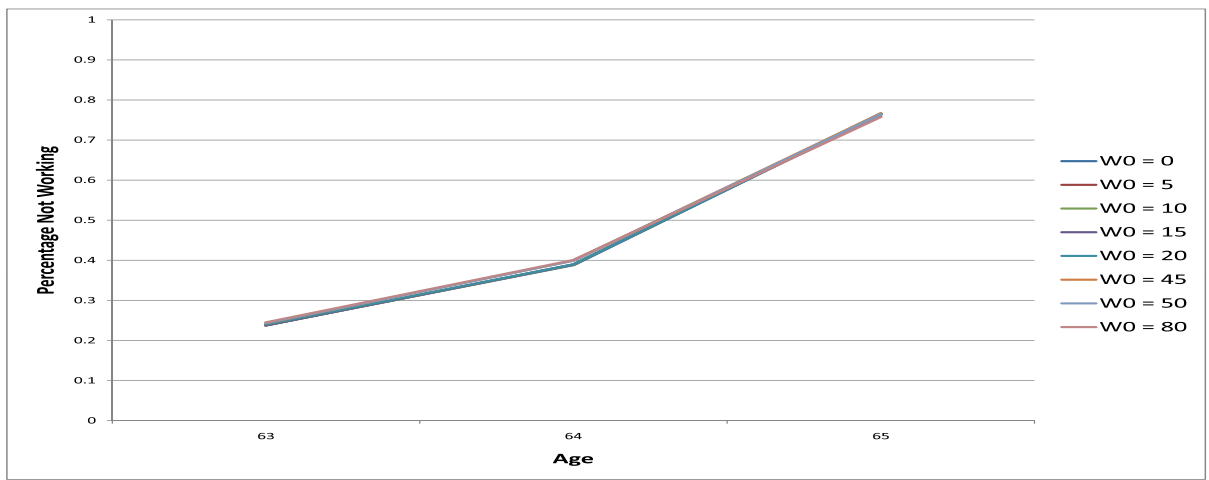

(c) Retirement Sensitivity

Figure 4.8: Sensitivity with respect to Initial Wealth

Given all realizations for the benchmark parameters, this figure illustrates the behavior as we vary the initial wealth level $W_{0}$. $4.8(\mathrm{a})$ depicts average consumption (in the first and second life phase) on the left axis and average labor supply (in the first and second life phase) and TDA contributions on the right axis as a function of $W_{0} .4 .8$ (b) illustrates how the the fraction of the thousand realizations that lead to participation in the TDA as a function of age varies with $W_{0}$. TDA participation is defined as contributing more than $1 \%$ of gross income $N_{t} Y_{t} .4 .8(\mathrm{c})$ shows how the fraction of the thousand realizations that lead to early retirement as a function of age vary with $W_{0}$. Early retirement is defined as 0 labor supply, $N_{t}=0$. 


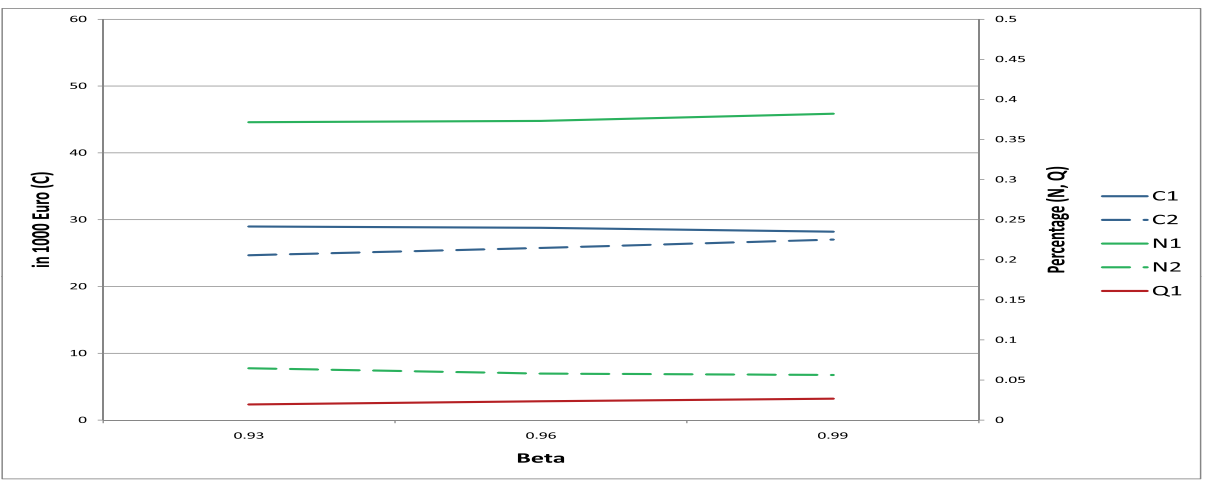

(a) Consumption, Labor Supply and TDA Contribution Sensitivity

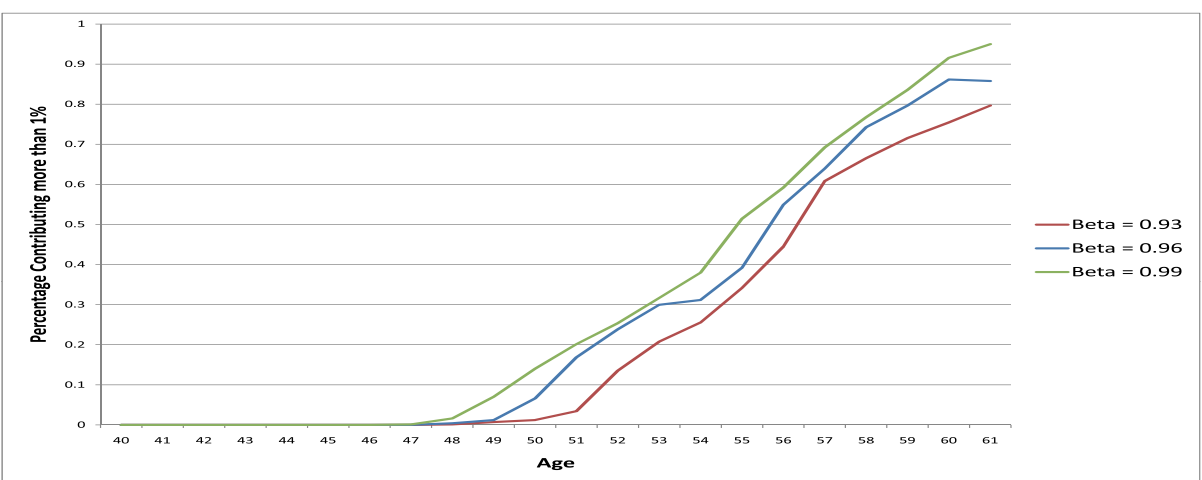

(b) Participation Sensitivity

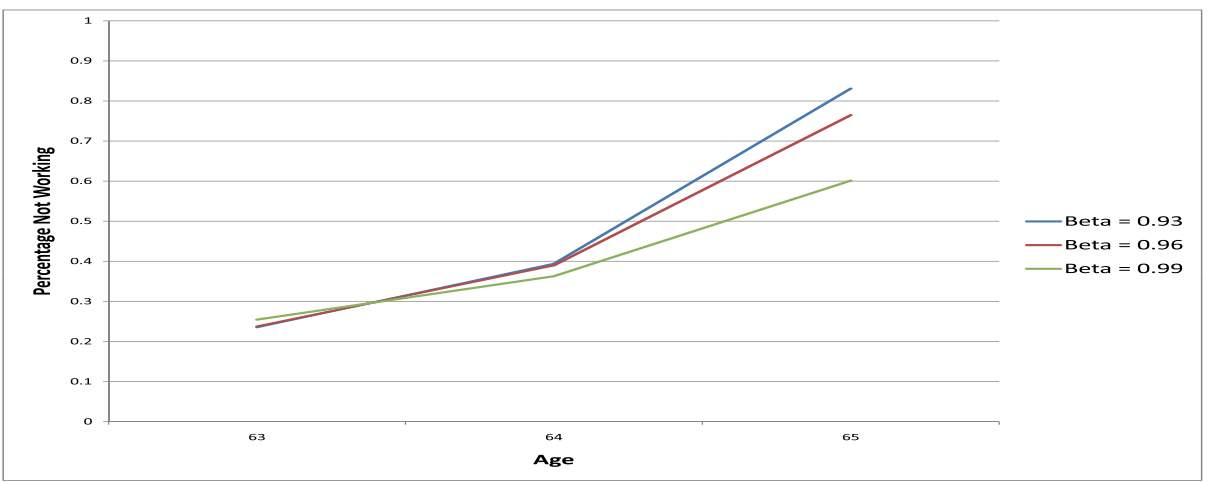

(c) Retirement Sensitivity

Figure 4.9: Sensitivity with respect to $\beta$

Given all realizations for the benchmark parameters, this figure illustrates the behavior as we vary the patience parameter $\beta$. 4.9(a) depicts average consumption (in the first and second life phase) on the left axis and average labor supply (in the first and second life depicts and life phase) a TDA contrion that lead to pa $N_{t} Y_{t} \cdot 4$ (c) shows how the fraction of the varies gross income $N_{t} Y_{t} .4 .9$ (c) shows how the fraction of the thousand realizations that lead to early retirement as a function of age vary with $\beta$. Early retirement is defined as 0 labor supply, $N_{t}=0$. 


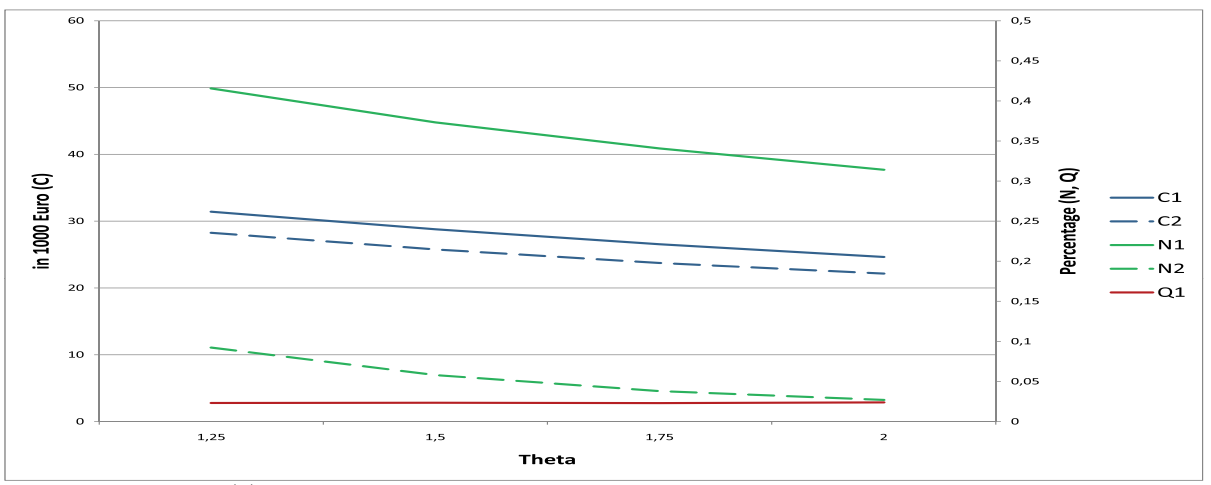

(a) Consumption, Labor Supply and TDA Contribution Sensitivity

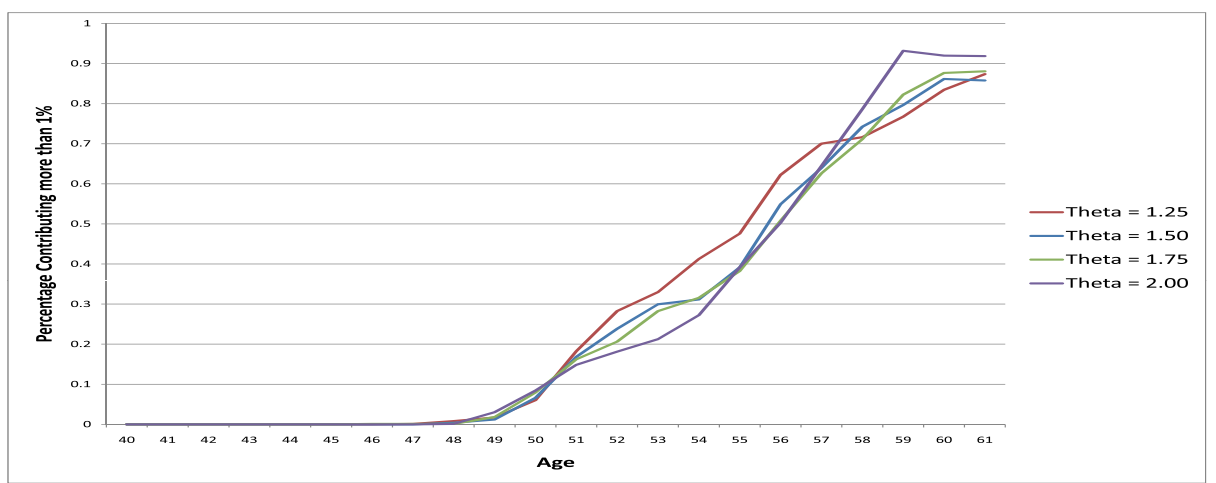

(b) Participation Sensitivity

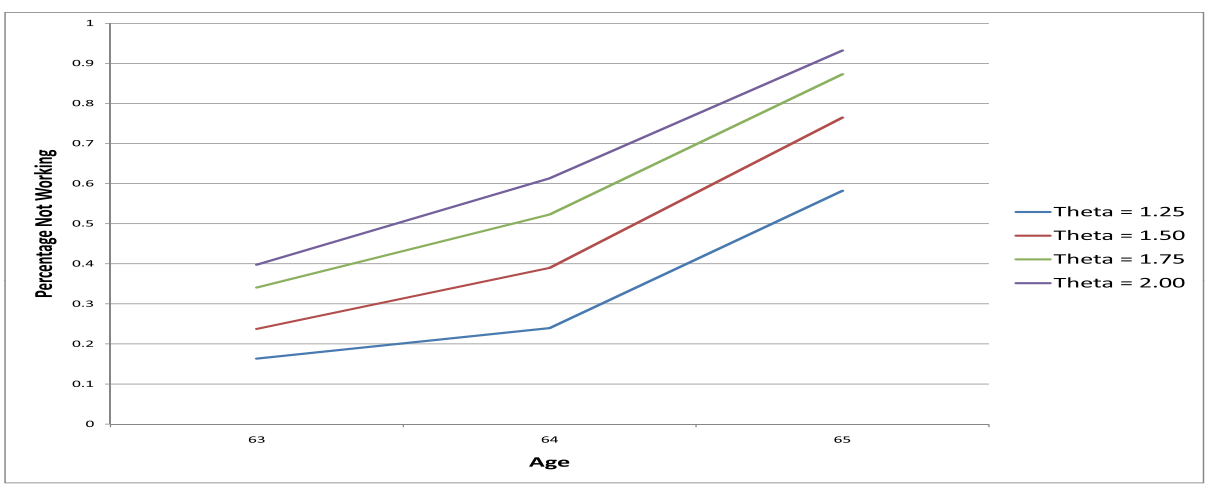

(c) Retirement Sensitivity

Figure 4.10: Sensitivity with respect to $\theta$

Given all realizations for the benchmark parameters, this figure illustrates the behavior changes as we vary the leisure parameter $\theta$. 4.10 (a) depicts average consumption (in the first and second life phase) on the left axis and average labor supply (in the first and second life phat and TDA consand realization of gross inco than $1 \%$ of gross income $N_{t} Y_{t}$. $4.10(c)$ shows how the fraction of the thousand realizations that lead to early retirement as a functio of age vary with $\theta$. Early retirement is defined as 0 labor supply, $N_{t}=0$. 


\subsection{Conclusion}

Providing TDAs makes people better off. As explained in the modeling section (4.2), people can save most taxes by contributing to a TDA when the marginal income tax is high and withdrawing when it is low. Additionally, we show that it can still be beneficial for the individual to contribute to the TDA when marginal income taxes are the same upon contribution and withdrawal if he contributes early in his life. This result is mainly driven by the wealth tax, which is specific to the Netherlands. In the deterministic setting we see that people indeed invest in the TDA if they make optimal decisions. The tax advantages are higher if people retire early than if they do not because they can spread the withdrawals over several periods, thereby reducing each withdrawal balance and accordingly the marginal tax rate. These results still hold in the stochastic setting, where the individual contributes at the highest marginal tax rates and withdraws at the next lower ones.

Independent of whether people have access to a TDA, we observe that people typically start saving in their late 40s. This late start of retirement savings has been noted earlier by Gourinchas and Parker (2002). From the 40s until potential early retirement, the saving rate increases. Shocks to income are mostly taken out on savings. This does not necessarily mean that people save less in the TDA. On the contrary, our results show that positive income shocks can also lead to more TDA savings. As people become older the proportion of TDA participants increases until age 61 . Many of them retire early.

The final wealth balances are similar for individuals, who may use a TDA, and for individuals, who cannot. The former is only $3 \%$ higher larger in the benchmark stochastic case. For less patient (lower $\beta$ ) or more leisure preferring (higher $\theta$ ) people, the change can be negative. This means that people mostly shift their wealth from the regular to the TDA and create only few, or less in case of a negative difference, additional savings. In line with Attanasio et al. (2004), our results suggest that a TDA such as the life-course savings scheme in the Netherlands mainly lead to a substantial substitution effect and only to a minor income effect. At intermediate ages, total wealth is much larger for TDA participants than for non-participants. This difference is largely eliminated upon regular retirement because the TDA-participants consume more savings during their early retirement because they work less.

Our results demonstrate that different initial wealth levels and leisure preferences lead to the sample participation profiles over age. Only more patience lead to higher participation profiles. We see that this translates into equal early retirement patterns for all initial wealth levels but higher early retirement patters for higher leisure preferences. More patience increases the proportion of three-year early retirees and less patience the proportion of oneyear retirees. Finally, providing a TDA increases people's utility by a certainty equivalent of 
$1.24 \%$ of annual consumption in the benchmark case. This CEQ percentage becomes larger as we increase $\beta$, except if people have the highest leisure preference. The $1.24 \%$ increase correspond to a lifetime consumption increase of $€ 5,630$ while the government loses $€ 11,970$ (a percentage decrease of about 15\%). The cash difference highlights that the increased happiness of the people due to the life-course savings scheme costs the government more than twice as much. Compared to the times of generous state early retirement schemes, it is probably cheap. However, compared to a situation without any early retirement schemes it may be expensive relative to the effect on people's happiness. 


\section{A Appendix A: Dutch Tax Parameters}

The Dutch tax system distinguishes between ordinary income and capital income. Both have separate provisions for the life-course savings scheme. Ordinary income tax is progressive. The marginal rate varies between $33.6 \%$ and $52 \%$. The top marginal rate is reached at annual taxable income of $€ 53,860$ (numbers from 2008). A second progressive element is the age-dependent tax credit for everyone active in the labor market. Taxable income is defined as $Z=N Y-Q-D$, where $N Y$ is labor income, $Q$ are TDA contributions and $D$ is an age dependent tax credit. Ordinary income tax is piecewise linear in taxable income,

$$
\mathcal{T}^{Y}= \begin{cases}0 & Z \leq 0 \\ \tau_{1} Z & 0<Z \leq I_{1} \\ \tau_{2} Z-\left(\tau_{2}-\tau_{1}\right) I_{1} & I_{1}<Z \leq I_{2} \\ \tau_{3} Z-\left(\tau_{2}-\tau_{1}\right) I_{1}-\left(\tau_{3}-\tau_{2}\right) I_{2} & I_{2}<Z\end{cases}
$$

where the $\tau_{j}$ parameters are the marginal tax rates and $I_{j}$ the income thresholds. Parameter values for $\tau_{j}, I_{j}$ and $D$ are summarized in Table 4.A5. The table is a slight simplification of the actual Dutch tax code. Some details on the tax credits and marginal rates that are inessential for the model have been omitted.

\begin{tabular}{cccccc}
\hline \hline age & $D$ & & $j$ & $\tau_{j}$ & $I_{j}$ \\
\cline { 1 - 2 } \cline { 5 - 6 }$<57$ & 1,594 & & 1 & 0.336 & 17,579 \\
$57-59$ & 1,848 & & 2 & 0.420 & 53,860 \\
$60-61$ & 2,100 & & 3 & 0.520 & \\
$>61$ & 2,352 & & & \\
\hline \hline
\end{tabular}

Table 4.A5: Income tax parameters (2008)

Capital income is taxed on an accrual basis at a rate of $\tau_{W}=1.2 \%$ of wealth (marked to market every year) and zero rates on dividend and interest income. For a household with two adults the first $€ 46,300$ of wealth is tax-exempt (numbers from 2008). The capital income tax is thus also piecewise linear,

$$
\mathcal{T}_{t}^{W}= \begin{cases}0 & \text { if } W_{t} \leq 46,300 \\ \tau_{W}\left(W_{t-1}-46,300\right) & \text { else }\end{cases}
$$

We assume that the tax parameters are adjusted annually to remain constant in real terms.

The TDA provides four different tax benefits. First, contributions are made from pretax income. Second, it is not subject to the wealth tax. For households with wealth above the tax-exempt threshold it is thus beneficial to add further savings to the TDA. 
Third, individuals receive a lump-sum tax credit when withdrawing funds from the TDA in years without ordinary income, i.e. during early retirement. Fourth, a bonus is paid on contributions to the TDA. The latter effect is more symbolic than of real financial value, since it is capped at a maximum of $€ 191$ per year.

\section{B Appendix B: Pensions and Final Wealth}

The Dutch pension system has three pillars: state, occupational and private pensions. State pensions provide a fixed amount to everyone independent of income. Private retirement provision is in form of an annuity and thus a function of wealth at the retirement age.

Occupational pensions are still mostly of the defined benefit type and related to the average lifetime real earnings per year. For computational reasons we avoid using average lifetime earnings as an additional state variable. We therefore follow Gourinchas and Parker (2002) and relate pensions to the permanent component of the final wage, which would be close to most older Dutch pension arrangements. The permanent component $x_{T}$ is already a state variable in the model. With final permanent income equal to

$$
Y_{T}^{P}=\bar{N} \exp \left(f(T)+x_{T}\right)
$$

we assume that the sum of occupational and state pension provides a replacement rate of $65 \%$ of the after-tax final permanent income,

$$
C_{B}=(0.65)\left(Y_{T}^{P}-\mathcal{T}^{Y}\left(Y_{T}^{P}\right)\right)
$$

We make the simplifying assumption that occupational and state pensions can be aggregated and are both independent of labor supply decisions during the active working life. Income is calculated at the average working week $\bar{N}=38$. This assumption simplifies the computational aspects, since it allows us to start the modeling at age 40, ignoring all earnings at younger age. It also avoids feedback from labor supply decisions on pensions payments. In the model labor, supply decisions only affect the amount of private wealth.

In the utility function we approximate the utility of pension income by a term involving final wealth $W_{T}$. We assume that the agent has the base pension of $C_{B}$ units of consumption in every period beyond age $T$. His private wealth $W_{T}$ is converted into an annuity which provides a perpetual consumption stream $C_{A}=r_{A} W_{T}$, with $r_{A}$ a fair annuity rate determined as

$$
r_{A}=\left(\sum_{j=1}^{\infty} p_{T+j} R^{-j}\right)^{-1}
$$

where $p_{t}$ is the survival probability through age $t$ (fraction alive at time $t$ ). The contribution 
of consumption after age $T$ to the lifetime utility thus becomes

$$
\begin{aligned}
U_{T} & =\sum_{j=1}^{\infty} \beta^{T+j} p_{T+j} \frac{\left(C_{A}+C_{B}\right)^{1-\gamma}}{1-\gamma} \\
& =\sum_{j=1}^{\infty} \beta^{T+j} p_{T+j} \frac{\left(r_{A} W_{T}+C_{B}\right)^{1-\gamma}}{1-\gamma} \\
& =\beta^{T} \phi \frac{\left(W_{T}+B_{T}\right)^{1-\gamma}}{1-\gamma}
\end{aligned}
$$

with

$$
\begin{aligned}
\phi & =r_{A}^{1-\gamma} \sum_{j=1}^{\infty} p_{T+j} \beta^{j}, \\
B_{T} & =C_{B} / r_{A}
\end{aligned}
$$

Adding $W_{B}$ to the final wealth in the utility function reduces the incentive for individual savings. Much of the pension provision is exogenous to the model.

\section{C Appendix C: Numerical Optimization}

To solve the problem we apply standard dynamic programming on a discretized state space. The state variables are $P_{t}, W_{t}, L_{t}, x_{t}$ and $t$, where $P_{t}$ indicates the retirement status $(0 / 1)$. It is set to 0 prior to age 62 . Unfortunately, we cannot reduce the number of state variables. The progressive income tax scheme leads to a problem that is non homothetic in wealth and permanent income. As tax incentives are crucial to the solution, we accept this reduced numerical speed. The grid is a cartesian product of the grids for the individual state variables. For wealth and tax deferred savings we use an exponential grid varying between 0 to 160 in 40 steps. We adopt a recombining tree structure for the permanent income component with the number of branches equal to the number of scenarios per state.

The recursion consists of repeatedly solving a state dependent optimization problem in the variables consumption $C_{t}$, labor $N_{t}$ and contributions $Q_{t}$. The optimal solution is determined by a grid search over $Q_{t}$ and $C_{t}$. $N_{t}$ is defined by the first order conditions (see Section 4.2 (4.16)). Thereafter, we repeat the grid search twice over a finer grid around the optimal solution of the initial decision grid. For the evaluations of the continuation value we interpolate linearly.

The figures are constructed by using monte carlo simulation to draw random income and return paths and applying the optimal decisions to obtain the values for the state variables. Note that the plotted paths correspond to those paths that lead to 25th, 50th and 75th percentile of lifetime utility. 


\section{Chapter 5}

\section{A Reduced Form Analysis of a Reform in Dutch Early Retirement}

\section{Arrangements}

\subsection{Introduction}

Ageing societies threaten the stability of pension systems all over the world due to their financial insustainability (Gruber and Wise 1997). For the last decade, researchers and policy makers have therefore looked for new pension system arrangements that mitigate the rupturing financial pension gap. In January 2006, the Dutch government has put amendments forward to adapt the Dutch pension system to an aging society, which provides an ideal natural experiment. The Dutch initiative reduced the nation's financial burden at the expense of shifting more responsibility to individuals. We will investigate how much individuals are capable of carrying this responsibility.

Pension systems generally have three pillars. The first consists of public pensions, to which basically everyone is entitled once he turns 65 (the "AOW" (=Algemene Ouderdomswet Wet) in the Netherlands), the second of occupational pensions, for which employees and employers are responsible and the third of private or individual pension income. In the Netherlands the average distribution among the pillars was $50 \%, 30 \%$ and $20 \%$ in 2001 (van Riel, Hemerijck and Visser 2003). On top of the already large share of the first pillar, Kapteyn and de Vos (1997) showed that there is a sudden drop in labor force participation once the Dutch turn 55. Most of these early retirees were also financed by the state through a generous early retirement arrangement, the "VUT" (=Vervroegde UitTreding). The amendments in 2006 aimed at shifting the financial burden from the state to private retirement arrangements (from pillar 1 to pillar 3). Accordingly, the "VUT" was abolished 
for individuals born after 1950. At the same time, the reforms introduced the life-course arrangement (Vervroegde UitTreding) as part of the third pillar to encourage individual responsibility for, especially early, retirement.

This life-course arrangement (LLR) enables individuals to retire early in agreement with their employer. Initially, it has been intended to finance sabbatical leave during individuals' working life as maternity leave for instance. Since most Dutch participate in the LLR to retire early (NIBUD 2007), this paper will focus on this LLR aspect. When working, individuals can make contributions to an individual LLR account. The size of the premium is left to the individual's discretion but may not exceed $12 \%$ of gross annual salary (except for individuals born between 1950 and 1955). Moreover, participants face tax incentives when retiring early with the LLR as opposed to retiring early using normal private savings as demonstrated in the previous chapter. Once the account holds more than $210 \%$ of annual taxable labor income, further contributions are not allowed. The early retirement period starts with the transformation of the accumulated LLR wealth into an annuity, which is then paid out as labor income over the early retirement years. This accumulated LLR wealth should be consumed within the early retirement years.

In the Netherlands another employee savings scheme, the Spaarloonregeling (SLR), also exists. It has turned out to be the LLR's fiercest competitor when looking at the participation rates. If people decide to participate in the SLR, they can save up to €613 (2007 value) every year and withdraw their savings tax free four years later. The two savings schemes are mutually exclusive. Individuals have to decide in the beginning of each year whether they would like to make contributions to the LLR or to the SLR. While the LLR has the pre-defined goal of early retirement (or unpaid leave in general), SLR wealth can be cashed out after four years for any reason. Due to the financial superiority of the LLR over the SLR for retirement purposes and our motive to investigate the choices that the Dutch make with regard to retirement, we ignore the SLR.

To model the choice that a Dutch faces regarding the LLR decision, we set up a stylized life-cycle model. Every period, an individual chooses how much to consume, whether to work, and how much to save, given some wage path. As savings vehicles, he has the choice between a regular wealth account and the LLR account. Our model goes beyond a simple life-cycle model, because we model taxes. As Dammon, Spatt and Zhang (2004), we augment the life-cycle framework by introducing a model that differentiates between the taxable (the regular wealth account) and the tax-deferrable but illiquid (the LLR account) account. Evidently, there is a trade-off between staying liquid and incurring higher taxes in the taxable account and vice versa in the tax-deferrable account, which has an impact on the LLR-participation decision.

This paper has two parts. The first part will consider the theoretical and empirical 
decision whether to participate in the LLR, while the second part covers the theoretical and empirical investment point of view conditional on participation. The paper hence proceeds by introducing the theoretical life-cycle model, which mimics the choice a Dutch individual faces regarding LLR participation, and illustrates the trade-offs inherent in the model. Subsequently, the model will be transformed into a reduced and empirically implementable form such that, after presenting our data in Section 5.3, in Section 5.4 we can analyze which type of individual indeed decides to participate. The second part will begin with an introduction of the investment opportunities within the LLR in Section 5.5. We then give a recap of theoretical considerations concerning investment decisions, and continue with an empirical analysis of the subject in Section 5.6. Section 5.7 concludes.

\subsection{The LLR-Participation Decision in a Life-Cycle Model}

We develop a stylized intertemporal life-cycle model for a Dutch individual, who, next to regular risk-free saving, has the opportunity to invest in a tax-deferred LLR account. We restrict our analysis for the LLR to finance up to three years of early retirement. Thus, the individual works at least until his 62 nd birthday and at most until his 65th, when the regular pension starts. We model LLR participation as a yes/no decision. The individual may annually decide upon consumption, LLR participation (and contribution) and, implicitly, regular savings, given a labor income path.

Since the LLR account can only be used to finance early retirement, the individual must have a strong preference for leisure in order to engage in the LLR because he foregoes up to three years of labor income. The complete set of preferences over consumption and leisure is given by

$$
\max _{\{\mathbf{C}, \mathbf{N}, \ell\}} Q_{t}\left(W_{t}, Y_{t}, X_{t}\right)=E_{t}\left[\sum_{s=t}^{64} \beta^{s} u\left(C_{s}\right)+\sum_{s=62}^{64}\left(1-N_{s}\right) \beta^{s} \theta\left(X_{s}\right)+\beta^{65} v\left(W_{65}\right)\right],
$$

where $t$ is current age, $C_{s}$ is consumption; $N_{s}$ the working state; $Y_{s}$ income; $\ell_{s}$ the contribution to the LLR as a percentage of $Y_{s} ; X_{s}$ a set of household characteristics; $W_{s}$ liquid financial wealth (hence, excluding wealth in the LLR account); $u(\cdot)$ the utility of consumption; $\beta$ the individual's time preference; $v\left(W_{65}\right)$ the indirect utility of retirement wealth; and $\theta\left(X_{s}\right)$ the preference for leisure as a function of $X_{s}$. Lifetime utility $Q$ thus consists of three components: The first one is the utility from consumption. The second component is the preference for leisure. In this stylized model we do not model the trade-off between labor supply and leisure during the working life. Individuals have no choice but to work full-time until their 62 nd birthday. Instead of modeling consumption in the retirement phase, we include a utility of wealth at $T=65$. 
The individual's choice until age 62 is subject to budget constraints for liquid wealth and the LLR account,

$$
\begin{aligned}
W_{s+1} & =R_{s+1}\left(W_{s}+\left(1-\ell_{s}\right) Y_{s}-\tau\left(\left(1-\ell_{s}\right) Y_{s}, W_{s}\right)+B_{s}\left(s,\left(1-\ell_{s}\right) Y_{s}\right)-C_{s}\right), \\
L_{s+1} & =R_{s+1}\left(L_{s}+\ell_{s} Y_{s}\right),
\end{aligned}
$$

where $R_{s}$ is the gross return on invested wealth; $\ell_{s}$ the contribution to the LLR account as a percentage of gross income $Y_{s} ; \tau\left(\left(1-\ell_{s}\right) Y_{s}, W_{s}\right)$ are taxes as a function labor income $Y_{s}$ and liquid wealth $W_{s} ; B_{s}\left(s,\left(1-\ell_{s}\right) Y_{s}\right)$ tax credits for employees as a function of their age $s$ and labor income; and $L_{s}$ the accumulated wealth in the LLR account. The gross return $R_{s}$ on liquid wealth and on the LLR account wealth are assumed to be the same.

For an individual who has participated in the LLR and retires at age $T<65$ the budget equation for liquid wealth changes to

$W_{s+1}=R_{s+1}\left(W_{s}+A_{s}\left(L_{62}\right)-\tau\left(A_{s}\left(L_{62}\right), W_{s}\right)+\tau B_{s}\left(s, 62-t, A_{s}\left(L_{62}\right)\right)-C_{s}\right), \quad T \leq s \leq 64$

where $A_{s}\left(L_{62}\right)$ are the annuity payments from the LLR account such that it is depleted at age $65 ; B_{s}\left(s, 62-t, A_{s}\left(L_{62}\right)\right)$ is a tax credit, which depends again on age, but also on the number of LLR-contribution years and $A_{s}\left(L_{62}\right)$. Since $A_{s}\left(L_{62}\right)$ is treated as labor income it is also subject to the tax credit for employees. To understand the trade-offs that are involved in the LLR-participation decision, one should realize that there are in fact three basic options: to not retire early (stay in labor force until 65), to retire early with the LLR, and to retire early without the LLR. Hence, the LLR has some characteristics that are advantageous over both alternatives but also some that are only superior over one alternative. Without going into the complexities of the Dutch tax law, there are four financial incentives that play a role in the LLR-participation decision.

1. As the LLR annuity, $A_{s}\left(L_{62}\right)$, is treated as (taxable) labor income, LLR early retirees are also entitled to the employee tax credits, which amounts up to maximally $€ 2138$ (in 2007 Euro) tax free labor income per year. The same applies to the individuals, who decide to keep working. Early retirees without the LLR retire using their liquid wealth and do not get these tax cuts. This is modeled in $B_{s}$.

2. LLR participants receive an additional of max $€ 188$ (in 2007 Euro) tax credit in real terms per contribution year when they take leave. Neither the ones who do not retire early nor the early retirees without the LLR are entitled to this advantage. We refer to this in $B_{s}$ as well.

3. There is a flat rate wealth tax of $1.2 \%$ per year (above a threshold) that applies to the liquid wealth account but not to the LLR account. Wealthy early retirees without the LLR are especially exposed it. 
4. The marginal tax rate on regular income is increasing from $34 \%$ to $52 \%$. Except for the very rich and very poor the effective tax rate on the deferred payments $A_{s}\left(L_{62}\right)$ will be substantially less than on the contributions $\ell_{s} Y_{s}$.

Contributions to the LLR account are limited to $12 \%$ of labor income per year. Also, no further contributions can be made when the account is larger that $210 \%$ of income,

$$
\begin{aligned}
0 \leq \ell_{s} & \leq 0.12 \\
\ell_{s} & =0 \quad \text { if } L_{s-1} \geq 2.1 Y_{s-1} .
\end{aligned}
$$

To get an intuition for the LLR-contribution period, consider an individual who wants to acquire $210 \%$ of his annual wage. If he saves at the upper bound of LLR contributions of $12 \%$, it takes him 15 to 20 years. The exact time period depends on a range of parameters as labor income and return on the LLR fund. ${ }^{1}$

A number of additional inequality constraints limit the choice of the individual. First, we assume that the individual cannot borrow against future labor income, such that liquid wealth $W_{s}$ must always be non-negative. The liquidity constraint forces individuals to retain a positive amount of financial wealth. In case of uncertain labor income, individuals with low initial wealth and/or labor income and/or high income uncertainty are less likely to participate in the LLR because of the precautionary savings motive. The LLR is more restrictive, since the money in the account cannot be used to smooth out temporary income shocks. Once a sufficient wealth and/or income level is attained the LLR becomes a feasible option and participation then depends on the intensity of the financial advantages and especially the preference for leisure. The tax credit and the wealth tax excepted nature of the LLR account, make the LLR account the preferred account from a return perspective.

The tax advantage of LLR participation can be large, but cannot compensate the loss of three years of labor income. To engage in the LLR the individual therefore needs to have a preference for leisure $X(\theta)$, which must be large enough to accept the financial loss. In 1994, 50\% of the male Dutch were retired at the age of 60 (Kapteyn and de Vos 1998), indicating a strong preference for leisure at least when subject to the generous "VUT". According to Hurst (2003), preferences for leisure are related to age, marital status and work related factors. Mastrogiacomo et al. (2004) have shown that retirement decisions are highly dependent among household-partners in the Netherlands and that singles and couples behave differently. They report that single household heads have higher transition rates into early retirement than household heads that have a partner despite the financial disadvantages of the former over the latter. Thus, singles seem to have a higher preference for leisure at retirement.

\footnotetext{
${ }^{1}$ Solving this model, requires numerical optimization and many more assumptions as shown in the previous chapter.
} 
The reduced form of the LLR-participation decision will depend on income $Y_{t}$, wealth $W_{t}$, leisure preference characteristics $\theta\left(X_{t}\right)$ as well as the current age $t$.

$$
\ell_{t}=f\left(t, Y_{t}, W_{t}, \theta\left(X_{t}\right)\right)
$$

Wealth and wage both empirically have a positive effect on the probability to engage in the LLR because of liquidity constraints. Age will also have a positive effect, since individuals are commonly impatient and therefore prefer consumption rather today than tomorrow. Derived from the findings of Mastrogiacomo et al. (2004), we expect the marital status to have a negative effect on the LLR participation decision. The sign of the age coefficient in leisure preference is somewhat ambiguous. However, there is evidence that it increases over age (Gustman and Steinmeier 2005). The assumptions that our model hinges on are thus the financial incentives and that individuals have to work at least until age 62 . Leisure is only able to affect utility in early retirement years.

\subsection{Data}

This research relies on cross-sectional data from 2006, which includes individuals who work in the civil service sector in the Netherlands, a total of 779,570 observations. We drop individuals, whose age, gender, birth year or income is unknown (2754) and those who were born before or in 1950 (another 97,215). We exclude those born before or in 1950 because they are still entitled to the VUT, which renders the LLR hardly useful for them. Furthermore, we drop employees of the fire brigade (5745) as different retirement patterns apply to these employees and their employer strongly encourages LLR participation by setting the default to participation, yielding a participation rate of $96 \%$. We have information on gross annual wages, hours of work per week, employer, age, presence of partners, area of residence, when they received an LLR-information package, the type of LLR-information package, LLR participation and the asset allocation within the LLR account. The hours of work per week are important because we have to acknowledge the possibility that part-time workers have another job outside the civil service sector, which we do not know. Thus, we only observe the wage that an individual earns within the civil service sector and have no information about household income.

Additional to this data set, we obtained income-ZIP-code profiles from 2005 from the Central Bureau of Statistics in the Netherlands for most of the ZIP-codes. We take this information as a proxy for wealth in order to complement the wage measures because income and wealth are closely linked. Missing income-postcode profiles and unknown sectors lead to dropping another 65,656 observations. Lastly, we drop those whose annual income exceeds $€ 200,000$ or is $€ 0$ (59) because they are untypical in the civil service sector. This results 
in 608,151 observations.

\begin{tabular}{|c|c|c|c|c|c|}
\hline AGE & $\% \mathrm{LL}$ & $\mathrm{N}$ & INCOME & $\% \mathrm{LL}$ & $\mathrm{N}$ \\
\hline$<25$ & 5.16 & 16232 & $<10$ & 4.56 & 241 \\
\hline$[25,30)$ & 4.85 & 43674 & {$[10,20)$} & 6.77 & 8494 \\
\hline$[30,35)$ & 5.47 & 52233 & {$[20,30)$} & 3.70 & 106489 \\
\hline$[35,40)$ & 5.49 & 64002 & {$[30,40)$} & 5.51 & 157883 \\
\hline$[40,45)$ & 5.65 & 84022 & {$[40,50)$} & 8.79 & 134106 \\
\hline$[45,50)$ & 6.94 & 106023 & {$[50,60)$} & 8.98 & 45980 \\
\hline$[50,55)$ & 9.10 & 108220 & {$[60,70)$} & 11.44 & 12741 \\
\hline \multirow[t]{6}{*}{$\geq 55$} & 42.16 & 1008 & {$[70,80)$} & 12.19 & 5061 \\
\hline & & & {$[80,90)$} & 13.82 & 1831 \\
\hline & & & {$[90,100)$} & 12.56 & 788 \\
\hline & & & {$[100,110)$} & 10.02 & 549 \\
\hline & & & {$[110,120)$} & 6.84 & 351 \\
\hline & & & $\geq 120$ & 6.11 & 900 \\
\hline \multicolumn{3}{|l|}{ GENDER } & PARTNER & & \\
\hline Male & 8.76 & 229306 & Yes & 7.49 & 324555 \\
\hline Female & 4.72 & 246108 & No & 4.91 & 150859 \\
\hline TOTAL & 6.67 & 475414 & & & \\
\hline
\end{tabular}

For each category the table reports the percentage of people who participate in the Levensloopregeling (\%LL) and the number people that are in this category $(\mathrm{N})$. Income is in thousands of euro per year. We only consider the response to the first offer.

Table 5.1: Descriptives: LLR Participation

Table 5.3 gives a first impression about LLR participants. We are only looking at the result of the first offer that people received, which reduces the data set further to 475,414 observations. LLR participation increases with age until it peaks in age category $[50,55)$ as expected. This oldest age group is close to retirement but is not entitled to the VUT anymore. As a transition measure they are allowed to cross the $12 \%$ upper bound on yearly premia. Almost half of them react with a positive response to the first offer. The youngest group constitutes an outlier because their motive to engage in the LLR is probably a sabbatical or maternity leave. As survey results from NIBUD (2007) show, there are about $27 \%(36 \%)$ of the Dutch population (women) that participates in LLR because of maternity leave. The majority, $67 \%$, invest with the goal to retire early. The percentage of LLR participants by income behaves similar to the one by age. Ignoring the first two income categories, the participation rate is hump-shaped and peaks in income category $[80,000 ; 90,000)$. 
Moving on to the gender categories in Table 5.3, it is striking to find women participating only half as much as men. Barber and Odean (2001) have shown that men prefer riskier and higher turnover investments compared to women. Further evidence for higher participation rates in pension plans of women stems from Huberman, Iyengar and Jiang (2007). Their results show that women are $6.5 \%$ more likely to participate in $401(\mathrm{k})$ plans than men. As the LLR is rather characterized to be a low turnover investment and a pension plan, it should suit women's preferences more than men's. The part-time factor is very likely to play a role in our descriptive counterintuitive evidence. Women with a low part-time factor are financially more constrained and might not be able to participate in the LLR. We will therefore continue with the results of the regression analysis, where we can control for various factors and return to this issue later.

\subsection{The LLR-Participation Decision empirically}

In the empirical analysis we run cross-sectional regressions to estimate the reduced form participation behavior of individuals in the first year that the life-course arrangement was operating. The dependent variable $I_{i}$ is equal to one if individual $i$ participates and zero otherwise. We run a Probit of the following form:

$$
\begin{aligned}
I_{i}= & \alpha_{0}+\alpha_{1} \ln \left(\text { wage }_{i}\right)+\alpha_{2} \text { age }_{i}+\alpha_{3} \text { age }_{i}^{2}+\alpha_{4} \text { age }_{i} \ln \left(\text { wage }_{i}\right)+\alpha_{5} \text { age }_{i}^{2} \ln \left(\text { wage }_{i}\right)+ \\
& +\alpha_{6} \ln \left(W_{i}\right)+\alpha_{7}^{\prime} Z_{i}+\epsilon_{i} .
\end{aligned}
$$

The functional form for the age and wage effects has been obtained by a preliminary specification search, where the interaction between the two variables proved to be an important element. This interaction can also be explained by a life-cycle model; people with higher income may reach the precautionary wealth buffer at younger ages than low income individuals.

To control for various other influences, we add a number of control dummies $Z_{i}$. Among these is the type of LLR-information package that the individual received, the sector he works in and GDP per capita of the year when he was 22 years old. As Browning and Lusardi (1996) note, the level of per capita income at age 22 can serve as a proxy for cohort effects when analyzing savings behavior. To avoid a potential bias arising from unobserved additional wages, we a include part-time dummy if people work less than $60 \%$.

The model does not account for all aspects of the LLR-participation decision. The first simplification we make is to ignore the SLR in the participation decision. Since the SLR has an upper bound on its contributions of $€ 613$ and its savings become liquid after four years, the people who chose the SLR are not the ones with an early retirement motive, which is the subject of our interest. Therefore, we do not expect a bias from this simplification. Another 
simplification we undertake is to assume that the decision to participate in the LLR and the decision in which LLR product to invest conditional on participation are independent as we analyze them separately.

In order to disentangle the effects that play a role in Table 5.3, we estimate (5.7) as a probit for the whole sample. The reference group are the full-time male employees at the national government.

\begin{tabular}{|c|c|c|c|c|c|c|}
\hline \multirow[t]{2}{*}{$\overline{\text { Variable }}$} & \multicolumn{2}{|c|}{ "Regression All } & \multicolumn{2}{|c|}{ "Regression $\geq 45$} & \multicolumn{2}{|c|}{ Regression $\geq 45$} \\
\hline & Coef & T-Ratio & Coef & T-Ratio & Coef & T-Ratio \\
\hline log_inc & 3.59 & 16.37 & 0.68 & 0.13 & 0.67 & 38.84 \\
\hline age & 1.25 & 11.27 & -0.14 & -0.06 & -0.32 & -3.53 \\
\hline age2 & -0.01 & -9.98 & 0.00 & 0.01 & 0.00 & 3.90 \\
\hline ageloginc & -0.13 & -12.25 & -0.02 & -0.08 & & \\
\hline age $2 \operatorname{loginc}$ & 0.00 & 11.06 & 0.00 & 0.16 & & \\
\hline log_wealth & 0.03 & 1.06 & 0.00 & 0.12 & 0.00 & 0.12 \\
\hline log_cohortgdp & 0.03 & 1.74 & 0.14 & 2.62 & 0.13 & 2.49 \\
\hline dumless60 & -0.28 & -3.55 & -0.26 & -2.42 & -0.26 & -2.45 \\
\hline gender & 0.06 & 8.68 & 0.07 & 6.58 & 0.07 & 6.59 \\
\hline $\begin{array}{l}\text { partner } \\
\text { controls }\end{array}$ & -0.11 & -13.57 & -0.09 & -6.87 & -0.09 & -6.85 \\
\hline $\mathrm{R}^{2}$ & 0.15 & & 0.20 & & 0.20 & \\
\hline $\mathrm{N}$ & 475414 & & 215251 & & 215251 & \\
\hline
\end{tabular}

Table 5.2: Regression Results: LLR Participation

This table contains the coefficient estimates and their T-Ratios from regression equation (5.7). Columns 1-2 contain the results based on the whole sample; Columns 3-4 those based on the sample that is restricted to people older than or equal to 45; Columns 5-6 those based on the sample that is restricted to people older than or equal to 45 but without agewage interaction terms. In all cases we only consider the response to the first offer. See Appendix for the complete regression output.

The left half of Table 5.4 shows the results of our reduced form model. The coefficients of age and age*wage from this regression help us to calculate the change of the likeliness to participate due to changes in age for given wage:

$$
\begin{aligned}
\text { age effect }= & \phi\left(\boldsymbol{\alpha} \mu\left(\boldsymbol{X}_{\boldsymbol{i}}\right)\right)\left(\alpha_{2}+\alpha_{3} \text { age }+\alpha_{4} \ln (\text { wage })+2 \alpha_{5} \text { age } \ln (\text { wage })\right), \\
& \text { for wage }=\{10,000,20,000, \ldots, 110,000,120,000\} \\
& \text { for age }=\{20,30,40,50,60\},
\end{aligned}
$$

where $\phi$ is the standard normal density, $\boldsymbol{\alpha}$ the column vector coefficients and $\mu\left(\boldsymbol{X}_{\boldsymbol{i}}\right)$ the row vector of explanatory variable means.

The graph resulting from (5.8) is plotted in Figure 5.1 for a single full-time male employees. For each age, we plot the age effect by income. Positive values imply an increase in the chance to participate. A positive slope implies that this positive impact becomes stronger 


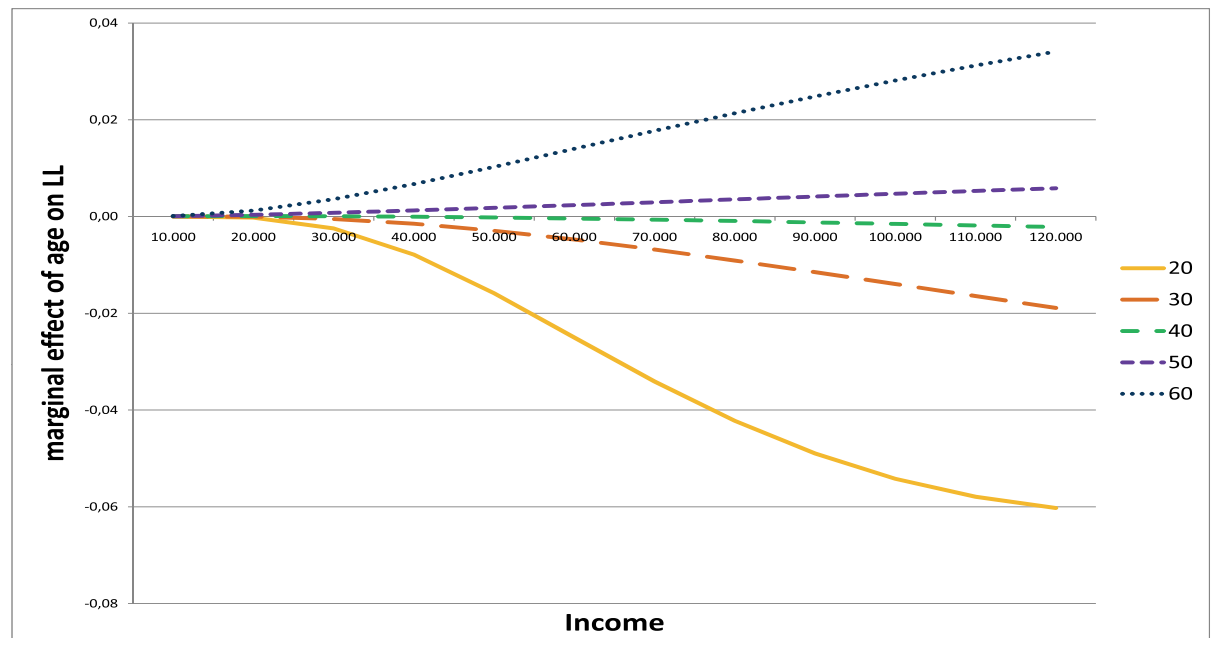

Figure 5.1: Age Effect on LLR Participation by Income

This figure plots the marginal effect of age on the likeliness to participate in the LLR. Given the outcome of regression (5.7) for the whole sample, we compute the marginal effects according to (5.8). They are conditioned on specific age $(20,30,40,50,60)$ and income $(10,000 ; 20,000 ; \ldots ; 120,000)$ levels. The lightest line (solid yellow) depicts the age effect for the youngest people (age 20); the darkest (dotted blue) depicts the age effect for people who are 60 years old.

as income increases. We can observe this effect for older people (dark lines). However, for people younger than 40 (light lines), the age effect on participation is negative and downward sloping in income. Under the assumption of early retirement motivation, this negative relationship does not make sense. If, however, the motive for the LLR participation was maternity leave or a sabbatical, it is straightforward that one is less likely to participate the older one becomes. We will thus reestimate (5.7), excluding individuals who are younger than 45 years. $^{2}$

Based on the estimates in middle half of Table 5.4, which exclude everyone younger than 45, we can calculate the new age effect on participation. This is depicted in Figure 5.2. Again, the lightest line (light green) depicts the age effect of the youngest in this sample (age 45) and the darker ones the ones of the older people. In contrast to Figure 5.1, there are hardly any negative age effects in Figure 5.2. Thus everyone's likeliness to participate in the LLR increases with age. The reason for this difference hence lies in the motives for LLR. It is typically the younger generation that saves for a sabbatical or maternity leave, and the elderly that save for the latter motive. Once we eliminate the youngest and hence most of the sabbatical motive of the LLR, we see the positive age effect on LLR participation which supports the early retirement motive. Thus, savings motives evidently

\footnotetext{
${ }^{2}$ We picked age 45 , because this is the first age that renders the age* wage interactions insignificant.
} 
Chapter 5 Analysis of a Reform in Dutch Early Retirement Arrangements

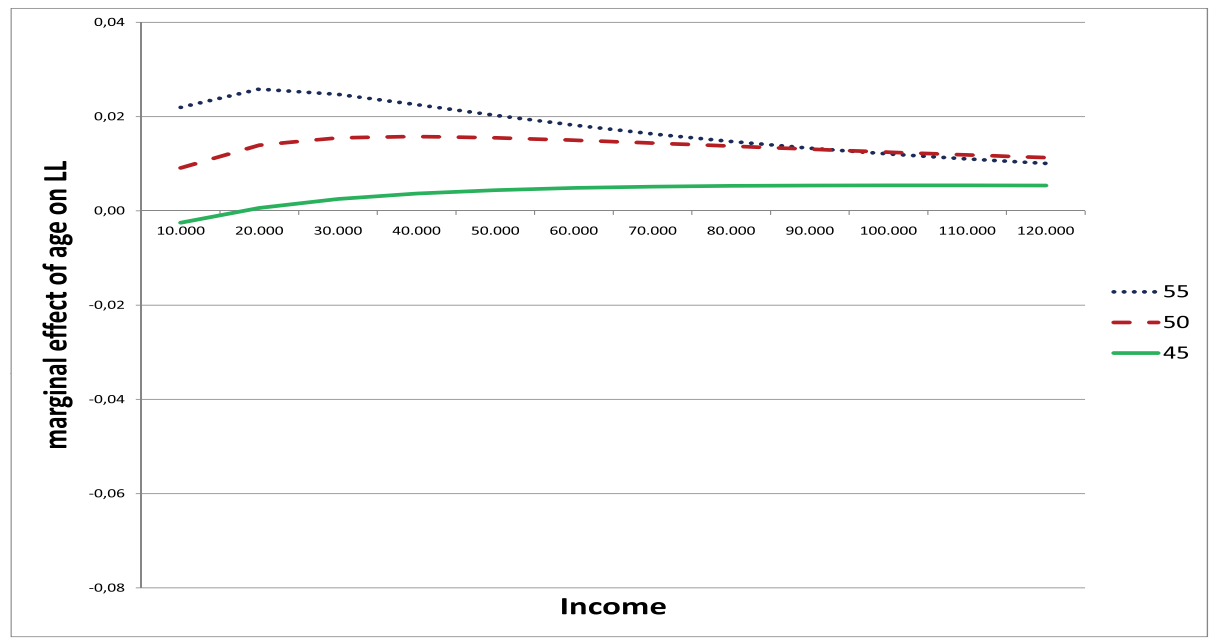

Figure 5.2: Age Effect on LLR Participation by Income

This figure plots the marginal effect of age on the likeliness to participate in the LLR. Given the outcome of regression (5.7) for the sample that is restricted to people being older than or equal to 45 , we compute the marginal effects according to (5.8). They are conditioned on specific age $(45,50$, 55 and income $(10,000 ; 20,000 ; \ldots ; 120,000)$ levels. The lightest line (solid green) depicts the age effect for the youngest people (age 45); the darkest (dotted blue) depicts the age effect for people who are 55 years old.

play a big role in the analysis of LLR participation. The second observation to be made is that, prior to an income of $€ 85,000$ the lines become darker from the bottom to the top as in the previous figure. Thus, people are more likely to participate in the LLR the older they become. The last observation to be made is that for people younger than 50 , the age effect becomes stronger the higher their income. For the people older than 50, the age effect becomes weaker the higher their income.

As we are interested in decisions that individuals take with respect to retirement, we ignore the youngest generation in the rest of this section and focus on individuals older than 45 to circumvent the sabbatical motive. The results of the reestimation of (5.7) without the interaction terms and without the young people are presented in the right half of Table 5.4. Most variables are significant at a $1 \%$ significance level. Higher wages and getting older, yield a higher LLR-participation probability, as predicted by our structural life-cycle model and supported by Figure 5.2. The higher the salary, the looser the liquidity constraint, and hence one can afford to put money into the LLR. The elderly are more likely to participate, because it is more urgent for them to finance their early retirement if desired. The cohort effect is positive, indicating that people who started working at higher per capita income levels (the younger cohorts) are more inclined to save (via the LLR). Wealth is insignificant 
in our analysis, indicating that wage levels are more present in individuals' minds. The part-time dummy is negative. For part-timers the additional leisure during retirement is less than for full-timers. Thus, their preference for additional leisure may be smaller and reduce the probability to participate in the LLR. Moreover, we find that individuals with a partner are more likely to engage in the LLR as indicated by the descriptive evidence in Table 5.3. Once we correct for income and part-time effects, we see females having a higher probability of participating than their equivalent males.

\subsection{The LLR-Investment Decision in a Life-Cycle Framework}

Conditional on participation, individuals have to chose between three products that the LLR offers: a bond fund, a life-cycle fund and an equity fund. The prospective clients receive brochures via regular mail and email or find the necessary information about the LLR and its products online. From a risk-return perspective, the general LLR brochure and the financial leaflets present the bond fund as the safest investment, yielding a predefined guaranteed return on the bond fund of approximately $4.5 \%$ in 2006 and 2007. The equity fund is described as a risky investment because capital is only invested in equity. This capital the individual cannot even be sure to receive back upon the end of the contract. People can download a mandatory risk leaflet, which placards the worst case scenario. The most complicated product is the life-cycle (LC) fund. It is designed such that the proportion of risky assets is decreased by the insurer towards the contract end. Contributions are guaranteed to the investor as a minimum return upon completion of his contract. Apart from the risk-return perspective, the insurer also draws the attention to the investment horizon. This moves especially the equity fund into a better light, which is now presented as being suitable for investment horizons of longer than eight years, depending on the individuals' risk preferences. For individuals, who aim at utilizing their LLR wealth after eight years and are rather risk averse, the bond fund is recommended. For intermediate cases, the LC fund is suggested.

Campbell and Viceira (2001) derive that investors should increase the position in safer assets (bonds) as the they get older and likewise have a larger position in riskier assets (stocks) when younger. These tendencies critically hinge on the assumption of riskfree (nontradable) human capital, which is equal to the expected discounted stream of labor income, and no or low correlation between shocks to unexpected stock returns and unexpected permanent labor income. In this case, labor income is treated as a riskfree asset and therefore reduces the proportion of safe assets (bonds). As soon as labor income carries too much risk, i.e. becomes an implicit risky asset, these optimal strategies break down and young and old individuals are better off tilting towards safer assets. 
Chapter 5 Analysis of a Reform in Dutch Early Retirement Arrangements

Benzoni, Collin-Dufresne and Goldstein (2007) elaborate on the repercussions of a correlation or even cointegration between human capital and the stock market. They find evidence for cointegration between the labor income and stock dividends for the years 1929 to 2004. Based on the latter assumption they set up a model, calibrate it closely in line with Campbell and Viceira (2001), and demonstrate that the age profile of stock market participation is rather hump shaped. In the early stage of life, people possess a lot of human capital, which is cointegrated with stock market returns. Due to this characteristic, individuals are overly exposed to risk and should compensate by going short in stocks and long in bonds early in life. As they get older, their human capital decreases and hence their risk exposure, which should then be compensated by reducing the amount of bonds and likewise increase the amount of stock.

Given the special, quite secure nature in the civil service sector we expect the size of the correlation between labor income and stock returns to be negligible and hence to find evidence in favor of Campbell and Viceira (2001).

\subsection{The LLR-Investment Decision empirically}

Following the argument in the previous section, we expect that the position of the bond fund should increase and the position of the equity fund decrease with age in the LLR account. As the LC fund is a life-cycle product that is adjusted automatically it should be invariant to age. Table 5.3 below reports the percentage of individuals holding a positive fraction of a certain LLR product by age. It demonstrates that our descriptives are, apart from the middle column, in line with life-cycle theory.

The first column of Table 5.3 refers to the safest LLR product, the bond fund. The fraction of individuals holding the bond fund is increasing with age by approximately $140 \%$ : starting with youngest participants with $40 \%$ and increasing up to $99 \%$ for the 55 year olds. Furthermore, note that the means from all but the youngest are statistically different from the means of the next age groups. Thus, the proportion of bond-fund holders increases significantly. Looking at the means for the riskiest product, we can firstly observe that hardly anyone invests in this fund. Next, we see the proportion of equity-fund holders to decrease with age as suggested by life-cycle theory. It amounts to a reduction of about $80 \%$ between age 45 and age 55 . The life-cycle fund also exhibits a downward trend of about $95 \%$ and hence behaves opposite to the age invariant nature as suggested by life-cycle theory. If individuals understood this product, they would not alter this position with age. We will investigate the partial effect of age in the regression analysis further below.

Table 5.4 is the counterpart to Table 5.3, presenting the fraction of individuals having a positive position in the respective product by wage. There are hardly any trends visible. 


\begin{tabular}{lllll}
\hline \hline Age & $\begin{array}{l}\text { bond fund }>0 \\
100 \% \text { bonds }\end{array}$ & $\begin{array}{l}\text { LC fund }>0 \\
\text { bonds and stocks }\end{array}$ & $\begin{array}{l}\text { equity fund }>0 \\
100 \% \text { stocks }\end{array}$ & $\mathrm{N}$ \\
\hline 45 & 0.404 & 0.764 & 0.057 & 1266 \\
46 & 0.389 & $0.776^{*}$ & 0.055 & 1372 \\
47 & 0.418 & 0.750 & $0.056^{* *}$ & 1490 \\
48 & $0.424^{* * *}$ & $0.739^{* *}$ & 0.041 & 1530 \\
49 & $0.469^{* * *}$ & $0.702^{* * *}$ & 0.035 & 1704 \\
50 & $0.522^{* * *}$ & $0.645^{* * *}$ & 0.027 & 1869 \\
51 & $0.616^{* * *}$ & $0.524^{* * *}$ & $0.022^{* *}$ & 1923 \\
52 & $0.707^{* * *}$ & $0.405^{* * *}$ & 0.012 & 2010 \\
53 & $0.777^{* * *}$ & $0.311^{* * *}$ & 0.010 & 2076 \\
54 & $0.906^{* * *}$ & $0.153^{* * *}$ & 0.006 & 1970 \\
55 & $0.986^{* * *}$ & $0.033^{* * *}$ & 0.012 & 425 \\
\hline all LL part & 0.596 & 0.537 & 0.029 & 17635 \\
\hline \hline
\end{tabular}

Table 5.3: Descriptives: Product Choice of LLR Participants by Age Categories

This table contains the percentage of participants, who are older than or equal to 45, investing in one of the three LLR fund products by age $(N=17,633)$. Column 1 contains the percentage of participants investing in the bond fund; Column 2 those investing in the LC fund; and Column 3 those investing in the equity fund. ${ }^{* * *} \mathrm{p}<0.01,{ }^{* *} \mathrm{p}<0.05$, and ${ }^{*} \mathrm{p}<0.10$ indicate the significance level of the difference between the respective mean and its successor. We only consider the response to the first.

\begin{tabular}{lllll}
\hline \hline income & $\begin{array}{l}\text { bond fund }>0 \\
100 \% \text { bonds }\end{array}$ & $\begin{array}{l}\text { LC fund }>0 \\
\text { bonds and stocks }\end{array}$ & $\begin{array}{l}\text { equity fund }>0 \\
100 \% \text { stocks }\end{array}$ & $\mathrm{N}$ \\
\hline$<10$ & 0.333 & 0.833 & $0.000^{* * *}$ & 6 \\
{$[10,20)$} & 0.563 & 0.571 & 0.045 & 112 \\
{$[20,30)$} & $0.501^{* * *}$ & $0.604^{* * *}$ & $0.019^{* * *}$ & 1034 \\
{$[30,40)$} & $0.567^{* * *}$ & $0.552^{* * *}$ & 0.034 & 3172 \\
{$[40,50$} & $0.633^{* * *}$ & $0.499^{* * *}$ & $0.032^{* * *}$ & 8359 \\
{$[50,60)$} & 0.568 & 0.578 & 0.017 & 3020 \\
{$[60,70)$} & 0.591 & $0.554^{*}$ & 0.023 & 1047 \\
{$[70,80)$} & 0.570 & 0.602 & $0.038^{* *}$ & 495 \\
{$[80,90)$} & 0.581 & 0.557 & $0.014^{*}$ & 210 \\
{$[90,100)$} & 0.618 & $0.579^{*}$ & 0.066 & 76 \\
{$[100,110)$} & 0.500 & $0.727^{* *}$ & 0.023 & 44 \\
{$[110,120)$} & 0.667 & 0.389 & 0.056 & 18 \\
$\geq 120$ & 0.548 & 0.595 & 0.024 & 42 \\
\hline all LL part & 0.596 & 0.537 & 0.028806 & 17635 \\
\hline \hline
\end{tabular}

Table 5.4: Descriptives: Product Choice of LLR Participants by Wage Categories

This table contains the percentage of participants, who are older than or equal to 45 , investing in one of the three LLR fund products by thousands of income $(N=17,633)$. Column 1 contains the percentage of participants investing in the bond fund; Column 2 those investing in the LC fund; and Column 3 those investing in the equity fund. ${ }^{* * *} \mathrm{p}<0.01,{ }^{* *} \mathrm{p}<0.05$, and ${ }^{*} \mathrm{p}<0.10$ indicate the significance level of the difference between the respective mean and its successor. We only consider the response to the first. 
The bond position seems to increase slightly while mixed fund position decreases slightly. The equity position remains very low.

To disentangle all effects, we turn to regression analysis. Except for the age wage interaction terms, the explanatory variables are the same as in (5.7). Some control variables are dropped due a lack of observations in some categories. The LLR participant has to decide upon investing in the three fonds simultaneously. Since the allocations are related, we estimate the likeliness to hold the respective LLR product as a multivariate probit model, which allows for correlation among the residuals of the three equations:

$$
\begin{aligned}
I_{i j}= & \alpha_{0 j}+\alpha_{1 j} \ln \left(\text { wage }_{i}\right)+\alpha_{2 j} a g e_{i}+\alpha_{3 j} a g e_{i}^{2}+\alpha_{6 j} \ln \left(W_{i}\right)+\alpha_{7 j}^{\prime} Z_{i}+\epsilon_{i j} \\
& \text { for } j=\{\text { bond fund, LC fund, equity fund }\}
\end{aligned}
$$

To analyze the age effect, we calculate the total effect for a full-time male employee according to (5.10) and plot the likeliness to invest in a certain product due to changes in age in Figure 5.3.

$$
\text { age effect }=\phi\left(\boldsymbol{\alpha} \mu\left(\boldsymbol{X}_{\boldsymbol{i}}\right)\right)\left(\alpha_{2}+2 \alpha_{3} \text { age }\right),
$$

where $\phi$ is the standard normal density, $\boldsymbol{\alpha}$ the column vector coefficients and $\mu\left(\boldsymbol{X}_{\boldsymbol{i}}\right)$ the row vector of explanatory variable means.

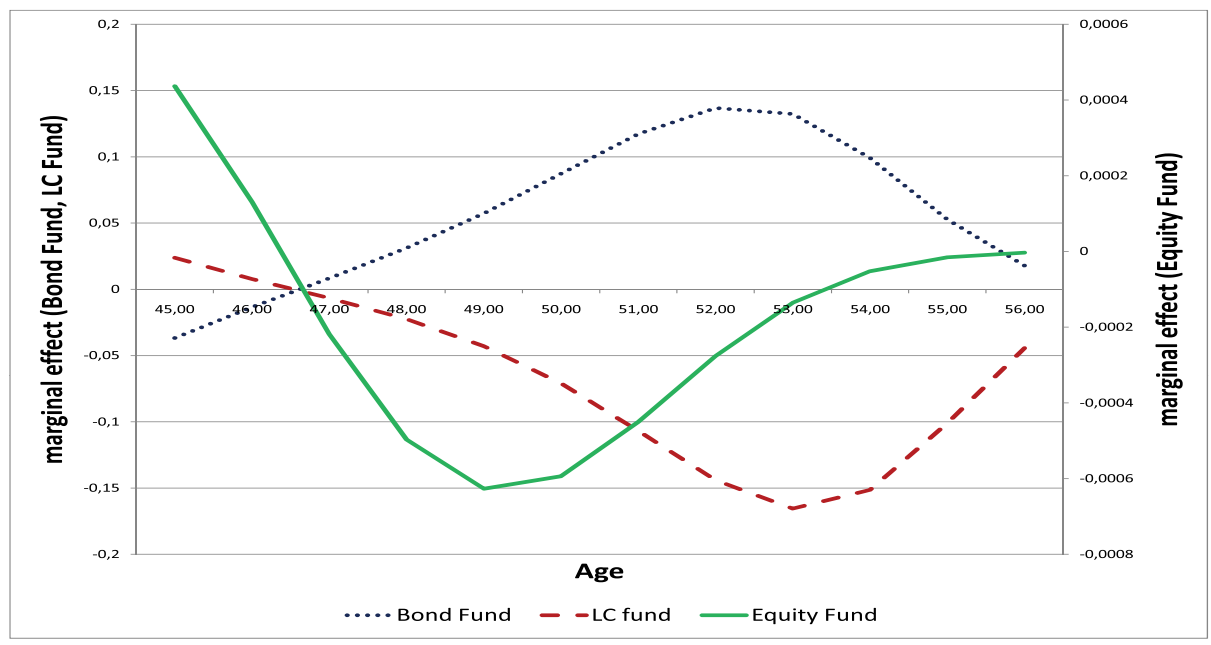

Figure 5.3: Age Effect on Product Positions

This figure plots the marginal effect of age on the likeliness to invest in the bond fund, the LC fund and the equity fund. Given the outcome of regression (5.9) for the sample that is restricted to people being older than or equal to 45, we compute the marginal effects according to (5.10). They are conditioned on specific age $(45,50,55)$ levels. The marginal effect with respect to the equity fund is depicted on the right y-axis due to its small scale in comparison to the effects on other two funds. 
The likeliness to invest in the bond fund the older one is is positive as of age 47 as the dotted blue line illustrates. Thus, there is an increasing number of people older than 47 who invest in the bond fund. As it is upward sloping until age 52, the effect becomes stronger the older the people. Consequently, the chance that a 52 year old invests in the bond fund is much larger than that of a 47 year old. After age 52 the adjustment process slows down. Because of the decreasing human capital over age, the LLR participants' choice to invest more in bonds the older they become adheres to standard life-cycle theory. The results of the equity fund are the opposite and hence also in line with life-cycle theory. The equity fund (solid green line) lies in the negative quadrant as of age 47, indicating the people are less likely to invest in the equity fund the older they become and it is downward sloping until age 49, indicating that the this trend becomes more extreme. The adjustment slows down again thereafter. Overall, the elderly decrease their risk exposure as a response to fewer riskless human capital. Contrary to life-cycle theory, the people are less likely to invest in the LC fund as they age as the dashed red line visualizes. It is mostly negative and downward sloping as the equity fund although it is constructed as an age invariant fund. Again, the LLR participants do not seem to understand this product.

The coefficient of the logarithm of wage in Table 5.5 is positively significant at the $1 \%$ level for the bond and the equity fund. We also find a positive but insignificant income effect for the LC fund. As the likeliness to invest in all funds increases with income, people spread their LLR contributions more the more they earn but unrelated to the level of implicit risk in their human capital. According to the behavioral finance literature, there is a difference in selected risk-exposure between men and women. Based on an American Online Broker Account data set Barber and Odean (2001) conclude that men are more prone to risky investments and higher turnover than women. Our research indicates that this tendency also holds for the Netherlands and choice of pension investments. As Table 5.5 demonstrates, Dutch females in the civil service sector are also in favor of safer assets while the males have a higher chance to allocate some LLR wealth to the LC fund.

Until now we have shown that our sample behaves in accordance with the life-cycle model regarding the holdings of a risky and safe asset but fails to meet the life-cycle model implications concerning the holdings of the LC product. We continue by investigating the portfolio weights of individuals' LLR accounts. We estimate least squares regressions simultaneously for the LLR products to supplement our previous findings:

$$
\begin{aligned}
y_{i j}= & \alpha_{0 j}+\alpha_{1 j} \ln \left(\text { wage }_{i}\right)+\alpha_{2 j} a g e_{i}+\alpha_{3 j} a g e_{i}^{2}+\alpha_{6 j} \ln \left(W_{i}\right)+\alpha_{7 j}^{\prime} Z_{i}+\epsilon_{i j} \\
& \text { for } j=\{\text { bond fund, LC fund, equity fund }\}
\end{aligned}
$$

Due to the additivity property of our dependent variable, it will only be once estimated for the bond fund and the life-cycle fund and obtain the equity fund by the identity $\sum_{j} y_{i j}=1$. 
Chapter 5 Analysis of a Reform in Dutch Early Retirement Arrangements

\begin{tabular}{|c|c|c|c|c|c|c|}
\hline \multirow{2}{*}{$\begin{array}{l}\text { Variable } \\
\log \text { _inc }\end{array}$} & \multicolumn{2}{|c|}{ Bond Fund } & \multicolumn{2}{|c|}{ LC Fund } & \multicolumn{2}{|c|}{ Equity Fund } \\
\hline & 0.11 & 2.60 & 0.02 & 0.53 & 0.44 & 3.99 \\
\hline age & -3.12 & -13.61 & 3.10 & 14.88 & 1.88 & 3.24 \\
\hline age2 & 0.03 & 14.08 & -0.03 & -15.42 & -0.02 & -3.38 \\
\hline log_wealth & 0.00 & 0.01 & 0.07 & 0.84 & 0.03 & 0.15 \\
\hline log_cohortgdp & 0.52 & 4.28 & -0.41 & -3.44 & -0.47 & -1.63 \\
\hline dumless60 & -0.18 & -0.59 & 0.26 & 0.91 & 0.35 & 0.40 \\
\hline gender & 0.21 & 7.27 & -0.24 & -8.55 & -0.11 & -1.36 \\
\hline partner & -0.03 & -0.97 & 0.03 & 0.89 & 0.16 & 2.29 \\
\hline genderdumless60 & 0.02 & 0.13 & 0.00 & 0.03 & -0.24 & -0.57 \\
\hline partnerdumless60 & 0.10 & 0.70 & -0.19 & -1.36 & 0.16 & 0.36 \\
\hline sector_code2 & -0.03 & -0.18 & -0.20 & -1.05 & 1.45 & 3.05 \\
\hline sector_code3 & -0.11 & -1.73 & 0.07 & 1.21 & 0.64 & 2.26 \\
\hline sector_code4 & 0.16 & 0.44 & 0.36 & 0.97 & -1.15 & -1.33 \\
\hline sector_code5 & -0.18 & -0.52 & -0.25 & -0.72 & & \\
\hline sector_code6 & 0.03 & 0.45 & -0.08 & -1.32 & 0.71 & 2.33 \\
\hline sector_code7 & -0.08 & -0.77 & 0.08 & 0.79 & & \\
\hline sector_code8 & 0.18 & 1.27 & -0.26 & -1.89 & & \\
\hline sector_code9 & 0.05 & 0.60 & -0.16 & -1.88 & 0.68 & 1.68 \\
\hline sector_code11 & -0.03 & -0.27 & -0.06 & -0.52 & & \\
\hline sector_code15 & -0.41 & -2.49 & 0.27 & 1.57 & & \\
\hline sector_code17 & 0.32 & 5.13 & -0.33 & -5.43 & & \\
\hline sector_code1316 & -0.07 & -1.00 & 0.05 & 0.69 & & \\
\hline sector_code1214 & -0.06 & -0.79 & 0.09 & 1.22 & 0.42 & 0.99 \\
\hline offer_type4 & 0.33 & 0.77 & 0.40 & 1.01 & 0.51 & 0.38 \\
\hline offer_type5 & 0.76 & 1.77 & 0.06 & 0.16 & 0.39 & 0.32 \\
\hline offer_type7 & 0.80 & 1.86 & 0.10 & 0.26 & 0.75 & 0.57 \\
\hline offer_type8 & 0.69 & 1.58 & 0.26 & 0.65 & -2.28 & -0.02 \\
\hline offer_type9 & 0.74 & 1.65 & 0.13 & 0.32 & -2.28 & -0.01 \\
\hline offer_type11 & 1.33 & 2.70 & -1.06 & -2.27 & 1.92 & 1.85 \\
\hline offer_date & 0.00 & -1.51 & 0.00 & 1.73 & 0.01 & 2.21 \\
\hline constant & 84.59 & 6.09 & -89.81 & -6.58 & -179.63 & -2.90 \\
\hline $\mathrm{N}$ & 17,633 & & 17,633 & & 17,633 & \\
\hline
\end{tabular}

Table 5.5: Regression Results: Portfolio Position of LLR Participants

This table contains the coefficient estimates and their T-Ratios from multivariate probit regression equation (5.9) based on participants older or equal to 45. Columns 1-2 contain the results for likeliness to invest in the bond fund; Columns 3-4 those for the LC fund; Columns 5-6 those for the equity fund. In all cases we only consider the response to the first offer. Offer types $2-4$ relate to the birth cohorts; Offer type 5 refers to people for whom the LLR would be integrated with the pension; Offer types 6-7 are standard brochures without any additional savings suggestions; Offer types 8-9 are standard brochures with additional savings suggestions; Offer type 11 was sent to employees of the police. Industries $2,3,4,5,6,7,8,9,11,15,17,1316$ and 1214 refer to employees in the Military, Education, Police, Judiciary, Municipalities, Provinces, Water/Maintenance, Other, Voluntary Participants, University Teaching Hospitals, Energy/Utility/Water industry, Research/Science and Adult Education, and Academics and Higher Educational Services, respectively. 


\begin{tabular}{|c|c|c|c|c|c|c|}
\hline \multirow{2}{*}{$\begin{array}{l}\text { Variable } \\
\log \text { _inc }\end{array}$} & \multicolumn{2}{|c|}{ Bond Fund } & \multicolumn{2}{|c|}{ LC Fund } & \multicolumn{2}{|c|}{ Equity Fund } \\
\hline & 0.02 & 1.27 & -0.03 & -2.01 & 0.01 & 3.70 \\
\hline age & -0.73 & -12.17 & 0.68 & 11.42 & 0.05 & 4.49 \\
\hline age2 & 0.01 & 12.85 & -0.01 & -12.04 & 0.00 & -4.81 \\
\hline log_wealth & -0.02 & -0.78 & 0.02 & 0.80 & 0.00 & -0.04 \\
\hline log_cohortgdp & 0.06 & 1.59 & -0.02 & -0.53 & -0.04 & -5.48 \\
\hline dumless60 & -0.08 & -0.92 & 0.06 & 0.66 & 0.02 & 1.34 \\
\hline gender & 0.07 & 8.43 & -0.07 & -8.38 & 0.00 & -0.73 \\
\hline partner & 0.00 & -0.30 & 0.00 & -0.03 & 0.00 & 1.70 \\
\hline genderdumless60 & 0.02 & 0.48 & -0.01 & -0.22 & -0.01 & -1.35 \\
\hline partnerdumless 60 & 0.03 & 0.64 & -0.02 & -0.58 & 0.00 & -0.33 \\
\hline sector_code2 & 0.02 & 0.33 & -0.04 & -0.66 & 0.02 & 1.68 \\
\hline sector_code3 & -0.02 & -1.30 & 0.02 & 1.12 & 0.00 & 1.45 \\
\hline sector_code 4 & 0.01 & 0.11 & 0.06 & 0.53 & -0.08 & -3.33 \\
\hline sector_code5 & 0.03 & 0.34 & -0.03 & -0.33 & & \\
\hline sector_code6 & 0.03 & 1.47 & -0.03 & -1.64 & 0.00 & 1.17 \\
\hline sector_code7 & -0.01 & -0.35 & 0.01 & 0.34 & & \\
\hline sector_code8 & 0.07 & 1.60 & -0.07 & -1.61 & & \\
\hline sector_code9 & 0.04 & 1.76 & -0.05 & -1.84 & 0.00 & 0.35 \\
\hline sector_code11 & 0.02 & 0.47 & -0.02 & -0.48 & & \\
\hline sector_code15 & -0.09 & -1.86 & 0.09 & 1.85 & & \\
\hline sector_code17 & 0.12 & 6.55 & -0.12 & -6.56 & & \\
\hline sector_code1316 & -0.01 & -0.67 & 0.01 & 0.63 & & \\
\hline sector_code1214 & -0.01 & -0.51 & 0.01 & 0.45 & 0.00 & 0.30 \\
\hline offer_type4 & 0.08 & 0.60 & 0.02 & 0.18 & -0.10 & -4.04 \\
\hline offer_type 5 & 0.21 & 1.64 & -0.11 & -0.87 & -0.10 & -4.02 \\
\hline offer_type7 & 0.20 & 1.60 & -0.10 & -0.83 & -0.10 & -4.04 \\
\hline offer_type8 & 0.16 & 1.27 & -0.06 & -0.49 & -0.10 & -4.05 \\
\hline offer_type9 & 0.19 & 1.41 & -0.09 & -0.65 & -0.10 & -3.97 \\
\hline offer_type11 & 0.46 & 2.98 & -0.45 & -2.97 & -0.01 & -0.19 \\
\hline offer_date & 0.00 & -1.92 & 0.00 & 1.69 & 0.00 & 1.28 \\
\hline constant & 23.69 & 5.61 & -20.92 & -5.00 & -1.77 & -2.18 \\
\hline $\mathrm{R}^{2}$ & 0.25 & & 0.25 & & 0.04 & \\
\hline $\mathrm{N}$ & 17,633 & & 17,633 & & 17,633 & \\
\hline
\end{tabular}

Table 5.6: Regression Results: Portfolio Weights of LLR Participants

This table contains the coefficient estimates and their T-Ratios from SURE regression equation (5.11) based on participants older or equal to 45. Columns 1-2 contain the results for likeliness to invest in the bond fund; Columns 3-4 those for the LC fund; Columns 5-6 those for the equity fund. In all cases we only consider the response to the first offer. For additional table notes see Table 5.5. 
Again, note that some control variables have been dropped due a lack of observations in some categories. The regression results can be found in Table 5.6.

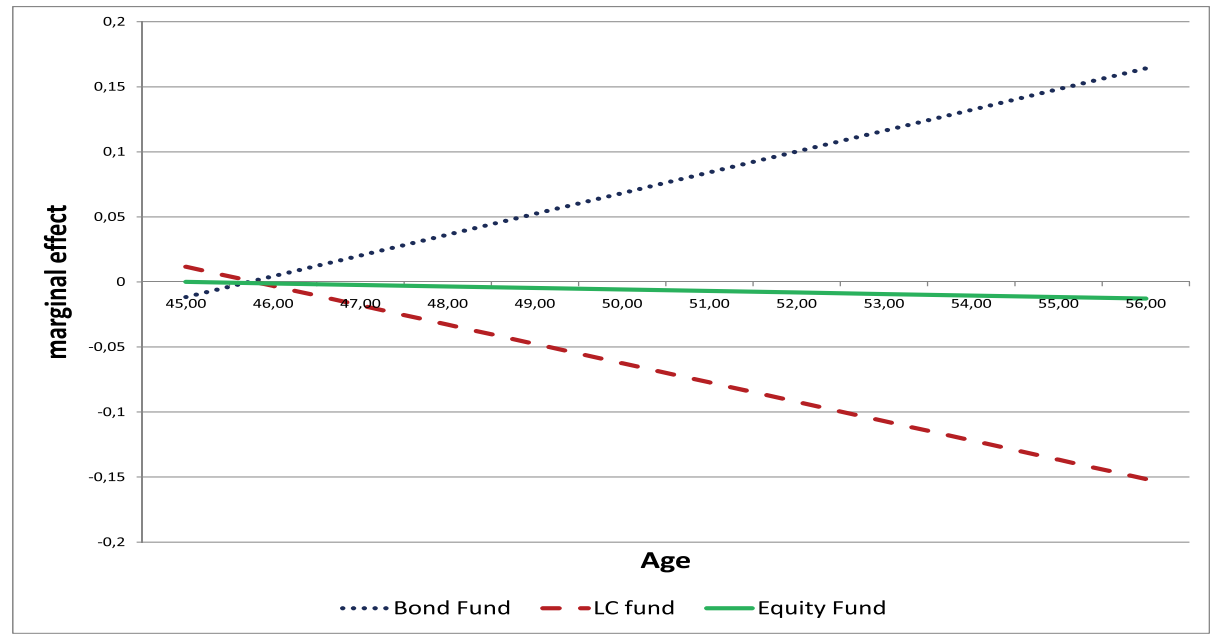

Figure 5.4: Age Effect on Portfolio Weights

This figure plots the marginal effect of age on the likeliness to invest in the bond fund, the LC fund and the equity fund. Given the outcome of regression (5.11) for the sample that is restricted to people being older than or equal to 45 , we compute the marginal effects. They are conditioned on specific age $(45,50,55)$ levels.

Figure 5.4 plots the age effect derived from the regression coefficients on the portfolio weights of the three funds. The dotted blue line is in the positive quadrant, which therefore provides evidence for individuals to tilt towards safer products as they age. As in Figure 5.3, it is also upward sloping, indicating that this effect becomes more extreme as people age until age 55. The LC fund (dashed red) and the equity fund (solid green) are predominantly in the negative quadrant, implying that these weights decrease with people's age. Both funds are downward sloping as in Figure 5.3. We come to the same conclusion as before. The LLR participants do not behave according to life-cycle theory when it comes to the LC fund.

The previous results suggest that individuals do not understand the age-invariant nature of the life-cycle product. Viceira (2008) has recently elaborated on the augmentation of Markowitz' Theory to modern long term strategic asset allocation by relaxing the assumptions of constant risk and return on investment opportunities and the independence between wealth and income. From relaxing these assumptions, it follows that there is no unique optimal portfolio for all investors as Markowitz and the mutual fund theorem imply. There is rather one for each investor, which depends on the investor's age and risk preferences. He discusses the implications from several theoretical and empirical life-cycle studies with regard to individuals' 401(k) portfolio (mis-) allocations and encourages setting 
the default fund to a life-course fund. Furthermore the life-course fund should offer some alteration possibilities depending on the participants' risk preferences. Since our results indicated that individuals do not understand the life-cycle product, it would also be helpful for the Dutch to set the life-cycle fund as a default within the LLR and explain its nature better to people. Individuals can then still alter the allocation weights depending on their risk preferences.

Agnew, Balduzzi and Sunden (2003) investigate asset allocations in US 401(k) plans from a behavioral perspective and find that most people choose extreme positions, where extreme refers to the case that the portfolio consists of one asset type only. In their sample, around $48 \%$ of the people have no equity and around $22 \%$ have only equity. Hence, the minority, only around $30 \%$, diversifies to some extent. This behavior is clearly at odds with the standard life-cycle propositions. Benartzi and Thaler (2001) analyzed the use and usefulness of the heuristic " $1 / \mathrm{n}$ rule" in US 401(k) plans. Based on experiments with 401(k) plan owners and their real-life accounts, they notice that on average individuals increase their equity allocations with the number of available equity funds. The welfare costs are in some cases substantial but hard to interpret ex post as well as ex ante. As displayed in Table 5.7, our data constitutes some support for the Agnew et al.'s observed extreme positions and less for Benartzi and Thaler's heuristic rule.

\begin{tabular}{lcccc}
\hline \hline position & Bond fund & LC Fund & Equity Fund & Total \\
\hline 1 & 0.458 & 0.386 & 0.003 & 0.847 \\
0.5 & 0.078 & 0.078 & & 0.078 \\
0.5 & 0.001 & & 0.001 & 0.001 \\
0.5 & & 0.005 & 0.005 & 0.005 \\
neither full nor half & & & & 0.069 \\
\hline \hline
\end{tabular}

Table 5.7: Descriptives: Positions of LL participants

This table reports the fraction of participants older than $45(N=17,633)$, who choose certain portfolio weights. We only consider the response to the first offer.

More than $46 \%$ of our sample chooses an extreme position, where most of them decide in favor of the safe and a few for the riskiest only. Since a $100 \%$ position in the life-cycle fund does not count as non-diversified, the fraction of non-diversified portfolios in our sample is lower than in the US case. Around 39\% of the LLR participants invest in the LC fund. Given the obvious misunderstanding of the LC fund it is doubtful whether these $39 \%$ chose this product conscious of its diversification. About $8 \%$ of the LLR participants allocate their premia evenly over two of the products; $7 \%$ not according to typical weighting. These allocations imply that about $54 \%$, conscious or unconscious, diversify to some extent. 


\subsection{Conclusion}

This paper investigated whether individuals are capable of taking responsibility for financial retirement choices with the aid of the newly introduced life-course savings arrangement (Levensloopregeling) in the Netherlands. We set up a structural life-cycle model, which illustrates the trade-off between, on the one hand, leisure and tax advantages and, on the other hand, three years of working. It became clear that the preference for leisure need to be sufficiently high for individuals to engage in the LLR. Moreover, due to human capital considerations life-cycle models propose a shift towards safer investments, i.e. the bond fund in the LLR, the older one gets and likewise towards riskier investments, i.e. the equity fund, the younger one is and an age invariant investment behavior with regard to the LC fund.

We find savings motives to play an important role in the participation decision. Focusing on the early retirement motive, the empirical evidence from the reduced form largely supported the implications from theory. There are still not that many Dutch employees in the civil service sector, who participate in the LLR, but those who do, do so in accordance with the model predictions. Participation increases with age and wage after controlling for other effects. Most of their portfolio choices also comply with theory. Individuals invest less in the bond fund the younger they are. For the life-cycle fund and the equity fund it is exactly the opposite way around. The inconsistencies regarding the life-cycle fund may be brought about by the financial instruction leaflet of the product. The government made information leaflets mandatory that present the equity fund, for instance, as a highly risky investment and the LC fund as a risky investment. Financially illiterate individuals could take this information for granted and rather refrain from this product choice. Thus, we further have to help the individuals to understand the usefulness of the LLR and the characteristics of the life-cycle funds or set it as a default fund as Viceira (2008) suggests. 


\section{A Appendix A: Complete Regression Output of (5.7)}

\begin{tabular}{|c|c|c|c|c|c|c|}
\hline \multirow[t]{2}{*}{ Variable } & \multicolumn{2}{|c|}{ Regression All } & \multicolumn{2}{|c|}{ Regression $\geq 45$} & \multicolumn{2}{|c|}{ Regression $\geq 45$} \\
\hline & Coef & T-Ratio & Coef & T-Ratio & Coef & T-Ratio \\
\hline log_inc & 3.59 & 16.37 & 0.68 & 0.13 & 0.67 & 38.84 \\
\hline age & 1.25 & 11.27 & -0.14 & -0.06 & -0.32 & -3.53 \\
\hline age2 & -0.01 & -9.98 & 0.00 & 0.01 & 0.00 & 3.90 \\
\hline ageloginc & -0.13 & -12.25 & -0.02 & -0.08 & & \\
\hline age $2 \operatorname{loginc}$ & 0.00 & 11.06 & 0.00 & 0.16 & & \\
\hline log_wealth & 0.03 & 1.06 & 0.00 & 0.12 & 0.00 & 0.12 \\
\hline log_cohortgdp & 0.03 & 1.74 & 0.14 & 2.62 & 0.13 & 2.49 \\
\hline dumless60 & -0.28 & -3.55 & -0.26 & -2.42 & -0.26 & -2.45 \\
\hline gender & 0.06 & 8.68 & 0.07 & 6.58 & 0.07 & 6.59 \\
\hline partner & -0.11 & -13.57 & -0.09 & -6.87 & -0.09 & -6.85 \\
\hline partner*dumless60 & 0.09 & 3.31 & 0.01 & 0.30 & 0.01 & 0.31 \\
\hline gender*dumless60 & 0.06 & 1.57 & 0.12 & 2.56 & 0.12 & 2.59 \\
\hline offer_type3 & 0.50 & 4.06 & & & & \\
\hline offer_type 4 & 0.76 & 7.57 & 0.78 & 6.02 & 0.77 & 5.98 \\
\hline offer_type5 & 0.55 & 5.42 & 0.51 & 3.97 & 0.51 & 3.93 \\
\hline offer_type7 & 1.00 & 9.89 & 1.10 & 8.52 & 1.09 & 8.49 \\
\hline offer_type8 & 1.01 & 9.68 & 1.01 & 7.64 & 1.01 & 7.61 \\
\hline offer_type9 & 1.57 & 13.50 & 1.67 & 11.43 & 1.66 & 11.39 \\
\hline offer_type11 & 1.76 & 17.48 & 2.01 & 15.89 & 2.00 & 15.88 \\
\hline offer_date & 0.00 & 6.69 & 0.00 & 4.95 & 0.00 & 4.93 \\
\hline sector_code2 & -0.50 & -11.29 & -0.50 & -8.43 & -0.50 & -8.42 \\
\hline sector_code3 & -0.06 & -3.58 & -0.07 & -2.89 & -0.07 & -2.84 \\
\hline sector_code4 & -0.24 & -4.66 & -0.24 & -2.82 & -0.24 & -2.80 \\
\hline sector_code5 & -0.13 & -1.32 & -0.19 & -1.43 & -0.20 & -1.45 \\
\hline sector_code6 & -0.11 & -6.09 & -0.13 & -5.40 & -0.13 & -5.37 \\
\hline sector_code7 & -0.03 & -1.25 & -0.02 & -0.52 & -0.02 & -0.50 \\
\hline sector_code8 & -0.01 & -0.26 & -0.04 & -0.73 & -0.04 & -0.71 \\
\hline sector_code9 & 0.11 & 4.63 & 0.13 & 3.97 & 0.13 & 3.98 \\
\hline sector_code11 & -0.04 & -1.28 & -0.07 & -1.53 & -0.07 & -1.53 \\
\hline sector_code15 & -0.66 & -20.31 & -0.74 & -15.25 & -0.74 & -15.28 \\
\hline sector_code17 & 0.90 & 48.37 & 1.02 & 39.97 & 1.02 & 39.98 \\
\hline sector_code1316 & -0.16 & -8.08 & -0.17 & -6.16 & -0.17 & -6.12 \\
\hline sector_code1214 & -0.23 & -11.17 & -0.22 & -7.73 & -0.22 & -7.68 \\
\hline constant & -54.96 & -16.01 & -24.97 & -0.46 & -24.64 & -5.19 \\
\hline
\end{tabular}

Table 5.A1: Regression Output of (5.7)

This table contains the coefficient estimates and their T-Ratios from regression equation (5.7). Columns 1-2 contain the results based on the whole sample; Columns 3-6 those based on the sample that is restricted to people older than or equal to 45; Columns 5-6 exclude the agewage interaction terms. In all cases we only consider the response to the first offer. Offer types 2-4 relate to the birth cohorts; Offer type 5 refers to people for whom the LLR would be integrated with the pension; Offer types 6-7 are standard brochures without any additional savings suggestions; Offer types 8-9 are standard brochures with additional savings suggestions; Offer type 11 was sent to employees of the police. Industries 2, 3, 4, 5, 6, 7, 8, 9, 11, 15, 17, 1316 and 1214 refer to employees in the Military, Education, Police, Judiciary, Municipalities, Provinces, Water/Maintenance, Other, Voluntary Participants, University Teaching Hospitals, Energy/Utility/Water industry, Research/Science and Adult Education, and Academics and Higher Educational Services, respectively. 


\section{Chapter 6}

\section{Conclusion}

Microeconomics teaches you simple economic principles. As the price for a good increases, consumer demand decreases. Similarly, as the price for labor increases, individuals' labor supply increases while employers' demand decreases. After years of studying economics, you therefore believe that individuals take their decisions according to simple microeconomic principles. After one month of analyzing the so-called "agents" using empirical data, you realize that there is more than prices that trigger decisions of "agents". The "agents" are also called individuals - for a good reason! They are very individual. And putting a thousand of them into one equation, where we aim to explain individuals' choices on the left hand side with the information we have about them on the right hand side, is hard. It requires us empirical researchers to think beyond simple microeconomic principles. Once we are able to explain a certain percentage of individuals' decisions, we are happy and dare to come to conclusions about individuals' behavior.

In the introduction, I promised to provide some conclusions about the following questions.

1. How should and how do people save adequately?

2. When should and when do people retire given official retirement regulation?

The second, fourth, and fifth chapter of my dissertation deal with the first, the third chapter with the second question.

\section{Chapter 2}

In Chapter 2, we analyze individuals' subjective financial well-being at retirement in the sense of retirement income adequacy in light of pension reforms in Germany. Since the reforms decreased the real return to the public pension system across birth cohorts, we hypothesize that younger cohorts feel worse financially prepared for their retirement than 
older cohorts, given that they have not retired yet. Additionally, the people who have not retired yet should acknowledge the importance of additional income sources more because they will facilitate saving in the second and third pillar. Our analysis reveals that individuals evaluate their financial situation broadly in line with sophisticated life-cycle models; that is, they are more optimistic about their (future) retirement income the more they earn and the better educated and wealthier they are. The negative birth cohort effect suggests that people are aware of the demographic and political risk and the reform implications. However, despite the awareness of a less prosperous position, the young cohorts do not put more weight on additional income sources. These conclusions are in line with each other because if individuals instead had additional income sources and appreciated them, thus making an effort to fill the pension gap, they would not have to feel bad.

This chapter contributes to the empirical aspect of Question (1): How do people perceive their retirement income and thus, implicitly, their savings? We can conclude that individuals evaluate their financial situation broadly in line with sophisticated life-cycle models and that they are aware of the reform implications. However, despite the awareness of a less prosperous position, the young cohorts do not put more weight on additional income sources. Further research is necessary to investigate why young cohorts do not evaluate additional income sources as more important for their future financial situation. Is it because they discount the future too much and / or procrastinate. Are there inertia? Or do they simply try to earn more labor income?

\section{Chapter 3}

Chapter 3 builds on findings that women's labor force participation has changed across cohorts. Women are better educated, are more often divorced, give birth to fewer children, and are more active in the labor force. The change is most accentuated for women in western Germany. Their employment life-cycle pattern converges to that of men. Consequently, they acquire more pension claims, which should affect retirement behavior of women, at least in western German. We investigate retirement behavior in the option value framework (Stock and Wise 1990). Our results show that the choice of the dependent variable is important. When taking employment exit we get a substantially higher preference for leisure than when taking retirement entry. We also see that there is a difference in this preference between men and women and people in eastern and western Germany. When plotting the option value and social security wealth, we see 1) regular drops in one year increments, which visualize the increasing eligibility for women and 2) the level rather higher for younger than for older cohorts despite the institutional advantage of the latter, which indicates that women have indeed gathered higher pension claims.

In our retirement explaining regression, we also include cohort trends that are related 
to the opportunity cost of work (number of children and the proportion of university graduates) to analyze the impact of the changing female employment patters. We learn that these trends are significant in determining the age at which someone leaves work or enters retirement. The trend related to education indicates later retirement while the trend related to kids indicates earlier retirement of later born cohorts in western Germany. In eastern Germany, we can only identify the latter regularity. As previous research by Hanel (2009), we also observe the time between labor force exit and retirement entry to widen for later born cohorts in western Germany. This does not hold in eastern German. Thus, overall we do not find strong evidence that increasing female labor force participation when young also leads to overall higher labor force participation of women. Younger western German women tend to leave the labor force earlier while younger eastern German women tend to postpone labor force exit. However, their behavior is still influenced strongly from market transition during the 1990s.

With regard to Question (2) we learn that cohort trends that are related to the opportunity cost of work are significant in determining the age at which someone leaves work or enters retirement. However, these trends only allow us to explain at most $1.9 \%$ more of the variation in retirement. In the future, it will be interesting to extend our analysis of retirement behavior to future cohort in order to see how recent changes in labor and child policies will influence labor market participation later in life. It would also be helpful to merge the data set with another one as SHARE to include indicators of private wealth and household income. Concerning the construction of SSW and the OV, one may consider to model uncertainty. Especially for younger people it is not certain that they are able to reach a certain retirement age without getting unemployed or sick in the meantime. To allow for this aspect could set up multiple pathways that take account of interrupted working lives.

\section{Chapter 4}

Chapter 4 highlights the importance of tax incentives in the optimal savings decisions. We solve a life-cycle model to determine optimal consumption, labor and savings for early retirement. This model is set up to mimic the Dutch Levensloopregeling that serves, amongst others, as an early retirement scheme. The agent therefore has a choice to save his money in a regular wealth account or in a tax-deferrable account (TDA). We show analytically that there is a contemporaneous relationship between consumption and leisure, which depends on the income tax incentives. If an agent hits one of the kinks in the income tax schedule by choosing a specific labor supply, he only adjusts his consumption to improve his utility. Furthermore, we point out that the TDA becomes financially more attractive relative to the regular wealth account the higher the wealth tax in the regular wealth account and the higher the marginal income tax rate upon saving relative to upon withdrawing. Given 
moderate patience, our results show that the agents save more in the TDA as they age. Our simulations demonstrate that the TDA facilitates early retirement after age 61. At age 62, about $20 \%$ of TDA users and not TDA users retire early. At age 63 and 64 , the percentage of early retired TDA users is much larger than that of not TDA users. Consequently, the TDA helps to achieve a longer early retirement period. In terms of certainty equivalent consumption, the TDA increases the agent's utility by $1.24 \%$ ( $€ 5,600$ of certain consumption over the lifetime) in the benchmark scenario. At the same time, however, the government foregoes about $14 \%$ ( $€ 12,000$ over the lifetime) of taxes compared to someone who is not using the TDA. Thus, there is an obvious mismatch.

With regard to the normative aspect of Question (1), this allows us to conclude that people should save in a TDA when it is offered to them. Depending on their time preferences they should start saving in the TDA at different ages. Given imperfect substitution between consumption and leisure, individuals do not need a higher savings rate in order to finance early retirement. At the same time, our simulations show that tax incentives to trigger individuals' saving can be costly for the government. Since it is often said that the Dutch Levensloopregeling is especially useful for high income earners, it would be interesting to vary the level and riskiness of income to see which type of income earner benefits most from the TDA. In the Netherlands, there are also debates concerning the applicability of the TDA. It is criticized that it cannot be used during times of unemployment for instance. Another interesting extension of this model may thus be to allow for unemployment risk and at the same time alleviate the illiquidity of the TDA during these times.

\section{Chapter 5}

Chapter 5 investigates the participation and investment decision that the Dutch have to make with regard to the Levensloopregeling empirically. The analysis of the participation and asset allocation decision in this chapter shows that the Dutch indeed adhere to the implications from the previously solved life-cycle model. Moreover, we find that our samples make their investment decision with regard to bonds and equities broadly in line with lifecycle theory: Conditional on participation, the likeliness to invest in a bond fund increases and the one to invest in an equity fund decreases with age. However, when it comes to the life-cycle fund, which is automatically adjusted to the age of the participant, the participants do not behave in line with life-cycle theory.

With regard to the empirical aspect of Question (1), we find that the savings motive makes a difference for the behavior. The younger people, who are probably more interested in a sabbatical or maternity leave, are more likely to invest in the LLR the younger they are. Moreover, young people with low income are more likely to invest in the LLR than young people with higher income. The older they become the larger the 
income effect. The most evident question left is, why do not more people use the Levensloopregeling? A survey in the future can shed light on this. It may also be useful to analyze these questions in a panel data framework to be able to identify time trends.

It remains a challenge to put a thousand individuals into one equation - or into a normative life-cycle model for that matter. However, if we carefully construct (possibly) complicated structural life-cycle models we get reasonably close to actual human behavior. And if we deduce reduced forms from the structural model and estimate them on the basis of the individuals, we realize that individuals, on average, get a lot of financial decisions right. And if it were much easier - what would our challenge lie in then? 



\section{Bibliography}

Agnew, J., Balduzzi, P. and Sunden, A.: 2003, Portfolio choice and trading in a large 401(k) plan, The American Economic Review 93(1), 193-215.

Alessie, R. and Kapteyn, A.: 1999, Wealth and savings: data and trends in the Netherlands, Serie Research Memoranda 0046, VU University Amsterdam, Faculty of Economics, Business Administration and Econometrics.

Ammermüller, A., Weber, A. M. and Westerheide, P.: 2005, Die Entwicklung und Verteilung des Vermögens privater Haushalte unter besonderer Berücksichtigung des Produktivvermögens - Abschlussbericht zum Forschungsauftrag des Bundesministeriums für Gesundheit und Soziale Sicherung, Accenture and Institute of Insurance Economics, University of St. Gallen.

Antolin, P. and Scarpetta, S.: 1998, Microeconometric analysis of the retirement decision, OECD Economics Department Working Paper 204.

Attanasio, O., Banks, J. and Wakefield, M.: 2004, Effectiveness of tax incentives to boost (retirement) saving: Theoretical motivation and empirical evidence, IFS Working $P a$ pers (W04/33), Institute for Fiscal Studies, London, UK.

Bäcker, G., Bispinck, R., Hofemann, K. and Naegele, G.: 2008, Sozial-politik und soziale Lage in Deutschland, Ökonomische Grundlagen, Einkommen, Arbeit und Arbeitsmarkt, Arbeit und Gesundheitsschutz, Westdeutscher Verlag, Wiesbaden.

Banks, J., Blundell, R., Disney, R. and Emmerson, C.: 2002, Retirement, pensions and the adequacy of saving: A guide to the debate, Open Access publications from University College London, University College London.

Barber, B. and Odean, T.: 2001, Boys will be boys: Gender, overconfidence, and common stock investment, Quaterly Journal of Economics 116(1), 261-292.

Benartzi, S. and Thaler, R.: 2001, Naive diversification stragegies in retirement saving plans, American Economic Review 91(1), 79-98. 
Benzoni, L., Collin-Dufresne, P. and Goldstein, R.: 2007, Portfolio choice over the life-cycle when the stock and labor market are cointegrated, Journal of Finance 62, 2123-2167.

Berkel, B. and Börsch-Supan, A.: 2004, Pension Reform in Germany: The Impact on Retirement Decisions,, FinanzArchiv 60, 393-421.

Berkovec, J. and Stern, S.: 1991, Job exit behavior of older men, Econometrica 59, 189-210.

Biewen, M.: 2000, Income inequality in Germany during the 1980s and 1990s, Review of Income and Wealth 46(1).

Blanchflower, D. G. and Oswald, A.: 2008, Is well-being u-shaped over the life cycle?, Social Science and Medicine 66(6), 1733-1749.

Blau, D. M. and Riphahn, R. T.: 1999, Labor force transition of older married couples in Germany, Labour Economics 6, 229-251.

Bloom, D., Canning, D. and Graham, B.: 2003, Longevity and life-cycle savings, Scandinavian Journal of Economics 105(3), 319-338.

Bonoli, G.: 2003, Two worlds of pension reform in Western Europe, Comparative Politics 35(4), 399-416.

Borghans, L., Dohmen, T. and Golsteyn, B.: 2009, De invloed van maatschappelijke ontwikkelingen op de inrichting van onderwijs, Technical report, Ministerie van Onderwijs, Cultuur en Wetenschap.

Borghans, L. and Nelen, A.: 2009, Learning on the job, the composition of tasks and the earnings of older workers, Technical report, Research Centre for Education and the Labour Market, Maastricht University.

Borghans, L. and Ter Weel, B.: 2002, Do older workers have more trouble using a computer than younger workers?, The Economics of Skills Obsolescence 21, 139-173.

Börsch-Supan, A.: 1992, Population aging, social security design, and early retirement, Journal of Institutional and Theoretical Economics 148, 533-557.

Börsch-Supan, A.: 2000a, Incentive effects of social security on labor force participation: Evidence in Germany and across Europe, Jounal of Public Economics 78, 25-49.

Börsch-Supan, A.: 2000b, A model under siege: A case study of the German retirement insurance system, The Economic Journal 110, 24-45. 
Börsch-Supan, A.: 2001, Incentive effects of social security und an uncertain disability option, in D. Wise (ed.), Themes in the Economics of Aging, University of Chicago Press, pp. 281-310.

Börsch-Supan, A., Brugiavini, A. and Enrica, C.: 2008, The role of institutions in European patterns of work and retirement, DSE Working Papers 44.

Börsch-Supan, A. and Jürges, H.: 2006, Early retirement, social security and well-being in Germany, Working Paper 12303, National Bureau of Economic Research.

Börsch-Supan, A. and Reil-Held, A.: 1998, Retirement income: Level, risk and substitution among income components, AWP Maintaining Prosperity in an Aging Society 3.7, OECD, Paris.

Börsch-Supan, A., Reil-Held, A., Rodepeter, R., Schnabel, R. and Winter, J.: 2001, The German savings puzzle, Research in Economics 55, 15-38.

Börsch-Supan, A. and Schnabel, R.: 1998, Social security and declining labor-force participation in Germany, AEA Papers and Proceedings 88, 173-178.

Börsch-Supan, A. and Schnabel, R.: 1999, Social security and retirement in Germany, in J. Gruber and D. A. Wise (eds), Social Security and Retirement Around the World, University of Chicago Press, pp. 135-180.

Börsch-Supan, A., Schnabel, R., Kohnz, S. and Mastrobuoni, G.: 2004, Micro-modeling of retirement decisions in Germany, in J. Gruber and D. Wise (eds), Social Security Programs and Retirement Around the World, University of Chicago Press, pp. 285-343.

Börsch-Supan, A. and Wilke, C. B.: 2004, The German public pension system: How it was, how it will be, Working Paper 10525, National Bureau of Economic Research.

Börsch-Supan, A. and Wilke, C. B.: 2005, Reforming the German Public Pension System, Paper Prepared for the AEA Meetings, Boston, January 6, 2006.

Börsch-Supan, A. and Wilke, C. B.: 2006, Gratwanderungen zwischen Generationenvertrag und Eigenvorsorge: Wie Europa die Herausforderungen des demographischen Wandels annimmt, Deutsches Institut für Altersvorsorge (DIA).

Bovenberg, A. and Wilthagen, A.: 2008, On the road to flexicurity: Dutch proposals for a pathway towards better transition security and higher labour market mobility, Open Access publications from Tilburg University, Tilburg University.

Browning, M. and Crossley, T. F.: 2001, The life-cycle model of consumption and saving, Journal of Economic Perspectives 15(3), 3-22. 
Browning, M. and Lusardi, A.: 1996, Household saving: Micro theories and micro facts, Journal of Economic Literature 34(4), 1797-1855.

Campbell, J. and Viceira, L.: 2001, Strategic Asset Allocation: Portfolio Choice for LongTerm Investors, Oxford University Press.

Carroll, C. D. and Weil, D. N.: 1994, Saving and growth: A reinterpretation, CarnegieRochester Conference Series on Public Policy 40, 133 - 192.

Crimmins, E. M., Hayward, M. D., Hagedorn, A., Saito, Y. and Brouard, N.: 2009, Change in the disability-free life expectancy for americans 70 years old and older, Demography 46(3), 627-646.

Dammon, R. M., Spatt, C. S. and Zhang, H. H.: 2004, Optimal asset location and allocation with taxable and tax-deferred investing, The Journal of Finance 59(3), 999-1037.

Deaton, A.: 1985, Panel data from time series of cross-sections, Journal of Econometrics 30, 109-126.

Diener, E. and Biswas-Diener, R.: 2002, Will money increse subjective well-being?, Social Indicators Research 57, 119-169.

Diener, E. and Seligman, M.: 2004, Beyond money: Toward an economy of well-being, Psychological Science in the Public Interest 5, 1-31.

Dimson, E., Marsh, P. and Staunton, M.: 2002, The Triumph of the Optimists: 101 Years of Global Investment Returns, Princeton University Press.

Fitzenberger, B., Schnabel, R. and Wunderlich, G.: 2004, The gender gap in labor market participation and employment: A cohort analysis for west Germany, Journal of Population Economics 17(1), 83-116.

Fornero, E., Lusardi, A. and Monticone, C.: 2009, Adequacy of Saving for Old Age in Europe, CeRP Working Papers, Center for Research on Pensions and Welfare Policies, Turin (Italy).

Gomes, F., Kotlifkoff, L. and Viceira, L.: 2008, Optimal life-cycle investing with flexible labor supply: A welfare analysis of life-cycle funds, American Economic Review 98(2), 297-303.

Gourinchas, P.-O. and Parker, J.: 2002, Consumption over the life-cylce, Econometrica 70(1), 47-89. 
Gruber, J. and Wise, D.: 1997, Social security programs and retirement around the world: Introduction and summary, Working Paper 6134, National Bureau of Economic Research. Phase 1 of the NBER's International Social Security Project.

Gruber, J. and Wise, D.: 2002, Social security programs and retirement around the world: Micro estimation, Working Paper 9407, National Bureau of Economic Research. Phase 2 of the NBER's International Social Security Project.

Gruber, J. and Wise, D.: 2005, Social security programs and retirement around the world: Fiscal implications, Working Paper 11290, National Bureau of Economic Research. Phase 3 of the NBER's International Social Security Project.

Gruber, J. and Wise, D. (eds): 1998, Social Security and Retirement Around the World, University of Chicago Press.

Gustman, A. L. and Steinmeier, T. L.: 1986, A structural retirement model, Econometrica 54, $555-584$.

Gustman, A. L. and Steinmeier, T. L.: 2004, Social security, pensions and retirement behavior within the family, Journal of Applied Econometrics 19, 723-737.

Gustman, A. L. and Steinmeier, T. L.: 2005, The social security early retirement entitlement age in a structural model of retirement and wealth, Journal of Public Economics 89, 441-463.

Hanel, B.: 2009, Financial incentives to postpone retirement and further effects on employment - evidence from a natural experiment, Labour Economics pp. 1-13.

Headey, B.: 1993, An economic model of subjective well-being: Integrating economic and psychological theories, Social Indiciators Research 28, 73-116.

Horan, S.: 2005, Tax-Advantaged Savings Accounts and Tax-Efficient Wealth Accumulation, Research Foundation of CFA Institute.

Huberman, G., Iyengar, S. and Jiang, W.: 2007, Defined contribution pension plans: Determinants of participation and contribution rates, Journal of Financial Services Research 31, 1-32.

Hurst, E.: 2003, Grasshoppers, ants, and pre-retirement wealth: A test of permanent income, Working Paper 10098, National Bureau of Economic Research.

Jansen, A., Kümmerling, A. and Lehndorff, S.: 2009, Unterschiede in den Beschäftigungsund Arbeitszeitstrukturen in Ost- und Westdeutschland, IAQ Report 3. 
Jäntti, M. and Sierminska, E.: 2007, Survey estimates of wealth holdings in OECD countries, Working Papers 17, World Institute for Development Economic Research (UNUWIDER).

Kalmijn, M. and Alessie, R.: 2008, Life course changes in income: An Exploration of ageand stage effects in a 15-year panel in the Netherlands, Panel paper 10, NETSPAR.

Kapteyn, A. and de Vos, K.: 1997, Social security and retirement in the Netherlands, Working Paper 6135, National Bureau of Economic Research.

Kapteyn, A. and de Vos, K.: 1998, Social security and labor-force participation in the Netherlands, The American Economic Review 88(2), 164-167.

Lumsdaine, R., Stock, J. and Wise, D. A.: 1992, Three models of retirement: Computation complexity versus predictive validity, in D. A. Wise (ed.), Topics in the Economics of Aging, University of Chicago Press, pp. 21-60.

Lusardi, A. (ed.): 2008, Overcoming the Saving Slump: How to Increase the Effectiveness of Financial Education and Savings Program, University of Chicago Press.

Maas, G.: 2009, Een nieuwe rol voor de levensloopregeling, Rabobank Themabericht $2009 / 21$.

Mastrogiacomo, M., Alessie, R. and Lindeboom, M.: 2004, Retirement behaviour of Dutch elderly households, Journal of Applied Econometrics 19, 777-793.

Mathers, C. D., Sadana, R., Salomon, J. A., Murray, C. J. and Lopez, A. D.: 2001, Healthy life expectancy in 191 countries, 1999, The Lancet 357, 1685-1691.

Meghir, C. and Pistaferri, L.: 2004, Income variance dynamics and heterogeneity, Econometrica 72(1), 1-32.

Meghir, C. and Whitehouse, E.: 1997, Labour market transitions and retirement of men in the UK, Jounal of Econometrics 79, 327-354.

NIBUD: 2007, Goed geregeld - geldzaken nu en later.

Ottnad, A. and Wahl, S.: 2005, Die Renditen der gesetzlichen Rente, Deutsches Institut für Altersvorsorge GmbH, Köln.

Radl, J.: 2007, Individuelle Determinanten des Renteneintrittalters - Eine empirische Analyse von Übergängen in den Ruhestand, Zeitschrift für Soziologie 36, 43-64. 
Riphahn, R. T.: 1997, Disability retirement and unemployment - substitute pathways for labour force exit? An empirical test for the case of Germany, Applied Economics 29, 551-561.

Rust, J.: 1987, A dynamic programming model of retirement behavior, Working Paper 2470, National Bureau of Economic Research.

Rust, J. and Phelan, C.: 1997, How social security and medicare affect retirement behavior in a world of incomplete markets, Econometrica 65, 781-831.

Sachverständigenrat: 2004, Jahresgutachten 2004/ 2005 zur gesamtwirtschaftlichen Entwicklung, Bundestagsdrucksache 934/04.

Schmidt, P.: 1995, Die Wahl des Rentenalters - Theoretische und Empirische Analyse des Rentenzugangsverhaltens in West- und Ostdeutschland, Lang, Frankfurt/M.

Seghieri, C., Desantis, G. and Tanturri, L.: 2006, The richer the happier? An empirical investigation in selected European countries, Social Indicators Research 79, 455-476.

Siddiqui, S.: 1997, The pension incentive to retire: Empirical evidence for west Germany, Population Economics 10, 463-486.

Stock, J. H. and Wise, D. A.: 1990, Pensions, the option value of work, and retirement, Econometrica 58, 1151-1180.

Thaler, R. H. and Sunstein, C. R.: 2008, Nudge: Improving Decisions About Health, Wealth, and Happiness, Yale University Press, New Haven.

Tigges, P., Rieger, A., Jonitz, L., Brengelmann, J. and Engel, R. R.: 2000, Risk behavior of east and west Germans in handling personal finances, Journal of Behavioral Finance $\mathbf{1}(2), 127-134$.

van Praag, B. and Ferrer-i-Carbonell, F.: 2004, Happiness Quantified: A Satisfaction Calculus Approach, Oxford University Press.

van Riel, B., Hemerijck, A. and Visser, J.: 2003, Is there a dutch way to pension reform?, in G. L. Clark and N. Whiteside (eds), Pension Security in the 21st Century, Oxford University Press, chapter 3, pp. 64-92.

Viceira, L. M.: 2008, Life-cycle funds, in A. Lusardi (ed.), Overcoming the Saving Slump: How to Increase the Effectiveness of Financial Education and Saving Programs, The University of Chicago Press, chapter 5, pp. 140-177. 
Wilke, C. B.: 2005, Rate of return of the German PAYG system - How they can be measured and how they will develop, Discussion Paper 097-05, Mannheim Research Institute for the Economics of Aging.

Winter, J.: 1999, Strukturelle ökonometrische Verfahren zur Analyse von Renteneintrittsentscheidungen, Working Paper 99-03, Sonderforschungsbereich 504. 


\section{Nederlandse Samenvatting}

Otto von Bismarck was de eerste die een nationaal sociaal zekerheidssysteem introduceerde, bestaande uit een zorg-, ongevallen-, arbeidsongeschiktheids- en pensioenvoorziening. In eerste instantie kon men pas aanspraak maken op de pensioenverzekering vanaf een leeftijd van 70 jaar, maar dit werd al snel aangepast naar 65 jaar. In het begin van de twintigste eeuw was de levensverwachting voor mannen en vrouwen respectievelijk 45 en 47 jaar. De pensioenvoorziening was zodoende alleen bedoeld voor mensen die niet in de gelegenheid waren om te werken. Veel Europese landen volgden het voorbeeld en ontwikkelden ook een dergelijk sociaal zekerheidssysteem in het begin van de twintigste eeuw.

De Europese sociale zekerheidssystemen werden genereuzer in de jaren zeventig, ondanks de stijging in de gemiddelde levensverwachting. Een opmerkelijk ontwikkeling was het vervroegd pensioen. Hiermee konden werkenden twee tot vijf jaar eerder met pensioen dan de referentie leeftijd van 65 jaar, zonder actuarile gevolgen. Vervroegde pensioenuitkeringen stegen ook door het gemakkelijk toekennen van arbeidsongeschiktheidsstatus aan mensen vanaf 55 jaar (Gruber and Wise 1997). De bewustwording kwam pas begin jaren negentig. Een stijgende levensverwachting en dalende vruchtbaarheid leidden tot een hogere ratio tussen gepensioneerden en werkenden. Beleidsmakers begonnen zich te realiseren dat het pensioensysteem onhoudbaar werd. Uit onderzoek blijkt dat er een sterk verband is tussen institutionele prikkels en het gedrag van individuen. Hierdoor zal een hervorming naar een actuarieel rechtvaardig systeem leiden tot een hogere pensioensgerechtigde leeftijd en een lagere belastingdruk.

In 1992 heeft Duitsland een normale pensioengerechtigde leeftijd ingesteld door middel van actuarile aanpassingen. In 2001 introduceerde Duitsland het pijlersysteem. Dit pijlersysteem bestond reeds in Nederland. Maar men hanteerde te genereuze bepalingen om vervroegd met pensioen te gaan. In 2006 heeft de Nederlandse overheid het vervroegd pensioen afgeschaft. Hiervoor in de plaats kwam de levensloopregeling: een persoonlijk spaarplan.

Om een beeld te krijgen van de consequenties van de beoogde hervormingen, gebruikten overheden de resultaten van zorgvuldig uitgevoerd onderzoek. Maar omdat de wereld blijft veranderen blijft goed onderzoek naar gevolgen van dit soort hervormingen nodig. In dit 
proefschrift analyseren we hoe individuen omgaan met pensioenhervormingen en hoe ze om zouden moeten gaan met het sparen voor het pensioen.

In hoofdstuk 2 bestuderen het financile welzijn van gepensioneerden in de context van de Duitse pensioenhervormingen. Omdat de hervorming een verlaging van het reel pensioenrendement betrof, verwachtten we dat jongeren zich financieel slechter voorbereid voelen op hun pensioen dan nog niet gepensioneerde, oudere cohorts, gezien de daling van de rele pensioenopbrengst. Verder verwachtten we dat mensen die nog niet gepensioneerd zijn, het belang van additionele inkomensbronnen onderschrijven en derhalve investeren in sparen via de tweede en derde pijler van het systeem. Onze analyse laat zien dat de manier waarop individuen hun financile situatie evalueren, overeenkomt met de beslissing van een rationale agent die zijn gehele levenscyclus financieel modelleert. Dit houdt in dat individuen met een hoger inkomen en opleidingsniveau optimistischer zijn over hun (toekomstig) pensioen. Het negatieve effect van de cohorten laat zien dat men zich bewust is van de gevolgen van de hervormingen en van de demografische en politieke risico's. Het feit dat jongere cohorten zich bewust zijn van hun ongunstige positie heeft echter niet tot gevolg dat ze meer waarde hechten aan aanvullende bronnen van inkomsten. De twee voorgenoemde conclusies zijn met elkaar in overeenstemming aangezien individuen die wel actief bezig zijn met het aanvullen van het pensioen ook optimistischer zijn over hun pensioen.

Hoofdstuk 3 gaat dieper in op het gegeven dat de arbeidsmarktparticipatie van vrouwen veranderd is door de jaren heen. Vrouwen zijn tegenwoordig zijn hoger opgeleid, vaker gescheiden, brengen minder kinderen ter wereld en zijn actiever op de arbeidsmarkt. Deze veranderingen zijn vooral goed zichtbaar bij vrouwen in West-Duitsland. Het patroon van hun arbeidscyclus convergeert naar dat van de man. Hierdoor maken zij ook meer aanspraak op pensioenvoorzieningen, wat het pensioengedrag van vrouwen in West-Duitsland benvloedt. In dit hoofdstuk onderzoeken wij het pensioengedrag binnen de 'optiewaarde' benadering (Stock and Wise 1990). Als we de optiewaarde uitzetten tegen het vermogen van de sociale zekerheid zien we 1) periodieke dalingen in de jaarlijkse toename, welke de stijgende pensioengerechtigheid voor vrouwen weergeeft en 2) vooral voor jongere cohorts een hoog niveau, ondanks het institutionele voordeel van de oudere cohorts, wat ook duidt op het feit dat vrouwen in toenemende mate aanspraak hebben gemaakt op hun pensioengerechtigheid.

Bij de verklaring van het pensioengedrag nemen we ook cohorttrends mee die gerelateerd zijn aan de 'opportunity costs' van werken, zoals het aantal kinderen en het aandeel universitair afgestudeerden, om het effect van veranderende arbeidspatronen van vrouwen te onderzoeken. We leren hieruit dat deze trends een significant effect hebben op de leeftijd waarop iemand stopt met werken of met pensioen gaat. In West-Duitsland leidt het stijgende opleidingsniveau tot later pensioen en het dalend aantal kinderen tot eerder pensioen voor de jongere cohorten. Voor Oost-Duitse cohorten kunnen we alleen het laatste con- 
cluderen. Echter, het toevoegen van deze cohorttrends verklaart slechts 1,9\% extra van het pensioengedrag. Net als in eerder onderzoek (Hanel 2009) zien we dat de tijd tussen het stoppen met werken en het met pensioen gaan langer wordt voor jongere cohorts in WestDuitsland. Dit geldt niet voor Oost-Duitsland. We concluderen dat er geen sterk bewijs is dat een stijgende arbeidsmarktparticipatie voor vrouwen op jonge leeftijd leidt tot een algemene stijging in arbeidsmarktparticipatie van vrouwen.

In hoofdstuk 4 en 5 analyseren we het gedrag van individuen naar aanleiding van de in Nederland gentroduceerde levensloopregeling. Door deze regeling verschuift de verantwoordelijkheid voor het pensioen van de staat naar het individu. De staat stimuleert de levensloopregeling door uitstel van belasting, belastingverlaging en subsidies. Mensen gebruiken deze regeling bijvoorbeeld om te sparen voor zwangerschap- of ouderschapverlof, sabbatsverlof of om eerder met pensioen te gaan. In de volgende twee hoofdstukken focussen wij op de mogelijkheid om eerder met pensioen te gaan. Een jaar na introductie van de levensloopregeling was de deelname nog niet hoger dan $5,5 \%$.

Hoofdstuk 4 beschrijft het belang van belastingprikkels bij het maken van optimale spaarbeslissingen. We modelleren de levensloopregeling met een levenscyclusmodel om de optimale hoeveelheden consumptie, arbeid en spaargeld te bepalen voor een vervroegd pensioen. Een individu heeft hierbij de keuze om te sparen via een normale spaarrekening of via een levenslooprekening. Over het saldo op de levensloopregeling hoeft vermogensbelasting te worden betaald en inkomensbelasting wordt pas betaalde bij opname. Onze resultaten laten zien dat individuen meer sparen op de levenslooprekening naar mate ze ouder worden. De levensloopregeling stelt hen in staat om op 61 jarige leeftijd met vervroegd pensioen te gaan. Enerzijds leidt de levensloopregeling gemiddeld tot een 1,24\% stijging in het nut van een individu (5.600 euro aan extra consumptie over een leven). Anderzijds leidt dit tot een daling van de inkomensbelasting van 14\% (12.000 euro over een leven). De stijging in individueel nut weegt dus niet op tegen de vermindering in het overheidsinkomen.

In hoofdstuk 5 bekijken we de levensloopdeelname en investeringsbeslissing in Nederland empirisch. Nederlanders blijken wat betreft deelname en beleggingskeuze in obligatiesfondsen en aandelenfondsen rationeel te handelen, in lijn met eerdere genoemde levenscyclus modellen. Naarmate men ouder wordt, investeert men meer in obligaties en minder in aandelen . Echter, bij het zogenaamde life-cycle fonds, dat zich automatisch aanpast aan de leeftijd van de deelnemer, is het gedrag van de deelnemer niet in overeenstemming met de levenscyclustheorie.

Het is erg moeilijk om het gedrag van individuen weer te geven in n enkele vergelijking. Hoe meer we nadenken over het idee achter levenscyclusmodellen hoe beter we het feitelijk 
menselijk gedrag kunnen benaderen. Ondanks dat de mens zich vaak niet gedraagt als een rationele econoom, is hij gemiddeld genomen toch niet volledig onbekwaam als het gaat om het maken van wijze financile beslissingen. 


\section{Curriculum Vitae}

Kathrin Nies was born on October 24th, 1982 in Langenfeld (Rheinland) in Germany. In 2002, she graduated (Abitur) from the Marienschule Opladen. Thereafter, she moved to the Netherlands to study Econometrics and Operations Research in Maastricht. In the course of her studies, she spent one semester at the University of Queensland in Brisbane, Australia. Finishing her Bachelor of Science in Econometrics and Operations Research in August 2005, she received the Master of Science in Econometrics and Operations Research with distinction a year later. From September 2006 till August 2010, Kathrin was employed as a $\mathrm{PhD}$ student by the Finance department in Maastricht. She also became a Netspar junior research fellow. Several months of her PhD studies she spent as a visiting scholar at the Mannheim Research Institute for the Economics of Aging (MEA) in Mannheim. The work she has produced during these four years has been presented at numerous Netspar conferences in the Netherlands, Switzerland and Germany. Since October 2010, Kathrin is employed by Allianz Global Investors AG as an economist in the field of international pensions. 